NBS SPECIAL PUBLICATION 342

\title{
Report of the 55th National Conference on Weights and Measures 1970
}

U.S.
RTMENT
OF
MMERCE
National
Bureau
of
tandards 
The National Bureau of Standards ${ }^{1}$ was established by an act of Congress March 3 , 1901. The Bureau's overall goal is to strengthen and advance the Nation's science and technology and facilitate their effective application for public benefit. To this end, the Bureau conducts research and provides: (1) a basis for the Nation's physical measurement system, (2) scientific and technological services for industry and government, (3) a technical basis for equity in trade, and (4) technical services to promote public safety. The Bureau consists of the Institute for Basic Standards, the Institute for Materials Research, the Institute for Applied Technology, the Center for Computer Sciences and Technology, and the Office for Information Programs.

THE INSTITUTE FOR BASIC STANDARDS provides the central basis within the United States of a complete and consistent system of physical measurement; coordinates that system with measurement systems of other nations; and furnishes essential services leading to accurate and uniform physical measurements throughout the Nation's scientific community, industry, and commerce. The Institute consists of a Center for Radiation Research, an Office of Measurement Services and the following divisions:

Applied Mathematics-Electricity-Heat-Mechanics-Optical Physics-Linac Radiation ${ }^{2}$ - Nuclear Radiation ${ }^{2}$ - Applied Radiation ${ }^{2}$ - Quantum Electronics ${ }^{3}$ Electromagnetics ${ }^{3}$ - Time and Frequency ${ }^{3}$ - Laboratory Astrophysics ${ }^{3}$ - Cryogenics ${ }^{3}$.

THE INSTITUTE FOR MATERIALS RESEARCH conducts materials research leading to improved methods of measurement, standards, and data on the properties of well-characterized materials needed by industry, commerce, educational institutions, and Government; provides advisory and research services to other Government agencies; and develops, produces, and distributes standard reference materials. The Institute consists of the Office of Standard Reference Materials and the following divisions:

Analytical Chemistry-Polymers-Metallurgy-Inorganic Materials-Reactor Radiation-Physical Chemistry.

THE INSTITUTE FOR APPLIED TECHNOLOGY provides technical services to promote the use of available technology and to facilitate technological innovation in industry and Government; cooperates with public and private organizations leading to the development of technological standards (including mandatory safety standards), codes and methods of test; and provides technical advice and services to Government agencies upon request. The Institute also monitors NBS engineering standards activities and provides liaison between NBS and national and international engineering standards bodies. The Institute consists of the following technical divisions and offices:

Engineering Standards Services-Weights and Measures-Flammable FabricsInvention and Innovation-Vehicle Systems Research-Product Evaluation Technology-Building Research-Electronic Technology-Technical AnalysisMeasurement Engineering.

THE CENTER FOR COMPUTER SCIENCES AND TECHNOLOGY conducts research and provides technical services designed to aid Government agencies in improving cost effectiveness in the conduct of their programs through the selection, acquisition, and effective utilization of automatic data processing equipment; and serves as the principal focus within the executive branch for the development of Federal standards for automatic data processing equipment, techniques, and computer languages. The Center consists of the following offices and divisions:

Information Processing Standards-Computer Information-Computer Services -Systems Development-Information Processing Technology.

THE OFFICE FOR INFORMATION PROGRAMS promotes optimum dissemination and accessibility of scientific information generated within NBS and other agencies of the Federal Government; promotes the development of the National Standard Reference Data System and a system of information analysis centers dealing with the broader aspects of the National Measurement System; provides appropriate services to ensure that the NBS staff has optimum accessibility to the scientific information of the world, and directs the public information activities of the Bureau. The Office consists of the following organizational units:

Office of Standard Reference Data-Office of Technical Information and

Publications-Library-Office of Public Information-Office of International Relations.

2 Headquarters and Laboratories at Gaithersburg, Maryland, unless otherwise noted; mailing address Washington, D.C. 20234.

2 Part of the Center for Radiation Research.

${ }^{8}$ Located at Boulder, Colorado 80302 . 


\section{Report of the}

\section{5th National Conference on \\ Weights and Measures 1970}

Sponsored by the National Bureau of Standards Attended by Officials from the Various

States, Counties, and Cities, and

Representatives from U.S. Government, Industry, and Consumer Organizations

Salt Lake City, Utah, July 13-17, 1970

Report Editors: Frances C. Bell Harold F. Wollin

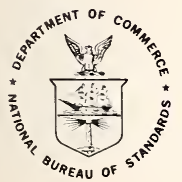

Nat. Bur. Stand. (U.S.), Spec. Publ. 342, 315 pages (April 1971) CODEN : NBSCA

Issued April 1971

United States Department of Commerce Maurice H. Stans, Secretary

National Bureau of Standards

Lewis M. Branscomb, Director 


\begin{abstract}
This is a report of the proceedings (edited) of the Fifty-fifth National Conference on Weights and Measures, sponsored by the National Bureau of Standards, held in Salt Lake City, Utah, July 13-17, 1970, and attended by state, county, and city weights and measures officials and representatives of the Federal Government, business, industry, railroads, and associations.

Key words: Conference, weights and measures-laws; weights and measures -regulations; weights and measures-technical requirements; weights and measures-history; weights and measures.
\end{abstract}




\section{CONTENTS}

(NOTE: Reports of the standing and annual committees and the Treasurer's report have been arranged together, beginning on page 225 , for easier reference.)

Officers and Committees

Page

Committee Meetings-Monday, July 13, 1970

\section{MORNING SESSION-TUESDAY, JULY 14, 1970}

Welcome to Utah, by J. H. Francis, Commissioner, Utah Department of Agriculture

and Measures, Medina County, Ohio

National Bureau of Standards

Government and Technology: The Challenge of the 70's, by Hon. Myron Tribus, Assistant Secretary of Commerce for Science and Technology The International Organization of Legal Metrology and "The Challenge of the 70's," by A. J. van Male, President, International Organization of Legal Metrology

Presentation of Honor Awards, by Dr. Lewis M. Branscomb

Presentation of Plaque to M. W. Jensen

\section{CONFERENCE LUNCHEON-TUESDAY, JULY 14, 1970}

Guest Speaker: Hon. F. E. Moss, U.S. Senator, State of Utah

\section{AFTERNOON SESSION-TUESDAY, JULY 14, 1970}

The Challenges Facing Government, Industry, and Consumers, by M. W. Jensen, Acting Director, Institute for Applied Technology, National Bureau of Standards

Forum on Packaging and Labeling:

Status of Federal and State Programs, by E. A. Vadelund, Program Manager, Fair Packaging and Labeling Act, Office of Weights and Measures

The Support and Concern of Industry, by J. F. Speer, Chairman, Industry Committee on Packaging and Labeling, and Executive Assistant, Milk Industry Foundation

The Support and Concern of Producers and Distributors of General Merchandise, by P. W. Schindel, President, Association of General Merchandise Chains

Forum Discussion

\section{MORNING SESSION-WEDNESDAY, JULY 15, 1970}

Forum on Weighing Technology:

The Challenge of the 70's from the Viewpoint of the Scale Manufacturers, by D. B. Kendall, Chairman, Technical Committee, Scale Manufacturers Association, and Chief Scale Engineer, Toledo Scale Company 
The Aim of NSMA, by E. H. Fishman, President, National Scale Men's Association, and General Manager, J. B. Dee and Company, Inc.

Keeping Pace through Training, by O. K. Warnlof, Weights and Measures Coordinator, Office of Weights and Measures

Forum Discussion

The Role of the University of Utah in Advancing Science and Technol-

ogy, by Dr. J. C. Fletcher, President, University of Utah

Forum on Measuring Technology:

The Meter Manufacturers Look at the 1970's by H. E. Siebold, Vice President, Engineering, Liquid Controls Corporation

The View of Gasoline Pump Manufacturers Toward Modern Measuring Technology, by M. S. Godsman, Service Manager, Bennett Pump Division, John Wood Company

Objectives of the API, by R. Southers, Coordinator of Operations and Engineering, American Petroleum Institute

Measurement Studies, by R. M. Mills, Head, Engineering Unit, Office of Weights and Measures

Forum Discussion

\section{WEDNESDAY AFTERNOON-JULY 15, 1970}

Outing for Delegates and their Families

\section{MORNING SESSION-THURSDAY, JULY 16, 1970}

The Management of Change, by W. E. Cushen, Chief, Technical Analysis Division, National Bureau of Standards

Forum on Organization and Management:

Third National Survey, by Dr. L. J. Gordon, Director Weights and Measures Research Center, and Special Assistant to the President, Denison University

Management Information Systems, by D. E. Edgerly, Weights and Measures Coordinator, Office of Weights and Measures

Analysis of Wisconsin Program, by D. E. Konsoer, Director, Bureau of Weights and Measures, Food Division, Wisconsin Department of Agriculture

The Consumer Movement in Chicago, by Mrs. Jane Byrne, Commissioner, Department of Consumer Sales, Weights and Measures, Chicago, Illinois

The Consumers' Council of Massachusetts, by D. P. Shea, Executive Secretary, Consumers' Council of Massachusetts

The Commercial Weights and Measures Survey, by S. L. Hatos, Manager, Commercial Weights and Measures Survey, U.S. Metric Study, Office of Weights and Measures

Forum Discussion

\section{AFTERNOON SESSION-THURSDAY, JULY 16, 1970}

(The Thursday afternoon session was devoted to reports of the Conference committees, which will be found beginning on page 225.) 


\section{REPORTS OF STANDING COMMITTEES}

Report of the Committee on Liaison with the National Government, presented by J. H. Lewis, Chairman, Chief, Weights and Measures Section, Dairy and Food Division, Washington Department of Agriculture

Report of the Committee on Education, presented by G. E. Mattimoe, Chairman, Deputy Director, Division of Weights and Measures, Hawaii Department of Agriculture

Report of the Committee on Specifications and Tolerances, presented by R. Rebuffo, Chairman, Chief Deputy State Sealer, Bureau of Weights and Measures, Nevada Department of Agriculture

Report of the Committee on Laws and Regulations, presented by J. F. Lyles, Chairman, Supervisor, Weights and Measures Regulatory Section, Division of Regulatory Services, Virginia Department of Agriculture

\section{REPORTS OF ANNUAL COMMITTEES}

Report of the Outgoing Executive Committee, presented by R. W. Searles, Chairman

Meeting of the Incoming Excutive Committee

Report of the Committee on Nominations, presented by C. C. Morgan, Chairman, Sealer of Weights and Measures, Gary, Indiana

Report of the Committee on Resolutions, presented by M. H. Becker, Chairman, Sealer of Weights and Measures, Los Angeles County, California

Report of the Committee on Auditing, presented by J. C. Boyd, Chairman, Chief, Standard Control, Weights and Measures Division, Iowa Department of Agriculture

Report of the Treasurer, presented by C. C. Morgan

Conference Registration List

Handbook 44 Promulgation Map 



\section{OFFICERS OF THE CONFERENCE}

President: Lewis M. BBANScomb, Director, National Bureau of Standards. Executive Secretary: H. F. WoLlin, Assistant Chief, Office of Weights and Measures, National Bureau of Standards.

Chaiman: R. W. SEARLES, Sealer of Weights and Measures, Medina County, Ohio.

Vice Chairmen:

M. H. BECKER, Sealer of Weights and Measures, Los Angeles County, California.

J. R. BIRD, Supervisor, Technical Services, Division of Weights and Measures, Department of Law and Public Safety, State of New Jersey.

L. A. Gredy, Director, Division of Weights and Measures, Board of Health, State of Indiana.

C. Wooten, Chief, Weights and Measures Section, Division of Standards, Department of Agriculture, State of Florida.

Treasurer: C. C. MoRgan, Sealer of Weights and Measures, Gary, Indiana. Chaplain: J. I. Moore, Superintendent, Weights and Measures Division, Department of Agriculture, State of North Carolina.

\section{EXECUTIVE COMMITTEE}
E. W. BALlENTINE
R. C. BAUMgarTNER
J. T. BENNETT
R. J. CORD
F. J. FALLON
B. R. HAUGHT
F. D. MORGAN
I. A. RICK
L. W. VEZINA
R. T. WILLIAMS

(All officers of the Conference are, ex officio, members of the Executive Committee.)

(Officers and Executive Committee members elected by the 55th National Conference to serve the 56th National Conference on Weights and Measures will be found in the report of the Nominating Committee, page 283.)

\section{STANDING COMMITTEES}

(The remaining term of office for each committee member, in years, is shown in parentheses following each entry. H. F. Wollin, Executive Secretary of the Conference, is ex officio nonvoting secretary to each committee.)

\section{EDUCATION}

G. E. Mattimoe, State of Hawaii, Chairman (3)

J. I. Moore, State of North Carolina (1)

B. A. Pettit, District of Columbia (2)

E. PRIDEAUX, State of Colorado (4)

W. I. Thompson, Monmouth County, New Jersey.

(D. I. OfFner, St. Louis, Missouri, was appointed for a five-year term to replace W. I. Thompson, whose term expired. Mr. Prideaux replaced Mr. Mattimoe as chairman.) 


\section{LAWS AND REGULATIONS}

J. F. LyLES, State of Virginia, Chairman

S. D. ANDREWS, State of Florida (4)

G. L. Delano, State of Montana (2)

M. R. DetTleR, Seattle, Washington (1)

R. W. Richards, State of Pennsylvania (3)

(R. M. LEACH, State of Michigan, was appointed for a five-year term to replace J. F. Lyles, whose term expired. Mr. Richards replaced Mr. Lyles as chairman.)

\section{LIAISON WITH THE NATIONAL GOVERNMENT}

J. H. LEWIS, State of Washington, Chairman

M. Greenspan, New York City, New York (3)

R. C. Primley, Cities Service Oil Company (1)

A. SANDERS, Scale Manufacturers Association (4)

E. E. Wolski, Colgate-Palmolive Company (2)

(L. D. Holloway, State of Idaho, was appointed for a five-year term to replace J. H. Lewis, whose term expired, and also replaced $\mathrm{Mr}$. Lewis as chairman.)

\section{SPECIFICATIONS AND TOLERANCES}

R. REBUfFo, State of Nevada, Chairman (1)

W. C. Hughes, State of Massachusetts (4)

D. E. KonsoER, State of Wisconsin (2)

J. C. MAYs, Dade County, Florida (3)

R. L. Thompson, State of Maryland

(W. S. WAtson, State of California,' was appointed for a five-year term to replace R. L. Thompson, whose term expired. Mr. Konsoer replaced Mr. Rebuffo as chairman.)

\section{ANNUAL COMMITTEES}

Nominations: C. C. Morgan, Gary, Indiana, Chairman; E. H. Black, Ventura County, California; J. E. Bowen, Newton, Massachusetts; S. H. Christie, New Jersey; G. L. Johnson, Kentucky; J. I. Moore, North Carolina; F. D. Morgan, Utah.

Resolutions: M. H. Becker, Los Angeles County, California, Chairman; T. F. Brink, Vermont; G. E. Miller, Arkansas; R. L. SharP, Fort Worth, Texas; H. E. Smith, San Mateo County, California; C. B. Whigham, New Mexico; G. E. YARD, Illinois.

Auditing: J. C. BOYD, Iowa, Chairman; B. S. CicHowiCz, South Bend, Indiana; S. J. DARSEY, Florida.

Associate Membership: A. SANDERS, Scale Manufacturers Association, Chairman; M. S. Godsman, John Wood Company; L. J. Moremen, Plate, Cup \& Container Institute; J. F. SPEER, Milk Industry Foundation; B. WASko Voland Corporation; E. F. Wehmann, Neptune Meter Company. 


\section{IN CHARGE OF LADIES' ARRANGEMENTS}

Mrs. H. F. WoLLIN

\section{IN CHARGE OF REGISTRATIONS}

Mrs. F. C. Bell, Mrs. E. M. Burnette, Mrs. B. A. Davis

\section{OPEN COMMITTEE MEETINGS}

Monday, July 13, 1970

Monday was set aside for meetings of the Conference committees. Notices of these meetings were carried in the Conference Announcement booklet, in all pre-Conference publicity, and in the printed Conference program.

The Conference committees that met on Monday were the Executive Committee, the Committee on Education, the Committee on Specifications and Tolerances, the Committee on Liaison with the National Government, and the Committee on Laws and Regulations.

Many delegates participated in the committee meetings, which were very well attended and informative to all. The discussions which took place in these meetings were particularly helpful to the members of each committee and played an important role in guiding the committees in their deliberation and preparation of their final reports.

The final reports of the committees will be found beginning on page 278 and will reflect the discussion that took place during the open meetings and the actions taken by the Conference at the time the final reports were presented to the delegates. 



\section{REPORT OF THE FIFTY-FIFTH NATIONAL CONFERENCE ON WEIGHTS AND MEASURES}

MORNING SESSION-TUESDAY, JULY 14, 1970

(R.W. SEARles, Chairman, Presiding)

Mr. J. I. Moore of North Carolina, the Conference Chaplain, delivered the invocation and led the delegates in the Pledge of Allegiance.

\section{WELCOME TO UTAH}

by J. H. Francis, Commissioner, Utah Department of Agriculture

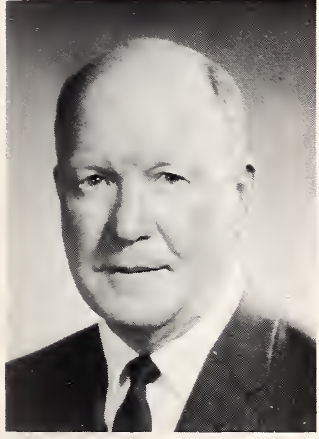

It is indeed an honor and a privilege for me to have this opportunity to welcome the 55th National Conference on Weights and Measures to the State of Utah. From the record and examples set at your past 54 meetings, I know you have brought to this Conference in Utah a considerable amount of enthusiasm and optimism, which are the basis for a successful Conference.

Your Executive Secretary, with the help of Fred Morgan and his staff, have put together a blue ribbon program, and the scheduled activities will prove to be a rewarding experience for all. However, as popular as you people are and as important as this Conference is, it would be an exaggeration of our hospitality for you to believe that all the banners put in the streets of this city were put up to welcome this Conference. As a result of your wisdom and good taste in selecting this time of year to hold your Conference, you share with us the rewarding experience of commemorating the history of the Mormons, who first came to Salt Lake Valley 123 years ago, on July $24,1847$.

Throughout the week you will be exposed to historical events which were responsible for the colonization of this area in the Rocky Mountain sector of our great nation. Time will not permit the reviewing of the many events that have brought about the industrial and social developments that have taken place during the past 123 years. Comparatively speaking, Utah is not a rich industrial state, and its monetary resources, though moderate and adequate for its population, would not show an impressive rating compared with other sectors of our nation. 
While our state is recognized to be only average as far as monetary values are concerned, you will find among the citizens of this state a high standard of faith in God, devotion to country, and dedication to constitutional government. In this area of national strength, Utah is not running second to any state.

As we review the problems of the nation today, it would appear we need a strengthening of our position and a positive action toward our democratic system of government by all citizens, especially those who are employed in government. The benefits and the greatness of our system of government are not only the responsibility of elected and appointed officials of state and federal government who are required to take the oath of office to support the system; it is also the responsibility of federal and state civil service employees to openly support our democratic form of government.

You, rather than laws and regulations, represent the image of our federal and state government. Your response is needed now. If a government employee, regardless of his stature, does not believe in our system of government or is not willing to commit himself to support it, he should resign.

While revolutionary and other groups will be knocking away at the system from now until the next Conference, federal and state employees will convene throughout our nation, and I challenge this and other such conferences to come out of dormancy and take an active position in the leadership to commit ourselves by a resolution at this Conference to affirm your position and your belief and personal activity to support our system of democratic government.

In conclusion, we are honored with the privilege of serving as host to your Conference. When it is concluded, we hope the environment which you have found to exist in Utah has measured up to your expectations. If so, we extend you an invitation to return soon. 
by R. W. SEARLes, Conference Chairman, Sealer of Weights and Meásures, Medina County, Ohio

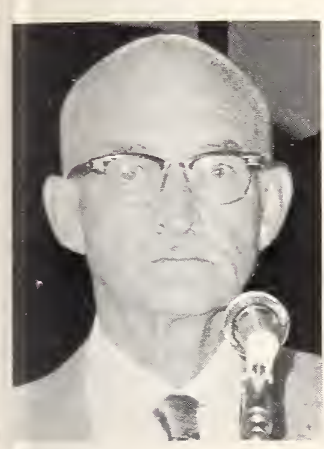

I am highly honored this morning to welcome you good people to the 55th National Conference on Weights and Measures. The program looks exciting and informative and offers us an opportunity to consider some of the challenges of the new decade.

I am impressed by the very warm welcome that was extended by our hosts, and we do thank them. Many of us are visiting Utah for the first time, and we are impressed by the beauty and grandeur of this great State.

Having attended the last 23 Conferences, I tried to remember when any Conference Chairman came from a "one-man" department such as mine. Finding none, I am doubly honored by serving as Chairman of the 55th Conference. Just a personal word about these National Conferences. It was not long after I entered weights and measures service that I found out that I did not need to work alone. The Ohio Division of Weights and Measures has always been ready to lend a hand. Also, there have been a host of friends and experts throughout the nation and in the National Conference on Weights and Measures on whose knowledge I have drawn. I have seen weights and measures grow from the days of the old. visible gasoline pump, the one with the glass bowl on top, to today's modern gasoline-dispensing systems; from the farm wagon scale to the automatic electronic scale; and from the open crackerbarrel to the thousands of prepackaged goods on the supermarket shelves. And so I hereby testify that my attendance at the National Conferences, starting with the 32 d Conference in 1946, has been one of the best things that ever happened to help me broaden my knowledge and keep pace with the changing times.

It was a great honor to serve on the Resolutions Committee during my second Conference in 1947. Dr. Edward U. Condon was President of the Conference that year, and Tom Kennedy from the District of Columbia talked on that perennial problem "Methods of Sale of Ice Cream," Ralph Smith of NBS explored the subject of "Regulation for Repairmen," Bill Bussey was still a lad from Texas, R. D. Thompson came over the line from Virginia, and Mac Jensen made it all the way from Madison, Wisconsin.

I got a bit dewy-eyed as I looked at the official photograph of that group taken on the steps of the Treasury Building in downtown Washington. First, I noted that I had a head of hair and 
weighed about 20 more pounds, but what really stirred me was the many familiar figures no longer with us. Ohio had four in attendance that year, and I am the only one left. I checked the registration of 265 delegates for the 33d Conference against the registration ten years later in 1957 and could find only 30 names repeated, and in last year's registration could find only nine names repeated. In 1947 only 26 States and the District of Columbia were represented. Last year 43 States, the District of Columbia, and Puerto Rico were represented and the registration numbered 477.

And so through the years our National Conference has grown in jurisdictions and in attendance by both industry representatives and active weights and measures officials. Each year we find more sophisticated weighing and measuring devices that require study by the Conference and a widening of our whole field of endeavor. Back in 1947, as right now, I found dedicated officials who took time to answer questions put to them by a country boy from Ohio. Over the years I have been privileged to serve as a Vice Chairman and have also served on the Specifications and Tolerances Committee. I was also pleased to have had a small part in the ceremonies of presentation of new State Standards to the States of Alaska and Hawaii shortly after they became States. But it was in 1951 that I came into my own, for I was then elected to look into the more spiritual side of the National Conference as its Chaplain. When I was informed last year that I might be elected Chairman for this Conference, I told the Nominating Committee that I would be very happy and content to continue as Chaplain-but here I am!

Now all of this is looking back, whereas our 55th National Conference on Weights and Measures has as its theme "The Challenge of the 70's." And so we shall try and project our planning and thinking into this new decade. It is well known that progress usually is built on what has been accomplished in the past. Many if not all of you belong to some State or regional weights and measures organization, and this is good, for you can best inquire into the local needs and programs within the smaller groups and thus help to promote more uniformity within the State. However, we also need to look beyond our State boundaries when we think of uniformity and new programs; and here our National Conference on Weights and Measures becomes a necessity, for here we find a common ground with the opportunity to exchange our views and ideas.

No single jurisdiction can bring about a major change in the national picture-for example, the adoption of the metric system. The history of accomplishment by the National Conference is clear evidence that, when we work together and combine our knowledge and strength with other interested groups, we can move mountains if need be. Let us continue, therefore, to share and to work 
together to implement national programs that will reflect back into our own jurisdictions. Thanks to the National Conference and to the help and capabilities found in the NBS Office of Weights and Measures, no jurisdiction should find it necessary to stand alone. Naturally, we must always keep in mind that which is best for those we serve. Being on the hospital board back home, we constantly talk about "what is best for the patient," not what is best for the doctor or even for the hospital. Perhaps that is why we like to operate our office under the banner of this Conference, "That Equity May Prevail."

The 55th National Conference on Weights and Measures has the task of setting the stage for another decade of progress in the field of weights and measures. Our efforts here this week will take us one step closer toward that highly desirable but sometimes elusive goal of equity. As Chairman of the Conference, I received copies of the interchange of correspondence between the Office of Weights and Measures and the standing committees of the National Conference, and I admit that I was very impressed with the variety of subjects involved. I accumulated a stack of mail this high, and I also admit that I was baffled several times in trying to understand some of the problems presented. Now I know why the appointment of members to the various Conference committees must be done with great care. Committee members must be not only knowledgeable, but they must have the necessary time to study new methods, new devices, and other changes proffered by weights and measures officials, sectional groups, and industry, all working together in our field of endeavor.

I remember some of the program items during the National Conference in 1947 consisted of a symposium on frozen foods, a recommendation for the method of sale of garden seeds, and a presentation on the hazards involved in the handling of liquefied petroleum gases. During this week we will consider the labeling requirements for pillowcases, the testing of tire air-pressure gages, and requirements for automatic temperature compensators. I suspect that perhaps some of the gentlemen who served on committees in 1947 might also feel baffled by some of this, but this is progress. Those of you who may be fortunate enough to attend the 65th National Conference in 1980 may look back and smile a little at what we accomplished this week. But I can guarantee that what is done here in the next few days will be toward that goal of equity and will be in a much broader field of endeavor than anyone envisioned in 1947.

Increasing every year, and particularly during the past several years, has been the cry for consumer protection. We have all watched the struggle toward fair packaging and labeling, and it has been necessary to adopt new laws and regulations. I personally 
feel there is much more to be done in this field, even though a giant step forward has been taken in this area. Yes, progress and change must be reckoned with! Although I think there will always be a need for someone to place a test weight on a scale and to use a test measure to check a meter, surely we all can see in the not too distant future the need for certain specialists in at least the State offices of weights and measures. Right now we must educate our public, keeping them abreast of what they should expect in the market place. We also need to educate and keep up to date all those enforcing the laws and regulations. It is very necessary that every jurisdiction underline the importance of weights and measures in the economy of the jurisdiction and the nation. Weights and measures officials should have a feeling of pride in their work and should welcome the opportunity to help bring about more equity in the market place. As prices continue to spiral upward, it is our responsibility to continue to move forward in every phase of our work.

I know that I speak for all members of this Conference when I tell of my high regard and appreciation for all the members of the Specifications and Tolerances Committee, the Laws and Regulations Committee, the Education Committee, and the Committee on Liaison with the National Government. I wish to express our appreciation to the various associations of industry and other groups who have continued their support of the National Conference. All of these and many more have worked long and hard that we might have a successful Conference. Our appreciation also goes, of course, to Thomas Stabler and Harold Wollin and their staff. You talk about dedication to their task-these men are just that, and we are grateful. And my personal word of appreciation to the officers and members of the National Conference, who have done so much. You will see and hear many of those mentioned during the ensuing week.

Finally, it is indeed a great pleasure to welcome our new Conference President, Dr. Lewis M. Branscomb, Director of the National Bureau of Standards. I know that all of you ladies and gentlemen will give him a very warm welcome.

And so, let us move on with the proceedings of this the 55th National Conference on Weights and Measures. With your attendance and full cooperation and participation, I am confident that we will successfully begin to meet the challenge of the 70's. 
by Dr. Lewis M. Branscomb, Director, National Bureau of Standards

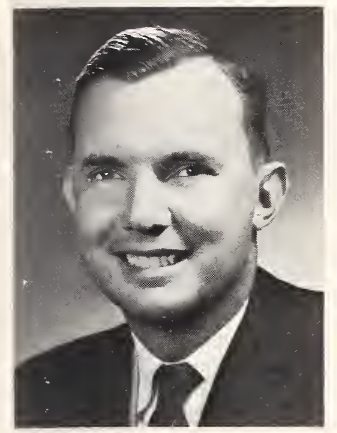

It is an honor as Conference President to assist in the opening of this 55th National Conference. What a pleasure it is to meet in this beautiful state and city where clarity of the air and brilliance of the sun match the warmth of our welcome. All of us owe a special debt of gratitude to Mr. Joseph H. Francis, Commissioner of Agriculture, and Mr. Fred D. Morgan, Supervisor of Weights and Measures, for this welcome. And I owe a special debt to the man who permits my duties to be honorary, your hard-working Chairman, Mr. R. W. Searles. I have another special reason for pleasure that Utah is our host, for you from Utah can welcome home one of your own sons whose distinguished shoes I try to fill and who was for 18 years the fifth Director of the National Bureau of Standards-Dr. Allen V. Astin. Dr. Astin had the pleasure in 1967 of presenting to Governor Rampton the new State Standards for Utah, which was the fourth state to receive them.

Although I count Colorado my legal residence and home state, I must admit that Utah provides a wonderful environment for her citizens and her guests. Of course, not everyone is happy with the clear air and sparkling waters of Utah's mountains.

Story: A man in Los Angeles, offered a big promotion to go to Utah, quits his job, packs up his family, says goodby to his boss, and leaves. A week later he calls his boss, "Joe, can I get my old job back-"

"Didn't they give you the responsibility and salary-"

"Not that."

"What's the problem-"

"Those people in Utah expect me to breathe air I can't see and drink water I can't chew."

People are adaptable, to be sure, but only up to a point. Today, many people, subjected to the many frustrations that accompany modern urban life, are expressing that frustration in the way the citizens in a democracy are entitled to express it. They say to their elected officials, "We don't know why things aren't right, but it's your job to figure it out and fix it." And when the source of the citizen's frustrations is also the source of his well-being (that is modern technology), the fixing may be very hard to do. 
How do we protect citizens from hazards, promote consumer satisfaction, enhance the nation's economic strength, preserve our natural environment, and do all this by means that preserve competition and free choice, encourage innovative technical solutions to problems, and minimize social conflict and excessive stress on our liberties and our domestic political system?

Modern technology and our integrated mass market are the source of our wealth and well-being; for high wages come from high productivity, and high productivity comes from advanced technology applied to production with large economies of scale. Two hundred million consumers in one market permit the capital investment that gives technology a chance to provide the goods we want. Modern communications permit the seller to reach that national market. Modern transportation permits the distribution at low cost of his goods from coast to coast.

But all of this would be impossible without a compatible system of state weights and measures and commercial regulations. Without it, our economy would be balkanized into 50 markets, a condition that was very nearly obtained before the turn of this century and that led to the formation of the National Conference on Weights and Measures. If you want a demonstration of what happens when local regulations, intended to protect consumers, in fact prevent a uniform national market accessible to our industry, look at housing construction, which is bulkanized by the great variations from place to place resulting from the variances of the building codes.

On the effectiveness of your work, and of your working together, the health of the national economy depends. But a national market also exacts a price.

(1) There was a time when you gained most of your product information across the counter from the man who sold the product to you. Sales persuasion is now a one-way conversation with the TV set. Salesmen cannot know much about a product designed by engineers 1,000 miles away.

(2) Many consumers have excessive expectations. They expect too much from technology, and are in some sense trained to do so. Marshall McLuhan in his book says that advertising trains us not so much in the value to be derived from a product as in training us in the emotional satisfactions that we should receive. Certainly it is true that advertising less and less seems to give us objective factual information about product efficacy or value. Perhaps consumers would be less emotional about frustration in the marketplace if they were told the mean life-to-failure of the product, whether to repair, and what performance to expect. 
(3) When consumption takes place on a national scale at present volumes, the unseen third party to every transaction (all the citizens in the nation other than the two involved in the transaction) is then affected by the entire cycle of natural resource exploitation, of the byproducts from manufacturing, and ultimately the waste-disposal problem when the product has ceased to serve a function.

(4) What is the basis for trust in the anonymity of the marketplace? Who made the product? Were they honest? How many bouillon cubes does the jar really contain? How many gallons of gas did I really get? The present system of dispensing gas as compared to the old-style manually operated gas pump is far more accurate and undoubtedly more fair and more honest, but it does require a greater act of faith on the part of the consumer that the machinery inside that pump is doing what the dial says it is doing.

It is clear that any market transaction requires a clear and unambiguous language in which price and quantity of the product are described and verified. If either part of this measurement (the billing on your credit card or the metering of your gas) is open to suspicion, the very idea of trade breaks down. Confidence in the integrity of a free market is essential if that freedom is to be preserved. The states have this constitutional responsibility, with the National Bureau of Standards setting the national measurement standards and, under law, "cooperating with the states in securing uniformity in weights and measures laws and methods of inspection."

It is right that this responsibility should be exercised at state level, close to the people, precisely because confidence in the honesty of the marketplace can best be reached when it is generated within one's community or one's state, close to home, by people that are familiar to you and responsive to your local government. For this reason it is important that your work be publicly visible to the citizens of your state. In the discussion of consumer protection that sweeps the land today, you don't hear very much about unfair quantities in the marketplace, and that is a tribute to the job that you and your predecessors have done in this National Conference and in your own states.

But confidence in honesty of price and quantity is not enough. One potato may be much like any other, at least as to weight, but this is not true of a lawn mower or a TV set or a motor car or carpet.

Increasingly, the consumer is at least as interested in performance as in quantity. But how can buyer and seller agree on how the promised performance is to be measured-And when the mat- 
ter of performance is technically complex and hard to discern in everyday use (as it usually is with gasoline octane ratings, detergent additives, electronic devices or vitamin pills), who will help the consumer to maintain his confidence in the marketplace?

Another factor affecting consumer confidence is product safety. The states, close to the local marketplace, are surely in the best position to exercise surveillance of what is actually in the marketplace and relate safety requirements to the needs of its own citizens.

In both product safety and in product performance, a larger role is being urged on the federal government. And in the area of both mandatory and voluntary standards, it is essential that there be sufficient uniformity across the nation to avoid fragmenting our national market. But as you who monitor the honesty of scales in retail trade know full well, factory-level inspection is not enough in many cases. A giant army of federal inspectors would be necessary if the states did not play a major role in the growing effort to make our lives safer and our marketplace one in which the citizens have confidence.

You may perhaps feel that these areas of concern such as product safety and the fair claims for product performance do not impose technical obstacles of quite the same kind as you are confronted with every day, but the testing program to verify compliance with a performance standard is always very much more complex than one to verify design standard. Yet this is the direction in which we must move, and the weights and measures laboratories of the states seem to me the best resource around which to build these capabilities.

Even within the scope of the present responsibilities, the concept of performance criteria for fair quantity arises with increasing frequency. The weight of shaving cream actually in an aerosol can is irrelevant if the entire contents cannot be dispensed. In dehydrated foods, it is the reconstituted quantity that is important to the housewife. In all such matters it is, in fact, the final performance of the goods when it is in use that is of concern to the buyer.

The National Burcau of Standards is proud to be a partner with you in meeting the challenge of the 70's. Our goal is to promote the strength of science and technology and their effective application for public benefit. We seek to establish the technical basis for the national measurement system, accurate enough to meet all the needs of science, industry, and commerce. And through collaboration with the National Conference, we offer our best effort to insure honesty and integrity in the commercial use of measurements, which covers every transaction made in the daily lives of our citizens in the marketplace. 
Often we must ask ourselves, "What is fair, and how do you measure fairness; how much accuracy is enough?" You face this problem constantly in the search of criteria for requirements set forth in Handbook 44 and in your state regulations. Here you face another challenge-to balance technical feasibility and economic cost of an improved accuracy requirement against the ideal of perfect accuracy in the marketplace. We at NBS have much to learn from your experience in the effort to put this decision on a more objective and rational level. I know the problem is a very difficult one, but I believe that ultimately we, industry, and even the citizen must learn how to decide what price each of us should pay for improved accuracy. The problem is made most difficult because our objective is, itself, subjective-confidence in our economic system and the fairness of our marketplace.

I am well aware of the fact that every state weights and measures laboratory is working with a minimum of resources and is struggling to keep up with the basic job of checking scales, measures, flow meters, and all of the other devices that are used in trade. I have had the very great pleasure in my first ten months on duty as Director of the Bureau of Standards to participate in three of the occasions of states receiving their new standards, and that has given me a chance to see a little bit of the inside of a few state operations.

You are a vital part of the team of technical people on whom the nation depends for the regulation of technology to protect the public, a public that, if it becomes sufficiently disillusioned with technology and service to our country, might follow the lead of some of the younger generation and reject technology, the good and the bad, and economic and political traditions along with it, if we cannot maintain confidence in the marketplace.

Thus, I would like to leave you with a few questions to stimulate your discussion and thought.

As we continue our relationship together, we should give some thought to the future and the additional responsibilities that it will bring, and how we might develop the resources to meet them.

No doubt we will be more and more concerned with metrication. We need your help now in our study of the advantages and disadvantages to the United States of possible increased use of metric language and metric usage. If and when this country decides that it should make a substantial move in the metric direction, then you will have a major educational as well as operational role in carrying out that transition. The basic question now is, what is the nation's best course in a world soon to be speaking a different measurement language?

We hear a lot in Washington about consumer frustrations and complaints, and we hear relatively few about short measure. But 
how good is the state-by-state surveillance of the effectiveness of our state weights and measures programs? Could the Conference develop a uniform methodology for evaluating the basis for public confidence in fair measure so that each state can know how well it is doing?

What is the role of the state weights and measures laboratory in the broader responsibility of the state government for consumer protection? Is not the technical capability that you and your laboratory colleagues represent a logical and perhaps even an essential resource around which to build state programs in product safety? Should the states extend their weights and measures activities to include inspection of product claims that depend on measurement, such as reconstitution of packaged commodities, octane ratings, etc.?

Can the National Bureau of Standards improve its service to the states in this vital field? Is there a need for better coordination of federal responsibilities in the area of weights and measures? In the area of packaged goods for interstate commerce, have the federal government and the states worked out the proper division of responsibilities and put in effect the needed inspection programs?

Finally, would it not be worthwhile to consider establishing a long-range planning committee to help the Conference evaluate the alternative directions for its development? If you take seriously the spectrum of responsibilities that I have been describing, then you would surely be forced to choose among them, because the burden will be very great indeed to attempt to do them all.

With a fine record of performance behind it and a very challenging set of opportunities for service in the future, the National Conference will in any case surely make a major contribution to our continued enjoyment of what has come to be known proudly as the American way of life.

Now as your President it gives me the pleasure to bring to your attention the appointments for service on standing committees. The individuals recommended for these committees have all had considerable experience in the weights and measures field and in the work of this Conference, and I believe they fully understand the obligations and opportunities of standing committee service, for which all of us are grateful to them. These appointees will serve a five-year term.

For the Committee on Education, Mr. Daniel I. Offner, Commissioner of Weights and Measures, St. Louis, Missouri, to succeed Mr. William Thompson of Monmouth County, New Jersey.

For the Committee on Laws and Regulations, Mr. Ronald M. Leach, Acting Chief, Food Inspection Division, State of Michigan, to succeed Mr. James F. Lyles from the State of Virginia. 
For the Committee on Liaison with the National Government, Mr. Lyman D. Holloway, State of Idaho, to succeed Mr. John H. Lewis from the State of Washington.

For the Committee on Specifications and Tolerances, Mr. Walter S. Watson, Chief, Bureau of Weights and Measures, State of California, to succeed Mr. Richard L. Thompson of the State of Maryland.

\section{GOVERNMENT AND TECHNOLOGY: THE CHALLENGE OF THE 70'S}

by the Honorable Myron Tribus, Assistant Secretary of Commerce for Science and Technology

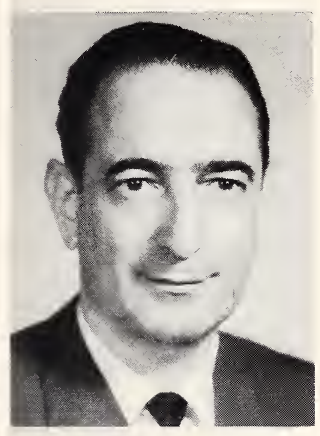

The weights and measures system of this nation is probably the leading model for cooperation involving State, local, and Federal governments and the private sector. Those who are interested in promoting the new federalism in other fields would do well to study what has been done by this organization over the past half-century or more. You have set a pace that has been helpful to the growth of our technological society. To keep it running we need to have special services which smooth the interface between technology and society. That, in a very broad sense, is what you do.

It is important to keep in mind that there is an enormous difference between the problems of creating wealth and of distributing wealth. This country, with most of the Western world, has demonstrated that in the creation of wealth there is no system which comes anywhere near matching the free, private enterprise system. But that system does not of itself guarantee anything about the distribution of the wealth created. Now that we have recognized the enormous potential that we have for the production of wealth, we are only lately turning our attention very seriously to how wealth is distributed. With the growth of technology and its effect on so many aspects of everyday living, we find it more and more necessary to pay attention not only to the direct effects of technology, but also to pay attention to its side effects as well. In these fields we have a great deal to learn, especially about things Government ought not to do as well as the many things which it must do.

Government must be in the act and in the future it must play a more significant role in technology than it has in the past. How to play that role without destroying the creative heart of the system 
is the challenge that we all must face. I recommend that everyone who tries to inject Government indiscriminately into the marketplace go back and read again the fable of the goose that laid the golden eggs.

I think it fair to say that you here represent one of the earliest kinds of Government intervention in the impact of technology on the distribution of wealth. This endeavor of yours is one of the finest and least controversial, for an honest system of weights, and measures benefits both buyer and seller and promotes the common good. Unfortunately for those of us who must be concerned with budget justification, it is extremely difficult to demonstrate in cold dollars and cents just how much good this system does. When Dr. Lewis M. Branscomb (Director of the National Bureau of Standards) was talking about the fact that your work allows people to maintain their faith in the system, I was struck by the thought that, somewhere, there must be somebody who will help me and Dr. Branscomb show others that indeed we do what we say we do.

There is a tendency to regard these standards activities as a minor extension of the law enforcement process, and to pay a great deal of attention to the policeman's role-or at least your role in providing the policeman with the evidence. But standardization is much more than that, as I am sure you are well aware. We still need to convince the public and the legislatures that standards are all-important to business and to the public. The fact that a kilogram in one state-you see we're going metric-means the same as a kilogram in another provides the assurance to a manufacturer that he can produce uniform products for the entire country. And, as Dr. Branscomb said, economy in production with efficiency in distribution is the key to our high standard of material wealth.

What we are coming to realize now is that something like your effort needs to be duplicated in a much wider variety of fields. Whether that duplication of effort will come by an expansion of your work, or by the creation of new institutions, I cannot say. There are too many political factors inherent in this for me to attempt to make a prediction now.

If I discuss a few of these fields with you, you might see some virtue in a closer examination of your role in society and a closer examination of what it is that makes your organization function successfully. At the very minimum, this would put you in great shape to answer the questions that I think will be directed at you by those who wish to attempt to learn from your experience. Take the field of housing. We desperately need to remove the barriers to better technology in housing. And one important way to achieve this goal is to make certain that a large enough market for housing components is created so that the cost savings of serial pro- 
duction can, in fact, be realized. For this savings to come about we need to be able to construct components and ship them all over the country with the assurance that when they arrive they will be acceptable to local codes and standards. This might mean that we should strive to achieve one national code or standard.

The National Bureau of Standards is now engaged cooperatively with the states in the development of a national conference dealing with building codes. This conference will bring together the people working in housing at the state level in the same fashion that occurs here in weights and measures. The format of the new organization is very similar to yours, partly because some of the same people in the Bureau are working on both meetings. The same problem of demonstrating to budgetary personnel their value to society arises for them as for you. Again it is hard to prove the worth of their efforts, particularly since they haven't done anything significant yet in terms of affecting the market-palce. I wonder if indeed the history of the beginnings of your organization has been properly documented and if the record has been examined, because there are some lessons there. If nothing else, it may be a comfort to those who start the new organization to go back and see what had to be overcome when this organization was started.

Well, don't be surprised if, on your return home, you are contacted by some friends in your state who want to know, for example, how you go about defending your budget.

Of course you are well aware of various annual conferences of states to deal with the problems of automotive safety and highway design and the like. I won't dwell on those. Certainly we're going to need similar ventures in the field of pollution, especially in the matter of enforcement of standards and finding agreement on measuring techniques. I doubt very seriously that these needs are properly appreciated in any of the important levels of decisionmaking in the field.

My guess is that-after the first few law cases have been decided, with the attendant publicity and quarrels-then the integrity of the measurement system will be acknowledged as important. Then it will be decided that we have to do something about it. Here too I suggest that your experiences can be of great value. By now you ought to know how to make calibrations and how to keep records which will stand up in court. This same ability to guarantee the technical integrity of what you have done and to make it absolutely clear to laymen will be required in other fields.

My job as Assistant Secretary for Science and Technology is to look over the whole technology and to try to anticipate some of the things technological advance will do to society. I thought you might like to hear some comments that I have about where I think 
we're going and what the challenges are. I've had enough different problems rolling across my desk that I think I see a pattern. Generally, I find myself having to deal with five elements :

First-because I happen to be one-there is the entrepreneur, the fellow who for one reason or another is trying to introduce the new technology. Second, there is the hardware of the technology itself, the gadget, the device, or the system. Third, there is the software, that is, the systems of laws and regulations, the organization, the business, the contractual arrangements, the human relationships. Fourth, there is the consumer or the sector of society most directly affected. Sometimes it is hard to define who the consumer really is. Fifth, there is the government at some level and perhaps at all levels.

All five elements-the entrepreneur, the hardware, the software, the consumer, the government-need to be considered.

When approaching a new problem $I$ find it useful to study all five elements separately and then look at their relationship one to another. Because if the total service to society is to occur, all five of those elements have to be in place and functioning in relation to one another reasonably well.

Let me mention each briefly:

The entrepreneur: Can he see sources of capital? Does he have to battle a confusion of laws and bureaucracies and public indifferences? Can he be rewarded for acting in the public interest, or, in fact, are the laws and the reward system so arranged that he is better off by not acting in the public interest? It pays to ask questions like these, yet it is interesting that quite often when you ask such questions, the very people that you are trying to help, think that you are out to get them.

The hardware itself : Is it really working? Do we understand it? Can we predict its behavior? Is it practical? Can it be produced, and at what cost, with what reliability, and the like?

We then have to think about the software. What kinds of institutions do we have that deal with this particular area of technology? What are the laws, and who wrote them? What did they think they were doing when they wrote them? Who has the authority to make decisions in the area?

The consumer: Who is he or she? Who speaks for the consumer, and who should speak for the consumer? Those are not the same question by a long shot. Who really knows what the consumer's preferences are? What is the consumer's state of knowledge, and for that matter what is the consumer's state of ignorance? If we don't understand that, we are likely to interfere in ways that are totally unpredictable.

Then finally the government: What does it do now? Who does it and with what authority? For what purpose? Who has the power 
and what are the political considerations? The thing that has been hardest for me to keep in mind is the most important lesson I've learned since coming to Washington. Namely, in any change the first question you ask is who gains power and who loses it? And if you have a technical education it is hard to overcome it and think of that problem first.

By way of example, I'd like you to consider with me one area in which it's clear that action is needed, and has been needed for some time. I only use it by way of example to show you how these five elements come together, and how one in my position thinks about them.

Consider the field of communications. Under Reorganization Plan Number 1 for 1970, President Nixon has created a new Office of Telecommunications Policy in the White House, and he has called upon the Department of Commerce to establish an office in support of this activity. We are now in the process of creating a new institution, something like a national bureau of telecommunications.

Among other things, I want this organization to be concerned with coordinating the work of the state directors of telecommunications, where they exist; and where they don't exist to try to persuade the governors to create them.

The first element- the entrepreneur-is there; in fact there are lots of them. They've got all kinds of new systems of communication that they would like to see put in place. And there are in fact important needs for them to meet. For example, radio systems installed along highways to give drivers warning of what the conditions are along the road. Out here you don't have very far to go to drive over a mountain pass. It is extremely difficult as you start up that mountain pass to get good, reliable information as to what it is like at the summit and just beyond. Or if there has been a serious accident along the highway you don't know about it until you come upon it. So we need systems like that. We also can use much better systems for providing statewide medical services, communications with ambulance systems, and the like. To develop these systems takes a lot of money. The entrepreneur needs to have a way of interacting with the market, and today the market is so badly fragmented in the 50 states it is very hard to get anything going.

The consumers, that is the state organizations which purchase for hospitals and police forces, if no action is taken, may continue to provide just too small a market, or make too wide a variety of demands, so that no one can afford to put in the money that is required for the system development required.

We in the Department of Commerce foresee the need to produce an institution which will bring these people together and which 
will provide a convenient form for the entrepreneurs, the consumers, and the general public to work together.

We have here in the telecommunications field, then, five elements of which I spoke. The entrepreneurs are there ready with confidence and, in fact, with the capital. The consumers are there. Most of the hardware is ready or can be made ready with rather small cost. What is lacking is the software, the institutional arrangements which facilitate the introduction of the technology.

What is called for, therefore, is the coordination of these interests. The state needs have to be made known on a continuing basis. With Government providing a basis for this, providing an office and smoothing this interface, we think we can allow the private sector to do what it ought to do for our society.

Of course it is also necessary to be aware of more than just what the new technology can do. We need to be sure there are no side effects. As you know, that phrase "side effects" takes on a great deal more meaning today than it did before. I think we can go back and restate the biblical question for today: am I my brother's environment? The answer is clearly yes.

We have come to recognize that there are now so many of us doing so many things that we get into one another's way. One man's side effect may be another man's disaster. I have to remind my hippie friends that the Ganges River is one of the most polluted rivers in the world, and it is polluted because all those Indians are busy doing their thing.

The field of pollution presents us with a particularly important example of the need for government action. I am extremely pleased that the President has proposed to consolidate the major pollution programs in one agency, to be called the Environmental Protection Agency. This is an important first step, and those of us who are in the sciences and those of us who have concern for measurement, as well as those of us who have responsibility for environmental sciences-you see my office has all three-are watching it with interest. We are doing our best within the Government to bring to the attention of all the decision-makers the fact that, in this new Environmental Protection Agency, it will be absolutely essential to guarantee the integrity of measurement. It will be absolutely essential that the people who make the important decisions in that organization realize that, even though it is extremely tough to prove to the Office of Management and Budget that a measurement at 5 percent level is acceptable, but one at 10 percent isn't good enough. If people lose faith in the integrity of what is said by those who are to protect the environment, they will lose faith in everything. I don't know how to put a dollar value on that.

Earlier I said that the production of wealth and the distribution 
of wealth were not the same thing. But they are, of course, related. Industry considers that marketing is as significant to its survival as is production. We now observe the problems of marketing being affected by Government in ways which are exceedingly complex and difficult to predict or even comprehend. Quite a few of these effects have been initiated under the general label of consumerism and consumer protection. They arise either out of the concern for the consumer's safety or his right to know what he is getting for his money.

The five elements of which I spoke are present here, too, and need to be considered one by one. This is a much more difficult undertaking because we're usually dealing with long-established practices and a multiplicity of entrepreneurs.

In the field of product safety the task is a little easier than it is in this general field called consumerism, which is concerned with honesty in the marketplace. Unsafe products are not too difficult to identify, in the extreme. With proper leadership, the Government can quite directly alleviate many problems of unsafe products.

I am quite pleased to see Mac Jensen (Acting Deputy Director, Institute for Applied Technology, NBS) in the audience here because Mac recently directed an activity that illustrates exactly what I mean. Not too long ago he discovered that there were quite a few deaths of children who had become imprisoned in small picnic coolers. It never occurred to me-and presumably not to manufacturers or to the public-that those might be traps. But little toddlers can climb into them or fall in them, the lid can bang down, and the latches close tight, and that nice insulated box becomes a death cell for a child.

On recognizing this problem, Mac was able to develop a voluntary program with industry to design safety features into these coolers. In due course, the results of his work will probably become part of mandatory legislation. But I'm quite certain that most of the job will have been done long before the laws can take effect by our working cooperatively with the representatives of industry, and even going so far as to show them alternative designs. Because they care-and I believe most businessmen are responsible-and because this is important to consumers, the matter will be corrected. I'm quite confident it will be corrected long before the Congress feels it necessary to pass a law.

A particularly interesting example of the creation of a special institution and a special approach to correct a problem of product safety has been the Flammable Fabrics Act of 1953 and 1967. I have the responsibility of administering these Acts for the Department of Commerce. Anybody who likes to be in the middle of consumers, distributors, and producers, in a game like this, can have a lot of fun in a job like mine. 
Here, of course, we have easily identified the entrepreneurs and the consumers. And we know a lot about the hardware. We haven't decided upon the software, that is the setting of mandatory standards. What holds us up is the fact that after we've examined the technology very carefully we find that it really isn't adequate.

We have been told for so long that our engineers and scientists can work any miracle, if we just give them some money and tell them to do it, that it's hard for people to believe when they don't always deliver. They suspect that somewhere there has been some culprit around holding them back. It is very difficult for people to believe that technology can't deliver in a particular instance. But the hard fact is that cotton clothing has been around since the early Egyptians. With the long history of technology behind it, cotton cloth is now one of the least expensive high quality products we can find. Unfortunately, cotton burns. To make it flame retardant means adding something to it, and that something generally costs a lot more than the cotton. The additive may affect the utility of the cloth in regard to how it feels, how long it lasts, how long it keeps its appearance and so on. There is a close connection between the problems of marketing and technology right here. People are very fussy about their clothing, and those of us who are charged with coming up with standards must always be concerned with the thought that the consumer might outfox us and simply ignore our standards.

The British put in a standard for children's nightwear, but the clothing was not very comfortable, so mothers just started making nightwear out of other cloth. In the U.S. we have this problem of going into the marketplace and trying to guarantee that something like 22.7 billion dollars worth of clothing, all at once, be made flameproof. BDSA says that is total domestic sales of clothing last year. We could be more selective and try to do it for, say, children's nightwear, leaving open the opportunities for consumer demands to be subverted. It is not an easy problem at all.

There will be similar standardization problems in regard to air pollution. The very severe requirements regarding auto transmissions in 1975 will probably compromise the performance of automotive vehicles. There will be a degradation in performance compared to what the automobile could have done without that penalty. In due course, automotive engineers will learn to design around those requirements and still get some of the performance we want. But some people who like to haul a boat behind their car up the mountain to that mountain lake may discover that those octane numbers were useful. At the moment, we don't know how to get clean air with lead in gasoline. We really want to have clean exhaust and the only way we know how to do it reliably and reasonably inexpensively is with catalysts that are poisoned by lead. 
Lead is the cheapest way we know to get high octane numbers. You can take ordinary gasoline, put a few drops of lead in it, and it's got a higher octane number. You can go up that mountain towing that trailer behind you, and the engine doesn't knock. You don't have to shift into second gear and let all of the other little cars pass you. Our problem is this: Will the people believe in the integrity of the system as a whole and accept that loss in performance as something they have to put up with? Or will they subvert the system either because they don't believe us when we tell them the connection between what goes on in their car and what goes on in the atmosphere, or because they believe somebody is making something out of it? Well, these are some of the problem areas in which we will all need to participate in the problems of Government and technology.

With our Nation's size and complex way of life, we are now so intimately bound up with one another's futures that cooperation has become mandatory. If this cooperation is not to infringe unduly on our freedom, then it must be carried out by a system in which we can indicate to one another what we're doing and what is acceptable.

I believe we often can learn to recognize what constitutes the common good. I believe we can strive towards it individually. But for each area of technology this means, in the end, the establishment of something analogous to the national system of weights and measures. Without genuine concern for integrity of information we shall soon be trapped by our own cleverness. That, it seems to me, is the challenge of the '70's. 
by A. J. VAN MALE, President, International Organization of Legal Metrology

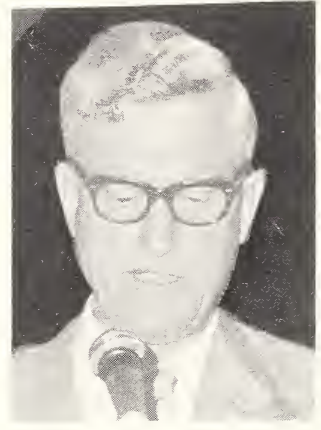

This is the second time that a President of the International Committee of Legal Metrology has had the privilege of receiving an invitation to attend and address the National Conference on Weights and Measures in the United States. Many of you will remember that it was in 1963 that my distinguished predecessor, Dr. Stulla-Gotz from Austria, attended and addressed the 48th National Conference.

I accepted the invitation of your President, Dr. Branscomb, with great pleasure, and I am delighted to be your guest in this country and, in particular, in the world famous Salt Lake City, in the midst of colleagues and other representatives who are concerned with weights and measures administration in your country today.

In 1963 my predecessor carefully defined the goals and purposes of the International Organization of Legal Metrology (which I shall refer to henceforth by its abbreviated French title (OIML)), and I do not think that it will be necessary for me to list these in detail again. I shall restrict myself here to suggesting what is the most important purpose of the organization, outlining its achievements so far and mentioning some of the things that have to be done in the coming decade.

The main purpose of OIML is to establish the necessary minimum technical requirements which measuring instruments have to possess in order for them to be approved by member states and for them to be recommended for international use.

After the Third International Conference on Legal Metrology, held in Paris in October 1968, and the meeting of the International Committee of Legal Metrology, held in The Hague in April of this year, minimum technical requirements have already been laid down in OIML International Recommendations for 19 subjects. These recommendations will be published shortly. They cover 19 subjects, namely:

1. Cylindrical weights from 1 gramme to 10 killogrammes (of medium class of accuracy).

2. Rectangular weights from 5 to 50 kilogrammes (of medium class of accuracy). 
3. Metrological regulation of weighing instruments with nonautomatic operation and commentaries concerning the determination of the errors on weighing instruments with discontinuous indication or impression.

4. One mark glass measuring flasks.

5. Meters for liquids (other than water) with measuring chambers.

6. General prescriptions for volumetric gas meters.

7. Clinical thermometers (mercury, in glass, with maximum device).

8. Working standard method for the verification of instruments for measuring the degree of humidity of cereal grains.

9. Verification and calibration of hardness reference blocks Brinell.

10. Verification and calibration of hardness reference blocks Vickers.

11. Verification and calibration of hardness reference blocks Rockwell B.

12. Verification and calibration of hardness reference blocks Rockwell C.

13. Correspondence symbol.

14. Polarimetric saccharimeters.

15. Instruments for measuring the mass per hectolitre of cereals.

16. Pressure gauges for instruments measuring arterial blood pressure.

17. Indicating pressure gauges, combined pressure and vacuum gauges and vacuum gauges, with pressure-responsive elements giving direct indications by means of a pointer and graduated scale (working equipment category).

18. Optical pyrometers with disappearing filaments.

19. Recording pressure gauges, combined pressure and vacuum gauges, and vacuum gauges, with pressure-responsive elements and recording directly by means of stylus and diagram (working equipment category).

These international documents have been prepared by a method which is customary in the OIML and which Dr. Stulla-Gotz has already explained to you in detail. There is, therefore, no need for me to refer to it again, particularly since it does not differ essentially from the methods used by other organizations, such as the International Organization for Standardization (ISO) and the International Electrotechnical Commission (IEC).

I would suggest, however, that the method provides a guarantee that the final documents represent the best possible compromise 
which one can expect, bearing in mind the originally strongly divergent opinions. It does not guarantee that all the countries concerned, not even those which belong to the working groups, will be in complete agreement with the final text. However, I am glad to be able to say that, generally speaking, members of the working groups are ready to accept compromise solutions. Two major factors are constantly borne in mind, viz., (1) the measuring instruments which are manufactured on the basis of the specifications to be drawn up must guarantee a reasonable certainty of accurate measurements in normal use, and (2) the interests of the industry producing the measuring instruments.

The first factor requires no explanation. As regards the second, it is obviously in the interests of the manufacturers to find as large as possible a market for a unified product. The ideal situation from OIML's point of view, therefore, would be that a manufacturer who constructs a type of measuring instrument in one country should be able to export it to any other country with the certainty that it will satisfy the legal regulations of that country.

To this end it is necessary that the member countries should implement the decisions of OIML by incorporating them in their national legislation. As you know, the treaty which set up the OIML imposes a moral obligation on the member countries to do this, and then only "as much as possible." The treaty cannot go further than this, but of course we hope that as many member countries as possible will honour this moral obligation.

It is thus not of great importance whether the recommendations are adopted in their entirety or only partially. In the present circumstances, it would be a considerable advance if their basic premises were accepted.

You may be asking yourselves what progress has already been made, or even whether, in fact, concrete results have already been achieved from the activities of our organization. I have no hesita-. tion in answering the latter question in the affirmative, albeit with some reservations.

I would like to look at this in a little more detail, and first I shall list those countries which have been responsible for the secretariats which have prepared the OIML recommendations already accepted by the International Committee of Legal Metrology. These are: Austria, Belgium, France, Germany, Holland, Russia, and the United Kingdom. Poland, as one of the Reporting Secretariats, has compiled an International Vocabulary on Legal Metrology in French. It is worth noting that the ISO Committee TC/48 is working on an English translation of this vocabulary.

It is interesting to observe that, of the eight countries mentioned, four belong to the group of six which together form the European Economic Community (EEC). If we were, in addition, 
to add up the total number of secretariats which these four countries hold, it would be obvious that the Western European countries have a relatively large stake in OIML. There may be various reasons for this, but there is little doubt that the major explanation is that these countries have the same objective, within the EEC, as OIML has set itself. For, in order to remove hindrance in trade in measuring instruments between the six countries, these have to draft guidelines aimed at harmonizing the national regulations applying to these measuring instruments. The very fact that the same experts are asked to do this work provides a guarantee that the draft guidelines of the EEC and OIML recommendations will not greatly diverge. In practice, indeed the EEC takes the view that, where an OIML recommendation already exists, this should, in principle, be adopted.

This is an important decision for the manufacturers of measuring instruments. Many of them, both inside and outside the EEC, have asked me repeatedly to try and achieve a situation whereby only one version of each of the international documents exists. In this connection it is interesting to note that other groups of countries have also sought contact in the metrological sector with the International Bureau of Legal Metrology.

I can also point to practical applications of the OIML recommendations. Various countries, for instance, have already legalised the weights of the OIML model and applied the OIML tolerances for weighing machines in their legislation.

Even countries which may not yet have adopted prescriptions from these or other recommendations are now at least aware of documents which differ from their own and are undoubtedly passing through a period of adjustment of their points of view which will lead eventually to adjustment of their legislation. I am sure you will agree that the confrontation of ideas and methods at international level is in itself a step forward from the time when each country worked out its own rules inside its own frontiers, and is indeed itself entitled to be considered as progress.

Thus, even those countries which are not already gaining practical experience with the application of the International dispositions are becoming increasingly aware of the international scene.

The experience referred to is valuable in the light of a problem for which the correct solution has, in fact, not yet been foundi.e., that international recommendations only achieve their maximum effect if they are interpreted everywhere in the same way.

Identical interpretation is essential, particularly in those cases where the regulations have a far-reaching importance-for example, in the EEC countries. After the coming into effect of the harmonized regulations which these countries are preparing in the metrological sector, the metrological services will have to recog- 
nize each other's type approvals and verification marks without further checking, and this has raised the perhaps typically European question of whether this is possible "just like that."

Since, as it were, this question can only be given a hesitantly affirmative answer, efforts have been made to lay down extremely detailed technical specifications in order to exclude as much as possible the likelihood of different interpretations. However, these detailed specifications involve another hazard, which is that the manufacturers are not given sufficient freedom in their designs, and that technical progress is thus impeded.

As President of the International Committee of Legal Metrology, I have therefore wondered whether the OIML is moving in the right direction with this trend towards greater detail. I already expressed my concern about this during a meeting held in West Berlin on the centenary of the Plenary Meeting of the PTB (Vollversammlung der Physikalisch-Technischen Bundesanstalt) in November 1969. Naturally, we must look for a satisfactory compromise on this question, but my personal opinion is that, particularly in this initial stage (OIML is not yet 15 years old), we must not try to introduce too much detail. The number of different types of measuring instruments for which regulations have to be laid down is considerable, and I would expect to obtain better results with less detailed specifications covering a larger number of types of measuring instruments. Only if it is found that differences in interpretation of a given specification are clearly leading to difficulties for everyone, would it be justifiable to produce the document in a highly detailed form.

I would now like to direct your attention to a matter which is in some ways connected with the foregoing-i.e., the methods of control which are used in the various countries. Most European countries have in principle a national type-approval system, followed by individual testing before the measuring instruments may be sold or put into use, and legally imposed periodic inspection, or a technical check on the measuring instruments at their operational location. These methods are extremely labour-consuming, and it is fair to ask whether the weights and measures administrations will be able to continue performing their task in this way in a period when human labour is becoming ever more expensive. It is also pertinent to ask whether it is in fact necessary. After all, the measuring instruments industry is becoming better equipped every day, and I wonder whether it is not possible to allow the industry itself a greater delegated responsibility for the accuracy of the measuring instruments which are brought onto the market. Naturally, one of the conditions would have to be that the companies involved have good testing equipment at their disposal and use standards which are traceable to those of the metrological service. 
Examples of such a delegation of responsibility can already be found in countries with widely differing social and economic systems. In Western Germany, for instance, recognized testing offices of factories and distribution companies have for years had the authority to test kilowatt hour meters, and it is planned to extend this authority in the future to gas meters, water meters, and other meters used in the general distribution sectors. In the Netherlands, too, there has been in use for some 30 years for certain types of measuring instruments a method which differs from the traditional European method. A prototype test is carried out, and if the model is approved the manufacturer is entitled to market all products which correspond entirely to the approved model, without having to have recourse to the metrological service. The manufacturer has the responsibility of ensuring that each instrument complies with the legally stipulated tolerance limits. As evidence that all of the regulations have been complied with, he provides the measuring instrument with a mark which is supplied by the metrological service. An instrument provided with such a mark is considered by the terms of the Netherlands Weights and Measures Law as a verified measuring instrument.

Similar delegation of responsibility to the industrial sector of the economy, under general supervision of the State Metrological Service, is likewise found in many of the countries of Eastern Europe.

Such methods are naturally labour saving for the metrological service, which can thus work with less staff. Dutch experience is that a socially and perfectly acceptable situation is however achieved.

I would like to mention here that the approval of qualified laboratories, for example in Britain (by the British Calibration Service (BCS)), is in fact an example of another kind of delegation. Once recognized, these laboratories have the right to issue an officially recognized certificate of calibration for an identified single instrument, for those measuring instruments which are not subject to legally binding regulations.

Another method which is also less costly in time is, of course, random sampling. This method is generally accepted for the checking of prepackaged commodities, but it is rather more difficult, from a legal point of view, to apply it to the legal checking of large numbers of measuring instruments. Nevertheless, examples of its use can be quoted. In a few European countries, for instance, large batches of new weights are treated by this method. Similar sampling methods are used for the official testing of gas and electricity (kilowatt hour) meters in some countries.

There is the example in my own country of the use by the business community of random sampling of the indications given 
by measuring instruments. The combined Dutch electricity undertakings have developed a system based on these principles which they use for delivery checking of kilowatt hour meters supplied to them by manufacturers. It appears that this method gives very satisfactory results, from which the metrological service will certainly wish to benefit. After all, why should a method which is generally accepted in the commercial world, and which is embodied in many supply contracts, not be able to provide good service in the legal metrology sector? This reminds me that the old inspection methods were often a duplication of what had already been done. I must admit that duplication of this kind irritates me greatly, particularly if others (and I am thinking here particularly of the industry which produces measuring instruments) have already done this work in a reliable and verifiable manner. In addition, one must not forget that technical developments, and in particular the use of electronics in the technology of measuring instruments, will make it virtually impossible for weights and measures administrations to check everything, as has usually been the case in most European countries in the past.

It is my belief that new test methods will have to be developed, in close cooperation with the relevant industries, for many measuring instruments which have to satisfy legal provisions. In fact, the weights and measures administrations are faced here with an entirely new type of problem. This will require a continuous adjustment, in particular by the experts of those services which have access to the know-how necessary to keep up with the rapidly evolving techniques. Their cooperation within OIML will provide valuable support in this respect.

I would like also to mention a comparatively new development in Western Europe which will influence the tasks of the metrological services. I am referring to certain international plans for legal provisions which will stipulate that certain specified foodstuffs may only be sold in standard quantities of, for example, $100 \mathrm{~g}, 200$ $\mathrm{g}, 500 \mathrm{~g}$, or 1 kilogram, requirements which already apply in a relatively small number of countries.

As is well known in your country, where great attention is paid to protection of the consumer, such provisions give the consumer a clearer overall view of the market. In other words, they enable him or her to calculate easily the price per unit of weight of an article and to compare it with other prices. Although an effective check that these regulations are being: complied with is predominantly in the interest of consumers, it also has its metrological aspects. From the practical point of view, it is preferable that trained weights and measures officers be used to ensure effective control, and, again, such legislation puts the need to lay down 
specifications for a verified measuring instrument, for example, in an entirely different light.

Regulations related to standardized quantities may, however, have an additional effect which metrologists cannot afford to ignore. If one country stipulates different quantities from another, trade hindrances are again likely to develop in the weights and measures sector, and I am therefore firmly convinced that in the 1970's OIML will have to concern itself with this subject of "unity in quantities."

This brings me to another problem which is of the utmost importance in this context, namely that of "unity in units." This is admittedly not the direct province of OIML, but an international organization issuing recommendations on measuring instruments cannot ignore the question of the units to be used. Moreover, you will understand that, as an inhabitant of one of the oldest metric countries in the world, I am delighted that in the 1970's Britain and Australia will be adopting the metric system. I would be even more pleased if your country and Canada could see their way to making the same decision. This would remove one of the most fundamental obstacles in our field, and would greatly facilitate the tasks of very many people who understand the realities and the requirements of the ever more rapidly developing conditions.

I am thinking here, for example, of the aid in the metrological sector which the developing countries can expect from the industrialized countries, and which will engage more and more of OIML's attention in the 1970's. OIML is already providing information on the organization of national services and preparing a recommendation for basic legislation in this field.

But the developing countries will also need assistance in the regulation of their basic or primary standards, providing technical facilities for laboratories, the education and training of their officers, and the equipment of their weights and measures offices.

I would like to conclude by giving you my view concerning what I consider might be the role of the USA and thus that of all of you in the work of OIML. First of all, of course, I would be delighted if your country decided to become a member of our organization, and I can assure you that the OIML member countries share my feelings. It is clear that your contribution to OIML would be of the utmost importance. I have already mentioned a number of new paths which legal metrology will have to follow under the influence of technical and social developments. It is obvious that my conceptions regarding these problems are coloured by the European influence in which I live. The frontiers between the various states in Europe have always been of a much greater significance than in your own country. Our developments in the field of legal metrology have taken place independently of each other within the 
national frontiers, and it is extremely difficult to depart from old time-honoured forms unless one is forced to do so by developments within one's own country. There have, of course, been incidental cases of new ideas emerging from such developments. I have already quoted a modest example from my own country, in which a delegated responsibility is laid on the business sector. I can also refer to the new metrological legislation which was introduced in Western Germany on July 1 of this year. However, in a gradually diminishing world, exchange of experience and coordination is indispensable, and it is my conviction that OIML is ideally suited for this task.

Until now, however, OIML has not been able to count on the contribution of your country with its rich experience in the metrological field. I regret this greatly, since I believe that I can observe clear signs of a move towards new ideas in your country. An example of such original conceptions is the Wisconsin Plan, which has been in operation for some years now. The "selective testing programme" has interested me greatly, and on the occasion of the centenary celebrations in West Berlin to which I referred a few moments ago I stated my cautious belief that it will at least influence our thinking and methods in Europe. However, I am also thinking of the experience of your other institutions, and of the views of many representatives of consumers' organizations which in your country are extremely interested in weights and measures administration, and whom I should expect to play a considerable part.

On the other hand, I must also assume that there is interest in your country in the activities of OIML. Your widely spread trade relations must have made it impossible for the discussions regarding legal regulations for measuring instruments, now underway in other countries, to have passed you by without creating some interest. It may even be that you yourselves will consult the recommendations of OIML when revising or complementing your own legal regulations.

Unfortunately the part you have played in their compilation has been limited to the account that the various OIML secretariats may have been prepared to take of corresponding United States official texts when drawing up their original drafts. Although your national departments have always been kindly prepared to furnish such documentation, your absence from the working groups, meeting and discussing the various technical drafts, has made it impossible for your specialists to explain and defend your ideas and thus has meant that their influence has so far been very small.

At the beginning of my address I told you that these recommendations always reflect a compromise. How can such compromise be complete if the ideas of a highly industrialized country such as 
your own have not been represented? I would go even further and say that the fulfillment of the ideal-which the initiators of OIML, including the USA, had in mind in 1937-will only be possible if at least all the industrialized countries make their contribution. This ideal was to make possible the mutual acceptance of the type approval and perhaps even of the verification of single instruments by all weights and measures administrations in the world.

Naturally, this ideal will have to be regularly adapted to new ideas. For instance, I have already stated my personal conviction that account will have to be taken of delegation of authority to the industrial sector. Yet whatever adjustments social progress will demand of us, the ideal will continue to point the way to the future.

We shall still have many obstacles to face on this road. The language problem springs immediately to mind, and I personally believe that OIML will seriously have to consider in the near future the possibility of using English as an additional operational language. It is not difficult to think of a number of other obstacles which may affect the issue. All of us, and I mean every country in the world, have, after all, had separate and different histories in metrology. But we have a common purpose. Let us, therefore, accept the challenge of the 70's-a common future in legal metrology.

\section{PRESENTATION OF HONOR AWARDS}

Dr. Branscomb presented Honor Awards to members of the Conference who, by attending the 54th Conference in 1969, reached one of the five attendance categories for which recognition is made-attendance at $10,15,20,25$, or 30 meetings.

\section{Award Recipients}

\section{W. A. SCHEURER}

A. T. ANDERSON

J. E. BOWEN

R. N. SMITH

H. F. WOLLIN

W. R. COPELAND

G. S. FrankS

W. S. FULLER

D. B. KENDALL

M. L. KINLAW

D. F. LAIRD

W. F. OPERER

Sylvia Pickell

R. L. SHARP

A. YOCHELSON
20 Years

Exact Weight Scale Company

15 Years

Cambridge, Massachusetts

Newton, Massachusetts

National Bureau of Standards

National Bureau of Standards

10 Years

Indianapolis, Indiana

Cumberland County, New Jersey

H. J. Fuller Company

Toledo Scale Company

North Carolina

Spinks Scale Company

Thread Institute

Scale Journal Publishing Company

Fort Worth, Texas

Advanced Equipment Company 


\section{PRESENTATION OF PLAQUE TO M. W. JENSEN}

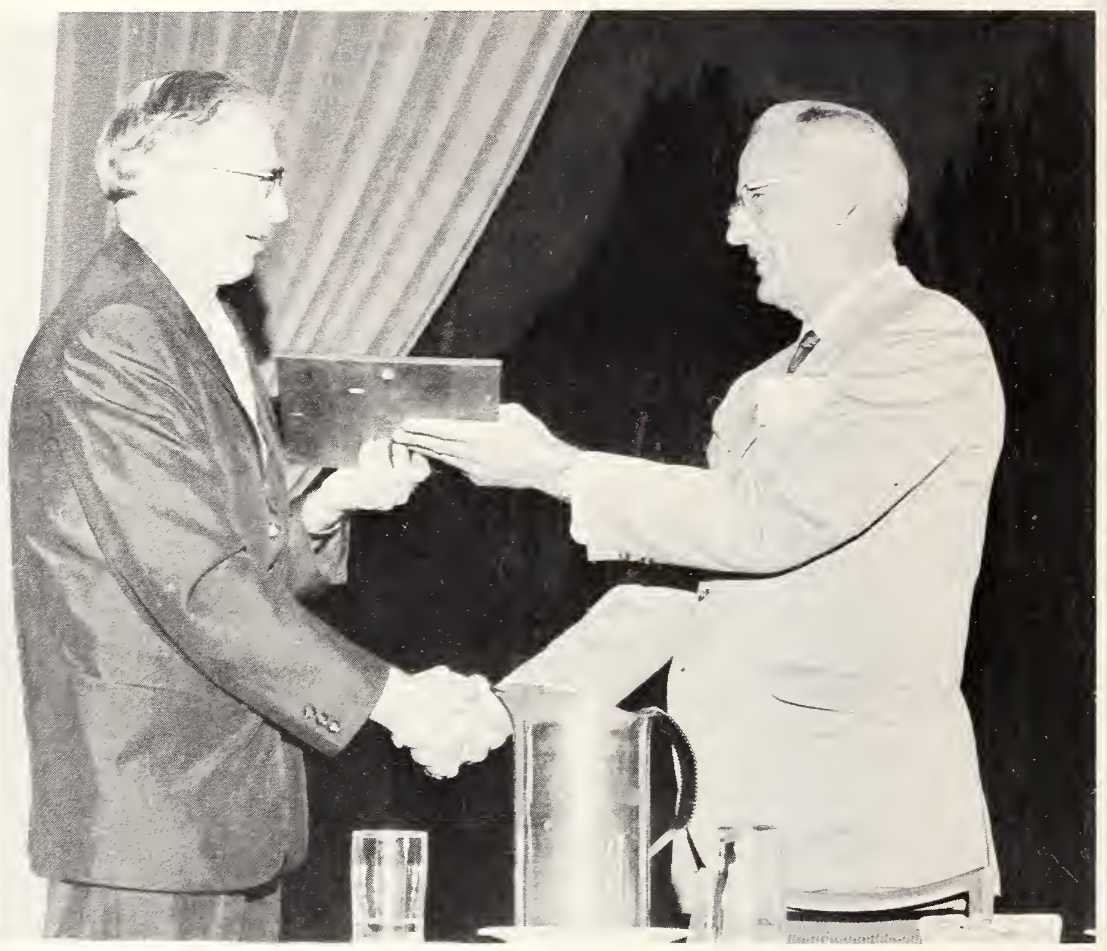

Dr. A. V. Astin presents M. W. Jenson with plaque embossed with special resolution of appreciation passed by the 54 th National Conference on Weights and Measures in 1969. 


\section{Guest Speaker: The Honorable Frank H. Moss, U.S. Senator,} State of Utah

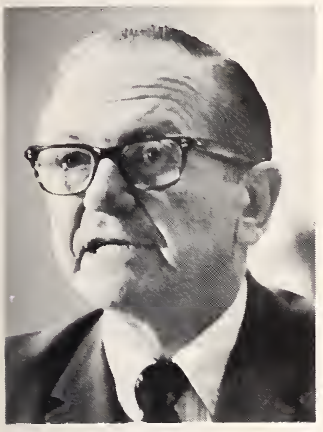

I appreciate the opportunity to address this distinguished group. I cannot resist the temptation to welcome Dr. Branscomb and Dr. Tribus to the great State of Utah and the wonderful City of Salt Lake. On a number of occasions, I have had the pleasure of welcoming both of these men to the Consumer Subcommittee, where they have delivered important and useful testimony on such subjects as consumer product testing, fair packaging and labeling, and flammable fabrics.

Today I would like to address myself to "Consumerism-A Perspective for the 70's." At close range, the outlook for consumerism in the 70's appears bleak. Compared to the troubled seas of Vietnam and the violent winds of a failing economy, consumerism may seem all but lost as a vital issue in the decade of the 70's. Those of you who are devoting your energies to the slow and sometimes painful task of assuring consumers their day in the marketplace may become discouraged when you are told that "consumerism is not a vital issue."

But I submit that it is an important and vital issue. As the economy continues to sag, it will become more and more important to the American housewife to shop for the best buys. The Fair Packaging and Labeling Act goal of facilitating value comparisons will become more crucial. It has been estimated that 10 billion dollars per year could be saved by American consumers if they were readily able to shop for the best buy. And in a declining economy consumers will search even harder for those products which are reliable and which offer warranties that mean what they say, and say what they mean.

Let me ask you to reflect for a moment on your own role as a consumer, even in these troubled times. Certainly you are concerned about Southeast Asia and the state of the economy, but this does not displace your concern when you return home one night to discover that your good wife has been mesmerized by a sweet talking salesman into signing away a healthy chunk of your next five years' earnings in order to purchase something really essential - either a Siamese fighting fish or a facsimile reprint of the entire Hardy Boys Adventure Series.

And how many of you have not been driven to clenched fists and gritted teeth when your friendly auto dealer tries to discover the 
source of a leak in the brake line of your brand new car-after ten trips to the shop? Or how many of you have not been frustrated when you discover that the guaranty on the brand new mixer that doesn't mix covers only those parts that don't move, or that to get it repaired you have to mail it, at your cost, to the factory on the opposite coast, or that labor was extra, or that according to the small print you have abused the product by taking it out of the carton?

And who in this room is not a victim of escalating auto insurance rates? If you have a teenage son, don't you sometime wonder if he is really worth it? Or maybe you have just had your automobile policy yanked out from under you because a drunk ran into your car while it was parked in your own driveway as you slept soundly and negligently in the house.

This, after all, is the stuff of consumerism. Even in these troubled times it is a vital issue. But where will it lead in the 70's? In order to find out where consumerism might lead in the 70's, it is necessary to review briefly the consumer decade of the 60 's.

As you well know, the modern consumer movement was launched in 1962 when President Kennedy delivered a special consumer message to Congress. In that message he reminded Congress "that consumers are the largest economic group in the economy, accounting for two-thirds of all spending." "Therefore," reasoned President Kennedy, "the federal government, by nature the highest spokesman for all people, has a special obligation to be alert to consumer needs and to advance the consumer interests." President Kennedy then set forth four basic consumer rights-the right to safety, the right to be informed, the right to choose, and the right to be heard.

For the past eight years, Congress has been passing legislation to assure these basic consumer rights. For example, the consumer's right to safety has been fostered through such laws as the National Traffic and Motor Vehicle Safety Act of 1966, the Child Protection Act of 1966, the Toy Safety Act of 1969, the Natural Gas Pipeline Safety Act, the Radiation Control for Health and Safety Act, and the Flammable Fabrics Act.

The consumer's right to information has been legislatively protected by the passage of the Cigarette Labeling Act, the Fair Packaging and Labeling Act, and the Truth-in-Lending Act.

Legislative proposals fostering the consumer's right to choose and the consumer's right to be heard were proposed in the 1960's. But those legislative proposals have not reached maturity. Therefore, as I see it, consumerism in the 1970's, while continuing to protect the consumer's right to safety and the right to be informed, will focus upon the consumer's right to choose and his right to be heard. The way in which these rights are guaranteed 
will depend upon the way the business community, consumer groups, and government at all levels respond to the phenomenon of consumerism.

At the federal level there has been a flurry of activity in the consumer area. Let me describe the activities of the Consumer Subcommittee since January of this year to give you an idea of how consumerism has been fairing early in this decade. On January 16 my Committee resumed oversight hearings on the Fair Packaging and Labeling Act, a law I know is of special interest to this group because of the weights and measures aspects. On the 20 th of January the Consumer Subcommittee began hearings on a comprehensive consumer products warranty or guaranty bill.

Then the Consumer Subcommittee turned to consideration of the President's consumer package which purports to upgrade the Federal Trade Commission, create a new consumer protection division within the Department of Justice, elevate Mrs. Knauer's shop to a statutory office, and give the consumer certain limited class action rights. On February 10 the Consumer Subcommittee held its final day of hearings on a bill that would provide American consumers protection against the insolvencies of insurance companies. The proposal for a federal insurance guaranty corporation parallels very much the existing Federal Deposit Insurance Corporation, which insures bank depositors against the insolvencies of banks. In March the Consumer Subcommittee moved to consideration of the administration's proposal for a consumer products testing act designed to increase consumer information and allow the shopper to compare the quality aspects of consumer products. On March 10 and 11 the Subcommittee returned to consideration of the warranty and guaranty legislation. And on March 26 the Committee held further oversight hearings on the Fair Packaging and Labeling Act.

By June the Consumer Subcommittee had held six days of hearings on three different subjects. Early in that month the Committee held extensive oversight hearings on the Flammable Fabrics Act. These hearings were designed to stimulate implementation of this important piece of legislation and to consider two important authorization bills which would provide funds for the Flammable Fabrics Act and for the Fire Research and Safety Act. On June 16 and 17 the Committee held hearings on a bill which regulates the activities of doctors in dispensing drugs or having ownership of repackaging companies. And the Subcommittee just finished hearings to receive the final report of the National Commission on Product Safety.

Let's see where we are at this point on these particular projects. On July 1 the Senate passed the Magnuson-Moss Consumer Product Warranty and Guaranty Bill. That bill sets up ground rules so 
that no manufacturer or dealer who plays the warranty game with larceny in his heart and fine print as his burglary tool can maintain an unfair competitive advantage over the vast majority of firms that play the game straight.

The bill does not require a supplier of a consumer product to warranty his product. He can sell the product "as is" or give a service contract in lieu of a warranty.

But if he gives an express warranty in which he promises to repair or replace a product without charge within a reasonable time, only then can he label the warranty a "full" warranty or guaranty. If he promises something less, then he must label that something less as a "partial" warranty.

If he gives a warranty, he can no longer use it as a shield for disclaiming the implied warranty of fitness which the law would otherwise impose on him. Finally, the bill requires a warranty to contain the basic information the consumer needs to find out what rights he gets and how to exercise those rights.

The Senate Commerce Committee has just ordered to be reported two important fire safety bills. S. 3765 authorizes a sum not to exceed $\$ 9$ million for Fiscal Years 1971 and 1972 to further implement the Flammable Fabrics Act. The bill also amends that act in order to provide for better flammable fabrics enforcement. The enforcement amendments to the act require a manufacturer to certify that the product meets the requirements of any applicable flammability standard or other regulation. Such certification is to be based upon a reasonable testing program conducted by the manufacturer and approved by the Federal Trade Commission.

The bill also aids enforcement by augmenting the penalty sections of the Flammable Fabrics Act. Any person who knowingly violates the act is guilty of a felony and, upon conviction, shall be fined not more than $\$ 10,000$, imprisoned not more than three years, or both. If a person violates the act without knowledge, he shall be guilty of a misdeameanor and, upon conviction, shall be fined not more than $\$ 1,000$ and imprisoned for not more than one year. Finally, the person who violates the act may be subject to civil penalties not to exceed $\$ 10,000$ for each violation. These important amendments are designed to detect flammable fabrics before they are placed on the market and effectively deter the future sale of flammable fabrics through the threat of meaningful criminal and civil sanctions.

Upon my return to Washington the Senate Commerce Committee will complete its action on the Consumer Protection Act which strengthens the Federal Trade Commission and creates class action rights for consumers. The class action provisions of the bill have been forged and only certain details related to the Federal Trade Commission authority have yet to be worked out. The Class 
Action Bill provides that consumers as a class can go into Federal Court if each of their claims amounts to more than $\$ 10$ and their cause of action is based upon certain specified acts or violations of a rule or regulation of the Federal Trade Commission. The class action legislation does not depend upon prior government action by the Justice Department or the Federal Trade Commission. There is no "trigger" device unless each claim is for less than $\$ 10$.

Upon completion of the action on this legislation, I expect the Committee to act favorably on the proposal to create a federal insurance guaranty corporation. In addition to these accomplishments, the Senate has also passed an important safety measure, the Poison Prevention Packaging Act, which authorizes the special packaging of certain dangerous household products in order to prevent the accidental poisoning of small children who innocently explore their environment only to be tragically poisoned by sweet smelling furniture polish or a harmless looking bottle of Aspirin.

The Consumer Subcommittee is about to consider the comprehensive Consumer Product Safety Bill which the National Commission on Product Safety has just recommended. This legislation is designed to insure the consumer's right to safe household products. And when the Department of Transportation completes its study of the automobile compensation system, the Senate Commerce Committee will undertake a thorough examination of automobile insurance practices in the United States and will formulate legislative recommendations.

In my opinion, the American people have reached a point of no return. They will no longer accept goods and services of inferior quality. They will no longer accept uncourteous treatment at the customer complaint window or from a form letter response spewed forth from some computer.

Because consumers are part of the American community and believe very much in the individualism which made this country great, they want to be treated with respect and dignity as individuals. They want the business community to listen to their problems and to react to those problems with a sincere effort to solve them.

In many instances governmental actions will be necessary to define the ground rules by which the business community can adjust certain inequities in the marketplace and move forward to restore a free market system where the consumer is sovereign and where businesses prosper because they serve the consumer better than their competitors.

The essential problem for us as we stand at the threshold of the 1970 's is to develop a system that will satisfy the wants of the consumer and the needs of the legitimate businessman. The ultimate success of the consumer movement depends upon the way in 
which the business community, government at all levels, and consumers work together. American businessmen have long promised that they will give the consumer whatever he wants. They are now discovering that he wants more than fancy frills and pretty colors. $\mathrm{He}$ wants reliable and safe products which do not destroy his environment. It is up to the business community, through the free market system, to provide the consumer with those wants. But government, particularly local and state government, play an important role in guiding the business community so that it is able to meet the consumer wants.

Unfortunately, the task is not easy nor the way sure. Thus, efforts of all of us will be required in the unchartered course ahead. Answers will have to be found for the complex issue of social costs and benefits. In the problem areas which we will face during the 1970 's, I do not feel that we can rely entirely on profit and loss columns of business. It will be necessary for the government to establish ground rules for all competitors. Without them, conscientious businessmen may not be able to "afford" to provide the consumer with his legitimate wants.

The main challenge for the 70's in the consumer area, then, is for the business community, consumers, and government to work together in creating rules and regulations which will guide us intelligently through the decade.

It is my sincere hope that the federal, state, and local governments can move forward together in the 70's to help achieve this fair balance between the need to produce at reasonable prices the goods and services demanded by the American consumer, without sacrificing important environmental needs or basic quality.

In my view, the real success of consumerism in the 1970's rests in the hands of people such as yourselves. The federal government alone cannot begin to solve the problems which face American consumers. This is not to say that continued federal activity is not necessary. I believe it is. But this activity must be carefully meshed with existing and future state and local programs-programs with which you are imminently familiar.

For example, when the Consumer Subcommittee began its oversight hearings on the Fair Packaging and Labeling Act, we were quite concerned about the lack of enforcement. In our initial hearings we had the pleasure of receiving testimony from Joe Francis, Commissioner, Utah State Department of Agriculture. Joe pointed to the vital role which the state weights and measures people could play in helping to implement the Fair Packaging and Labeling Act.

The federal government could provide funds, and the state people could carry out an effective enforcement program. At the present time the Department of Commerce and the Department of 
Health, Education, and Welfare are working very closely with the state weights and measures people to implement a cooperative program of standard setting and enforcement. This kind of federal-state cooperation is absolutely necessary if consumer programs initiated at the federal level are to meet with success.

Enforcement of laws requiring accurate weights and measures was among the earliest consumer protection activities. It has a continuing role in the growing consumer movement. And those of you in this field have an opportunity to take on new and important functions being created by the legislation we are developing in Congress.

No national program for consumer protection can succeed without a concerned and dedicated group of people such as yourselves at the local and state level. Consumerism in the decade of the 70's has only as bright a future as your dedication to helping the consumer and the businessman create a just marketplace which protects the rights of both. 



\section{(L.A. GREDY, Vice Chairman, Presiding)}

\section{THE CHALLENGES FACING GOVERNMENT, INDUSTRY, AND CONSUMERS}

by M. W. Jensen, Acting Director, Institute for Applied Technology, National Bureau of Standards

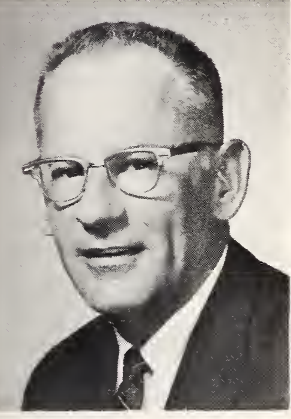

comb, Dr. Tribus, and Senator Moss, and we hear a lot in Washington. But looking at it as a whole we come to the conclusion that you and your predecessors have been deeply involved in this movement for many centuries in fact, and that your motto, "That Equity May Prevail" is about as concise a statement of the aims of the consumer movement as anyone could come up with.

I need not tell you that you are where the action is, you have been there for a long time, and you do your job well. I am grateful for having been a part of it.

The topic of my discussion as you well know seems to have been touched on rather firmly by a number of speakers throughout the sessions thus far. I should like to narrow the subject to the marketplace, although we all are aware that major challenges face all of us in world peace and in our environment, social equities, and even in product safety.

It seems to me that I could have handled the assignment in any of three ways. The first would be a single word and the biggest challenge of all is "communications." I think I might have developed a laundry list of challenges and just articulated these and see if any of you would like to discuss any of them. Or I could present a reasonably descriptive discussion of the topic. With your indulgence I will do this. My aim will be to examine the public interests in materials, products, and services in the marketplace. To examine certain problem areas and to suggest certain approaches. 
I would like to start with a premise, and I think this is well proven and almost universally acknowledged, that most of the residents of our fifty States do enjoy a high standard of living. Technology has brought to the marketplace and has brought to the home both the necessities and many luxuries of life: From the multiplicity of choices to good wholesome food products available in the grocery market to the highly useful and pleasureful and complex appliances; from the great convenience of high speed service in air transportation systems to the many and varied recreation spots that thus can be reached; from the readily available nonprescription home medical care items to the highly sophisticated medical care centers.

All of this is true as I am sure you will agree as is the confusion in the minds of the consumer that has resulted in the world that technology has delivered.

We know when we want to buy a new refrigerator or a television set or automobile or even a packaged commodity that we have no way of knowing what single one of the many makes, models, brands, or manufacturers is best suited to our particular need, to our desire, and to our dollar capability. As Senator Moss mentioned we know that guarantees and warranties are a part of what we pay for a product, but the legalistic language of most of them prohibits us from evaluating one from the other. We can be sure that almost everything we buy is going to need maintenance and may well need repair, but we seldom have confidence that the maintenance or repair as is required through time will be performed quickly, effectively, and economically.

So, just as other speakers have said, we do live in a fine world, it is a technological world, it is a complicated world, and I am not sure we all really understand it. I suspect that the identification and solutions of these types of social, economic, and political problems are among the most serious challenges facing all of us. But are solutions really feasible? Perhaps, but only if we are willing to admit the existence of the problems, at home, in the marketplace, and ultimately, of course, in the legislative and the executive branches of government. We must stop talking about generalities and get down to specifics, specify the dimensions of the problems and then devote our talents to their solutions.

Not long ago I had the view that technology created the problems and technology was responsible for their solution. Now I know that the problems are not all technology based. The problems lie in the social world and in the economic world and in the political world. Are avenues to solutions really available to us? I think perhaps they are.

You recall I mentioned I might have delivered this talk with a single word, the word being "communications." I say this because 
having attended many meetings and having sat with a lot of people, individually and in formal and informal conferences, I am convinced, deeply convinced, that officials in government, decison makers in industry, and household consumers simply do not understand each other. They do not talk the same language.

Each of us is so absorbed in his own interest and his own problems that we really are unable to look honestly and objectively at the other fellow's problems. Each of us has his own incentives and motivations, and these, unfortunately, do not always coincide with his. We need a way to communicate, we need a way to translate, we need a way to understand-all leading to a serious way of becoming concerned. Well, how do we go about it?

Quite frankly, I do not think we need many more laws, we have books and books and books full of laws, and I am convinced if we go about the business of enforcing and implementing, fraud and deception can be largely eliminated from the marketplace.

Next, and this is a conviction I would like to share with you, I think there is a possibility of a common language, and this language may very well be the language of standards. What a standard really is is a form of communication. It is intended to establish a basis of understanding between buyer and seller, specifier and supplier, industry and the consumer. Whether it fixes the quantities of the contents of a particular packaged commodity or the safety characteristics of a complicated mechanism, a standard is designed to eliminate ambiguity. Handbook 44 is a standard-it tells the manufacturer, the installer, the mechanic what performance is expected of a device and it tells the user and the customer what each of them has the right to expect. The weights and measures official translates, interprets, and enforces this standard. Handbook 67 is a standard enforcement guide. Laws are standards of behavior generally or of performance or of operation; regulations are standards in greater detail, they are authorized by law. As a matter of fact the Ten Commandments are standards.

I believe we do need standards for the marketplace, standards covering performance, durability, and quantity of course, perhaps quality, and certainly safety. We need standard terms and standard symbols and standard definitions, all part of a standard language.

The American Society for Testing Materials has a monthly journal in which there normally is found a page that has the title "Member Affairs." In the most recent issue, and with some editorial liberty, I would like to quote from an item written by Bill Cavanaugh, the new Managing Director of ASTM. 
Language is a system of terms that have meaning described by consensus and use. When you think about that it is obviously what the American language is. A standardization effort is, through consensus and use, to generate a language, an engineering language of measurement, evaluation, and perceptions. This language is a tool that enables us to store experience and to protect our interest, that is, to effect a degree of control over events. The validity and the utility of practical technical language is absolutely crucial to the process of relating advances in technology to the existing culture, constructively. Without such a language we cannot communicate, we are unable to assess or control either nature or ourselves, and the result is chaos.

Well what is happening? Those who do not know are drawing away from those who know, and fear is taking over. Fear of technology could destroy our economy and should thus be reconciled to reality in a creative and realistic way if this is to be avoided. Concerned people in the 70's have a central role to play; we all should be gearing to that role.

I think Bill said an awful lot in a few rather short sentences, and I think there is meaning there worthy of thought by all of us.

It is not difficult, I know, to say what needs to be done. What frequently is difficult is a how-to-do-it plan. Permit me to offer a few suggestions.

Government, it seems to me, has the capability to establish priorities on the basis of benefit/cost or benefit/risk. There is no doubt that industry has ample information on design, production, distribution, and marketing. Consumers should be able to translate their needs and desires into meaningful terms. We should be able to work together through established channels, or, if necessary, through mechanisms that we invent.

Model laws and regulations and technical requirements for the implementation of these are essential, but only when they are necessary for the well being of the people. Voluntary industrial and consumer standards are designed to serve where mandatory standards are deemed not necessary. A united effort leading to the enactment of model laws, the promulgation of model regulations, and the development of voluntary standards, I believe, offers an avenue that should be successful.

Perhaps even this is too general. I shall try to be more specific. As I view the scene the principal challenges facing government in the areas of concern to this Conference are to act rationally and on the basis of real need, to justify action through sound cost/ benefit or risk/benefit data, to follow a well developed order of priorities except in rare emergencies, to provide vigorous leadership essential to uniform action leading to uniform results, to see to it that all parties with interest are properly represented in the decision making process, to provide the vehicle for both the maximum utilization of technological developments in the interest of 
the general public and the pursuit of further technological developments, and finally, of course, to communicate.

The challenges facing industry might include to consider the effect of the product upon man and his environment as well as the market potential, to provide for ample consumer choice without total consumer confusion, to participate with government in the decision-making process rather than stand off and wait until something is about ready to happen and then gather forces to object, to take affirmative, contributing positions on major and minor public issues, to recognize that the government is made up of all the people, not just a group of government officials in Washington, or Salt Lake City, or Topeka, to devise more effective mechanisms to determine what consumers really want and then to attempt to fill those wants specifically. (By this I do not mean to put a number of items on the market and say well, the consumer is buying that one, thus I know that is what he wants.) To participate more objectively in the standards-making process, and finally, to communicate openly.

Perhaps the challenges facing the consumer are to exercise the power of the dollar more effectively, to utilize existing organizations and to devise new ones if necessary, to see that consumers are actively and articulately represented in those processes and procedures that bear direct effect upon consumer safety and consumer economics, to become a meaningful participant in the processes of government, to evidence greater faith in the system and be more concerned with improvements than in indictments, to learn and to use knowledge effectively, and to communicate-to communicate among themselves, communicate with industry, communicate with government, and thus to exercise their right of inquiry and complaint.

Why do each of the lists end with communicate? Because I believe absolutely that if we can talk together openly, if we can work together, we do have the capability politically, technologically, socially, and economically to solve almost any problem. Public officials, industry, business, and consumers operating through this National Conference on Weights and Measures have proven over some 65 years of activity that people of good will who talk together and work together do succeed.

Essentially, what I am saying to you is that yours is an example that is worth following, it is an example that is good enough for you as individuals and as a group to pursue in other areas of concern to our nation. 


\section{FORUM ON PACKAGING AND LABELING}

\section{E. A. VAdelund, Office of Weights and Measures, Moderator}

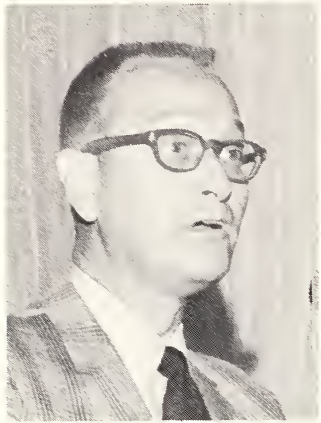

It is my pleasure to be here in the 15th hour of the 14th day of the first month in the fourth year in the life of the Fair Packaging and Labeling Act; or as someone has said, the longest continuous floating labeling game in town.

First I would like to introduce my two able colleagues this afternoon. Mr. John Speer is here as Chairman of the Industry Committee on Packaging and Labeling, a group that has worked with the National Conference in the past. Mr. Speer is Executive Assistant with the Milk Industry Foundation and the International Association of Ice Cream Manufacturers.

Our other panel member is Mr. Philip Schindel, who is President of the Association of General Merchandise Chains. He has been active for some time in the general merchandise field, and currently serves on the Committee on Consumer Issues and Manpower Development of the U.S. Chamber of Commerce. Mr. Schindel will detail for you the cooperative efforts between his organization and the National Conference, and will also give voice to some of their concerns.

I would now like to briefly review for you the status of packaging and labeling requirements at the federal and state levels, particularly with respect to the Fair Packaging and Labeling Act.

\section{STATUS OF FEDERAL AND STATE PROGRAMS}

by E. A. VAdelund, Program Manager, Fair Packaging and Labeling Act

The Fair Packaging and Labeling Act has just observed its third anniversary. Needless to say, this statute has created a variety of problems for both state and federal enforcement officials. It would seem to be appropriate at this time to review the short history of this unique picee of legislation to see what is, what has been, and what might be expected in the area of package labeling.

One of the more engaging statements about the Act, at the time of its passage, described it as, "an ill-assorted collection of poorly matching parts, forming a distressing whole." The statement obviously referred to the fact that the Law combined both mandatory and voluntary aspects, while, at the same time, splitting au- 
thority and responsibility between three federal agencies. In addition, the Act preempted state and local laws and regulations, but only in one area-package quantity labeling. Finally, a new concept in labeling was introduced by requiring certain packages to bear dual quantity statements in terms of the largest and smallest unit of weight or measure.

The chronology of events leading to the implementation of the Act began in March, 1967, with the issuance of proposed food package labeling regulations by the Food and Drug Administration, Department of Health, Education, and Welfare. This initial action was followed by the issuance of a series of proposed regulations, final orders, amendments, exemptions, extensions, exclusions, and the like. Each of the documents published in the Federal Register was suitably analyzed by the Office of Weights and Measures and distributed to all State weights and measures officials. The sequence of events for the bulk of the mandatory labeling requirements appears in the following table.

\section{FDA}

\section{(For foods)}

First proposal published March 17, 1967

Revised proposal published July 21, 1967

Final order published September 20, 1967

Effective date December 31, 1967, for new labels being reordered.

Effective date July 1, 1968, for all packages.

(For drugs, devices, and cosmetics)

First proposal published August 22, 1967

Final order published June 28, 1968

Amended order published March 6, 1969

Effective date December 31, 1969.

FTC

First proposal published June 27, 1967

Revised proposal published March 19, 1968

Final order published May 27, 1969

Effective date September 10, 1969. 
Subsequent to the publication of the three major regulations dealing with package labeling, there began to appear in the Federal Register, with frequent regularity, proposals designed to exempt particular packages or products from the full burden of the mandatory requirements. Many of the proposed exemptions dealt with items with which weights and measures officials had long been concerned. This was particularly true of the exemption proposals issued by the Food and Drug Administration for many staple commodities such as fluid milk, ice cream, butter, margarine, eggs, and flour products. Generally, these exemptions were supported by weights and measures officials since similar consideration had been given to such items long before the passage of FPLA.

The situation with respect to exemptions issued by FDA was at times confused, by both officials and industry people, because of a tendency to refer to extensions as exemptions. While exemptions were under consideration, more than 3,000 manufacturers were granted extensions of time to use up nonconforming labels. Many interested parties mistakenly equated the two and concluded that the legislative intent was being administratively emasculated. The record, however, indicates that FDA has granted only 17 exemptions to date. Furthermore, in no instance has a total exemption been given. For the most part, the exemptions are conditional upon some other method of presenting the required information, or are granted because a particular commodity is packaged in reasonably standardized quantities fully familiar to the buying public.

The circumstances concerning the granting of extensions and exemptions by the Federal Trade Commission have been somewhat different. The FTC, for example, avoided the problem of granting extensions of time for the use of nonconforming labels by simply postponing the effective date of their regulations for one year. This, of course, had the effect of granting all those subject to FTC Regulations an additional period of time to comply.

Exemptions at the FTC have undergone a more colorful experience. Periodic exemption proposals were issued during the year between the issuance of final regulations and their effective date. These proposals were published in the Federal Register, comments were received and duly noted, amendments were made, and, in some cases, final orders were issued. Everything seemed to be proceeding smoothly until the final week before the effective date of the FTC regulations.

At that point, the Commission decided to deal with the knotty problem of exemptions by indefinitely postponing -the effective date of their requirements. Approximately six weeks later the problem of exemptions was largely resolved by a pronouncement 
from the FTC that all those items subject to consideration for exemptions were not really covered by the Act in the first place. A list of product categories was published in the Federal Register with a notice that such items were excluded from the definition of consumer commodity and thus not subject to regulation under FPLA. The net result of all this activity is that there is only one exemption, issued by the FTC, currently on the record.

Concurrent with Federal activity in the package labeling field, the National Conference on Weights and Measures was proceeding to make changes in its basic documents-The Model State Weights and Measures Law and The Model State Packaging and Labeling Regulation. Little, if anything, was done during the first year of the new Law because of the express preemption contained in section 12 of the Act. However, the Conference undertook and carried out a major revamping of the Model Regulation in 1968. The changes were made to harmonize the requirements of the regulation with those issued by federal regulatory agencies, while still providing for the proper regulation of all those commodities not subject to FPLA. Unlike the situation at the Federal level, the responsibility and authority for package control is usually vested in a single state agency which normally does not have the luxury of excluding numerous types of commodities from coverage.

Again in 1969, the Conference undertook and completed a restructuring of the Model Regulation to bring it up-to-date with federal activity during the year. More importantly, the format was changed in an effort to present all requirements in a more usable fashion.

Individual state activity in the regulation making field paralleled Conference activity. Little or nothing was done in 1967 because of the uncertain status of federal regulations. Beginning in the 1968-69 period, the states began to move to update their regulations. The new regulations, based on the Model, became effective in five States. Since July 1, 1969, nine more states, and one local jurisdiction, have completed the adoption of new comprehensive packaging and labeling regulations. We have also been informed that an additional eight states are in the process of promulgating new requirements.

The bulk of the state activity has taken place east of the Mississippi River, with a decided concentration in the Middle Atlantic and Northeast regions of the country. This is true in both cases; i.e., where a new regulation has been adopted and where a new regulation is in process.

Overall, there has been a noticeable predilection to delay the adoption of new state requirements. This attitude seems to be based on two premises. The first is that the states do not want to move until they can be certain that new federal regulations will 
not require additional changes. The administrative procedures for the adoption of regulations at the state level vary considerably. In many jurisdictions, it is an extremely cumbersome and time-consuming process. In view of this, many state administrators would prefer to wait until federal activity is complete, rather than be forced to periodically amend state requirements.

Secondly, there appears to be the feeling that the promulgation of regulations at the federal level, under FPLA, will resolve all problems. This wishful notion has been expressed by both enforcement officials and industry members, and seems to be based on the idea that the preemption statement in the Act means a lot more than it says.

It seems reasonable to predict that the situation with respect to federal regulation of package labeling will remain in a state of flux for some time. Still to come under FPLA are regulations concerning size characterizations, savings representations, ingredients labeling, and slack fill conditions. In addition, Federal regulations dealing with meat and meat products, poultry and poultry products, and other items excluded under FPLA, should be surfacing in the near future. Obviously, some of these will materially affect weights and measures. In light of this situation, it would not be feasible for individual states to divorce themselves from the packaging and labeling field for any lengthy period of time in the hope that they could then catch up all in one swift recovery. Weights and measures officials are perfectly comfortable with frequent annual changes in the regulations governing weighing and measuring devices, and perhaps this sense of comfort can be shifted to cover frequent changes in packaging and labeling requirements.

The theory that enactment of FPLA regulations by federal agencies, coupled with the preemption feature of the Law, somehow resolves the problem for State and local jurisdictions is mistaken. The Fair Packaging and Labeling Act is a Federal law that can only be enforced by Federal officials. There is no authority, granted or implied, for state or local officials to enforce the Act's requirements.

There has been much discussion concerning state and local enforcement of FPLA by very knowledgeable officials. The assumption underlying all such discussions has been that the states will enforce FPLA requirements only after each individual jurisdiction has adopted the requirements through its own legislative or administrative processes. In other words, it is expected that the states will move to amend and update their mandatory labeling provisions to parallel or complement Federal requirements, and then move to enforce those provisions. This is made clear in the Law itself. Section 9 of the Act directs the Secretary of Commerce 
". . . to promote to the greatest practicable extent uniformity in state and federal regulation of the labeling of consumer commodities." As can be seen from the language of this Section, Congress anticipated state and federal regulation of consumer commodity labeling; it did not anticipate state enforcement of federal requirements.

Given the availability of a comprehensive Model State Packaging and Labeling Regulation, prepared and disseminated by the states themselves through their own organization, it is hoped that its acceptance and promulgation can reach the same level as its sister document, Handbook 44. The Office of Weights and Measures is prepared to provide all possible assistance to any state or local unit that wishes to adopt the Model Regulation or its counterpart, the Model City Ordinance.

\section{THE SUPPORT AND CONCERN OF INDUSTRY}

by J. F. SPEER, JR., Chairman, Industry Committee on Packaging and Labeling, and Executive Assistant, Milk Industry Foundation and International Association of Ice Cream Manufacturers, Washington, D.C.

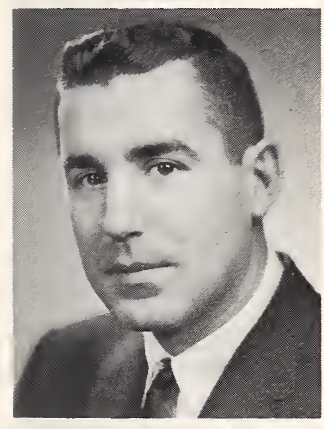
marks this morning should not be construed to be necessarily those formulated and espoused by the several members of the Industry Committee on Packaging and Labeling. The keystone of this ad hoc group is that no individual or association member will speak for any other member of the Committee.

It may be helpful to briefly sketch the history and makeup of the Industry Committee and why this unique cooperative group was formed in the first place.

The year 1962 was a period of labeling difficulty. Numerous state legislatures and weights and measures administrators were considering the adoption of what were then regarded as objectionable proposals for the requirement of quantity declaration on 
packaged commodities. Even the National Conference on Weights and Measures was divided on this subject, and departures from the Model State Law and Regulation were presenting a serious danger to uniformity of regulations.

So in 1963 there was informally organized, out of industry attendance at National Conference proceedings, what was then called the Industry Committee on Quantity Declaration. Its name was changed to the Industry Committee on Packaging and Labeling in 1965.

The Industry Committee has no charter, bylaws, initiation fee, or dues. But it does have a remarkable membership, numbering upwards of 175, and includes corporate and association representatives from a wide range of manufacturers and distributors of consumer commodities-food, drugs, cosmetics, chemicals, and soap and detergents, paper, polishes, etc. It has a clear and conspicuous objective-assistance in the development of reasonable and uniform labeling regulations enuring to the benefit of consumers, government, and industry.

Its cooperation with the National Conference constitutes a unique and gratifying event in government-industry relations, and its operation has been an effective instrument in assisting in the drafting of model uniform state packaging and labeling regulations.

The need for an Industry Committee to represent diversified affected industries brings into focus an interesting concept of uniformity of opinions and belief. It is always amusing to me that, when reference is made to the positions of regulatory officials or industry representatives, we invariably ask: "How do the regulatory officials feel about the matter?" "What is industry's position?" In most instances we receive a singular answer to these questions and thereby assume that all regulatory officials hold identical opinions or that industry's thoughts on the matter are unanimous. We all know this is not necessarily true, for each individual or groups of individuals comprising one industry, for example, may hold certain concepts that do not totally jibe with the thoughts and policies of others.

The analysis of these differences in opinions and objectives, which on many issues are minor when openly discussed, continues to be the major purpose of the Industry Committee on Packaging and Labeling. Its role is that of a catalytic agent-to bring together and produce a desirable positive action of its member constituents.

In the past, various standing committees of the National Conference and your Executive Secretary, H. F. Wollin, and before him M. W. Jensen, have utilized the ICPL as an industry sounding board on several important matters, many of which eventually 
have become a part of the Conference Model Law and Regulation. IVe welcome this opportunity to work cooperatively with state and local weights and measures officials in developing meaningful consumer regulations as they relate to packaging and labeling. We remain ready to be of assistance to the Conference in the years ahead.

For a moment, consider another form of uniformity-uniformity as it relates to federal, state, county, and municipal weights and measures laws and regulations. With few exceptions, consumer foods and goods which are subject to the provisions of the Model Law and Regulation move in commerce and are subsequently regulated by a multitude of regulatory agencies. One cringes when he contemplates what a disastrous situation would exist if this Conference were not formed to prepare and disseminate uniform, meaningful, and equitable model weights and measures regulations.

There are over 10,000 political subdivisions within the United States which possess the authority to regulate the method of sale for consumer commodities. If all of these jurisdictions promulgated varying requirements, the food industry as we know it today would grind to a screeching halt and we would return to the packaging and labeling practices of the late ninteenth century. However, this state of affairs has not taken place for a good degree of uniformity in weights and measures regulations and interpretations has been achieved by state and local weights and measures officials. The accomplishment of the National Conference and its leadership over the last several decades in consumer labeling should be looked upon with pride by all of its members.

Prior to the passage of the Fair Packaging and Labeling Act, enforcement of provisions relating to a product's quantity of contents declaration was primarily the function of the state weights and measures officials. It was therefore possible, through the National Conference, to develop and promote uniform model regulations for labeling the quantity declaration. However, Congress, through the Fair Packaging and Labeling Act, charged the Secretary of Health, Education, and Welfare and the Federal Trade Commission with the promulgation of specific regulations regarding the prominence and placement of the quantity statement. Additionally, the Secretary of Commerce was given the responsibility of developing voluntary product standards in cooperation with affected industries if it is shown that there exists undue proliferation of weights, measures, or quantities in consumer packages.

With the issuance of FPLA regulations by the Federal Food and Drug Administration and the Federal Trade Commission, a new dimension has been added to the uniformity.picture. In addition to state and local officials as represented by the National Conference 
on Weights and Measures, there now exist several federal agencies (FDA, FTC, Department of Agriculture, and Alcohol and Tobacco Tax Division, Department of Treasury) that have the authority to enforce packaging and labeling regulations. While the authority delegated by FPLA to the Department of Commerce is in the area of package proliferation, it too is vitally concerned with packaging and labeling regulations because of its important role as scientific advisor and its assistance in the administration of the National Conference programs.

It is, therefore, incumbent upon all of us, federal, state, and local regulatory officials and industry representatives alike, to work in concert toward the common goal of uniform packaging and labeling regulations. The desirable goal of uniformity can and must be achieved if the consumer is to be served adequately. The road may be rough at times, because all parties may not agree how a requirement should read or how uniformity can best be achieved.

At its meeting held in February of this year, the Executive Committee of ICPL discussed, in depth, its concern for nonuniform regulations affecting the packaging and labeling of consumer commodities. It was only natural that the adoption by the several states of the National Conference Model Law and Regulation entered into and was an important part of this discussion. At the request of the Executive Committee, a resolution was drafted and forwarded to all members of the Industry Committee. The contents of this resolution will be discussed at the ICPL meeting on Monday, July 13, and if approved, it will be presented at the Packaging and Labeling Forum Tuesday afternoon.

The efforts of the National Conference Committee on Liaison with the Federal Government should not go unnoticed, for it represents a positive step toward achieving the uniformity urged in the resolution. In its tentative report this year I was particularly pleased to see this statement: "The Committee intends to maintain the line of communications already' established with federal agencies and to aggressively pursue all matters involving federal and state relations in the weights and measures area."

If it could be arranged for representatives of all federal agencies concerned with packaging and labeling to meet several times a year, I believe that, out of such exchange, many of the pitfalls standing in the way of uniformity would be avoided. For example, while the Food and Drug Administration substantially adopted the Conference's request for the labeling of multi-unit packages, the final order differs slightly in that the total contents is required to appear within parentheses. Small as this variance in requirements may be, it illustrates the problem industry faces when different regulations are imposed for the same labeling provision. An impossible situation results for conformance when both applicable 
requirements cannot be met. It is quite possible that this minor labeling difference between the Conference requirement and that promulgated by FDA could have been resolved if the affected parties had been meeting with one another on a regular basis.

Representatives of the Industry Committee have contributed to the effort to have the requirements of the Model Law and Regulation in substantial conformance with applicable federal packaging and labeling regulations. The tentative report of the Conference Committee on Laws and Regulations contains many recommendations designed to achieve uniformity between state and federal regulations, and this effort is applauded by the entire membership of the Industry Committee.

There is a definite need to continue to involve all persons, agencies, and organizations which have a stake and responsibility in sound, uniform regulations in the development of such regulations. The officers and members of the Industry Committee are ready to assist the National Conference in achieving uniformity of state and federal packaging and labeling regulations.

It is vitally important for each of us in industry and at all levels of government to proceed on the assumption that workable and uniform regulations for packaging and labeling are attainable goals.

\section{THE SUPPORT AND CONCERN OF PRODUCERS AND DISTRIBUTORS OF GENERAL MERCHANDISE}

by P. W. Schindel, President, Association of General Merchandise Chains, Inc., New York, New York

\section{Introduction}

Thank you for inviting representation from general merchandise retailing to take part in this 55th National Conference on Weights and Measures. The members of the Association of General Merchandise Chains, which I represent, operate over 16,000 retail stores of various sizes, from small to modest, in all parts of all 50 states. They include several billion dollar volume companies, a number in the hundreds of millions category, and they range all the way to those with only a store or two. They comprise a substantial part of general merchandise retailing.

We are honored to be part of an endeavor which through the years has achieved preeminence as an outstanding example of 
intergovernmental cooperation at the local, state, and national levels. We look forward to working with NBS and with state weights and measures officials who are professionals of the highest order and who have traditionally demonstrated the validity of a government-business partnership approach to solving problems.

It is appropriate right at the start to acknowledge the special help we have received from officials of the National Bureau of Standards and to publicly thank them for their interest and guidance.

Those who sell general merchandise items have not had serious weights and measures problems. Most of our merchandise, we were told by sponsors of the Federal Fair Packaging and Labeling Act, was exempt from federal coverage. The National Conference preFPLA version of the Model Packaging Regulation was flexible enough to accommodate any of our problems. We did not take part in the post FPLA updating of the Model State Regulation. Frankly, it never occurred to us that changes were being made to accommodate the FDA and FTC technical regulations. You of the National Conference were the experts, and we expected that others would recognize this and follow your lead. Since discovering the truth, we have been working with NBS, with Conference officials, and with your Laws and Regulations Committee ever since.

From this, you can understand why my participation for the first time in one of your annual meetings will lead me to treat the assigned topic in inverse order and first discuss the "concern" of the general merchandise segment of industry and end with some observations on "support."

\section{Concerns}

Our first and principal "concern" has to do with uniformity. Long ago you of the National Conference recognized the need for uniformity in packaging laws and regulations. It was to make practical uniformity possible and to facilitate the free flow of interstate commerce of packaged consumer goods that motivated a major part of your work together over the years.

Our concern about uniformity is not that individual states will promulgate different rules and interpretations, because we are sure that you will not. Rather we are concerned about the application of supermarket-oriented regulations to general merchandise items. Can your present regulations which have been changed to accommodate FDA and FTC rulings be made reasonably applicable to other merchandise? Can regulations designed for five or six thousand supermarket items, displayed quite uniformly on shelves, be made to fit fifty thousand or more items of general merchandise 
sold in so many different ways from so many different kinds of fixtures?

We think that the answers to these questions can be "yes, if" or "yes, provided." "Yes, if" or "yes, provided" the Model State Packaging and Labeling Regulation can be interpreted and applied with reasonable, practical flexibility.

Several of our specific concerns were explained to the Conference Committee on Laws and Regulations at its interim meeting last February. Most but not all of these would be taken care of by the adoption of the Committee's tentative report as it appears on pages 64 to 68 of the Conference Announcement.

It has been suggested that this paper describe these concerns (the ones accommodated as well as those still pending) on the basis that mutual understanding always facilitates better solutions.

\section{Principal Display Panel}

The regulations require that net quantity must be designated in the lower 30 percent of a "principal display panel." For many items of general merchandise it is important to note that the "principal display panel" is usually not the entire prime surface of a package. It must be possible to designate a "principal display panel" by layout, typography, and/or the use of color. Many practical illustrations come to mind. Perhaps the easiest to visualize is the way packaged zippers are displayed and sold from specially built racks which have a series of pockets in which packages are placed so that only the top one-third or so is visible.

The pockets are arranged in rows which rise one higher than the other, like steps, so that customers can quickly and easily find the length and then the color that is wanted. The bottom half or two-thirds of the package is hidden by the fixture. The principal display panel requirements must be met by the upper part of the face of the package, which is where the attention of the consumer is primarily focused. The space below the principal display panel is properly used for other information.

Another "principal display panel" involves the cellophane or pliofilm bag which has a cardboard header. In many cases the header is the logical and obvious place for the required principal display panel information. But it seems reasonable to permit other information and perhaps illustrations to be printed on the bag portion. So long as this is not deceptive and if it helps consumers, why should it not be proper to print supplementary net quantity or identification of the merchandise below the "principal display panel" package header? 
These are examples of the kind of reasonable flexibility with which the Model State Packaging and Labeling Regulation, revised to fit federal standards, can and we hope will be interpreted when or if it is applied to general merchandise.

The interpretation proposed by the Conference Committee on Laws and Regulations in its tentative report in paragraph 4 on pages 66-68 of the Conference Announcement is clear and will be helpful.

\section{Supplementary Quantity Declarations}

The proposed interpretation in paragraph 1 on page 65 deals with supplementary quantity declarations in a very understanding and satisfactory way. It is understood that this flexibility would have been extended to packages of which the principal display panel is the header, as noted above, except for a technical ruling by FDA. It is our plea to you that, as you live with and adjust to FDA and FTC rulings, you apply them in principle rather than literally to general merchandise items which are displayed and sold in so many different ways in so many different kinds of stores and from so many different kinds of fixtures.

\section{Quantity Statements by Count}

We endorse and hope that you agree with the recommendation of the Committee in paragraph 3 on page 66 , which specifies that a net content of "one" does not have to be stated on the principal display panel when that fact is clearly evident. But there are instances when the principle could be extended.

It may be necessary for FTC and FDA to require specific quantity designations for the canned or packaged merchandise under their jurisdiction. But it seems somewhat unnecessary to require, for example, that a card on which four buttons are displayed be printed with such obvious and redundant information. The Conference pre-FPLA exemption for less than six units readily visible to the purchaser should still be retained and applied.

\section{Declaration of Indentity}

With respect to the declaration of product identity, we ask you to reestablish section 2 of your 1966 Model State Regulation as an interpretation for general merchandise. This section stated that identity should be clearly specified "unless the commodity may be identified through the wrapper or container." 
The tentative report of the Committe on Laws and Regulations, in interpretation No. 2, states that a request of ours for protection against retroactivity was unnecessary. We had suggested that all packaging regulations issued in any jurisdiction contain a clear and specific statement that any newly issued regulations would not apply to any packaged merchandise already in the stream of commerce. In other words, no retroactivity.

All merchandise properly and legally in the stream of commerce should be permitted to clear. The regulations which have been issued in New York, Illinois, and Pennsylvania apply to those states. They will soon enough have the practical effect of national regulations, but they should not apply retroactively in other states when such states adopt the Model. Each time the Model Regulation is adopted by a state, it should include protection against retroactivity.

This request was not implemented undoubtedly because we did not present a good case. This is an important basic principle which will be needed in the future. We will re-present our request through proper channels, but we want you to understand it and to know why we press the point.

There is ample legislative precedent for this no-retroactivity clause. The Textile Fiber Products Identification Act, in section 15, states: "The Commission shall provide for the exception of any textile fiber product acquired prior to the effective date of this Act." Based on the authority of this section of the law, FTC was able to issue a clear, saving regulation that protected distributors and retailers, provided they could prove by invoices that merchandise had been received prior to the effective date of the law.

This philosophy was accepted by the Congress and made part of FPLA. Section 6 (d) contains these words: "nor shall any regulations under this Act preclude the orderly disposal of packages in inventory or with the trade as of the effective date of such regulation."

There is no way to put a specific "time" in a labeling type law that will fit all categories of merchandise. Some seasonal goods will be ordered in January for October-November delivery to stores, and it is not unusual that some small stores may carry some of it over till the following winter season-almost two years.

Manufacturers and distributors are entitled to "clear" all goods which were properly produced, labeled, or packaged before the effective date of any new law or regulations. The only exception should involve safety.

We know from experience that state weights and measures officials are practical and reasonable. We appreciate the good sense 
and the partnership approach which have produced compliance without disruption. But we push the issue of specific protection against retroactivity because (1) there are important elements of time and capital involved in the preparation of packaging; (2) the time for clearing stock of some general merchandise items is uncertain and may be longer than for food or drug products; (3) occasionally, local enforcement does not have a broad understanding of this problem, and therefore it is highly desirable to have protection spelled out in the regulations; and (4) producers and distributors who are conscientiously trying to be in full compliance with all laws and regulations should not be subject to this uncertainty.

In any jurisdiction, we seek this "no retroactivity" provision to apply to new regulations, not to old established rules which may be reissued as part of an updated, consolidated guide.

\section{Support}

From the above, it is evident that there are a number of areas of concern about the National Conference proposed Model State Packaging and Labeling Regulation on the part of producers and distributors of general merchandise. But there has also been support, and there will be more, so let's switch to and end on a positive note.

We have acknowledged the great help that we received from the people at the National Bureau of Standards when we discovered that the changes you had made in your Model Regulation because of FPLA might affect our merchandise too. We have taken some positive steps which will be described. There is much more that we can do together.

First, we reproduced copies of the current Model Packaging and Labeling Regulation and distributed these to our retail company members. In addition, we placed this information in the hands of some of our major suppliers-those from whom retailers buy their packaged merchandise. This was augmented by verbal contacts between retail buyers and their resources.

It was soon evident that this was not enough. It was difficult to know precisely what was required, by whom it was required, and why. Meetings with NBS followed in Washington and in New York. These led to the preparation of a pamphlet which was designed to facilitate understanding of the proposed state packaging regulations. This pamphlet was received from the printer in January of this year. Several thousand copies have been distributed. This helped, but it generated some fundamental questions too. 
It seemed prudent to resolve some of these questions before proceeding with the extensive education program which will be required. Certain immediate questions have been dealt with in the tentative report of the Committee on Laws and Regulations on which the Conference will act on Thursday.

NBS officials suggested that after this Conference will be the time to consider how best and most effectively to let thousands of manufacturers and producers know about proposed packaging regulations. It will be time then to explain that, even though FPLA does not apply, there are proposed Model State Packaging and Labeling Regulations which may apply and which in fact have already been officially adopted in several commercially important states.

Packaging problems for general merchandise are mainly technical. Consumers in general know what they are getting. They know or can see what the items are, and they know through experience the facts of weights and measures. But if your packaging regulations do, or are intended to, apply to general merchandise items, a widespread understanding of the technical details will require a major educational effort.

We hope that you agree that the immediate need is to spread the word, answer questions, and meet any unforeseen technical problems. We offer our support to the Conference, to the National Bureau of Standards, and to any and all state weights and measures officials in whatever educational plans it is decided are appropriate.

\section{Summary and Conclusion}

Producers and distributors of packaged general mechandise items which are not covered by FPLA have not had weights and measures problems, or at least they did not know that they had any until they realized that the National Conference on Weights and Measures had altered its proposed Model State Packaging and Labeling Regulation to accommodate the regulations of FDA and of FTC which are designed for supermarket items and supermarket selling.

Uniform regulations are far better for everyone than varying regulations and numerous exceptions. It appears that the present Model Regulation can be adapted to general merchandise packaging and selling if these are interpreted and applied with reasonable flexibility based on practical experience. Without this, the technical difficulties of covering all packaged merchandise with one set of regulations will be immense.

We have explained some of the concerns of general merchandise producers and retailers in the belief that a partnership solution is 
desirable and possible. We will gladly do our part in whatever partnership äpproach may be made to the educational task that lies ahead.

Thank you for providing this opportunity to express our "concerns" and our "support."

\section{FORUM DISCUSSION}

Mr. D. I. OFFner (St. Louis, Mo.) : This discussion has all been constructive, but it also raises some questions. I do not think FPLA has caused quite as much confusion as we thought it would three years ago. I happen to be from a city that is not current with the present version of the Model Law, located in a state whose law is also behind the times. The explanation is quite simple. We have been reluctant to move too fast until this is stabilized, so that we do not have to make too many changes too frequently.

I find, however, that even though we cannot enforce FPLA, indirectly we can accomplish much by calling the attention of the labeler to the federal requirements and to the Model Law. The phrase "accepted practice" is one problem that is going to plague us in FPLA and in its echo in the Model Law. Without definite guidance we will not get uniformity, because what I consider to be acceptable practice may not be considered to be acceptable practice by someone in another jurisdiction.

I also have a comment to make on the matter of communication. The final report of the Liaison Committee states that individual labeling problems encountered by the states should continue to be sent to FDA and FTC for interpretive rulings. If a state encounters a question and communicates with FDA and gets an interpretation, that state has an authoritative interpretation. But other jurisdictions, who do not know that this letter was written, do not have this interpretation.

Mr. VADELUND: I think we can safely say that the Liaison Committee knows this. They view the FPLA Manual and its interpretation section as the appropriate vehicle for disseminating this information.

I would now like to ask Mr. Schindel to detail further for you the tremendous number of types of retail outlets that his organization represents, and to distinguish, for example, between this and the National Retail Merchants Association.

Mr. Schindel: Variety companies are in department stores, junior department stores, discount houses, and so on. So we identify this activity by calling it the chain store business. We have different kinds and sizes of stores, from 6,000 to 10,000 square feet, and up to 250,000 square feet. We have items that are not covered by federal law and that are, more and more, being sold in packaged form. 
MR. VADELUND: This situation probably points out the need for the adoption of the Model Regulation, which does cover the merchandising, packaging, and labeling of these items, unlike the federal statute.

Mr. SCHINDEL: Frankly, once the several states have adopted this regulation, you don't need much more. Our problem is to get an interpretation that we can all agree on and live with, and then get folks to do what they are supposed to.

Mr. A. J. LADD (Akron, Ohio) : Mr. Schindel, are copies available of the Practical Guide for Complying, to which you referred earlier?

MR. SCHINDEL: I have some here and will be glad to make them available to anybody that wants them. We would like to have some criticism of it, because we recognize now that this was an amateur effort on our part, and even the expert help was not quite helpful enough to bail it out and make it a good document.

Mr. J. M. Chohamin (Middlesex County, N.J.) : There is one avenue that apparently has not been explored, and that is the printing of labels. I found a particular supply of canned sweet potatoes that was labeled 8 ounces above the actual net weight. Investigation proved that it was a printer's mistake and not the fault of the packager of the product; however, he should have caught it. If we could educate the printers of labels, they could concentrate on the salability of the label as well as the accuracy of the required label information.

Mr. SPEER: I do know that the label manufacturers, at the time of the promulgation of FPLA regulations, bent over backwards to work with their people, and their people, in turn, with the various suppliers of foods and other consumer goods. I do not think there is really any answer to this; it is usually a case of someone making a mistake.

Miss I. I. Boone (Pennsylvania): Mr. Schindel, will you expand on your statement that supermarket selling is different from selling packaged items of general merchandise?

MR. SCHINDEL: I would ask all of you, the next time you go into a general merchandise store of any size, from a little stationery store where you buy the newspaper to the big one, to look at the various ways, mixtures, and kinds of fixtures from which merchandise is sold. The bottom 30 percent of a principal display panel is great when nearly everything is sold on uniform shelves where it is pretty easy to get used to looking at that bottom 30 percent. It means something there under those circumstances. The 30 percent should not be the legal principal display panel for all general merchandise items.

MR. J. R. BIRD (New Jersey) : Can you give us any information on recognition of and attention to misrepresentation by over-large 
packages, such as some candy packages that are made overly large and made up with excessive paper dividers?

Mr. J. Gomilla (U.S. Food and Drug Administration): Historically, the Food and Drug Administration had the authority to take action against products that were in containers that were so formed as to be misleading, but we lost every case. We felt that, with the advent of the Fair Packaging and Labeling Act and the added authority in that Act to control nonfunctional slack fill, we might have another shot at this problem. We did not have access to the kind of data we needed to support the issuance of regulations to control nonfunctional slack fill; so we are currently entering into contracts with 11 states (who bid for these contracts, incidentally, on a competitive basis) to gather this data for us, to actually collect samples, and make analyses of commodities, one of which is candy, which seems to be a frequent source of complaints. We hope that these data will at least give us an insight into what is in the marketplace, where the problems are, and give us some help in putting out regulations that will solve these problems.

MR. VADELUND: The question has been raised as to how this concerns FPLA. Section 5 of the Act provides discretionary authority for both the Food and Drug Administration and the Federal Trade Commission to control the problem of nonfunctional slack fill.

MR. A. LeMke (Wisconsin): I wonder if the Fair Packaging and Labeling Act did not preempt more state laws than the one on quantity labeling. Did it not preempt the state law on slack fill and possibly the state law on standardization of packages, and possibly even the very definition of the word package?

MR. VADELUND: I assume you are referring to the voluntary standards established under the voluntary standards portion of FPLA, sections 5 (d) and (e), administered by the Department of Commerce and specifically by the Office of Weights and Measures. This is the effort to get industries to agree to package in specified sizes. This program is voluntary, and we have worked with a great number of industries in attempting to reduce the number of sizes used. But this has little relationship to labeling. These standards will not preempt state statutes. I know of no instance, for example, where the specified agreed-to quantities have preempted state laws. As to the definition of a package, the federal definition is similar to the state definition.

Mr. Chohamin: Do you see any large number of exemptions coming in the near future?

Mr. VAdELUND: No. Most of the activity with respect to exemptions is over, and there are currently on the books only 17 by the Food and Drug Administration and one or two by the Federal Trade Commission. There may be, from time to time, particular items, but no large amount. 
Mr. F. J. FALlon (New York): I had hoped by this time we would be far enough along in enforcing the Packaging and Labelng Act to come up with a cutoff date, on a national basis, for ccepting any labels that did not comply with the FPLA. After istening to Mr. Schindel and a few others, it would appear we ave years to go before we have uniform labeling enforcement cross the country.

New York has adopted regulations that are consistent with the requirements of FPLA and we would like to enforce them. But I nave been reluctant to tell the city and county sealers to see that hey are enforced because of the many exemptions the federal gencies have granted, plus the many commodiites that now are excluded from the definition of consumer commodities. I think hat, if we are going to do justice to our weights and measures fficials and to the industry, we should try to arrive at a cutoff late on a country-wide basis.

Mr. SCHINDEL: The State of New York was the first that triggered us who had merchandise not covered by the federal law to he fact that we had a problem. We started an educational camoaign, knowing that we were in trouble and that our suppliers were in trouble in your state. Early in the spring we were advised hat the educational process which we must jointly engage in pught to follow the meeting that we had with FTC and with the Office of Weights and Measures. I don't quite understand why your regulation in New York should apply to any state that has not yet promulgated something.

Mr. FAlLoN: I don't think it does. But I think, to be fair to ndustry and to weights and measures people across this country, we should have some uniformity in the cutoff time. Now actually he Fair Packaging and Labeling Act is almost four years old, and $t$ supersedes any and all state and municipal regulations.

Mr. ScHINDEL: Of course, I am talking about merchandise not subject to the federal law.

Mr. FALLON: That is where we have a lot of problems, because we have very little merchandise that is not subject to state regulations.

Mr. H. N. Couden (Safeway Stores): I am in the merchandisng industry, and it is often to our advantage to merchandise a oroduct for 59 cents or 39 cents. To do this, of course, calls for accurate labeling as to quantity. As the raw product price of the merchandise changes, the quantity changes in order to maintain a orice. This leads to a type of proliferation that has not yet been considered-the proliferation of quantities when merchandising on the basis of price rather than just on the basis of quantity. Who is going to make this type of decision? The vending machine 
is built to take quarters. Twenty-five cents then becomes the basis for the package size and not the package weight. What about 25-cent packages?

MR. VADELUND: You are suggesting the standardization on the price and not the quantity?

Mr. COUDEN : Yes, what happens then? Who makes the decision whether a package can be sized according to its price or according to its net content?

MR. VADELUND: This was considered when Congress passed the Fair Packaging and Labeling Act, and they still directed the Secretary of Commerce to work with industry to develop voluntary standards based on quantity, and we have done so. Where a particular problem with respect to pricing has arisen, such as packages for use in vending machines, in which the dimensions of the vending machine and the U.S. coinage system have presented problems, exceptions have been made. Obviously, comparisons between a package sold in a vending machine and packages sold in a supermarket are never made. In every industry that we have worked with in establishing package quantity standards where there has been a vending machine problem, we have taken care of it.

Mr. S. H. Christie (New Jersey): This is the second time we are involved in a labeling situation because of our statutory requirements. The other time was in about 1955-56, when it had to do with food in packaged form only. As a result, there were millions of labels involved in the United States and in the foreign field, and we found out that the printer does have the interest of his client at heart and will try to find out what changes have to be made in the labels in order to make them comply. Second, we found that the packer was the one who determined the artwork and the positioning of the quantity statement. The people in the art field could demonstrate the fact that it was their right to color the artwork so as to make a pretty picture. But as soon as the officials of the companies involved put their foot down, this situation was clarified, and we have very little of this problem today.

MR. SCHINDEL: Let me offer further explanation of our concern regarding supplementary quantity statements. The proposed interpretation of supplementary quantity declaration (item 1 under "Interpretations" in the tentative report of the L\&R Committee), deals with this subject in a very understanding and satisfactory way. It is our plea to you that, as you live with and adjust to FDA and FTC rulings, you apply them in principle rather than literally to general merchandise items, which are.displayed and sold in so many different ways in so many different kinds of stores. The interpretation says we can designate a principal display panel typographically or by color, and we need this. But you say to us, as I understand it, that a supplementary quantity statement can- 
not be placed on a package unless it is above the principal display panel. You cannot put it on a bag where the header is the principal display panel. You cannot put a supplementary count statement on the bag below the header label.

To illustrate my point, there is a disposable diaper package that has all the required information down at the bottom of the panel, with additional count information (12 or 24, depending on the package), up at the top and very prominent on the face of the package. This is the type of information the customer wants to know. This is the kind of thing we want to do with packages and that we are accustomed to doing for the consumer's benefit.

Mr. G. E. Mattimoe (Hawaii) : It was mentioned that some 15 states have adopted the Model Regulation and that we might have a problem generated because of some existing state laws requiring information different from the Fair Packaging and Labeling Act regulations now in effect. I submit that that is not factually the way I read the committee report on S-985, which amplified that particular preemptive section and stated something to the effect that "different from" meant "inconsistent with." Am I wrong, and has this been changed, or is this a different interpretation at this time?

MR. VADELUND: The preemptive section reads, "less stringent than or different from," with "different from" meaning "inconsistent with." This means, in essence, that the states could be more stringent if they so chose.

Mr. Mattimoe: I submit that if a state had a quantity requirement in an area that was more definitive than the federal regulation, there would not then be chaos in that state or the law in that state would not be invalidated.

MR. VADELUND: Generally, I believe that, if a packager exceeds state requirements, he will meet the less stringent requirements in effect in a particular state. He can exceed the FPLA requirements if he so chooses with respect to type size or something of that sort.

MR. M. B. WEIR (American Paper Institute): The proposals in the tentative report of the $L \& R$ Committee are excellent. Everyone should very clearly make the distinction between what is a repetition of a portion of the required statement and what is a supplemental statement. This is very well spelled out in the committee's report. This is to clear up the illustration of the package of diapers where the packager would like to repeat the number 12 elsewhere on the principal display panel. If you read the proposed interpretation, you will see this is exactly what the Committee on Laws and Regulations is seeking to do. If 12 is a portion of your required statement, it is perfectly clear, under the proposal, that 
you could properly repeat that number elsewhere on the package, including elsewhere on the principal display panel. I think it is very important that everyone understand this provision that definitely permits a repetition of a portion of the required quantity statement elsewhere on the principal display panel and elsewhere on the package.

Mr. E. W. Johnson (Federal Trade Commission): An interpretive bulletin issued by the Federal Trade Commission recognizes that a uniform place has been designated for the principal display panel for the required mandatory information. Therefore, we do not permit the repetition of any of this information. Also, the regulations do not permit supplementary information on the principal display panel. Thus you will find your quantity statement on an FTC-controlled package in the lower 30 percent only on the principal display panel.

Mr. SPEER: Mr. Johnson, do you consider, or have you considered, amending your regulation in any way to permit the repetition of the mandatory quantity statement or a portion thereof?

MR. JOHNSON: I will say pointblank No at the present time, because, very frankly, we have it on the books passed by the Commission in the form of an interpretive bulletin. I believe we published it first. I am not going to say we stand fast on it by any means, and of course we are open to an approach at any time. The Commission is open to change in the regulations-a modification if they see correctly that they need it.

MR. SPEER: Is there any particular reason for the prohibition?

Mr. JoHnson: Yes. We feel that the law itself reads that a uniform place means just that. Secondly, we talk in terms of deception, and I think that if you put the term 12 up above, it stands for 12 in number, but 12 of what? Disposable diapers come out in three sizes. You want to know that it is 12 of a specific size, and the size is given next to it. Under the circumstances, 12 is misleading by itself; so we said keep it together on the principal display panel. Therefore, we said, emphasize the 12 in the proper position, and that is permissible. In other words, you can make the 12 large so that immediately the buyer knows he is getting 12 or 24 or 36 by observing this, but he knows what size he is getting because it is immediately adjacent to the count.

MR. VADELUND: This would prohibit the use of stock identification numbers on the sides of packages? Let us assume a manufacturer had three sizes, one, two, and three dozen, and for stocking purposes, for example, he wrote on the side of the package 12, 24, 36 , would this be prohibited?

Mr. JoHnson: No. That is a supplementary statement on the side of the package. But if it is on the front, it would be a piece of mandatory information required as such. 
MR. VADELUND: If you put the 12 on the side, it is permissible; ut if you put it on the front, it is not permissible?

Mr. JoHNsON : It is addressed under supplementary statements. MR. VADELUND: But it is not supplementary. It is simply a epetition of a portion of the mandatory statement. It does not upplement; it says the same thing.

MR. JoHNSON: It is a part of the mandatory statement on nother panel, but you could not repeat it on the main panel. It is ermissible on the side panel. You can create an alternate princial display panel as well.

Mr. SCHINDEL: On the header-type package for zippers, does he bottom 30 percent have to be the principal display panel, and $\mathrm{s}$ that where the quantity statement has to be placed, where the ustomer can't see it?

Mr. Johnson: No. We said that you could design your own principal display panel. You could use a header label on the zipper ackage because it is displayed in slots. Label information cannot ppear below the header label.

Mr. S. F. VALTRI (Philadelphia, Pa.) : Mr. Johnson, as I undertand it, you said that printing would be permitted below a header abel provided it was not label information, is that right?

MR. JoHnson: No label information, no printed, graphic, or written material may appear below. Now, if the package has some imple artwork which carries out the design of the package, as pposed to informational label material, that is permitted below a header.

MR. VADELUND: I have two comments to make with respect to hat, Mr. Johnson. Packaged zippers are not subject to FTC conrol, and your interpretation of the use of header labels differs from that of your sister agency, the Food and Drug Administraion.

MR. JoHnson: Ours is printed in our interpretive bulletin, oassed by the Commission. I don't know whether FDA's is complete, and did not realize that it was different.

Mr. VAdELUnd: It is. In fact, the Food and Drug Administration interpretation of the requirements for header labels is precisely the same as appears in the Model Regulation.

MR. K. GULLEDGE (Dayton, Ohio) : May I offer these labels for your examination? My reason for this question is that an official of a packaging company said that he had just come from Washington on the matter of the labeling of quantity and was told that the label had to read 12 ounces instead of $3 / 4$ pound.

Mr. VADELUND: The label reads, "Net weight $3 / 4$ pound." This would be illegal under the Model State Regulation, and I am happy to see that USDA agrees with us. This fraction is also illegal under FTC and FDA rules. 
MR. GULLEDGE: Are you saying, then, that the meat industry is not exempt from FPLA?

MR. VADELUND: No, these labels must get prior approval from the Meat Inspection Division of the U.S. Department of Agriculture, and generally it has been our experience that adherence to the Model State Packaging and Labeling Regulation will not conflict with any of their requirements. However, their requirements are not identical with nor as stringent as the Model's requirements. For example, they do not have the requirement yet that the statement appear in the lower 30 percent of the principal display panel. However, if a meat packer puts it there, he does not conflict with their requirements.

Mr. CHohamin: Has the declaration of percentages as a supplementary statement been entertained-such as 3 percent butterfat?

MR. VADELUND: That would refer to ingredients or the quality of the product, and not the quantity. I do not believe that it would be held to be a supplementary quantity statement of any kind.

Mr. J. H. LEWIS (Washington) : Mr. Johnson, when a portion of the required quantity statement appears on other than the principal display panel, does this, then, make the other panel a principal display panel?

Mr. JOHNSON: You can put a portion of the mandatory statement of the net quantity on a side panel, for instance, and not have an alternate principal display panel. In our Interpretive Bulletin No. 5, the Commission has stated that, if you put a portion of identity and net quantity together, you create another principal display panel, and you must meet the requirements that govern. You would have to have the full quantity statement in the lower 30 percent, and you would have two principal display panels at that point. But if you want to state only the quantity, you can certainly do that without putting the identity with it. The customer then goes to the principal display panel to get the full information.

Mr. VAdELUND: I believe Bulletin No. 5 says that, when any element of identity and quantity appears on any panel, this creates a new principal display panel, and all of the technical requirements must be met. This suggests that you create a new principal display panel when you put the quantity of servings, uses, or applications with the identity of the product. Serving, use, or application statements are permitted, and are required to have the quantity included in the statement.

Mr. LEENERTS: In the interest of having uniformity between the Model Regulation and the FTC regulations, is the Committee on Laws and Regulations going to reconsider the interpretation 
where they say part of the mandatory declaration can be repeated?

MR. VADELUND: This matter will be acted on during the Committee's report on Thursday.

Mr. L. A. RICK (St. Louis County, Mo.) : I think we need much more communication on this than we have.

MR. VADELUND: Sessions of this kind are designed to overcome precisely the problem you pose, and this is what we need more of. Certainly the Committee on Liaison with the Federal Government has attempted to set up communication channels so everybody can get a clear picture of what the requirements are. You can be sure this effort will continue. 



\section{(J. R. BIRD, Vice Chairman, Presiding)}

\section{FORUM ON WEIGHING TECHNOLOGY}

R. N. Smith, Office of Weights and Measures, Moderator

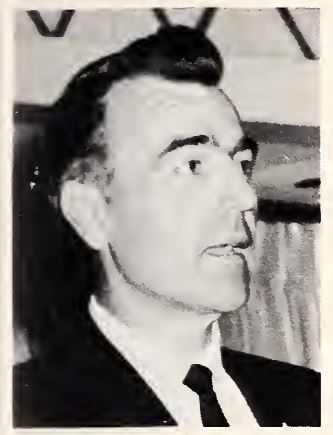

As you can see in your program, we have four open forums this year. The success of these forums depends upon you. This is an opportunity for back-and-forth communication between and among the officials and industry members.

I would first like to introduce the panel members. Don Kendall is here this morning in his capacity as Chairman of the Technical Committee, Scale Manufacturers Association. As most of you know, he is Chief Scale Engineer for Toledo Scale Company, and has been continuously employed by Toledo since 1933.

Gene Fishman is here in his capacity as President of the National Scale Men's Association. He is General Manager of J. B. Dee and Company, and has been quite active in the Hoosier Division of NSMA for many years. He has occupied all the chairs of that division, and has served on various NSMA committees, including its Executive Committee. Gene was also recipient of the Mark Pickell Award in 1969.

Otto Warnlof joined our staff approximately three years ago, and is in charge of our technical training program in the Office of Weights and Measures. Before coming with us, Otto worked 17 years with the Minnesota Weights and Measures Department, nine of those as Assistant Supervisor. 
by D. B. Kendall, Chairman, Technical Committee,Scale Manufacturers Association, and Chief Scale Engineer, Toledo Scale Company, Toledo, Ohio

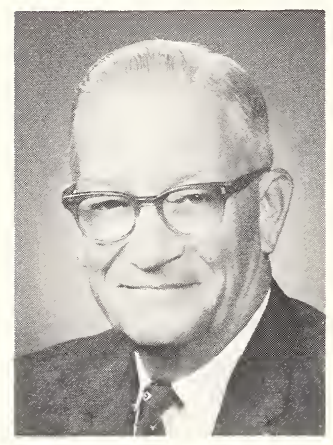

The decade of the 60's was an eventful period. In 1961 the Russians placed a man in orbit around the earth, and in 1969 the United States put four men on the moon. East Germany built the Berlin Wall in 1961, and the New York Mets won the World Series in 1969. In the middle of the 60's, in 1965, the third edition of Handbook 44 was published. In the 60's automatic labeling scales became quite common devices, and the railroads were weighing cars coupled-in-motion. A lot happened in the 60 's. Will we coast through the 70 's or will we move at an even faster pace? Only time will tell.

One of the big challenges of the 70's will be living with and working with computers. Computers are not strangers to the scale industry. For years automatic labeling scales have included small special-purpose computers. There are far simpler, however, than the fantastic machines which started out as toys to predict elections and developed into the very powerful tools which were absolutely necessary for flights to, and particularly from, the moon. Scales now provide input to such computers for exotic process control systems operated and controlled by computers. Examples are the manufacture of cement and steel and the scientific production of beef. As computers become faster, smaller, and less expensive, they will undoubtedly play a bigger part in direct weighing operations. For instance; a series of force measurements, differing in time and position, can be fed into a computer which is programmed to consider a multitude of factors and compute true weight. This approach could improve the accuracy of weighing railroad cars or motor trucks in motion, weighing material moving on a belt conveyor, or filling containers.

Another challenge of the 70's is that of adjusting to digital indication. With some help from the tremendous technological developments associated with the space program, true digital scales have been developed. It should be remembered that an odometertype indicator used on gas pumps and some electronic scales is not really digital because the fine wheel turns continuously. For some time scales have had digital printing devices and digital indicators, such as scoreboards, driven by analog indicators. Here the 
analog indicator is inspected for weighing accuracy and the digital recorder or scoreboard is checked for correspondence with the analog indícator. On a 1,000-pound by 1-pound analog scale, a reading of $1661 / 2$ means the indicator is midway between 166 and 167. If the indication is digital, $1661 / 2$ means the scale reads 166 and 167 alternately.

As digital indicating scales become more popular in the commercial weighing field, there may have to be some changes in $\mathrm{H}-44$, or at least some interpretations of requirements. For example, will it be satisfactory to indicate the weight only on demand, such as by pressing a button? This would be comparable to a beam scale, where the weight can be measured only when the poise is moved to a point where the beam balances. Considering UR.1.1.8. in H-44, which states that the minimum graduation on certain scales shall not be greater than 0.1 percent of the nominal capacity, is a 999-pound by 1-pound scale acceptable? Is one part in 999 close enough to 0.1 percent to permit omitting the extra equipment needed to indicate that last pound between 999 and 1,000? The inspector and the scale serviceman will determine that a digital scale is on zero by putting a weight equal to one-half increment on the scale and determining that the indication alternates between zero and the first digit. The operator will put the scale on zero by setting the zero balance adjustment midway between "minus" and the first digit.

Another challenge, which is with us now and will develop as we go into the 70's, is weighing in motion. Improvements in load cells and instrumentation, together with increased experience and understanding of basic problems involved, have made possible dramatic progress in the performance of scales for weighing railroad cars, not only in motion but coupled-in-motion. It is entirely possible that the 70's will see satisfactory commercial weighing of highway vehicles in motion. Suitable test procedures have to be developed for inspecting the performance of a dynamic system. It is possible that a separate section of $\mathrm{H}-44$ will have to be developed to properly deal with the whole subject of weighing in motion. It is recognized that there are significant differences between these dynamic systems and conventional static weighing scales.

Another possible challenge of the 70's could be the start of conversion to the metric system by the United States. Since all scales could not be converted overnight, for some time inspectors would be carrying a double set of test weights. It is interesting to note, however, that one of the most popular weights would be lighter. The 50-pound weight would undoubtedly be replaced by a $20-\mathrm{kg}$ unit weighing 44.0925 pounds. In the true metric system, with steps of 1,2 , and 5 , a $25-\mathrm{kg}$ weight would be out of place. 
However, whereas forty 50-pound weights make a customary ton, it takes fifty $20-\mathrm{kg}$ weights to equal a metric ton. All those who would rather handle lighter weights, but more of them, will probably vote for the metric system.

Conversion to the metric system would require more changes to $\mathrm{H}-44$ than just revising terms and tolerance tables, and there would have to be changes to other regulations. For instance, the Model Packaging Regulation permits decimal fractions of a pound, but only to two places. That means that .01 pound is the finest increment permitted. Since 0.01 pound is approximately 5 grams, would the regulation be revised to restrict the finest increment to $0.01 \mathrm{~kg}$ or $0.005 \mathrm{~kg}$ ? Details of these changes to regulations would have quite an effect on the cost of converting some scales. For instance, H-44 now requires not greater than 20-pound graduations for vehicle scales. If a revised $\mathrm{H}-44$ permitted $20-\mathrm{kg}$ graduations, scales could be converted by a simple lever change. If 10-kg graduations are specified, many scales would require a change in dial, beams, and printing device. One decision, very important to the cost and time involved, refers to the tolerance to be applied to converted scales. If acceptance tolerances are to be applied to all converted scales, many old devices would require major overhaul or replacement. The added cost would have to be considered against the obvious advantage of upgrading much of the existing weighing equipment.

Four challenges-computers, digits, motion, and metric-have been discussed briefly. There may be many more in the 70's. To keep pace with rapid changes in technology, it is essential that regulations be kept up to date. For the weighing industry and all weighing operations in the United States, it is fortunate that a practical and workable procedure was developed for keeping our regulations up to date. Key factors which make this possible are the organization of the National Conference, with its Specifications and Tolerances Committee working in close cooperation with the Office of Weights and Measures of the National Bureau of Standards, and the organization of the various scale manufacturers into the Scale Manufacturers Association, which has over 30 members who manufacture about 85 percent of the scales built in the United States. SMA is organized into six product sections, depending on the patricular interest of the manufacturers. There are four standing committees, including the Technical Committee, whose prime responsibility is to maintain liaison with the $\mathrm{Na}$ tional Conference on matters pertaining to NBS Handbook 44 and other regulations affecting the weighing industry.

The Technical Committee has a representative from each of the interested product sections of SMA. Technical Committee proposals and recommendations regarding $\mathrm{H}-44$ are generally submitted 
formed the Northwest Association of Scale Experts and elected as officers C. C. Neale, President, C. G. Stoody, Secretary, F. L. Berry, Vice President, and A. C. Johnson, Treasurer.

This group met again the following year at the same place, with a greatly increased attendance. At this meeting the name was changed to the National Association of Scale Experts and a constitution and by-laws were adopted. The National Association of Scale Experts continued to meet regularly and to increase their knowledge by association, but restricted their conversation to heavy-duty scales such as railroad track, large hopper, and vehicle scales.

In the meantime, about 1912, a similar organization, known as the American Scale Men's Association, had been formed at St. Louis, Missouri, by scale men employed in the southern and southeastern States.

In 1915, following some negotiations, the two separate associations agreed to consolidate. In 1916 they merged to form the National Scale Men's Association, with J. A. Schmidtz as President and A. G. Ziebel as Secretary. During the years 1916 through 1930, NSMA grew to maturity by increasing its membership to 200 and expanding its scope of activity to include representatives of the steel industry, the weighing and inspection bureaus, sales and engineering staffs of scale manufacturers, weights and measures regulating agencies, and scale mechanics.

Much of the association's growth and progress in the early years must be credited to the Scale Journal, which at that time was under the management of J. A. Schmitz and Mark Pickell, both of whom were strong supporters of NSMA. The Scale Journal was used as an effective medium for disseminating helpful information to members and for sustaining interest in the association's affairs. It is appropriate to remember the men who contributed so much to the growth and progress of our association. They were J. A. Schmitz, Mark Pickell, Dr. C. A. Briggs of the National Bureau of Standards, H. O. Helms of the Toledo Scale Company, Dr. Fritz Reichman of the New York State Bureau of Weights and Measures, Eugene Motchman of the Standard Scale Company, and E. D. Gorden of the Buffalo Scale Company.

In these early years NSMA exercised great influence to promote standardization and uniformity of test car design and operation and scale design and manufacture, as well as the repair and maintenance of scales. The technical data thus developed by NSMA were later adopted and incorporated in the requirements by the National Conference on Weights and Measures, the American Railway Engineering Asscciation, and some other agencies.

The impact of the great depression, which started in 1929 and lasted for more than ten years, quite seriously affected the mem- 
bership of the association, and many members could not afford the annual $\$ 4.00$ dues. In order to keep the association from falling apart, the dues for 1933 were remitted and the annual convention scheduled for Milwaukee was canceled. The membership was reduced to the low level of 75 active members. In spite of these adverse circumstances, our association was held together by the patience and untiring efforts of those members still in the association, and by 1938 the membership had reached 200 .

In order to spread the benefits of the association's activities and sustain the interest of its members during the months between annual conferences, the association adopted the policy of forming local divisions. The first local division formed was in Chicago, and the second in Pittsbugh. The success of these two divisions influenced the formation of other divisions, thus increasing our membership to more than 350 members. World War II brought a halt to our growth and slowed our progress, as it became necessary to cancel annual conventions for the years 1941-44, and the roster of members declined to 190. Since 1947 the progress and growth of our organization has been amazing, and we now have 25 divisions in the United States and Canada, with a membership of about 1,100 . Most of the 25 divisions are very active, and their influence is being felt in their respective communities.

Our organization at present encompasses railroad men, manufacturers of scales, weights and measures officials, scale dealers, suppliers of component equipment, and scale maintenance men. This composite group has found a common vehicle to gain technical knowledge and communicate current problems. The technology of our industry makes it almost mandatory for the individual to endeavor to stay abreast of new techniques. We are indeed living in an atmosphere of change. It is noted with interest that Dr. W. E. Cushen will talk on the subject of change. For those willing to cope with change, our industry and association should have an exciting future.

NSMA's technical committees have been alive and alert. Our Legislation and Technical Committee, ably chaired by Mr. C. G. Gehringer, is an excellent liaison between the industry and the National Conference on Weights and Measures. Under his guidance, a better understanding and cooperation has taken place, and we have been apprised of pending legislation and recommendations affecting the industry and NSMA.

Our Handbook Committee, under the guidance of Past President William S. Fuller, has accomplished what seems is a never-ending job. He is constantly seeking publications for the handbook. The first big project, the publishing and disseminating of William Lynn's "Repair and Installation of Mechanical Scales," is in the 
hands of our membership. This committee is now involved in the first phase of a special project to compile a bibliography of practically everything written about scales and weighing devices. This is a joint venture with the Scale Manufacturers Association. Funds have been appropriated to pursue this project, and the Chief Librarian of Alfred Tech, Mr. Fred Hoffman, and his staff are correlating this information. It is ultimately proposed in subsequent phases to have this compiled information available for some type of ready recall.

Our Program Development Committee has been effectively chaired by Mr. John Landvater. His technical background has resulted in program ideas geared to stimulate the division, district, and national seminar-type meetings.

Our Measurement Science Advisory Committe, currently under the able guidance of Mr. Charles Silver, has worked diligently with Alfred Tech. To broaden the scope, the new curriculum will be known as Electro-Mechanical Technology in lieu of Measurement Science. Through the diligent efforts of our associates in the western States, California State Polytechnic College at San Luis Obispo will offer this fall a full curriculum leading to a B.S. degree in Measurement Science. The NSMA Executive Committee will assist, when called upon, the local advisory committee of any school of higher learning or trade school to promote and further our industry.

Probably the greatest challenge to NSMA today is to prove to our membership that our association can provide the common meeting place to further the industry. Only with a professional attitude and approach can we diligently do our jobs. With knowledge, we can serve the consuming public, not only from a sales and engineering standpoint, but from a regulatory one as well. As our membership increases, we must provide additional administrative help and funds to allow our Executive Secretary to operate efficiently.

Also at this time a task force comprised of NSMA and SMA members is investigating the problems confronting the Scale Journal. While the Scale Journal is a private publication, it is obvious some type of assistance is necessary to perpetuate this worthy and much desired publication. To assure the success of the objectives of this task force, it is urged that scale men, weights and measures officials, and scale manufacturers strongly endorse the support of the Scale Journal.

It has been asked, "What is NSMA's concern toward weights and measures administration in the United States?" It is a certainty that good regulatory practices are a must. It has been my pleasure to meet and work with many weights and measures offi- 
cials. They are dedicated people with a single purpose, to administer the law. We need and will support good weights and measures.

What is NSMA's concern toward the National Conference on Weights and Measures. To the best of my knowledge, NSMA has supported the National Conference and will continue to do so. Much of the work performed by your committees vitally concerns all of us.

Comment was requested from NSMA regarding the Model State Law on Weights and Measures. The Model State Law, for all practical purposes, when and if enacted in the various jurisdictions, should bring about uniformity and clarification where necessary. It is hoped that enactment of ths law will recognize the professional status of the personnel involved and provide adequate remuneration.

Comment was also requested as to NSMA's attitude toward Handbook 44. It is accepted that this is the Bible, the ground rules for playing the game. Without the specifications and tolerances established by Handbook 44, there would be utter chaos in the industry. In lieu of simplifying the language of Handbook 44, it is suggested that NSMA divisions consider building a program on Handbook 44 at their meetings or at district and national seminars to promote a better understanding of this vital rule book.

We have also been asked if uniformity of law, regulation, testing, and enforcement among the States really is important to scale men. Our answer should be yes, emphatically yes! Most of us do business in more than one State, whether we are maintaining, manufacturing, or selling scales. How can NSMA assist in the attainment of this desirable goal? It would be appropriate to consult with our State weights and measures department, approach the pertinent State legislative members or committees, and render whatever publicity, lip service, and data are needed to get the job done.

We have covered the past and the present. Let us take a moment to look toward the future. Where is NSMA going; what will it be involved in? Someone made a statement that there is nothing as permanent as change. We would like to think that possibly some day we might become the International Scale Men's Association. In a small way, we are now.

Possibly one day the Scale Manufacturers Association and the National Scale Men's Association will join together as one organization to work with weights and measures organizations in the effort to professionally uplift the industry technically, enforcementwise, educationally, and fraternally. The emergence, then, of a cohesive organization, oriented in all phases, manufacturing, distributing, weighing, and measuring, should be of beneficial service to the consuming public and our great nation. 
We all should probably foresee the day when the United States should change to the metric system. It is felt that, if we do not, we will become an island unto ourselves.

In closing, I would like to cite the Code of Ethics by which the members of the National Scale Men's Association has always been governed:

1. Keep uppermost in mind the fundamental importance of the weighing scale to our way of life.

2. Endeavor to impress upon all the vitally significant part which scales play in providing the most important measurement of most of the world's mediums of exchange, including real goods and monies.

3. Diligently promote the use of scales as the most precise means of measuring mass or weight.

4. Conduct myself according to the highest standards of professional ethics in regard to representations of, and charges for, goods or services rendered, and to thereby reflect credit on my association and the scale industry.

5. Strive diligently at all times to render services in keeping with the best policies of proper weights and measures interpretations.

6. Take an active interest in existing laws and regulations, in proposed legislation pertaining thereto, and to aid in procuring such laws and regulations as are in the best interest of the general public.

7. Keep abreast of new developments in weighing equipment and methods, to encourage the procurement of, and to recommend the proper usage for, equipment which will effect greater precision and efficiency in weight measurements.

8. Support the National Scale Men's Association, its policies and programs, and to participate in local division activities for the mutual benefit of all its members and the clients which it serves. 9. Endeavor to earn, and to carefully guard, a reputation of good moral character, good citizenship and common honesty, and to support and promote all the uplifting influence of the community.

10. Strive to raise the standards of efficiency of myself and my associates, and to elevate the professional standing of the scale man to a position in keeping with the responsibilities of the weighing industry.

"LET ME BE WEIGHED IN AN EVEN BALANCE THAT GOD MAY KNOW MINE INTEGRITY."

Job 31:6 


\section{KEEPING PACE THROUGH TRAINING}

by O. K. WARnLoF, Weights and Measures Coordinator, Office of Weights and Measures

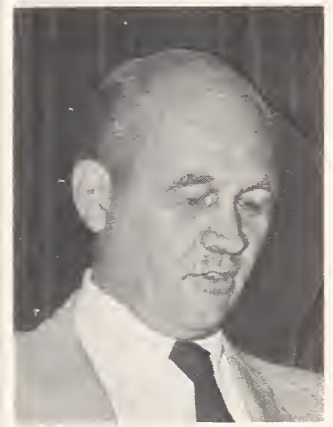

The factors necessary for more rapid progress and uniformity in weights and measures are numerous, but none so evident to me as training. The weights and measures official is called upon to undertake an endless variety of technical and difficult tasks with many legal implications. If he is to succeed, he must have certain qualities of character, the basic skills of his profession, and an intense determination to be a good public official. In addition, he must have the training necessary to fit him for the many diverse and complex decisions he must make regularly.

The modern era of weights and measures began in 1911 with the passage of the first Model Law by the Sixth National Conference on Weights and Measures. From that time until the mid 1950 's there was little evidence of management interest in a comprehensive training program. During that period, what qualifications did the weights and measures official possess and what was the extent of his job preparation? Essentially, he was a man with reasonable physical ability, a high school education, and able to pass a civil service examination or have sufficient political affiliation. He had little knowledge of weights and measures supervision, except for the few with limited related experience in other government agencies or private industry.

To prepare him for his new position in weights and measures, he was usually assigned to work with an experienced inspector for a short period of time. He was then "turned loose" in his own territory, where he had the responsibility of complete supervision over all commercial devices and quantity transactions. He may have been occasionally visited by a supervisor and he may have attended an annual meeting. The rest was up to him.

That was the situation to a large extent until 1957, when the National Bureau of Standards Office of Weights and Measures technical training project was formally established. This training program has been expanded steadily and is now one of OWM's major efforts.

The National Bureau of Standards provides training assistance to the states in a number of ways. Two or three-day sessions in all phases of weights and measures supervision are conducted at the faciilties of requesting states. Special field training in procedures 
and use of testing equipment, such as LP Gas liquid-meter provers, fifth-wheel calibration, and the laying out of a measured course is a part of the program and has been requested by a number of states.

Under the new state standards program, laboratory metrologists are, for the first time in this modern era, provided many weeks of training in all phases of laboratory activity.

Although a great deal of progress has been made in providing in-service training to field and laboratory personnel, it has been found that the manager and his supervisors need instruction in the newer concepts and procedures of management and personnel relations. Formal week-long seminars are now held semiannually for program administrators. These are concentrated and comprehensive seminars which present the latest information available on a variety of subjects pertinent to administration, management, and weights and measures supervision, and provide an open forum for exchange of ideas between program managers.

The National Bureau of Standards provides publications and other training aids in the weights and measures field. Among these are Handbook 82, Weights and Measures Administration; Handbook 94, Examination of Weighing Equipment; Handbook 67, Checking Prepackaged Commodities and its four supplements; Handbook 98, Examination of Farm Milk Tanks; Handbook 99, Examination of Liquefied Petroleum Gas Liquid-Measuring Devices; Handbook 105-1, Specifications and Tolerances for Reference Standards and Field Standard Weights and Measures; NBS Report on Examination of Mileage-Measuring Devices; and Examination Procedure Outlines for Device Examinations. The Office of Weights and Measures bimonthly Tech Memo is also a continuing source of information. The slide and tape series provides instructional procedures in the following: Examination of a Single Product Motor-Fuel Dispenser, Examination of a Computing Scale, and Examination of a Livestock Scale.

A number of states now hold their own semiannual or annual training sessions with National Bureau of Standards guidance and staff participation. But this alone is not enough for weights and measures to progress to a satisfactory level of public service and recognition.

What, then, is the solution? What should weights and measures administrators be working toward today in personnel recruitment and in-service training-today, a time when an inspector encounters mechanical devices, electronic devices, digital readouts with nixie tubes and segmented display tubes, motion weighing, new reporting systems including computer applications, statistical methods of precise package quantity control, and advanced mer- 
chandising methods? With the technological advances in evidence in recent years, it is a reasonble prediction that weighing and measuring devices will be more sophisticated than ever before, with wholly new concepts in quantity determinations and merchandising practices.

From the standpoint of personnel selection, rigid qualifications should be established. Youth, physical strength, neat appearance, outstanding character and reputation, and the ability to communicate with people at all economic levels and varying responsibilities are essential. Other particular prerequisites include mechanical aptitude, experience in law enforcement and management, and any background in physics, chemistry, electronics, and statistics. The applicant should be dedicated to public service and satisfied with the few rewards usually associated with it.

Generally, recruitment should be at the trainee level, and a proficiency developed through on-the-job training. A program should be scheduled that will include planned study, open discussion, and simulated and actual field practice, and that will provide for written and oral examinations. Time and guidance should first be provided for the study of the law and regulations. The statute is the basis for any enforcement program. It should be thoroughly understood-with a working knowledge-by the entire staff involved in its enforcement.

Instruction should be provided in all phases of the program. The operation of the office, the reporting system, records maintenance, and financing should be explained. The state standards, their relationship to the national and international standards, and their use and maintenance should be included. Training should be provided in the operation and use of all laboratory equipment. For many years this information has been zealously kept by too few people. A thorough knowledge of all laboratory procedures by the entire staff will prove an asset to any weights and measures program.

After such general training and exposure, the trainee should be brought into the special area in which he is to operate. Observation, study, and supervised practice should be provided. The theory, design, and operation of all weighing and measuring devices with which he will come in contact are essential. Several days in the shop of the various service agencies is a valuable tool in this effort. There he can witness the actual repair of the device and learn its operation, and be provided service manuals for further study. An official who has the responsibility of determining the accuracy of a device and assuring its proper use cannot be effective without a thorough knowledge of its design and operation. Visits can be made to various industrial plants to observe the operation of the various types of packaging machines and to be- 
come familiar with the quantity control methods used in private industry.

Field training should include a month or more with several experienced inspectors. The trainee should have a working knowledge of all the equipment used in weights and measures enforcement, the proper procedures for device examinations and package checking, and all other weights and measures responsibilities. An important phase of activity that is often overlooked is investigation and court procedure. The trainee should participate with an experienced official in several investigations and prosecutions. $\mathrm{He}$ should learn the fundamentals of the gathering of evidence and courtroom demeanor.

After this proficiency has been established in the area in which he will operate, then and only then should there be a change in job title, a salary increase, and individual responsibility.

But should formal training end at this point? Absolutely not! The need for continued in-service training and study is obvious. Increased efficiency, professional development, and job progress are attainable primarily through additional training. As was mentioned earlier, technology is expanding and methods changing so rapidly that, without continued study, the official will find himself able to operate effectively only in that area in which traditionalism prevails. As the law and regulations cannot preclude innovation, there must be experienced and knowledgeable officials to develop equitable, adequate, and technically correct changes to these requirements. Administrative and operating procedures must constantly be reevaluated if weights and measures is to make a full contribution in a changing world. The need for training is not limited to field personnel, but to all levels of management.

Experienced officials can continue their training in many forms. Most state universities, colleges, and high schools offer adult education courses that can contribute to continued growth in weights and measures. The Federal Civil Service training program now provides for participation by state and local government employees. The reading and study of trade journals and NBS and other technical publications, attending the National Conference on Weights and Measures and state and regional meetings, and discussions with private industry representatives should be routine.

A training officer should be designated in each jurisdiction. His responsibilities will include the scheduling of training schools, developing training aids, and provide available information on courses and educational material.

Each state should hold a regularly scheduled training school annually. This meeting should include participation and attendance by weights and measures officials and industry representa- 
tives and, whenever possible, be a combined effort with two or more states. The value derived from sharing knowledge and exchanging ideas between neighboring jurisdictions cannot be overemphasized.

A major aim of the National Bureau of Standards training effort is the establishment of weights and measures as a model for professional regulatory activity in the United States. It is to this end that the Bureau offers its resources, to the limit of staff and funds available to it. Together we can guarantee continued progress in weights and measures administration and hope to achieve national uniformity and accurate commercial measurement.

\section{FORUM DISCUSSION}

Mr. M. Greenspan (New York City, N.Y.) : Those who are now coming into the area of weights and measures officialdom are not the very young, but predominantly the middle-aged, and in most cases they do not have a technical knowledge of or background in weighing and measuring devices. The problem of training these people is a little more difficult. I happen to be involved right now in just such a cross training and upgrading of 150 field inspectors. One of my biggest problems is answering the question, "Why do we have to follow the NBS Examination Procedure Outlines?" My difficulty has been in obtaining material such as simple diagrams that would explain the construction of the equipment and therefore show them why the EPO procedures are essential.

Is it possible for scalemen, pump manufacturers, and other equipment manufacturers, with their engineering background and knowledge, to help us in supplying simple diagrams of equipment operations, so that in our training program we can more adequately present a comprehensive understanding of what is happening in a piece of equipment and therefore give the inspectors a better understanding of our test procedures?

MR. WARNLOF: I agree that this is absolutely necessary. We have had many years of experience in mechanical devices, and I think most of us in weights and measures are thoroughly familiar with the design and theory of mechanical devices. Our problem now is with electronic devices.

In my remarks I made mention that we should have combined training efforts with several weights and measures jurisdictions and with industry participation as well. Industry can aid in developing simple schematics illustrating the theory and design of equipment, so that weights and measures officials may readily understand it. I think it is important to understand why certain procedures are being followed rather than to conduct an examina- 
tion in a superficial or perfunctory manner. It is embarrassing for a weights and measures official to come upon a scale in a supermarket and have to ask that little girl who is using the scale how to operate it before he can test it.

Mr. Greenspan: Very definitely, we are going into the age of computerized and electronic devices. However, there is still a tremendous amount of other devices that are purely mechanical. In my training program I use slides and overhead projectors. The problem is to obtain simple schematics that could be used on the overhead projector. Such schematics, whether pertaining to mechanical or electronic devices, would assist everyone of us in whatever training program we may devise in our own jurisdiction.

Mr. SMith: We have discussed this at some length in our office, and it was pointed out that we are soliciting industry attendance, support, and participation in our training effort, and we hope that we will have the opportunity of participating in some of the industry training efforts with service people.

MR. KENDALL: This has brought up a very important point, and it is one of the interesting things that came out of the work in setting up the Metrology Course at Alfred University. The fact is that there is very little published information on scales. Jim Brown, who set up the course at Alfred Tech, had to start from the ground and work up. It was pretty much a one-man effort. I believe that this is a fertile field. There is a need for more readily available information on how scales work. The National Scale Men's Association is working on it. My feeling is that there should come from Alfred Tech, the Scale Manufacturers Association, the National Bureau of Standards, and manufacturers some basic information on how different types of scales work.

MR. FISHMAN: It would be a simple thing to ask for help in this area from the chairman of NSMA in New York. There are plenty of scale people who would be willing to sit down and chalktalk with you so that you can understand the simple mechanics of your devices.

MR. K. E. DAnielson (Contra Costa, Calif.) : We had an experience recently where we received help from industry. A local gasoline-pump repairman had a three-hour session with our nine inspectors, explaining the mechanics of the meters and computers, which proved to be very enlightening. I think we should consider making more use of people that are willing to come in from industry to help us.

Mr. C. Wooten (Florida): Mr. Warnlof, should industry be included in the state training programs?

MR. WARNLOF: Yes, industry participation is important and should be included in the technical training programs at all levels. 
Mr. F. W. Love (Dresser Industries): Mr. Fishman, does NSMA have a handbook on scales available to its members?

MR. FISHMAN: We have available through our executive office in Naperville, for a small fee, Bill Lynn's Handbook on Scale Service. It is well diagramed, and anybody who read it would promptly be able to understand the mechanics of a scale.

Mr. L. A. RICK (St. Louis County, Mo) : I feel that all we actually need is a basic explanation of the operation of weights and measures equipment. We need more training in testing procedures than in design principles.

Mr. SMith: Our aim is not to make mechanics out of the weights and measures officials. But no one should attempt to test a device unless he understands the mechanics of the device.

Mr. F. P. Gallo (Ohio): In 1905 the National Conference was established for the prime purpose of bringing about uniformity. The Office of Weights and Measures has done a superior job for us in Ohio, and it is my hope that we can continue to count on assistance from OWM in conducting our training schools.

Mr. G. L. JoHnson (Kentucky) : I would like to ask the panel members what they feel will be the main problem of the enforcement officials in the weighing field in the 70 's. What should we prepare for in the next 10 years?

Mr. KENDALL: I feel that one of the things is digital indication. And if the United States goes metric, of course that will start in the 70's: In-motion weighing will increase. Everybody wants to do things faster nowadays. The whole pace of life has increased, and there is a lot of concentrated pencil sharpening. One way to cut costs is to take less time for operating, particularly in the railroad industry. The old-fashioned way of weighing a railroad car was very time consuming and expensive. The railroad industry is doing an excellent job to get more efficient and more rapid weighing means. I think this trend is going to expand. USDA is confronted with dynamic weighing of carcasses. Today's weighing operations are changing equipment requirements and test methods.

Mr. Fishman: I feel that you are going to have to orient yourself electronically. Although I do not think the electronic scale will replace the mechanical scale, our trend is very definitely turning to electronics and hydraulics in weighing.

MR. WARNLOF: Our problem is to join together the philosophy that is expressed in Handbook 44 toward these new designs that we are unfamiliar with. We have developed test procedures that have been adequate in predicting that the mechanical equipment will operate effectively and accurately beyond ranges of which we have capability for testing. But electronic equipment leaves a 
question in our minds as to whether we have adequate testing equipment and testing methods to accurately predict the capabilities of electronic equipment.

Mr. N. Dimarco (Cumberland County, N.J.) : One of our main problems is the consumer. The housewife seems to be confused with decimal weight values. Charts have been made, and there has been some progress in trying to educate the consumer. I believe that we should concentrate in this area and, with the cooperation of industry and government, try to enlighten the consumer in decimal indications and recorded representations.

Mr. R. L. THOMPSON (Maryland): What is the definition of training? Is it the same for Maryland as for New York City or for Pennsylvania? I think not, I think each of us has various degrees of expertise and interests. Is training simply going over the handbook each year, or is it the development of a program that would incorporate practical application on the inspector's part, and indeed on the administrator's part? I think our neighboring states, Pennsylvania and Virginia, have recognized this, as they had indicated to me that their training meets individual needs, and sometimes, in lieu of practical application, includes a study of Handbook 44.

Thanks to the gasoline pump manufacturers and the scale industry, we have been able to develop what we call a county-fair method. By this method, industry provides the instruction in each area of the participant's responsibility. The state office reserves the right to provide interpretations of Handbook 44. We have had tremendous help from industry and from NBS, for which we are grateful. We like to establish the needs of our program and ask for their assistance.

Mr. R. D. Thompson (U.S. Department of Agriculture) :Mr. Kendall mentioned the interest of the scale industry in motion weighing of carcasses and packing plants. He said in his talk that suitable test procedures have to be developed for inspecting the performance of dynamic systems. I wonder if he would tell us some of his ideas on test procedures for dynamic systems.

Mr. KENDALL: We have discussed this somewhat with the USDA people. Weights and measures officials have done a wonderful job with the groundwork. The tests that officials now perform have satisfied them as well as the manufacturers that to hang weights on hangers and move them across the scales to simulate the carcass is an effective way to test these devices. Occasionally comparisons have been made with another scale. My feeling is that, by using actual test weights, a suitable procedure can be developed. This will work in some motion-weighing systems, but not in others. It is more of a problem with the railroad industry, because it is difficult to make a test car that simulates all of the 
various types of cars which might be put over the scale. We are going to continue to work with you on developing and improving test procedures for your application.

Mr. R. D. Thompson: Mr. Fishman, we, in conjunction with the Office of Weights and Measures of NBS, have assisted in a training program and have noticed that there is a general lack of knowledge of Handbook 44 on the part of the average scale mechanic. What can NSMA do to familiarize the scale mechanics with Handbook 44 ?

MR. FISHMAN: This is an area where NSMA should conduct seminars. I also feel that the program of state weights and measures association meetings should include a seminar on Handbook 44 and that industry should be invited to participate. Ohio had two industry seminars this year. I would certainly like to be able to participate in a seminar in Indiana some day.

MR. S. J. DARSEY (Florida) : When the first automatic prepackage scale was put on the market, there was an effort by the scale manufacturers to educate the public as to how the indications on its food packages changed from pounds and ounces to pounds and hundredths of pounds. In most cases I know of, this information stayed available to the public for only a short time, until it got in the way of some butcher and he threw it away. Perhaps this is our responsibility, but I think the users of these devices should run some kind of periodic campaign to educate their customers. For instance, why not, from time to time, have available on the prepackaging meat counter a handout which would explain to the public the meaning of the indications on these packages? This should be done on a periodic basis, due to the changing population in the community. Maybe it could be a publication that the scale manufacturer could publish and sell to the supermarket chain, and thus be a cooperative effort of the producer of the device and the user of the device to educate the public as to how the scale operates.

Mr. R. W. SEARLES: (Medina County, Ohio) : There seems to be a great mystery about how the customer is going to interpret the weight on the package. I think one simple way would be to relate the weight of the decimal system in packaging to the monetary system. Everybody understands this.

MR. KendALL: I agree with the idea of putting the demonstration labels up again, and it might be a good idea to do this periodically. But I wonder if it is a problem with the decimal, or just the fact that it is a fraction of a pound. I cannot believe that it is harder to figure with 2.15 pounds than it is with 2 pounds $21 / 2$ ounces. I think the manufacturers should continue passing out the conversion tables as an aid to customers. 
Mr. Smith: We view our training program in the Office of Weights and Measures as one of our very vital and important programs. And we never go out on any kind of training effort without learning as much as, if not more than, the people who are receiving the training. This is a two-way proposition. It is an opportunity to keep our operation current, to stay in touch with the field, and to identify problem areas. Through your help, cooperation, and feedback, we are able to do this.

\section{THE ROLE OF THE UNIVERSITY OF UTAH IN ADVANCING SCIENCE AND TECHNOLOGY}

by DR. J. C. FletcheR, President, University of Utah

\section{The Individual Scientist}

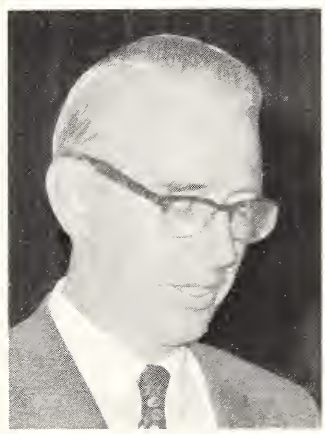

A key component in our American scientific programs will always be the integrity, ingenuity, and competence of the individual scientist. The role of the University in developing these qualities is fundamental, because universities are where our scientists and engineers are created.

\section{Academic Scientists}

Among our finest scientists in the United States are our academic scientists-teaching scientists who spend most of their lives on university campuses. Most of our Nobel

Prize winners, for example, serve on university faculties; and since university training is the common background of virtually all the scientists and engineers in this country, the influence of the teaching scientists is considerably greater than their numbers would indicate.

\section{What the University Can Do for Science}

The role of the university in furthering science and technology is a complex one. First, a university should strive to create the atmosphere in which scientific discovery and teaching can thrive. The campus should be a sort of sanctuary for free and objective enquiry, keeping emotion and irrationality at bay. Most modern universities are fulfilling this purpose rather well. In the scientific arena there are essentially no external restrictions on the purusit 
of truth; however, radicals inside are questioning the relevance or need for free, objective enquiry. The job of the university, then, is not only to protect free speech and academic freedom from external pressures, but also to preserve the pursuit of truth as a prime value in academic enterprise.

A more obvious responsibility of the university has to do with teaching and learning, and I believe that universities fulfill these rather well. One function which is not being handled so well, however, is that the university could and probably should provide some of the mechanisms by which scientific knowledge can be translated into meaningful and beneficial technology. This job is harder because many universities, with some notable exceptions, do not seem to have the resources to solve complex technological problems.

\section{Science, Applied Science, and Technology}

Before continuing the discussion on science and technology in a meaningful way, I must first remind you of some definitions.

1. Pure science is man's attempt to study nature (meaning the whole universe) and how it operates.

2. Applied science consists of man's studying nature with the idea of improving it from his point of view. That is, he is still searching for truth, but particularly for those truths which can be used for benefiting mankind.

3. Technology is less involved with the nature of the universe, but rather uses pure and applied science for the development of tools, processes, and techniques for improving man's position in the world.

\section{Humane Science}

It is sometimes exceedingly arbitrary to differentiate between man and nature. In fact, pure science should not do so. For, technically, what is man if not a product of nature? Applied science and technology necessarily involve man in contradistinction to nature, since both involve the improvement of nature for man's benefit. The problem with technology particularly is that often our attempts to change nature for man's benefit produce side effects which result in a harmful impact on man (either because our technical knowledge is limited or because our value systems are dimly perceived or poorly thought out). These harmful effects often overbalance the expected benefits. 
Man is unique among animals in being able to pass on to future generations by way of the learning process a truly complex, yet refined, cultural heritage. Were it not for his remarkable ability to learn through the spoken and written word, man would probably not be very different from the other animals. It could be said that the primary distinguishing feature of man is learning. Therefore, it is not unreasonable to assume that it should be his primary business.

\section{Science in the 21st Century}

The next three decades will conclude the twentieth century. During this time, there are going to be many discoveries taking place in all areas of science. Particularly promising are the areas of biology, ecology, and astronomy.

Curiously, the first two have particular relevance to social need; but the last, though rapidly developing, serves more to provide man with an enormous inferiority complex. These sciences will develop naturally in universities without any special changes in current roles of universities. However, it is in the arena of applied science and technology that major changes are needed. Universities tend to "sneer" at areas of applied science and do practically nothing for technology.

On the campus of the University of Utah, without neglecting our primary responsibility, which is the educating of young people, we are trying to do what we can to create viable mechanisms for the translation of scientific knowledge into meaningful and beneficial technology.

\section{The Research Park}

We are just beginning the establishment of a new 300 -acre University of Utah research park which we hope will serve as the nucleus for a center of excellence around which high-technology industry can be expanded here in Utah. From the time that we received title to the land last November, we have developed this research park faster than any of which I know, including that at Stanford. The long-range potential of this type of project is impressive. We expect that eventually (i.e., within 15 to 25 years) it will draw between three and five hundred million dollars annualy into the State of Utah, which, through the multiplier effect, will create six hundred to a billion dollars in additional state income. 
Through our Bureau of Economic and Business Research, the university is currently working on another project which we hope will further technological growth in this area. We are developing a comprehensive, instant data system to organize all the information that may be of interest to technological projects locating in this area. Besides being available to help new industries get established in Utah, this data bank will also be useful to existing industries here in their efforts to expand.

\section{Computer Center}

By way of additional resources, we also have perhaps one of the largest and finest computer-science programs in the United States and an extremely creative and competent computer center. Our people are pioneers in developing the field of computer graphics.

\section{Patent and Product Development Program}

Another effort that is bringing favorable results is our patent and product development program. In a little more than two years we have filed 40 patent applications on inventions developed here at the University of Utah, and there are a number of Utah and national firms licensed to develop some of these inventions. Several of these are "spin-off" corporations formed as a direct result of university efforts. There are about a dozen such firms now in operation, and we expect to see many more when the research park is fully operational.

Spin-off corporations are not unique among universities. Indeed, Cal Tech, Stanford, and M.I.T. are known worldwide for their spin-off corporations. What is perhaps unique here at the University of Utah is the deliberate and organized effort to produce such companies. In fact, we have attracted faculty from each of these prestigious institutions because of the opportunities to participate in some of the spin-off companies developing in Utah.

\section{Intermountain Regional Medical Program}

Another beneficial technological project at the university is our intermountain regional medical program. This was funded by a federal grant in the fall of 1966 as a sort of continuing education project for medical doctors in the remote areas of the western United States. 
It establishes direct liaison with doctors in the smaller communities by means of medical coordinators who live and practice in the various local areas by regular communication of medical news and techniques via radio, closed-circuit television, and on-site visits. The result of the program has been to up-grade and update the practice of medicine throughout the six-state area.

In 1966, for example, there were approximately seven coronarycare units in the intermountain region. As a direct result of the intermountairi regional medical program, there are now more than 100 , and many lives are being saved each year.

\section{Instrument Development in Biology and Medicine}

One of the persistent gaps in biological and medical science has been the lack of appropriate instrumentation. In fact, some of the most important advances in the last two decades were a direct outgrowth of instruments developed in other disciplines. In the past, medical and biological people have waited for others to develop instruments in their field, whereas the people in the physical sciences have characteristically developed their own instruments.

This trend is changing, and in the future a variety of new biomedical instruments may be developed by newly evolving interdisciplinary teams of biomedical engineers.

In fact, our own Department of Biophysics and Bioengineering has developed techniques and instrumentation for testing artificial hearts and other organs, as well as techniques for computer monitoring, relating and almost instantaneously interpeting a variety of vital symptoms. These measurements, along with a complete medical history, are fed into a computer to facilitate instant diagnosis and treatment.

\section{Center for Environmental Biology}

Many universities have centers for environmental biology which are heavily involved in research, publications, seminars, classwork, and symposia on the study of how man can relate to his environment in a positive way.

We regard this is one of the crucial questions of our time. Man is altering his environment at a dangerous and accelerating rate, and this rate of alteration must be slowed down. Man must learn to see himself as an integral part of nature and learn to develop ecological problem-solving systems that can operate with reference to future problems that may be creating in the present. We must pay much closer attention to the decisions of today that may tamper with our environment tomorrow. 
One thing that could be very useful is for universities to set up a number of branch offices to help small businesses in solving their problems, and also to help our rural communities make the transition from agriculture to industry and commerce. Engineering experiment stations were to have served this purpose when they were first set up, as were state geological surveys.

What is needed is to reorient these programs from primarily a service role to more of a leadership role. We could well ask what the state of agriculture would be in this country if we had not devoted so much energy and so many resources to the solution of agricultural problems.

The same sort of concept might be applied to the solution of urban problems in our large cities. The primary role, of course, will always be that of the politician, but often universities, by their essentially nonpartisan flavor, can play a facilitating role (i.e., University of Utah, city, and county government).

\section{Applied Behavioral Science}

One of the most enlightened suggestions recently made to the approach of pressing social problems would be to establish institutes for applied behavioral science at several of our major universities. I suppose that "social engineering" would be an unfortunate choice of terms, but what I would suggest are institutes that would apply the scientific method to the solution of social problems.

At present, our social scientists are not oriented toward solving problems-merely toward understanding them. One difficulty is the failure of most social scientists to apply the requirements of the scientific method (the rigorous objectivity and mathematical precision) to social experiments (e.g., education and learning, crime, low-cost housing).

Experimentation, however, is only one facet of applied behavioral science. Problem solving is another. Sometimes our social problems are the fault of the social systems that we have designed, and what is required to solve the problem is to restructure the systems. An example of this would be our system of health care, which unfortunately is not designed to keep people well, but rather a system that is designed to cure people when they are sick. We should redesign this system so that its principal objective is to keep people healthy.

Another example of a badly structured system is that of our major cities. Anyone can see that our cities are inadequately ful- 
filling human needs and that they must eventually be redesigned to clear up urban blight.

Socially constructive alternatives should also be developed in the field of education, where the system should be redesigned to emphasize learning rather than teaching.

\section{Social Indicators and a Social Report}

One suggestion that would highlight our progress toward solutions of social problems is the development of appropriate social indicators-measures which accurately reflect the quality of life for our people, particularly in its noneconomic aspects. In conjunction with these social indicators, an annual social report developed by independent and objective sources has been suggested, which would be presented annually to the American people, somewhat on the order of the current national crime report, describing accurately the quality of life that our citizens experience. In this regard, perhaps we can invent the social equivalent of the economic G.N.P. Just how universities would contribute here is not especially clear, except that techniques and trained personnel used would likely come initially from universities.

\section{University Involvement in the Big Problems of Society}

The question of how universities translate scientific knowledge into technology for the benefit of society raises the even larger question of just how involved a university should be in the major problems of our society.

Does the university have a legitimate role in the solution of such problems as pollution, poverty, racial discrimination, housing, population, warfare, peace, international relations, disarmament, etc.? The answer appears to be yes, the best universities are contributing heavily in these areas at the present time. They are using their capital resources in plant and facilities, seeking special funds for manpower needs, and, through research and service agencies, solving practical problems at the same time they teach.

Yet most contemporary problems that demand action are left to industry and government agencies. This is natural, since universities traditionally have not involved themselves in such large problems, with some exceptions of course. The difficulty with government is that often it is so immersed in coping with day-to-day problems that it has difficulty addressing itself to "the big picture" required for long-term study of national problems.

Private industry, on the other hand, is well equipped, but often not well motivated, to solve the problems. Industry in our system 
must be profit-motivated, but as yet profit incentives for solving these pressing problems are not sufficiently compelling to require the expenditure of large resources and manpower for the solution of social problems. Campus radicals continually remind us of this fact.

Perhaps the time will come when we will redesign our political systems to make it profitable for industries to clean up pollution or recondition slum areas. At present, however, businesses are not deeply committed except in quite specialized areas.

This may leave the universities in a role of singular importance in providing leadership and assuming responsibility for wider involvement of business and government in appropriate solutions to long-range societal difficulties. I believe universities have the talent and the motivation, but must first gain the confidence of other elements of society by showing constructive approaches to social problems instead of seeming to contribute to the problems.

\section{FORUM ON MEASURING TECHNOLOGY}

\section{S. HAsko, Office of Weights and Measures, Moderator}

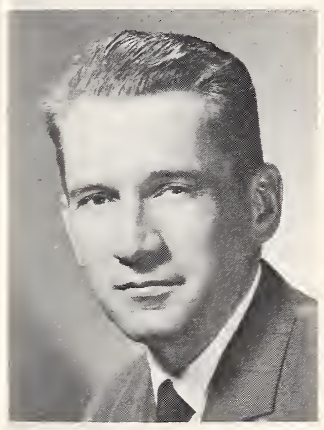

Our panel this morning is composed of a respected group of men in the area of measurement technology. Each of these experts will give a short talk on measurement technology as it pertains to his particular area of interest.

The members of the panel are (1) Mr. Howard Siebold, Chairman of the Meter Manufacturers Technical Committee and Vice President of Liquid Controls Corporation;

(2) Mr. Mitch Godsman, Service Manager of the Bennett Pump Division, John Wood Company, and a member of the Gasoline Pump Manufacturers Association; (3) Mr. Dick Southers, Operations and Engineering Coordinator for American Petroleum Institute; and (4) Mr. Bob Mills, Unit Leader of the Engineering and Standards Unit of the Office of Weights and Measures. 
by H. E. Siebold, Vice President, Engineering, Liquid Controls Corporation, North Chicago, Illinois

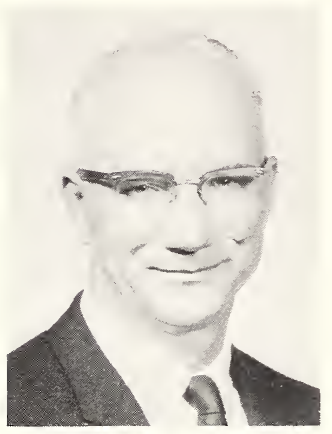

This is intended to present the views of the meter manufacturers, who have had an opportunity to edit this presentation. We can presume that they concur to some extent with these statements.

It might be well to point out that there is no Meter Manufacturers Association. The fact that the Meter Manufacturers Technical Committee exists sometimes leads to the conclusion that there is a parent group. The original purpose for this Committee was to deal only with weights and measures technical problems. The Committee was first developed to assist in writing Handbook 44, and the Committee still proves to be a valuable group available to work on current weights and measures technical problems. We encourage direct communication by individual weights and measures officials on any problem involving meters, their installations, use, or testing. The original title of the Committee specified "Weights and Measures Technical Committee." In recent years some problems have arisen that did not involve weights and measures, but required action by the meter manufacturers as a group on national and international standards. It was agreed that the Technical Committee should handle such problems and the "Weights and Measures" was removed from its title.

Actually, except for the two areas mentioned, there is little need for group action by the meter manufacturers. The Technical Committee is capable of handling all technical problems that may arise. It is doubtful that an association could be justified considering that the need is so small.

One of the major challenges facing the meter industry in the next decade will be increased competition. This is a healthy situation, as it will insure that a constant effort will be made to improve the performance of meters in general. Any manufacturer who does not make the effort is likely to find that competition has left him behind. "Performance" here means both accuracy of measurement and long life. The longer life with less maintenance is a constant goal. We are always investigating new materials, new techniques, and new designs to achieve a better meter. Improvement of meter accuracy characteristics is also a continuing effort. Progress in this area will be slow unless some technical problems in testing equipment are solved. These will be discussed later. 
Another challenge that will be evident in this period will be new forms of liquid-measuring technique. You are all familiar to some extent with the turbine meters that have been promoted during the past ten years. It is possible that they will be able to equal the positive-displacement meters in performance and cost in the near future.

There is a need in industry for a mass flow meter which will register in pounds delivered rather than volume. Some of these have already been introduced, but you will see new approaches during the next ten years. One of the problems that arises in introducing a new type of measurement device is the problem of proving the accuracy of the device. You had an excellent example of this same problem in recent years for proving weighing-inmotion scales. Proving a mass flow meter will present a somewhat similar problem, and a method of testing or a code will be needed for its calibration. This particular problem will be not only a challenge to the industry, but to the weights and measures area as well. Industry will have to depend on the National Bureau of Standards and on those in weights and measures for assistance on this problem.

We have watched the weights and measures administration in the United States grow from a group of relatively few States to the present fairly complete coverage. Our memory of our past association with the various weights and measures officials is one of complete cooperation. There is no doubt that part of the cooperation is aided by the National Conference on Weights and Measures. Here we have an opportunity to compare notes and express opinions. If there should ever be any question regarding the value of the National Conference, it should only be necessary to point to Handbook 44 as an illustration of what can be accomplished in meetings of this kind.

We look at Handbook 44 with admiration and respect. It is a very serviceable set of technical guidelines and requirements. This is not meant to imply that there is no room for improvement. The various meter codes have areas that are not properly covered. The problem is that we have not been able to suggest better ways of handling these particular sections. The requirements in Handbook 44 are generally recognized as being fair and equitable. They adhere to what is specified in the section on "Fundamentals," which we consider to be the best explanation of the philosophy of weights and measures that it is possible to write.

In our contacts with the weights and measures officials in the field and at the National Conference we seldom find that we are in disagreement, and this is to be expected. Our aim, like yours, is to provide the best and most accurate liquid measurement possible. 
When there is a difference of opinion, it is almost always traceable to a difference in interpreation of some portion of Handbook 44.

This has given us some concern in the past, and we welcome the cooperative attitude of the Conference committees such as the Specifications and Tolerances Committee. They seem to be most willing to discuss the interpretation of any particular section or paragraph. Such a relationship is necessary for mutual understanding.

We particularly appreciate the policy of the NBS Office of Weights and Measures. That is, if they feel the interpretation of a section or paragraph is being questioned, it is an indication that the section or the paragraph may need to be rewritten so that the meaning is clear. Such matters are referred to the Specifications and Tolerances Committee, which acts as the deciding body in this area. Final action, of course, rests with the voting membership of the National Conference on Weights and Measures.

One other area of concern also involves interpretation, and it has to do with the statement of "purpose." This appears on page 2 of Handbook 44 and is repeated in almost all State weights and measures laws or regulations. It says, "The purpose of these technical requirements is to eliminate from use, without prejudice to apparatus that conforms as closely as practicable to the official standards, weights and measures and weighing and measuring devices that are false, that are of such construction that they are faulty (that is, that are not reasonably permanent in their adjustment or will not repeat their indications correctly), or that facilitate the perpetration of fraud."

When this appears in weights and measures law or regulation, it is often used to cover situations that are not specifically covered by any other part of the law or regulation. This is good. A general-purpose section like this strengthens the rest of the law or regulation. Our problem comes from the interpretation of that final phrase, and the keyword is "facilitate." There seems to be an increasing tendency for some officials to interpret this to mean that a meter must prevent the perpetration of fraud. If those who wrote this paragraph had wanted it to mean that, they would have said it just that way. Webster defines "facilitate" as "To make less difficult." Whenever you are tempted to apply this section to a piece of equipment, simply substitute these words. This will tell you if you are on the right track.

Uniformity of weights and measures laws and regulations among the States is of major importance to the meter industry. It is obviously of great assistance to know that the requirements applied to a meter will be the same regardless of where it is used. This simplifies every step, from the design stage until the meter is shipped and installed. 
Uniformity of enforcement is most desirable. A different interpretation of the same requirement in one State from that obtained in another can leave the manufacturer in a difficult situation. An illustration might be the widely divergent treatment of slow-flow meters. Many jurisdictions have no equipment or facilities for testing these meters. This is in spite of the work by the Office of Weights and Measures in the development of proper testing equipment and procedures.

The testing of metering systems should by all means be uniform, as was so clearly demonstrated in the project undertaken by the American Petroleum Institute, with the cooperation of the meter manufacturers, to test various types of meter installations in order to find out what meter tolerances might be. About all that was established after almost two years of work was that the variables introduced by testing methods and proving equipment were so great that the meter characteristics could hardly be determined. This is not to infer that all meter testing by all weights and measures officials is inadequate or inaccurate, but rather that those having the equipment and the testing procedure to perform precise meter tests are probably in the minority. Some of the provers encountered in this project could not be considered really dependable. Two of them should be rebuilt to make them usable. One would not drain properly, and the other could trap air.

There is a need for a standard covering the volumetric provers used in meter testing. With the National Bureau of Standards and industry working together on this, we feel confident that such a standard can be produced in the near future.

One of the most important factors in meter testing is usually ignored. This is the possible change in temperature of the liquid between the time that it passes through the meter and when it is gaged in the prover. Two degrees of temperature change with kerosene, for example, will change the reading in the prover by $1 / 10$ of 1 percent. There have been some big improvements in the accurate measurement of temperature in recent years. It is safe to predict that it will be possible to determine the temperature of the liquid passing through the meter and the temperature in the prover far more accurately than we could in the past. The suggested standard for volumetric provers should include instructions and requirements for their proper use. It should also specify the correction for a temperature difference when this is necessary.

There are several areas in which progress can be made by the combined efforts of industry and weights and measures officials working with the National Bureau of Standards. One of these is the improvement of the accuracy with which the field working standards are calibrated. The Bureau is currently verifying test measures and primary standards with a maximum uncertainty of 
two parts in 10,000, or two-hundredths of 1 percent. These customarily are not large enough to be used directly in testing meters. They are used primarily for checking larger provers which will be used in the field for meter testing.

The Bureau sends out a correction figure for each test measure that it calibrates. The user should be careful to apply this correction factor whenever the test measure is used in the calibration of field testing equipment.

The meter proving systems which utilize a moving ball or plug appear to be capable of a wide range of applications in meter proving. Naturally, in using a prover of this type, we must use care to see that the proving run is under the same operating conditions that apply when the meter is normally in use.

This type of prover is basically a positive-displacement measuring device operating on one measurement cycle at a time. When properly applied and used, these provers can allow meter proving with a high degree of accuracy on liquids that otherwise might be difficult to handle in a volumetric prover. In this area, we need an evaluation of these proving systems with approval, or perhaps tentative approval, for use in some of the problem areas.

These problem areas exist because some liquids have characteristics that make proving in the regular manner difficult or impossible. One example would be meters measuring asphalt or residual fuels, and another example would be meters measuring cryogenic liquids. The fact that meters measuring these liquids cannot be proved with a volumetric prover does not change the need for accurate measurement of these liquids.

The most convenient approach is to weigh the amount of liquid measured, converting the weight to volume. The problem here is that the meter accuracy can be no better than the accuracy of the scale used for proving.

Another method sometimes used is the use of a master meter that has been calibrated at some time on the liquid being measured. Here again, the results obtained would be open to some doubt, since the master meter would be several times removed from a primary standard.

The displacement-type prover would seem to be most applicable to the proving of meters on difficult liquids of this kind. What we need is a study of its capabilities together with tentative approval at least during the period that it is being studied.

The National Bureau of Standards has been working on the problem of testing meters handling cryogenic liquids. A special meter proving system has been installed at its facility in Boulder, Colorado. While it is basically a gravimetric prover which will weigh the amount of liquid delivered, it is fitted wth some special features to accommodate the cryogenic liquids. It is not likely that 
any of the individual States would be able to install a meter testing facility of this kind. Even if they could, it would be difficult to arrange for meter testing on a statewide basis.

It has been suggested that master meters could be proved at Boulder and then used by weights and measures officials for testing cryogenic meters. Although this would be contrary to previous policy, it is quite likely that the results would be more accurate than the present method of proving the meters according to the amount delivered and weighed over a commercial scale.

We sincerely hope that some consideration will be given to these problems in the near future. If we can find some of the answers to these problems, it will greatly benefit the science of liquid measurement.

We expect that the 1970's will see better communication between industry and the various weights and measures agencies. This will result in greater cooperation among those concerned, to the benefit of all.

\section{THE VIEW OF GASOLINE PUMP MANUFACTURERS TOWARD MODERN MEASURING TECHNOLOGY}

by M. S. Godsman, Manager, Field Service, Bennett Pump Division, John Wood Company, Muskegon, Michigan

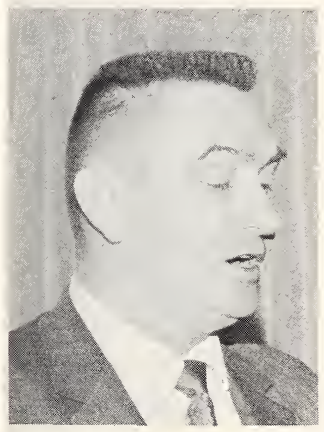

You will note in the program that my name appears under Meter Manufacturers. This is correct in that there is a meter in every gasoline pump; however, there are two classes of meter manufacturers. Mr. Siebold, who just spoke, represents meters which are used independently in loading operations and the like. I represent meters as they are used in service station pumps, and these meters are basically lower capacity than those Mr. Siebold talked about.

The organization which I represent on this forum this morning is called the Gasoline Pump Manufacturers Association.

We of the GPMA, in an effort to reduce communications for you and for us, have a Weights and Measures Committee. This committee has been active for many years, and it works closely with your Specifications and Tolerances Committee and also the American Petroleum Institute and the Meter Manufacturers Committee.

For coordination of our activities, one of us acts as chairman each year. This year it is Frank Love. The term of the chairman is geared to the annual meeting of the National Conference on Weights and Measures. In order to better coordinate with you and 
your procedures, and in order that designs are in keeping with adequate customer protection, we are constantly guided by this Conference.

Our committee is responsible to the GPMA for all design guidelines dictated by Handbook 44 . We therefore have the serious task of preparing recommendations for Handbook 44 changes which are in keeping with the intent and spirit of good consumer protection, while at the same time making it possible for the consumer to enjoy the benefits of improved technology.

If from time to time you have a question, any member of our committee will be happy to discuss your question with you. That is, unless the question has to do with another manufacturer's equipment. Now that you know us, let's talk about pumps.

The word pump is a catchall descriptive word which is no longer completely accurate in describing the housing which sits on the island in some service stations. In recent years there has been quite a transition to what is technically described as a remote pump. The result of this transition is a system which is used in many large service stations. In this newer system, the electric motor and the pump are actually in the bottom of the service station gasoline storage tank.

The move of the pump and motor from the housing on the island to the gasoline storage tank was the most dramatic change in the pump industry since air elimination was required by this Conference in the early 1930's. The remote pumping system makes gasoline much easier to handle and also makes the large modern service station a practical solution to today's problems of high volume output with low installation and maintenance cost per hose outlet.

Even though remote pumps have been in use for almost 15 years and account for some 40 to 50 percent of all the systems being sold, they nevertheless should be afforded a little more attention at this point. I say this because I am sure this method of handling gasoline is not fully understood by all the people who work with this equipment. Therefore, I feel you also would appreciate a little further discussion on this subject.

In order to better understand remote pumping, we should first look at the conditions which made it a necessity. We are familiar with vapor lock and its effect on the carburetor in your automobile. Gasoline pumps are subject to the same condition.

Prior to remote pumps, all pumps were what are technically known as vacuum pumps. This means that the pumping unit creates a vacuum and that atmospheric pressure does the work to push the product from the tank to the pumping unit. At sea level, the maximum available atmospheric pressure is 14.7 pounds per square inch. Here in Salt Lake City, it is considerably less, due to the altitude of 4,366 feet above sea level. 
Quite often the available atmospheric pressure is not sufficient to keep gasoline from turning into a vapor. When this happens, the conventional or vacuum type gasoline pump vapor locks with the same symptoms you experience with your automobile. Everything stops.

The condition of vapor lock can be accentuated under conditions which are quite common. The conditions include such commonplace happenings as an increase in temperature or a decrease in atmospheric pressure. Also, many of today's motor vehicles have higher compression engines and require a more volatile gasoline. This higher volatility increases the tendency for gasoline to vaporize.

There is another set of circumstances which add to this tendency of gasoline to vaporize. These are the conditions which are brought about by the design of the modern day service station. The length of the gasoline piping from the tank to the island has been greatly increased, due to the number of islands and the need to put the tanks where they can be filled without a large transport truck blocking the service station driveway.

Under average conditions, the limitations for the conventional vacuum pump is somewhere in the neighborhood of 75 feet, so when this is exceeded it is necessary to compensate for this increased distance in some economical manner.

The use of remote pumps answers the need, because the cost is reasonable in a multipump station. Only one pump is required for as many as eight hoses. Also, the remote pump places the gasoline under pressure immediately at the bottom of the tank. This pressure is normally about double that of atmospheric pressure, so that it is much more difficult for the gasoline to make the transition to the vapor state. Thus, the simple application of pressure to the entire pumping system has not only solved a problem of vapor lock, but has made it possible to construct service stations in keeping with the needs of the motoring public.

At the same time that remote pumping has been making its debut, other important changes have also taken place. The visigage has been eliminated, the automatic nozzle has become quite commonplace, and the semiautomatic computer has replaced the hand crank set-back computer.

All of the foregoing innovations are physical changes which improved service, but did little, if anything, to change basic marketing concepts. The change in basic marketing concepts has probably been the most complicating thing that has happened in our industry. I say complicating, because it has brought about so many and varied possibilities. Up to this time, the marketing of gasoline has followed a straight and narrow path, with necessity being the mother of invention, and the necessities have been much the same for everyone. 
We have now reached a point in the growth of the oil marketing and pump industries where expanded thought, motivated by new and changed conditions, has led to many innovations. One interesting thing that is taking place with some of these recent innovations is that their popularity varies by geographic location. This trend dates back to remote pumping, which enjoyed almost instant acceptance and success in the West, but is still an unexplored mystery to some oil companies.

Before we talk more about new systems, it must be emphasized that measuring technology has not been affected to any great degree by any of the systems which I have mentioned, nor will it be affected by the systems which I am about to talk about. There will, however, have to be some flexibility of thinking in testing procedures; but I know from past experience that you are capable of adapting to new ways. In the areas where new type equipment has been in use, the weights and measures sealers have worked closely with industry to establish new and, in many instances, unique testing procedures.

Most of the ideas which have been put into use and which will in the near future be put into use revolve around the concept of self service and improved bookkeeping and inventory control programs.

One of the first of these was in some southern California selfservice stations, where the equipment was built without any reset lever on the side of the pump. The reset mechanism was there, but it had to be operated by a special key. The key was generally carried by a pretty girl on roller skates, who collected from the customers after they had served themselves. She then reset the pump to zero with her special key, enabling it for the next customer.

Since girls first roller-skated in service stations, there have been many other self-service systems put into use. In fact, one of them dates back considerably before the girls on roller skates, and that is the coin-operated gasoline pump. I remember an old visible pump with a quarter coin slot that I bought gasoline out of in Colorado back when I was in high school, some 30 years ago.

The coin-operated pumps of today are much more sophisticated than the visible pump with a quarter slot. They accept dollar bills, quarters, and halves in combined amounts that will fill the average tank. The same system also offers both regular and premium products. Credit certainly should be given to those pioneers of the coin-operated pump industry who have been working on this concept for many years, especially out here in this part of the country.

Further applications of self-service equipment include equipment where the customer serves himself after first paying for his 
gas, or can pay for it after he has filled his own tank. In the pre-pay system, the concept is generally limited to small convenience stores who have a gasoline pump and a remote console by the cash register. If a customer has any change left from his grocery shopping, the clerk asks him if he wants to take the change in gasoline. If he does, the clerk electronically credits the amount of money into the remote console box on his counter. This is done by pushing buttons similar to an adding machine which activate the pump on the driveway, and the customer can then serve himself. When an amount of gasoline equal to the pre-set amount of money has been delivered, the pump shuts off, the customer hangs up the nozzle and drives away.

The post-pay type of equipment is such that the customer comes in and serves himself and pays a cashier before leaving. This system has many variations, most of which point to the basic honesty of the American motorist. Right here in Salt Lake City you can see installations where there is one attendant in a station, and he activates as many as 10 hoses from his location. He also collects money from the customers, who must come to him to pay before leaving the station. From his vantage spot, he can also remotely reset the equipment to zero and make it ready for the next customer.

Probably the biggest change that weights and measures people will see in self-service equipment will be due to the fact that most self-service equipment can be fitted with an additional primary indicating element at a remote location, such as the remote console by the cash register which I just mentioned. Therefore, when the sealer checks the equipment, he will be checking the accuracy of the additional indicating elements also.

The only restriction that I know to be placed on this type of equipment is by the National Fire Protection Association's "Model Law," and that is merely that the equipment must be attended. Therefore, most locations will have an attendant on the premises who can assist an inspector when necessary. There are jurisdictions which do not require an attendant, and special testing arrangements are then necessary.

Self service in the forms I have mentioned are here with us today, and I am certain that there will be other concepts introduced which are variations from those which I have described, and they will be equally as accurate.

There are some other areas of development which will appear in the marketplace within the foreseeable future with which you will at least want to be familiar. These are also devices and systems for the purpose of saving time and manpower and to eliminate errors due to handwritten sales tickets and bookkeeping entries. 
Before I talk further about these, I should mention snorkel filling. We anticipate in the not too distant future that all automobiles will be equipped with a pressure seal orifice in the gasoline storage tank, and all of these orifices will be exactly in the same location on all models and makes of automobiles. When an automobile drives into the service station, it will be lined up in a predetermined, fixed location. A snorkel will be activated on signal, and it will enter the orifice of the storage tank and fill the tank under pressure.

Snorkel filling, of course, will take some coordination between manufacturers of both automobiles and service station equipment, as well as service station designers. With the pressure put on by ecologists to eliminate fumes, this development should not be too far off. By having a tight fitting between the dispenser and the gasoiine tank, the amount of fumes discharged during filling can be reduced to an absolute minimum.

The following illustrations are designed to relieve the workload of the service station operator. Again let me say that you will see nothing on these illustrations that will change the accurate measurement of liquids as we know it today.
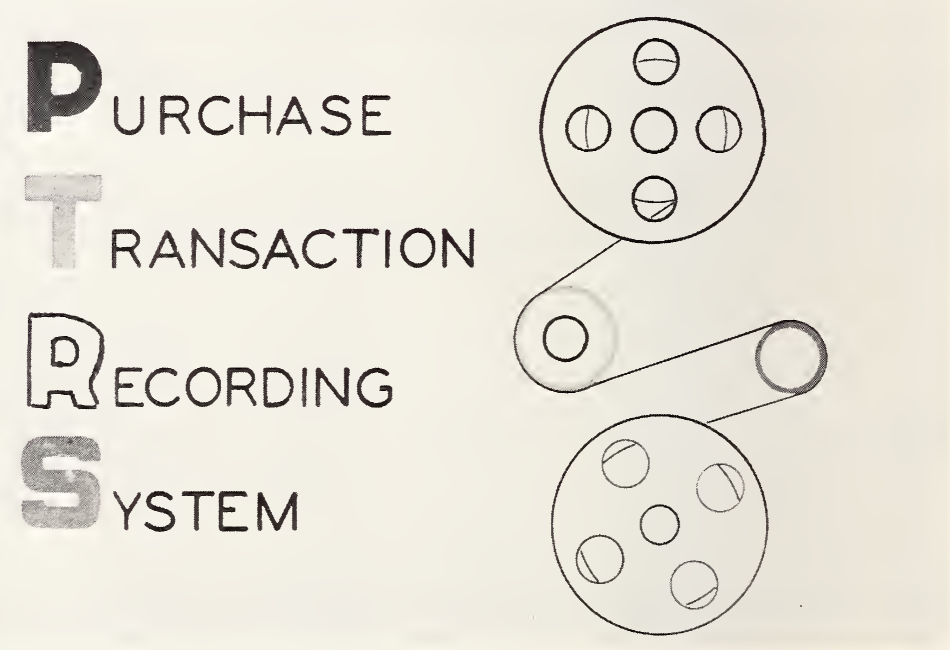

Everything must have a name, so let's call this equipment Purchase Transaction Recording System. This system records service station transactions. It is a time and work saving system which works hand in hand with a computer system. 


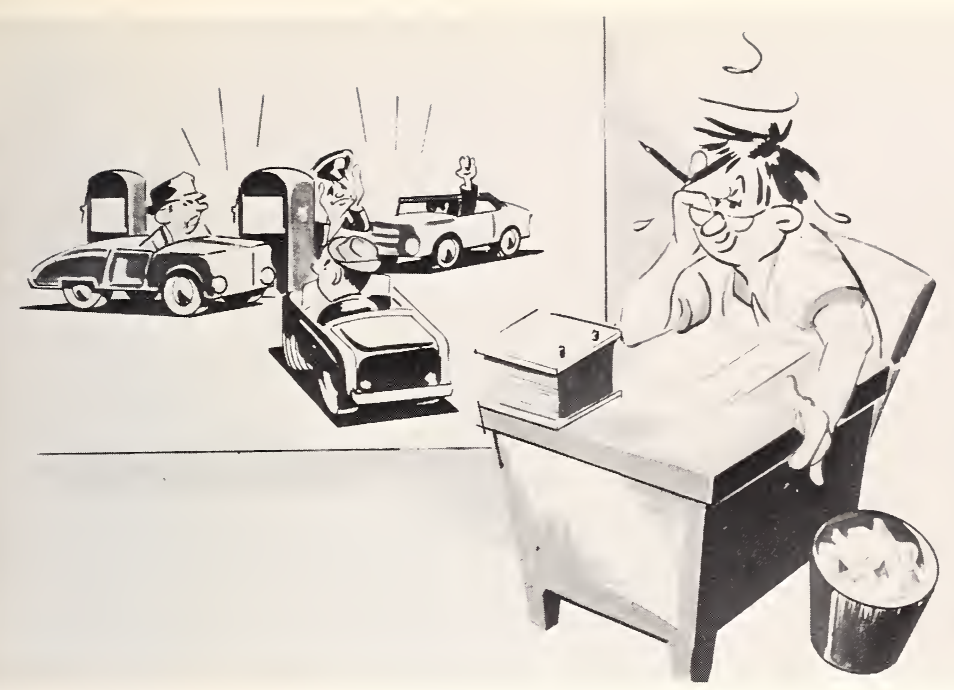

Those of you who are familiar with the complete service station picture know that the dealer is a businessman with a large bookkeeping responsibility. This is in addition to his customer servicing function, which is a full-time job all by itself.

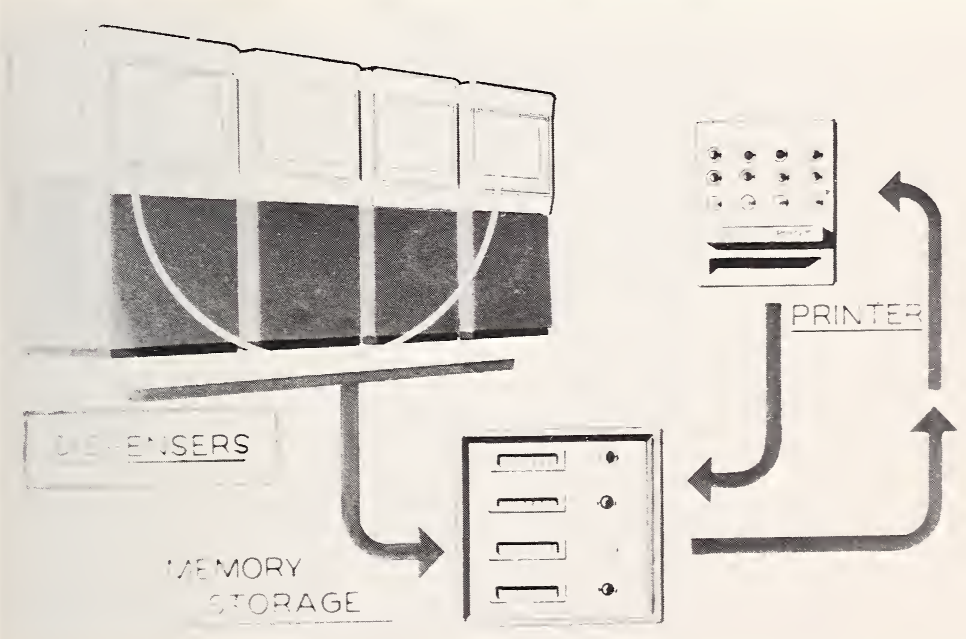

With this system, the dispensers produce electronic impulses as they deliver product. The pulses are transmitted to a memory storage bank. When the customer arrives at the cashier to pay or sign for his purchase, the cashier pushes a button and the memory storage transmits the stored pulses to the ticket printer. When the printing is complete, the memory storage bank is cleared for the next customer transaction. 


\section{IAM AN IMPUTER}

I LeT THE CASHIER

DIAL IN T.B.A., LUBE COC SO THE TOTAL SALE IS RECORDED IN MACHINE READABLE LANGUAGE .

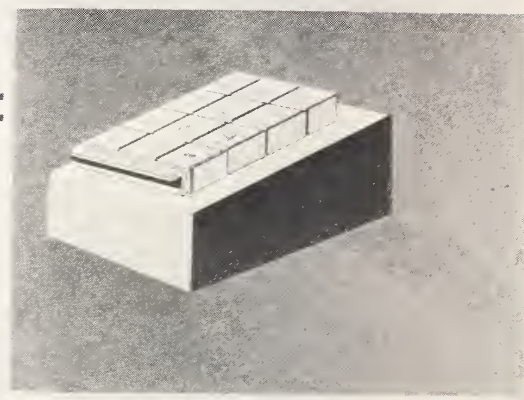

The system may be further enlarged to include another electronic input device, which we could call an "Imputer." With this device, purchases other than fuel can also be added to the ticket before it is printed. Please note that such sales can be recorded in machine-readable language-you know, the kind of hieroglyphics you see on checks.

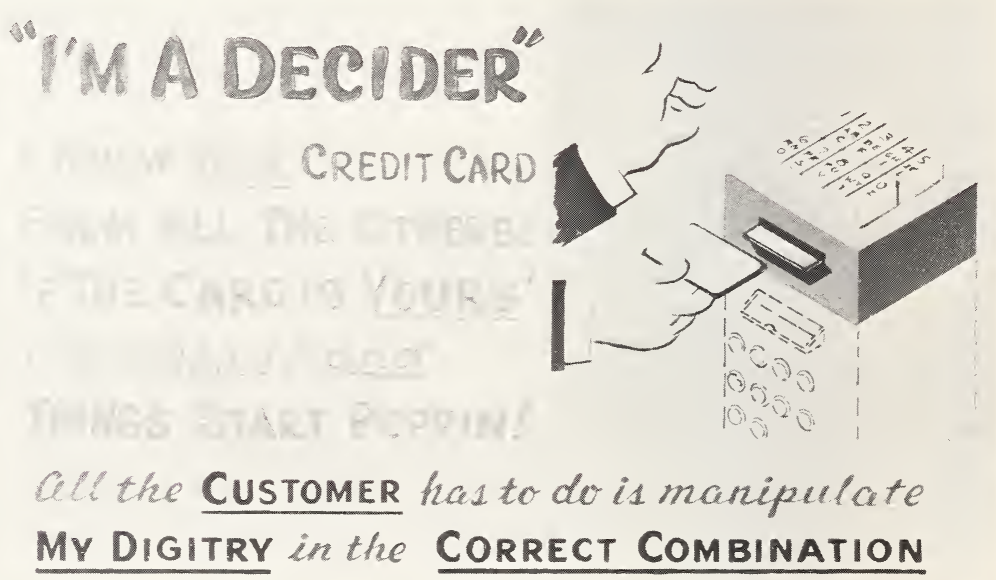

Still another device can be added. Let's call it a "Decider." This is a most necessary innovation. It accepts or rejects credit cards, and it goes one step farther; it can identify whether or not the person presenting the card is the legitimate owner of the card. This is done by pushing buttons in the correct sequence, known only to the card Owner. This correct sequence, together with the card, identifies the owner-just like your Army serial number, it is yours, and yours alone. 

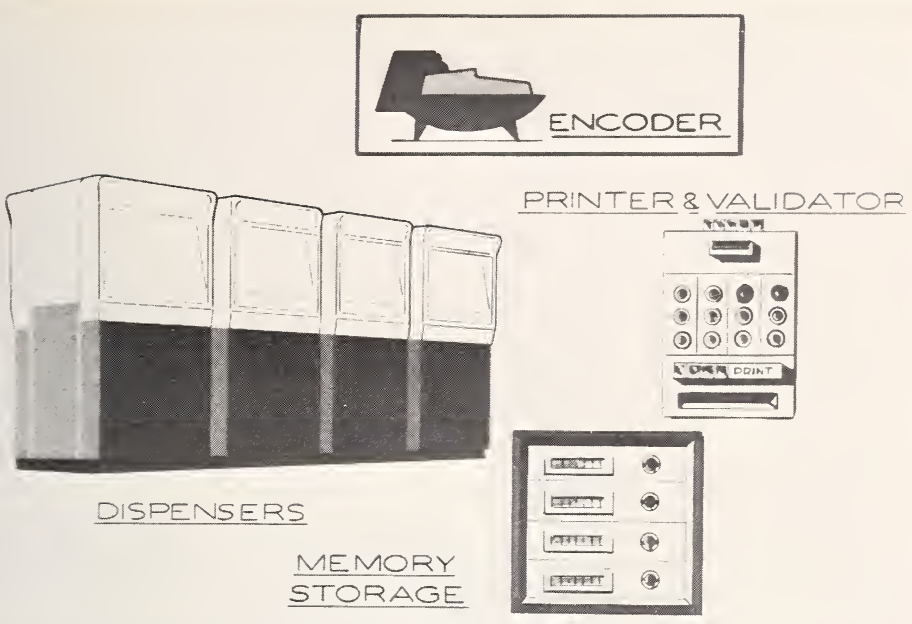

An "Encoder" can be added to take all of the information that was printed on the ticket and place it also on a punch tape. This, electronically speaking, enters the transaction on the service station books.

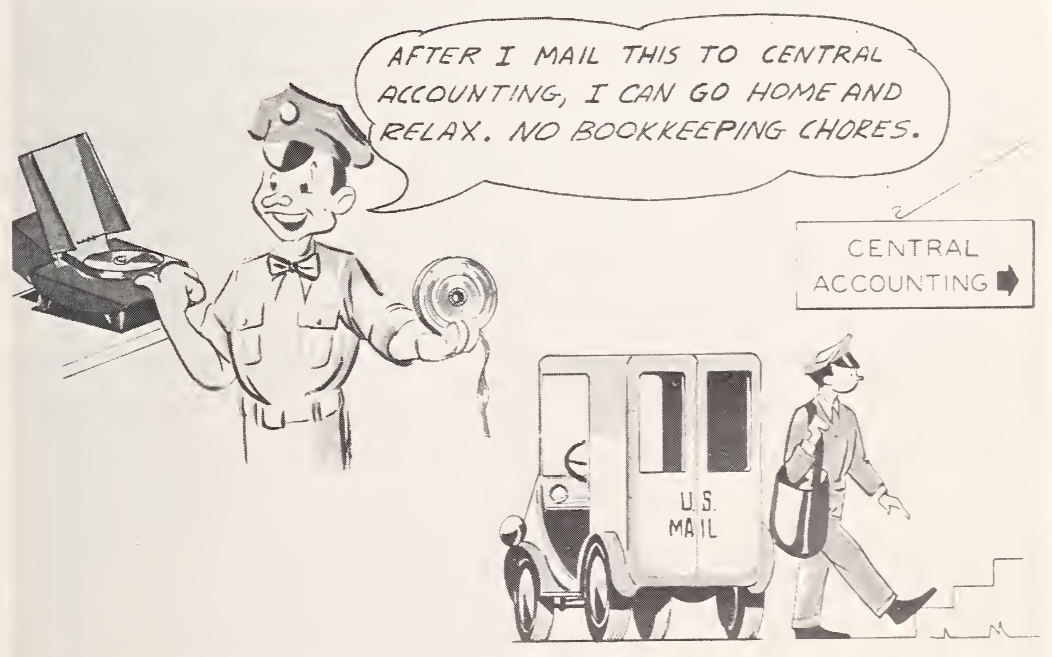

At the end of the day, the dealer removes the tape and mails it to Central Accounting, or it could be possible to have a direct line to transmit the tape electronically. 


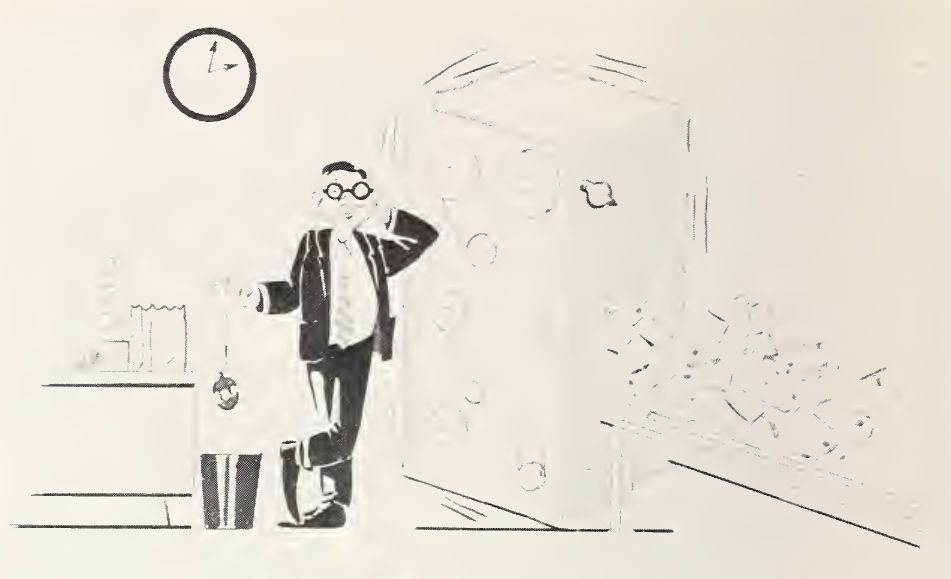

At Central Accounting, the information is fed into a computer which sorts, stores, edits, checks, rejects, and mails bills to customers and commission checks to the dealer.

I am certain that you can see from the foregoing the need for an emphasis on one of the points that is a keystone of this Conference - uniformity. Without uniformity of law throughout the 50 states, progress would be greatly hampered and cost would be prohibitive to the development of this or almost any new weighing or measuring system.

Without equipment built to specifications, based on uniform requirements, both servicemen and weights and measures inspectors would find their jobs much more complicated and frustrating.

This Conference has always been most cooperative with the reasonable desires of both consumers and manufacturers. We of the GPMA commend you for your foresightedness and look forward to a future of continued mutual understanding and cooperation. 
on items of interest or concern to the industry, and providing a means for the industry to express its position to the government or the public in general.

Whenever there is substantial agreement among its members, the Institute can and does function in the broad field of national interest and concern. It does not and cannot concern itself with matters affecting the competitive posture of its member companies.

It is very important that the preceding statement be thoroughly understood. The need for substantial agreement (not just majority) plus the avoidance of matters affecting the competitive posture can at times either cause considerable delay in taking action or preclude any action at all. A person not familiar with the legal limitations which are placed upon a trade association might logically but incorrectly interpret such delays or inactions as lack of concern.

Policies of the Institute are determined and guided by its board of directors. The board is composed of individuals directly engaged in various phases of oil industry operations who are elected by API's general membership at the Institute's annual meetings.

Members of the board, in turn, elect an executive committee from within their own ranks. Also elected by the board members are a chairman of the board, a president, who is the chief executive officer of the Institute, vice presidents of the six operating divisions, a treasurer, and a secretary.

In implementing the policies as determined by its board of directors and executive committee, the Institute is concerned not only with internal industry matters, but also with the petroleum industry's relationships with those outside the oil business. Accordingly, the Institute's activities fall into two major areas, industry affairs and public and environmental affairs. For administrative purposes, two staff vice presidents, one for industry affairs and another for public and environmental affairs, assist the president in carrying on the day-to-day activities of the organization.

Industry affairs include those internal industry matters that are primarily of a technological nature. Six divisions of the Institute, each of which parallels a branch or aspect of petroleum industry operations, comprise the elements of the "industry affairs" area. These units are:

Division of Finance and Accounting

Division of Marketing

Division of Production

Division of Statistics

Division of Refining

Division of Transportation. 
Activities of each of the Institute's divisions are directed by industry vice presidents and general committees named from industry ranks. Members of the general committees are elected from each division's membership. The industry vice presidents, who also serve as chairmen of the general committees, appoint regular and special working committees to function in particular areas of interest within the scope of each division's programs and activities.

Public and environmental affairs activities include those matters involving the relationship of the industry as a whole to the consuming public and to government. The units that function in this area are:

Committee for Air and Water Conservation

Committee on Public Affairs

Committee on Environmental Affairs.

These committees are somewhat similar to the divisions of the Institute. Their memberships are appointed by the president and their professional staffs are employees of the Institute. None of the three committees has large industry "divisional memberships."

The Weights and Measures Subcommittee of the Operations and Engineering Committee in the Division of Marketing has been designated to represent the petroleum industry in contacts with the National Conference on Weights and Measures. This designation was made because the people who are named to the committee come from the segment of the industry having a direct concern for the affairs of the Conference and its membership. I am, of course, referring to the marketers of petroleum products, and more specifically to the operating or engineering personnel responsible for the design and operating procedures used at bulk plants, terminals, and service stations. It is our opinion that people who are involved in technical problems gain little satisfaction from contact with a public relations type of individual.

Another reason for designating the Weights and Measures Subcommittee as the contact with weights and measures regulatory officials and the National Conference is the belief that such involvement helps to create an awareness of your problems, attitudes, and goals, and thereby broaden the base of understanding for those most likely to be affected. Were it not for the realization of this need for the petroleum industry to provide a formal and permanent means of communication with weights and measures regulatory officials, there would not be a Weights and Measures Subcommittee. All other phases of the industry's measurement concerns, primarily intra-industry, are handled by the Committee 
on Petroleum Measurement, which is a free-standing or nondivisional type of committee.

Incidentally, you might be interested to know the importance placed upon your area of activity by comparing it with the other areas of concern represented by the other subcommittees of the Operations and Engineering Committee. These other areas are:

Aviation Technical Service-providing communication with the aviation industry.

Major Codes-providing liaison with the major code-making bodies in the United States.

Marketing Facilities-seeking information about and solutions to problems associated with marketing facilities.

The major part of the Institute's work, in both the industry and public affairs areas, is carried on by hundreds of working committees and subcommittees to which thousands of oil company people voluntarily contribute their time and talents. Full-time API staff members coordinate and assist in administering the many programs.

Our staff members perform almost the same functions for industry that the Office of Weights and Measures personnel perform for you in the National Conference.

In general, no activity is undertaken by any unit within the API unless it has been formally proposed by a group of oilmen and unless there is general support of the activity within the industry.

Membership in the Institute is limited to companies and individuals engaged in the petroleum industry or an allied industry. We do not, however, limit participation in API activities or attendance at meetings to members. In most instances, we seek participation by as wide a cross section of interests as we can get from parties willing and able to contribute their time and talents to a particular project or committee.

Other than a library, which is open to the public, API maintains no facilities other than those necessary to house the various staff functions and personnel. Such activities as research are carried out on a contractual basis with independent firms or in the facilities of our member companies. This is one of the reasons why API became interested in the research associate program at the $\mathrm{Na}$ tional Bureau of Standards.

In case some of you do not know, the NBS Research Associate Program is a program which enables scientists and engineers from industry to work temporarily, but on a full-time basis, at the laboratories of the National Bureau of Standards on research projects agreed upon by NBS and the sponsor. Most of you are 
probably aware of the previous API involvement in a project to develop standard specifications for provers. It is to further this effort that Mr. D. J. Hine is now working as a Research Associate at the Bureau under the supervision of the Office of Weights and Measures.

Mr. Hine is a member of Phillips Petroleum Company's general engineering staff. However, while working at NBS, he will be representing the entire petroleum industry and his salary and expenses will be paid by API.

The increase in the petroleum industry's interest and participation in the affairs of the National Conference made us aware of the need to do more. Thus, to improve communications, it was decided to increase our contacts with regulatory officials in the interim between the meetings of the National Conference and state or regional conferences. It was also for this reason that Bill Kerlin was hired by API to serve as its special representative in the area of weights and measures. In general, Bill's job is to keep the petroleum industry aware of actual or developing problems which regulatory officials may have and to make recommendations for corrective action. At the same time, it is hoped that he may be able to answer some of the questions which officials may have about the petroleum industry and its practices.

During the year that Bill has been working for API, he has had the opportunity to visit many state and local jurisdictions and he has participated in the program of several weights and measures conferences. We hope that his efforts have been helpful. If you want to utilize Bill's services, be sure to contact him sometime during the Conference. At other times of the year he may be reached through my office.

In summary, let me once again restate the objectives of API:

Afford a means of cooperation with the government in all matters of national concern.

Foster foreign and domestic trade in American petroleum products.

Promote in general the interests of the petroleum industry in all of its branches.

Promote the mutual improvements of its members and the study of the arts and sciences connected with the pertoleum industry.

As you can see, three of these objectives are being served by our participation in the National Conference on Weights and Measures by (a) cooperation in the affairs of the Conference, (b) promotion of uniform laws and enforcement to achieve greater standardization of equipment and procedures, which is certainly 
in the best interests of the petroleum industry, and (c) sponsorship of a Research Associate at the National Bureau of Standards to promote the study of the arts and sciences related to the measurement of petroleum.

In summing up, let me say that I hope you now have a better understanding of API and some of its objectives. More than once I have mentioned the need for understanding. I am sure that you will agree that no one can get too much of it.

As we have demonstrated our desire to cooperate with you, we have found an equal response on your part. Our mutual problems can only be solved satisfactorily on a cooperation basis. We pledge to continue to work with you for the good of all concerned-the weights and measures officials, industry, and the consumer.

It really is a pleasure when we can move forward side by side.

\section{MEASUREMENT STUDIES}

by R. M. Mills, Head, Engineering and Standards Unit, Office of Weights and Measures, National Bureau of Standards

\section{Introduction}

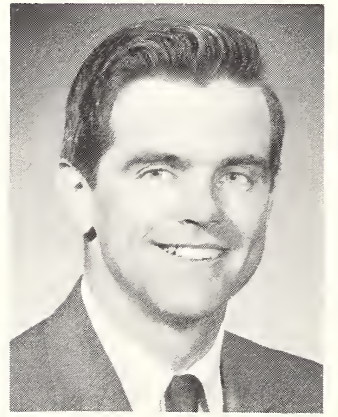

are called upon to undertake.

It is my privilege to report the status of some of the measurement studies being conducted by the NBS Office of Weights and Measures engineering staff. Projects to be reviewed are:

1. Odometer Testing

(a) Three-turn test.

(b) Accuracy of roller-type road simulators.

(c) Truck odometer testing.

2. Grain moisture meter testing.

3. Timing devices.

4. Bar soap weight loss.

5. Service station air towers. 
6. Peat moss packaging study.

7. Test procedures for checking disposable gas cylinders and calking compound cartridges.

8. Fabric measuring device test.

\section{OWM Engineering Projects}

This document is a progress report rather than a final report. Credit will be given to individuals on our staff who conducted the various studies by mentioning the name of the principal researcher in the review of each project.

\section{Odometer Testing}

A. The Three-Turn Test.-A simulated road test has been developed which will facilitate the testing of odometers, especially in congested traffic areas. Since a complete report is to be available in the near future, my aim here is to offer an introduction to the nature of the three-turn test. The method used is to find the rolling circumference of a tire in one operation and the number of tire turns per indicated odometer mile in the second operation. The product of these two quantities equals the actual distance traveled by the vehicle per indicated odometer mile. This is exactly the information needed to test the odometer. Expressed as an equation:

$$
\begin{gathered}
{\left[\frac{\text { actual distance traveled }}{\text { per tire revolution }}\right] \times\left[\frac{\text { tire revolutions }}{\text { per indicated odometer mile }}\right]} \\
=\frac{\text { actual distance traveled }}{\text { per indicated odometer mile }}
\end{gathered}
$$

The quantity represented by the first set of brackets is the "rolling circumference." For statistical reasons, the rolling circumference is found by measuring the actual distance traveled per three tire revolutions; hence the name "three-turn test." The rolling circumference increases with speed, since centrifugal forces cause the tire radius to expand. Data obtained by Mr. James Little, the OWM engineer who developed the three-turn test, suggest that a speed correction factor of +35 feet per mile should be used for conventionally constructed tires to correct to $45 \mathrm{mph}$. Bias belted and radial ply tires have an insignificant expansion at $45 \mathrm{mph}$ and, therefore, require no speed correction factor.

The quantity represented by the second set of brackets is determined by the mechanical linkage between the odometer and the driving wheels. This number is obtained in the test by attaching counters to the driving (i.e., usually rear) wheels. The rear wheels 
are rotated until the odometer indicates exactly two miles (two miles instead of one mile for improved accuracy) by using one of the three options stated below:

(a) Running the test vehicle with its rear wheels on rollers.

(b) Running the test vehicle with its rear wheels jacked off the ground.

(c) Running the test vehicle in the normal manner on a road.

Unlike the fifth wheel, the three-turn test does not require a two-mile test course (unless option (c) is used), and does not require an exact test speed of $45 \mathrm{mph}$, since the mechanical linkage is independent of speed. These are the features which will make the three-turn test especially attractive in urban areas.

The uncertainty of the three-turn test is 0.28 percent (using two standard deviations) plus the error in the value of the speed correction factor. Strictly speaking, the speed correction factor varies from tire to tire. Total uncertainty is estimated to be about 0.5 percent. Uncertainty using a properly calibrated fifth wheel is between 0.2 percent and 0.3 percent.

The cost of the two wheel counters required in the three-turn test totals about $\$ 200$. The rollers, which are needed only in option (a) above, cost an estimated $\$ 800$. A fifth wheel costs roughly $\$ 800$.

B. Accuracy of Roller-Type Road Simulators.-The Office of Weights and Measures has investigated the accuracy of a rollertype road simulator used in checking odometers and taximeters. A schematic diagram of the simulator is shown in figure 1 . It is equipped with two pairs of rollers on which the rear wheels of a test vehicle can rotate. The number of roller revolutions is counted electrically and this number converted to a simulated test distance in miles. The device can also be used to measure vehicle speed.

The accuracy of the road simulator was determined by comparison with a standard fifth wheel (a fifth wheel calibrated on a measured course). An odometer of a test vehicle was checked with the fifth wheel and also with the road simulator. The results of the two tests were then compared.

The odometer test results indicated a significant difference between values obtained with the fifth wheel and those obtained with the road simulator. This difference ranged from 1.5 to 2.5 percent for nine test vehicles, averaging 1.9 percent. In all cases, the simulator indicated fewer miles than did the fifth wheel. Therefore, in our tests, if 1.9 percent were added to the simulator results, the accuracy would then satisfy the H-44 fundamental requirement for standards : \pm 3.75 percent $\div 4$. 


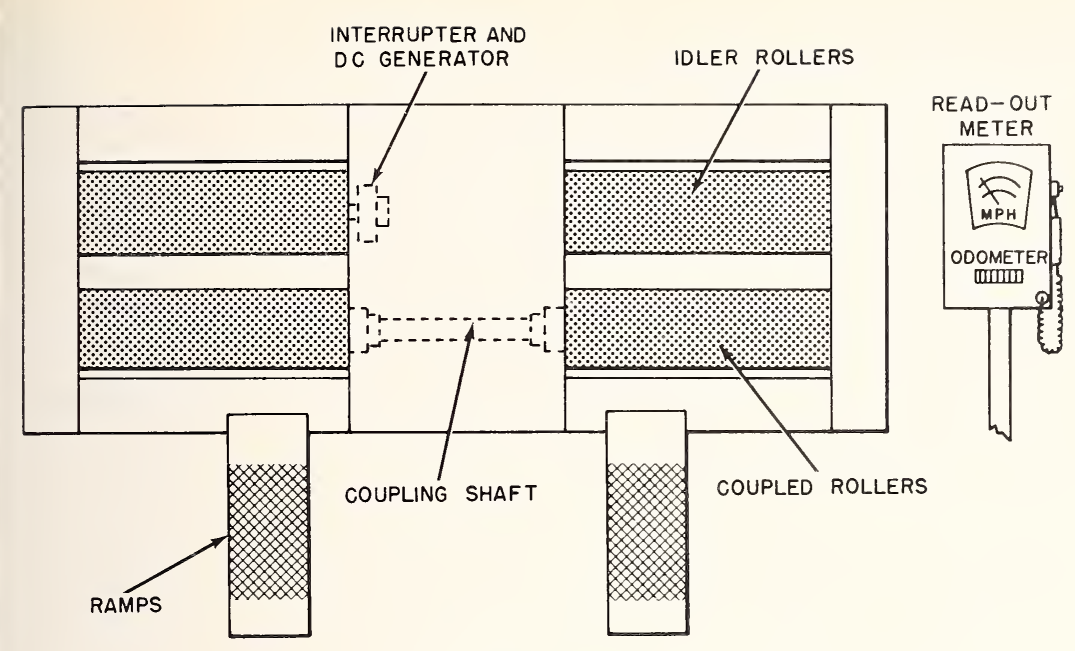

PLAN VIEW

FIGURE 1. Schematic diagram of road simulator.

However, it should be understood that this average of 1.9 percent cannot be used as a universal systematic correction factor for all simulators. The proper correction value will depend on the diameter of the rollers on each simulator, the weight of the test vehicles, and characteristics of the tires on the test vehicles (i.e., number of plies, tire pressure, etc.).

In testing taximeters, a single correction factor for the simulator cannot be used because of more stringent tolerances for taximeters. It is expected that separate correction factors will have to be employed for taxi weight classes and tire types.

The speedometer test results indicated that the road simulator overregistered at an average of 3 percent. However, the amount of error depended upon the test speed, tire sizes, and vehicle weight. A stopwatch was used with the fifth wheel for checking speedometers, and the results were compared with those of the road simulator.

Apparently, the difference between test results for the fifth wheel and the road simulator is due to the differences in rolling radii of tires. On the simulator a tire is concavely flexed at two separate points in contrast to the flat single area of contact existing under normal road conditions. This is illustrated in figure 2. The effective rolling radius of a tire, which determines the distance moved by the vehicle for each wheel revolution, is altered. 

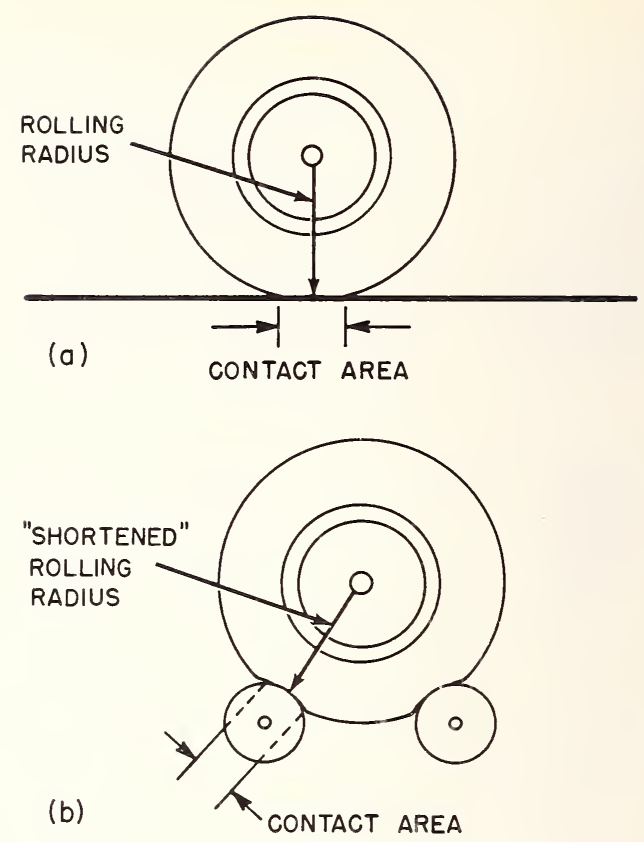

Figure 2 (a) Schematic diagram of vehicle wheel on road surface showing effective rolling radius. (b) Schematic diagram of vehicle wheel on road simulator showing "shortened" effective rolling radius.

It is concluded that road simulators must be individually calibrated. They should not be used by weights and measures officials for testing odometers and taximeters until they have been compared with a standard fifth wheel. The calibration of a road simulator should be performed with a variety of tire types and vehicle weights that are representative of those encountered in actual test vehicles, and correction factors established to compensate for simulator inaccuracies. Accurate results cannot be obtained by measuring the circumference of the rollers and multiplying this by the number of roller revolutions.

Data for this investigation were collected by Mr. Charles Schreyer.

C. Truck Odometer Testing.-The calibration of truck odometers is affected by the size of the cargo load. It is to the rental truck user's advantage to have the odometer calibrated at full load, and to his disadvantage to have it calibrated at zero load. The Specifications and Tolerances Committee has suggested that testing truck odometers at 50 percent of the rated load capacity is 
a fair compromise, since most rental trucks are loaded only about half of the driven distance. Recognizing that test weights and lifting equipment will not, in most cases, be available for checking truck odometers at 50 percent rated cargo load, the Office of Weights and Measures is determining appropriate weight correction factors to be used when testing trucks at zero cargo load.

Our data, obtained by Mr. Schreyer, are not yet extensive enough to report definite values. It appears, however, that the weight correction factor will be less than 0.5 percent. It has been determined that odometer error varies linearly with the size of cargo load. The data are being obtained using both a fifth wheel and the three-turn test, so that three-turn test speed correction factors can be found for trucks.

Stabilized tire pressures (i.e., tire pressure after the tire temperature has become stabilized through normal use) for trucks are also being observed and appear to conform with "cold tire pressure... plus 10 percent . . . (minimum of 4 psi gage above cold tire pressure)" as proposed in N.1.3.2. of H-44 Odometer Code.

\section{Grain Moisture Meter Testing}

By act of Congress, oven drying is the official reference method and is used by the Department of Agriculture to check electrical impedance moisture meters. However, because of the required drying time, the oven method is unappealing to weights and measures officials. Depending on the type of grain, drying may take from 1 to 72 hours.

We have shown that a gas chromatograph can measure grain moisture content of 1 sample in 10 minutes, or 4 to 5 samples in 30 minutes. Results of the oven and gas chromatograph agree to within 0.1 to 0.2 percent. This fact and the precision of the electric meters to be tested suggest that a practical tolerance value will be about \pm 1 percent.

The gas chromatograph will be used to determine the moisture content of test grain samples. These samples will then be used for checking electric moisture meters used in the field or, perhaps, standard electric meters used by the inspectors.

Mr. James Little is conducting this investigation. He has determined the optimum operation of the gas chromatograph for this application. The number of test samples (having different moisture content) and the interval between rechecking these samples with the gas chromatograph are presently being considered.

Equipment cost for using the gas chromatograph in grain moisture measurements will be between $\$ 3,000$ and $\$ 5,500$. Our equipment adds up to the higher value; but now that instrument requirements are better defined, cheaper more specialized equipment 
can be purchased. For example, a cheaper gas chromatograph can probably do the job adequately. It may be possible to replace the recorder and associated integrator with a cheaper electronic integrator. These possibilities must still be checked.

In looking over the list below, it will be noted that the apparatus is laboratory equipment. It will be possible to transport and use the equipment in a clean remote indoor location with power receptacles and reasonable temperature control.

OWM Equipment

Gas chromatograph

$\$ 1,850$

Recorder

Integrator

700

Printer

850

Grinder

200

Balance

600

Other

200

$\$ 5,500$

\section{Timing Devices}

The widespread interest in this subject among weights and measures officials evidences the need for a timing devices code. Mr. Stephen Hasko, senior engineer on the OWM staff, expects to have a draft of such a code ready for informal review and comments at the 1970 National Conference on Weights and Measures. Of course, this code cannot be presented officially to the Conference until 1971.

The Office of Weights and Measures has made a brief study of four types of timing devices-coin-operated clothes driers, coinoperated car washes, parking meters, and parking lot (or garage) clocks. Mr. Charles Schreyer did the legwork in collecting this data.

Timing errors of clothes driers were fairly symmetrical, about zero error (i.e., averaged to zero), and the standard deviation of these errors was just under 8 seconds.

In checking the coin-operated car washes, a disturbing number of machines were found to be out of order or turned off due to extremely cold weather. At several locations, the customers lost their coins, as no "Out of Service" sign was posted.

Parking meter errors of 10 percent were common. There are two sources for error in parking meters-the initial or "fly-up" 
setting and the rate at which the indicator returns to the "violation" setting.

Individual parking lot (or garage) clocks were found to be accurate as expected, since they are tied to the AC powerline frequency. The problem may be with "in" and "out" clocks, which are not synchronized. Several states have discovered examples of unsynchronized clocks, but our investigation revealed none.

\section{Bar Soap Weight Loss.}

Manufacturers of bar soap will label by weight the soap leaving their factories after July 1, 1970. This labeled weight is to be the anticipated average in-store weight as determined individually by each manufacturer.

Bar soap contains water and other volatile substances. Unless the product is hermetically sealed, drying will cause weight loss. The rate of loss will depend on the efficiency of the wrapper to retard moisture loss, on storage and display conditions, and on the age and composition of the soap itself.

The Office of Weights and Measures has obtained some freshly manufactured soap and is determining the rate of weight loss to be expected under typical shelf display conditions and under extreme or accelerated moisture loss conditions. After almost 70 days of observation, the typical weight loss is roughly 2 to 4 percent and has not stabilized. $\mathrm{Mr}$. Stephen Hasko is responsible for this project.

\section{Service Station Air Towers.}

This subject is introduced in the following article, "Engineers Survey Air Tower Accuracy," which originally appeared in the NBS Technical News Bulletin and has since been reproduced in the OWM Tech Memo. It cites the connection between improper tire pressure and the threat to safety and tire life. It also summarizes the results of a study done by the NBS Office of Vehicle Systems Research (NBS Technical Note 512-copies will be available at the Conference) which indicates that there is widespread inaccuracies in service station air towers. 
Engineers Studying Tire Wear AND SAfety at the NBS Institute for Applied Technology recently measured the accuracy of tire inflation equipment at 50 service stations. Such a study was needed because station air towers are almost never tested, once installed, despite the importance of maintaining correct inflation pressures. This survey was performed by the Institute's Office of Vehicle Systems Research as part of its research for the Department of Transportation. OVSR engineers Bert Simson and Richard Radlinski found air tower errors to be so great that there is a 45 percent chance that tire inflation will differ by at least 3 psi from the pressure the tower is set for. ${ }^{1}$

The pressure to which automotive tires should be inflated is specified by the vehicle manufacturer for various loads. Inflating tires to these pressures reduces the likelinood of tire failure and results in the best compromise between long tread life and good ride quality. Under-inflation by only 5 psi can significantly reduce tread wear, impair handling, and lead to tire failure.

To find out how accurate air tower settings are and to assay the threat to safety and tire life posed by tower error, NBS tire systems engineers conducted a brief survey. Using a random sample of 50 service stations in the Maryland suburbs north of the District of Columbia, they measured pressures by inflating a spare tire, to which an accurate pressure gage ${ }^{2}$ and a release valve were permanently connected, and recorded the tower pressure setting and the actual pressure. The nominal pressures used were $20,24,28,32$, and $36 \mathrm{psi}$; all five were used at each station, but in randomized order.

The distribution of the deviations of delivered pressure from the pressure setting was found to have a standard deviation of 4 psi. A motorist using air towers like those tested would have only one chance in five of inflating a tire to within $1 \mathrm{psi}$ of the desired pressure. On the other hand, he is likely to get larger deviations according to the following table:

$\begin{array}{lc}\text { Pressure Deviation } & \text { Probability (\%) } \\ \pm 2 \text { psi or more } & 62 \\ \pm 3 \text { psi or more } & \\ \pm 4 \text { psi or more }--- & 45 \\ \end{array}$

Since most of the errors found could be reduced by periodic calibration and adjustment of the air tower, this is recommended for consideration by service station operators, wholesalers (who service much station equipment), and local authorities. In the absence of such a program, however, the individual car owner can greatly improve inflation pressure accuracy by using his own tire gage to check the air tower setting. Personal pressure gages are inexpensive and some of them are reported to be accurate to within $1 \mathrm{psi},{ }^{3}$ if not abused.

The Chairman of the National Motor Vehicle Safety Advisory Council has asked that we participate in a national effort to up-

I Simson, B. G., and Radlinski, R. W., The accuracy of air tower pressure gages in suburban Washington, D.C., NBS Tech. Note 512 (Jan. 1970), available from the Superintendent of Documents, U.S. Government Printing Office, Washington, D.C. 20402, for 25 cents. Order by SD Catalog No. C13.46:512.

2 The test gage used was a $0-60$-psi model, calibrated at the beginning and end of each day's testing against a master gage at the Bureau.

${ }^{3}$ Automobile tire gauges, Consumer Reports 33, 94-96 (Feb. 1968). 
grade the accuracy of air towers. The 1970 tentative report of the Committee on Specifications and Tolerances contains the following comment:

It is recognized that some weights and measures jurisdictions may be constrained in participating in a testing program that is outside the field of "commercial" weighing and measuring. However, the Committee believes that, since the program under consideration would not be a regulatory one, most officials would be interested in providing assistance as a public service.

Mr. James Little, working with the Office of Vehicle Systems Research, has compiled an equipment list for the test apparatus shown in the Technical News Bulletin article. The spare tire in the inspector's car conveniently serves as a ballast volume and insures that the air towers are tested under normal operating conditions. Most of the items listed are available from automotive parts jobbers or refrigeration supply houses.

1. Vehicle spare tire in sound condition

(It is recommended that the tire be equipped with an all metal tubeless valve.)

2. Gage, 4" diameter, range of 0-60 psi, accuracy of $1 / 4$ percent or $1 / 2$ percent full range, mirror scale

3. $\mathrm{T}$ adapter tire valve stem

4. $1 / 8 "$ pipe $\mathrm{T}$

5. Coupling $1 / 8$ " pipe _- 1

6. Nipples $1 / 8$ " pipe _-_-_-_- 3

7. Adapter elbow $1 / 8$ " pipe to $1 / 4$ " pipe 1

8. $1 / 4$ " nipple _-_-_-_-_-_- 1

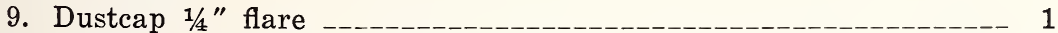

10. $1 / 4$ " flare to $1 / 8$ " male pipe fitting _.__________________-_ 2

11. Valve, $1 / 8$ " pipe to $1 / 8$ " pipe _-_________________-_ 2

12. Charging hose $1 / 4$ " flare to $1 / 4$ " flare

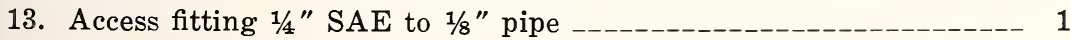

The NBS Office of Weights and Measures will check the accuracy of gages, similar to item 2 , which are sent by states undertaking to provide air tower checks. It is recommended that states purchase an extra 1/4 percent gage (item 2) for use as a reference gage. By keeping this gage in the laboratory, and frequently (beginning and end of each day's testing if possible) comparing the gages taken into the field, defective gages can be discovered.

The gage in item 2 costs about $\$ 50$. The entire apparatus shown in the article costs roughly $\$ 75$, so a state can equip at least one inspector's car to check air towers for less than $\$ 150$.

The recommended test procedure is simple. Air towers should be checked at 24, 28, and 32 psi for accuracy, and at 40 psi principally to see that they shut off properly. The test gage should be 
protected from the tower's pressure surges by the closed valve during inflation of the tire.

1. Bleed tire pressure to approximately 16 psi through vent valve.

2. Set tower to exactly 24 psi.

3. Check to be sure valve to gage is closed.

4. Inflate tire until tower stops ticking.

5. Remove tire inflation chuck.

6. Open valve to gage and read pressure. Record pressure on data sheet.

7. Set tower to exactly 28 psi and close valve to gage.

8. Repeat steps 4,5 , and 6 .

9. Set tower to exactly 32 psi and close valve to gage.

10. Repeat steps 4,5 , and 6 .

11. Set tower to exactly $40 \mathrm{psi}$ and close valve to gage.

12. Check to see that tower shuts off. Sometimes it does not. Be careful not to explode tire!

13. When finished, deflate to normal pressure.

An inspector's sample report form is attached. The tolerance should be \pm 1 psi. Air towers should not be condemned, since they are provided for the convenience of the customer. Unsatisfactory towers can be adjusted or referred to the station manager. Satisfactory towers, on the other hand, can be tagged to certify their accuracy. Both the station manager and the weights and measures department stand to benefit if the public is educated to understand the meaning of certified air towers. 
TIRE TOWER

Inspection Report

Location:

Make:

Serial Number:

Model:

Date:

\begin{tabular}{|l|l|l|}
\hline Set Pressure & True Pressure & Error \\
\hline 24 & & \\
\hline 28 & & \\
\hline 32 & & \\
\hline 40 & & \\
\hline
\end{tabular}

Inspector:

Owner: 
The Model State Regulation for Peat and Peat Moss as adopted by the National Conference on Weights and Measures in 1968 states in section 4.2 :

If the commodity is labeled in terms of compressed cubic measurement, the quantity declaration shall represent the quantity in the compressed state and the quantity from which the final product was compressed (the latter declaration not exceeding the actual amount of material that can be recovered).

In other words, techniques for measuring both the compressed and the "expanded" volumes are needed for checking peat moss.

Mr. Blayne Keysar has investigated the simple techniques of measuring the outside dimensions of the compressed bale and loosely filling a box having internal dimensions of $12^{\prime \prime} \mathrm{X} 12^{\prime \prime} \mathrm{X}$ 12 " with "fluffed" material. His report is below :

Material.-Canadian Sphagnum (3/4, $\mathrm{ft}^{3}$ compressed) (slightly damp).

Dimensions.-Approximately $12^{\prime \prime} \times 12^{\prime \prime} \times 81 / 2^{\prime \prime}$ outside.

NOTE: No statement on package of volume before packaging (loose state).

Test Equipment.-

(a) Box made of $1 / 2^{\prime \prime}$ plywood. (Internal dimensions $12^{\prime \prime} \times$ $12^{\prime \prime} \times 12^{\prime \prime}$.)

(b) "Strike-off" board.

Procedure.-Peat moss removed from plastic package and fluffed by working it through the fingers a handful at a time. Some lumps would not loosen by this method. These were small (about $1^{\prime \prime}$ square). No attempt was made to loosen these if they would not break up by working through hands again. Also, several wood sticks were included and were left in the peat. The peat was placed in a pile on the floor. Next, it was scooped up and placed loosely in the box. This was done by either using both hands to transfer it to the box or using a dustpan. Each worked equally well. Care was taken to see that corners were filled and that it was in no way packed or settled. The. box was slightly overfilled. The excess was then stricken off with the board by passing it across the top of the box, using a sawing motion. 
This filled box was dumped, making a separate pile, and the remainder of the peat placed in the box as before. It filled the box to approximately 8 inches in depth, and this amount was recorded. (The interior of the box is marked at 1-inch intervals.) This measuring procedure was repeated for a total of five measurements with the following results converted to cubic feet.

Data.-

Observation:

(a) $1.62 \mathrm{ft}^{3}$

(b) 1.66

(c) 1.64

(d) 1.66

(e) 1.66

Average: $1.65 \mathrm{ft}^{3}$

The measurement of the height of the peat in the box was estimated to the nearest 0.1 inch.

Conclusion.-On the basis of this test, this procedure appears to be a satisfactory one for baled Sphagnum peat moss. This peat could not be passed through a $1 / 2$ " mesh screen as required in the ASTM method, due to the lumps and sticks. There is no apparent need for ASTM settling method. This lowered level in box about 1 inch. Vigorous shaking lowered level by 2 inches.

Material.-Canadian Sphagnum (5.5 $\mathrm{ft}^{3}$ compressed bale) (dry).

Dimensions.-Approximately $14^{\prime \prime} \times 34^{\prime \prime} \times 19^{\prime \prime}$.

NOTE: No statement on package of volume before packing (loose state).

Test Procedure.-Test procedures the same as those for the $3 / 4 \mathrm{ft}^{3}$ bale described above.

Data.-

Observation:
(a) $9.92 \mathrm{ft}^{3}$
(b) 10.00
(c) 9.96
(d) 9.96

Average:

$9.96 \mathrm{ft}^{3}$ (fluffed)

Conclusions.-Conclusions the same as for $3 / 4 \mathrm{ft}^{3}$ bale, except that these larger sizes are time consuming, mostly in breaking up the bale (fluffing). This takes a couple hours. Total test time about one-half day. 
Mr. Hasko of our office has prepared drafts of test procedures for checking small disposable gas cylinders and calking compound cartridges. These drafts are reproduced below for your comments.

A. Checking Liquefied Gas Products Packaged in Disposable Cylinders.-This draft covers the checking of liquefied gas products packaged in disposable cylinders, and has been prepared as an addition to the package-checking procedures presented in NBS Handbook 67. Reference to other procedures are those contained in Handbook 67. Because of the hazardous nature of this product, it is recommended that plant inspections be made of this product where possible. Plant inspections of this commodity are simpler in detail in that tare weights can be easily determined and exhausting procedures are not necessary. This procedure is concerned with package-checking procedures to be used in the field when necessary and where plant inspections are not possible.

Hazardous Substance Warning.--Inspectors are cautioned to exercise extreme care throughout the package-checking test procedure of liquefied gas products packaged in disposable cylinders. Liquefied petroleum gas is a compressed flammable product that may have a vapor pressure as high as 175 to 200 pounds per square inch at $100^{\circ} \mathrm{F}$.

Liquefied petroleum gas in the liquid state will cause frostbite if it comes in contact with the skin. Consequently, protective gloves should be worn by the inspector when working with the cylinders. It may be advisable for the inspector to use safety glasses during tests to protect the eyes.

It will take approximately two or more hours to burn off the contents of a normal disposable propane cylinder. A more rapid exhausting procedure (approximately 6 minutes) can be used with a modification to the torch assembly and the gas is not burned but dissipated if the following precautions are followed. Emptying procedures should be conducted away from all sources of ignition in an open field on a breezy (not still) day to permit rapid dissipation of the vapors. Gas-air mixtures of less than 1.9 percent gas are too lean to burn. Since the vapor of liquefied petroleum gases are heavier than air (about 1.5 to 1), they will tend to hug the ground, and consequently the test site should not be a low lying area, but rather level or the highest point of elevation. There should be no low pockets in the test area where the gas could collect. Exhausted vapor and liquid should be directed in the direction of wind. The exhausting procedure is not designed to be conducted on the premises of the vendor. 
Step 1.-Select a sample of 10 or more identical cylinders (identical as to labeled weight, brand, product, and lot or packaging period) and mark.

Step 2.-Check the gross weight and determine the lightest and heaviest cylinders in the sample. Record the gross weight of the lightest and heaviest cylinders. These should be retained for possible use in the exhausting procedures. The others should be held off sale until the test is completed. (The seller's complete stock should not be tied up by the test.)

NOTE: The products should not be below $60^{\circ} \mathrm{F}$ prior to exhausting procedures, and the container should not be below this temperature when the exhausting procedure has been concluded.

Step 3.-Exhaust the lightest cylinder by one of the following methods :

(a) Using the largest available burner tip on a conventional torch assembly, burn off the gas. This will take two or more hours.

(b) First, ground the cylinder to be emptied with a suitable grounding cable to prevent a static electric differential buildup during the exhausting procedure. A suitable grounding cable may be prepared from an appropriate length of No. 18 stranded wire (insulation is optional) with a battery clamp at either end. Clamp one end to the torch and the other end to a suitable ground (i.e., water pipes, guy wire anchors, metal fence posts, or a metal rod driven at least one foot into moist ground). Using a conventional torch assembly without a torch tip with a modification available from the torch manufacturer for rapid expulsion of the product, empty the contents of the cylinder, observing precautions indicated "Hazardous Substance Warning." The cylinder should be inverted during the exhausting operation, and the flow of vapor and liquid directed horizontally, to promote maximum dissipation. The cylinder may be hand-held or placed in a suitable holder several feet above ground. Continue exhausting procedure until audible and visible flow of vapor ceases (approximately 6 minutes).

Step 4.-Dry and weigh the empty cylinder to determine the tare.

Step 5.-Subtract the cylinder tare from the gross weight to obtain the net weight of the lightest cylinder.

Step 6.-If the net weight of the lightest cylinder at least equals the declared net weight, it may be reasonable to assume that the lot is satisfactory. 
Step 7.-If the net weight of the lightest cylinder is less than the declared weight, it will be necessary to treat the 10 cylinders as a sample of the lot and proceed to weigh them individually to determine individual errors. For this procedure, it will be essential to arrive at an average tare weight to be added to the labeled net weight of the cylinder to determine a "standard" gross weight with which the cylinders will be compared.

In order to arrive at a representative average tare weight for the sample, steps 3 and 4 must be repeated with the heaviest cylinder to obtain its tare weight. The average of the two tare weights may then be accepted as the tare weight for the weighing of individual cylinders. (The inspector is cautioned that the tare of a single cylinder is not considered acceptable as an average tare, and also that no "permanent" or "reference" record of tares is acceptably reliable.)

Step 8.-With standard weights in an amount equal to the "standard" gross weight for the sample cylinders on one side of the scale (or as the "standard" gross weight in the "substitution" procedure if an equal-arm scale is not used), weigh the remaining cylinders of the sample and record the error of all sample cylinders. Exclude, by circling, any errors $( \pm)$ that are unreasonably large and determine an average error for the sample. (See steps 1 , 2, 3, 4, and 5 of section 8.1, NBS Handbook 67.)

Torch assemblies for rapid exhaustion of propane cylinders are available at cost from the following:

Bernzomatic Corporation

740 Driving Park Avenue

Rochester, New York 14613

Turner Corporation

821 Park Avenue

Sycamore, Illinois 60178

Clayton \& Lambert Mfg. Co.

Buckner, Kentucky 40010

B. Checking Cartridge-Packed Calking Compounds and Other Viscous Products.-This procedure covers the checking of cartridge-packed calking compounds or other viscous products and has been prepared as an addition to the package-checking procedures presented in NBS Handbook 67. Reference to other procedures are those contained in Handbook 67.

The step-by-step procedure set forth below has been developed as a parallel to steps 1 through 7 on page 12 of Handbook 67, which is directed to conventional standard-pack packages. Because 
of cleanup requirements, this is basically a laboratory procedure, or the cleanup should be conducted in a well ventilated area or outdoors, with the solvents retained for disposal at the laboratory.

Step 1.- Select a sample of 10 or more identical packages (identical as to labeled weight, brand, and commodity).

Step 2.-Check the gross weight of each package to determine the lightest and heaviest packages in the sample. Record the gross weight of the lightest and heaviest package.

Step 3.-Take the lightest container and transfer sufficient product into a preweighed 5-fluid-ounce density cup (see fig. 3) to fill the cup to excess. (The use of a calking gun with cartridgepacked products facilitates the reduction of trapped air.)

Step 4.- - Place the slicker plate down over approximately threefourths of the open-end area of the density cup, press down, and slowly move across the remaining area (see fig. 4). This reduces the amount of trapped air and makes cleanup of the exterior surfaces less troublesome. Clean all exterior surfaces.

Step 5.-Weigh density cup with product to the nearest 1/32 ounce or 0.002 pound.

Step 6.-Subtract weight of density cup from value obtained in step 5.

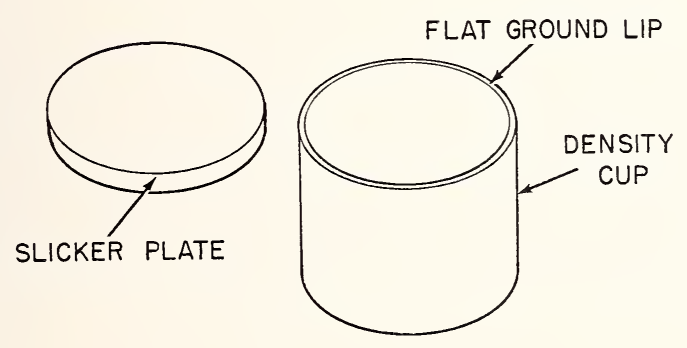

FiguRE 3. Empty density cup asd slicker plate.

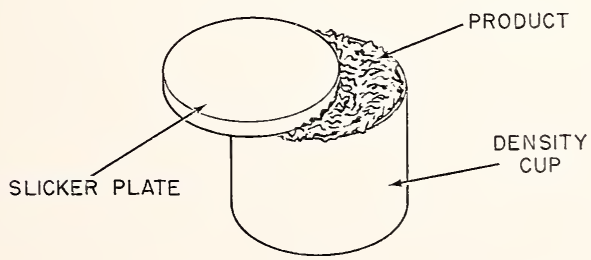

Figure 4. Density cup filled with product. 
Step 7.-Divide weight determined in step 6 by the capacity of density cup (in fluid ounces). This gives the pounds or ounces (avdp.) per fluid ounce of the product.

Step 8.-Clean out the container with a putty knife or spatula and determine the tare of the lightest package. Cartridge-type containers should be cut open for cleaning.

Step 9.-Subtract the tare (step 8) from the gross weight of the lightest package (step 2). This is the net weight of the product.

Step 10.-Multiply the labeled volume of the product by the pounds or ounces (avdp.) per fluid ounces of the product (step 7) to obtain the weight of the labeled volume of product.

Step 11.-If the net product weight of the lightest package (step 9) at least equals the weight of the labeled volume of the product (step 10), it may be reasonable to assume that the lot is satisfactory.

Step 12.-If the net product weight of the lightest package is less than the weight of the labeled volume of the product, it will be necessary to treat the 10 packages as a sample of the lot and proceed to weigh them individually to determine individual errors. For this procedure it will be essential to arrive at an average tare weight to be added to the weight of the labeled volume of the package to determine a "standard" gross weight with which the packages will be compared.

In order to arrive at a representative average tare weight for the sample, the heaviest package must be opened and the tare weight of this package and of the previously opened lightest package be determined to the nearest $1 / 32$ ounce or 0.002 pound. The average of these two tare weights may then be accepted as the tare weight for the weighing of individual packages. (The inspector is cautioned that the tare of a single package is not considered acceptable as an average tare, and also that no "permanent" or "reference" record of tares is acceptably reliable.)

Step 13.-With standard weights in an amount equal to the "standard" gross weight for the sample packages on one side of the scale (or as the "standard" gross weight in the "substitution" procedure if an equal-arm scale is not used), weigh the remaining packages of the sample and record the error of all sample packages. Exclude, by circling, any errors $( \pm)$ that are unreasonably large and determine an average error for the sample. (See steps 1 , 2, 3, 4, and 5 of section 8.1, NBS Handbook 67.)

Step 14.-If desired, these errors may be converted to liquid measure by dividing them by the value determined in step 7 .

The 5-fluid-ounce density cup may be prepared by cutting off a sufficient length of the bottom of a $65-\mathrm{mm}$ test tube or a $150-\mathrm{ml}$ 
beaker with an abrasive saw and grinding the lip flat on a lap wheel. The cups can be made by glassblowing shops if glass-working equipment is not available. The slicker plates are available commercially. The approximate cost of a unit should not exceed $\$ 10$. Since it would be just as easy to make two or three, or more, rather than just one, it would be advisable to have several made at one time.

The complete unit (cup and slicker plate) should be weighed and calibrated with respect to volume (fluid ounces) prior to use. It is not necessary to recalibrate for each test; however, the pieces of one unit should be marked so that no interchange of cup or slicker plates is possible.

\section{Fabric-Measuring Device Test.}

OWM has collaborated with industry to design a test tape suitable for use by weights and measures officials in checking fabricmeasuring devices. The Measuregraph Company, 4245 Forest Park Boulevard, St. Louis, Missouri 63108, now sells these tapes in a very attractive container. It is my understanding that they will accept orders through August 1970.

Mr. Hasko of OWM has revised the test procedure for checking fabric-measuring devices reproduced below :

NOTE: If the inspector is not familiar with the operation of the device, he should have this explained to him by the user. When releasing rollers on the device, be careful not to operate the lever actuating the fabric-cutting knife or the tape will be cut. Observe the action of this lever and use a screwdriver rather than the fabric-cutting lever to actuate the roller release. If this cannot be done, pull the tape beyond the 12-yard graduation and slide the tape out of the device.

Fill in pertinent information on report form.

Step 1.- Insert the test tape into the device and advance it to the point where a precise tape reading of the zero is obtained. A good zero reference is the metal sideplate on the right side of the device.

Step 2.-Clear the device to produce zero indication.

Step 3.-Advance the tape until the indicator of the device is in coincidence with the 1/4-yard graduation. Determine if the error is within the applicable tolerance as defined by the tolerance graduations on the tape. Measurement of actual error is optional.

Step 4.-Repeat step 3 at the $1 / 2,3 / 4,1,2,3,4,5,6,7,8,9,10$, 11 , and 12-yard graduations. Check money-value computations at several of the graduations. Where the error on a normal observation is in the direction of overregistration and approaches the 
value of the applicable tolerance, conduct a backlash test* at this particular graduation.

Step 5.- Remove the tape from the device, being careful not to operate the fabric-cutting knife when releasing the roller (see note above). Wind the tape back into holder.

Complete report form.

\section{Conclusion}

It is my hope that this paper has been informative enough to stimulate further inquiries. Questions may be asked during the NCWM Open Forum on Measuring Technology in Salt Lake City, or by contacting us at the Office of Weights and Measures, National Bureau of Standards, Washington, D. C. 20234.

Early man made his first meaningful measurements after he learned to count. Since then, the nature of the measurements undertaken has reflected his development. The need for credible measurements in commercial transactions has played an important role in developing measurement skills, and will probably con. tinue to do so in the future. The "Challenge of the 70 's" will be partly manifested to weights and measures officials by the nature of the measurements he is called upon to perform.

\section{FORUM DISCUSSION}

Mr. L. O. Leenerts (Purex Corporation, Ltd.) : Mr. Mills, in your weight loss in soap bars, I presume that you are testing wrapped bars and unwrapped bars, as well as in the different styles of wrapping, such as foil or paper.

Mr. Mills: That is correct. But we found that that seemed to be a small factor.

MR. LEENERTS: When do you expect to have the final results?

Mr. MILls: That depends on when the soap stops losing weight.

Mr. R. W. Buchanan (Pennsylvania) : Mr. Siebold, does the Meter Manufacturers Technical Committee feel that a separate code for slow-flow meters is necessary, and do they feel they can make on-site tests of slow-flow meters, or are they considered laboratory tests?

Mr. SIEBOLD: The manufacturers of those devices who belong to the Technical Committee find quite a problem in this area. While the Bureau in the beginning worked up a test procedure, they have found that very few of the local weights and measures offices have such equipment. Therefore, most of the time it is necessary to return the small meter to the manufacturer or somewhere else for

* A backlash test consists of advancing the tape several inches beyond a graduation and then returning back to the graduation on the device without overrunning it in the reverse direction. Determine if the error is within the applicable tolerance as in step 3. 
testing, and they have recommended that some thought be given in this area to alleviate the situation.

MR. R. L. THompson (Maryland) : Mr. Southers, how long will your representative be working with the National Bureau of Standards in relation to the development of these provers, and how long has he been there to date?

MR. SOUTHERS: He has been there since approximately May 1, so he is just getting started. As in any kind of research work that is done, we really do not know the length of time he will be there. We are hopeful that he will move fast in finding an answer to the things that both you and we are concerned with-namely, the best design for the devices that we are using to check our meters. Our best guess at this time would be approximately four years.

Mr. M. Greenspan (New York City, N. Y.) : Mr. Siebold, about two years ago I raised a question that I believe is becoming more important now, in view of the considerations of air pollution, whereby more and more heating fuel is being changed from bunker oil to No. 4 oil. In this process, one of the important factors is the quick turnaround, and as a result we have found more and more breakdowns on meters. Further investigation has disclosed that, while a meter has been designed for a certain maximum flow and with a specific pump pressure in mind, the owners of the devices have been changing the pumps. Now, we recognize that the meter manufacturers have no control over this. But in order for us to properly correlate these two factors and determine whether an installation has been properly made, it is necessary for us to obtain the specifications from the meter manufacturers as to their recommendations on pumps. We have tried to get this from many meter manufacturers and have been very unsuccessful. Can you and your Technical Committee arrange for this information to be made available where necessary?

Mr. SiEBold: We have discussed this ever since the first time you brought it up, and it is not easy to find an answer to this question. All I can promise is that we can continue to try to come up with some recommendations for you that will be of help. Once the meter is shipped and in the hands of the installation people, there is not a great deal we can do. Maybe, by working together, we can do more than we have in the past.

Mr. GREENSPAN : I realize that you cannot do anything about it. However, H-44 says the installation shall be made according to the manufacturer's specifications. If an installation is improperly made, we can condemn it, but we need basic information. We do not have the technical knowledge as to what maximum pressures may be applied to a specific meter by a pump; but if we can get this information from the meter manufacturer, we can then continue our investigation. 
DR. A. V. Astin (National Bureau of Standards): I have a general question directed to the entire panel. Since the Conference Chairman said yesterday the theme of this meeting is the challenge of the 70 's, I am rather surprised that there has been no discussion of the measurement of octane rating. I understand that half a dozen states now do this, but it seems to me that to put all the emphasis on the measurement of volume of gasoline and ignore the octane rating is not taking the broad approach that the Conference should take.

Mr. S. D. ANDREWs (Florida) : Although I am not a member of the panel, I would like to answer Dr. Astin's question. We feel that this is not germane to weights and measures. This is quality control, and in our state this is covered by separate legislation. I think other states should follow this lead. This is the argument I have been presenting in our committee meetings during the entire Conference. I think we in weights and measures are beginning to go too far afield and getting into too much quality control instead of concentrating our efforts on our specific purposes of weights and measures. Leave quality control to those people who are delegated this responsibility.

While I am on my feet, I would like to address a question to Mr. Siebold. I have been somewhat concerned in our state at the number of meters that are sold to dealers that are clearly marked "not to be used in commerce." If these meters are not reliable enough to be used in commerce, what particular purposes do they serve? We, of course, refuse to calibrate these meters, which makes the owner quite unhappy.

Mr. SiEBoLd: I am afraid you have me at a disadvantage. I do not know if members of our Technical Committee ship meters of that type. I would have to guess that the registering equipment or the counter system is so marked because it does not meet the requirements of Handbook 44. If any of the meter manufacturers are here who do furnish meters with that marking, they may wish to answer your question. Is this used in the measurement of petroleum products for sale?

Mr. ANDREWs: Yes.

Mr. Southers: I can answer that question for you. There are any number of devices that are manufactured for the intended use of a consumer for inventory control or for whatever reason he might want to keep track of what he is using. These devices were manufactured with this thought in mind. Now, this does not stop someone from buying one of these and putting it in for commercial purposes. But the person who manufactured it did not intend it for commercial purposes, and therefore you would find that it does not meet all the requirements of Handbook 44 . 
MR. ANDREws: As mentioned previously, we refuse to calibrate these and, in addition, are applying a prominent tag which states that it is not to be used in commerce. The meter is actually labeled "not to be used in commerce," but this is rather hard to see on cursory examination. On several occasions the owners of these meters have convinced our inspecters that they were not aware of this and that they purchased the meter in good faith, thinking it would meet our requirements. I am just a little concerned that this is not emphasized enough in the sale of these meters.

Mr. A. Lemke (Wisconsin): Mr. Godsman, what equipment were you talking about when you mentioned new and unique testing procedures?

Mr. GODSMAN : I was referring at that time specifically to the coin-operated equipment which is sometimes unattended. This has created some problems. For example, how do you get your money back when you have to use your cwn money to make a surprise test on unattended equipment? You do not have to tell the owner you are going to be there, but you have to work out some kind of arrangement. However, this is something I know all of you can work out, since you know the people that you are working with and the companies.

Mr. SOUTHERS : I would like to add a word in response to Dr. Astin's question. The petroleum industry, of course, has given a great deal of time and consideration to the number of proposals across the country with regard to the posting of octane rating on gasoline pumps. There is a very serious problem in any posting of octane rating in that it is no real assurance to the customer of the quality that he is buying. Octane, you know, speaks to only one requirement in the gasoline, and that is its anti-knock quality. In addition, there are two basic types of tests that can be made-the research test and the road octane test. These give different results, and there is no unanimity of opinion as to which one gives the best results.

Mr. L. D. Holloway (Idaho) : The coin-operated situation was aired somewhat at the last Western Association Conference. Sometimes it is very difficult to make the necessary arrangements. Sometimes the farmer out there who has invested in a coin-op is very difficult to locate.

I have a twofold question that I would like to address to $\mathrm{Mr}$. Siebold. First, are turbine meters being contemplated as replacements for positive displacement meters in any of the metering systems now in use? Second, would turbine meters be applicable for use as liquid fertilizer meters, especially for complete mixeś?

Mr. SIEBOLD: In answer to the first part, turbine meters have been under consideration for replacement of positive displacement meters on loading racks for, I would say, 10,12 , or 15 years. In 
my paper I point out that this is one of the developments you might look for in the 1970's. Progress has been rather slow, but there has been progress; and I think that one or more of the manufacturers are getting close to the point where they can say, "This will do an equal job."

With regard to your second question, turbine meters can be manufactured quite easily compared to positive displacement meters because of metal requirements. It is not as much a problem to manufacture and provide a stainless steel turbine meter as to manufacture a positive displacement stainless steel meter. This is evident because there are very few stainless steel meters available in the positive displacement field. When the time comes, if turbine meters are equivalent to positive displacement meters, then they may be used in the liquid fertilizer field, especially for complete mixes, very quickly.

Mr. J. H. AkeY (Wausau, Wis.) : Mr. Mills, on these air tower tests you are using a high of 40 pounds. I think it should be pointed out that many boats and camping trailers specify 65 pounds air pressure. This is a very high pressure; and, of course, using such a small tire, it is quite dangerous from a safety standpoint if you get much above that pressure if the tire should blow when somebody is filling the tire. I wonder if we should not include something like this in the future.

I also have one other question, and that is, what is the approximate cost of the measuregraph tape?

Mr. HASKo: $\$ 76.50$.

Mr. MiLls: Insofar as our being able to measure larger pressures is concerned, we are gathering facts toward a separate package of meters and test equipment that would probably go up to about 120 pounds to be used for the tires that you speak of and for trucks. We recognize that they are an important part of the vehicles that are on the road.

MR. J. R. BIRD (New Jersey) : I have an open question for all the inspectors here. We had some experience in New Jersey on other effective means on rack meters, requiring an individual inspection of each installation. The inspection involved the investigation of the type of pump, the inventory procedures, the gaging methods, vortex protection, and the amount of retention time in the storage before the product was allowed to be metered. We based each approval on an individual inspection. Later we returned to see if the inventories and tanks were reduced below the point that the engineers said would cause a vortex. I wonder what experience others have had with this.

Mr. G. E. Mattimoe (Hawaii) : The theme of this Conference is the challenge of the 70's, and I think Dr. Astin threw out the first meaningful challenge. For us to say that his point is not 
germane to weights and measures is to say that measuring the type size on the outside of a package is very meaningful in reverse. I think that, if the challenges are to be accepted, we should take a good hard look at those things which are new and stop sticking our head in the sand and living only with those things to which we are exposed.

MR. ANDREWS: I simply pointed out that there are others who are just as diligently at work in quality control as we are in quantity control. I happen to wear two hats, being a member of Committee D-2 on Petroleum Products of the American Society for Testing Materials and also an active participant of their Technical Division A, which is vitally concerned with gasoline quality, setting up specifications, and enforcing these specifications. I say, let us wear our hats in this field, and let us confine our weights and measures people to weights and measures activities.

Mr. MatTimoE: We are not unfamiliar with the illustrious ASTM, but I certainly was unmindful of the fact that they are in the field of enforcement.

Mr. W. N. SEWARD (American Petroleum Institute) : Of course we are not in the field of enforcement. As far as ASTM is concerned, we have been discussing the test methods there for some time. The problem is essentially that the oil industry and ASTM, representing consumers and users of gasoline, feel that the octane number as currently defined is a characteristic of gasoline, not necessarily a measurement of its quality. It tells you a bit about its performance, but it does not give you the total picture. Possibly we should be looking for another method of quality measurement.

Mr. HASK0: Mr. Godsman, what is being done in conjunction with the closed fuel filling system, and what is going to happen to the tank vapor or liquid overrun during the filling procedureWho gets the vapor?

Mr. GoDSMAN : You mentioned this, I am sure, because you saw it in my paper. Snorkel filling is one of those things that we approach from our standpoint, with the ability to do it. In other words, to stick the snorkel in the gasoline tank to fill the tank in a closed system. The method of designing the tank and where those fumes go, somebody else is going to have to answer.

Mr. N. DiMarco (Cumberland County, N. J.) : This is probably a minor problem, but a problem that I am confronted with. When we test the nozzle check valves in our area, we find there is a shortage of these check valves. Whenever a test nozzle is checked and the valve does not operate correctly or is probably worn out, our law requires that the valve must be replaced due to a sloppy hose. When we go back six months or a year later, the operator says he cannot get the valves or cannot get the correct sizes. I understand that there are about three different types of valves, 
one in the hose, one in the nozzle, and one just at the end of the nozzle. This seems to be a big problem in my area. Is there anything the petroleum industry could do, in cooperation with the manufacturers of the nozzles, to distribute these check valves more evenly?

MR. GoDSMAN : I think they are giving you a snow job. I have never heard of the parts not being available if something needs fixing. In our company alone (and, of course, some of these work for other people), there are 725 people under contract to do warranty service for our company throughout the country, and nearly all carry a stock of these valves. In your part of the country they are highly concentrated. The nozzles that are used today are not so old that a valve cannot be obtained at least to screw in between the hose and the nozzle.

Mr. W. I. ThOMPSON (Monmouth County, N. J.) : Mr. Godsman, while we are on the ground level talking about the end drip check valves, is there any way in the construction of the gasoline pump of today that makes it possible for a sealer to get in and affix his seal without dismantling the entire exterior?

Mr. Godsman: Once a piece of equipment has been put in the field, it stays there a long time; and, of course, you begin to see it after it has been there a long time. When the third edition of Handbook 44 was printed, it stipulated that adequate space was to be made available to affix the seal. Immediately, in those instances where it was not available, everybody went to work on the problem. Now, you do not cure these problems overnight, and the equipment is still out in the field. Are you saying that new equipment is coming out without this adequate space?

Mr. THOMPSON: I prefer the old equipment. We can get in there, but today it takes a midget.

Mr. GoDsman: When you say today, are you talking about a pump that came out of a factory last year, or three or four years ago?

Mr. THOMPSON: One that was installed within the last month. Brand new equipment which is almost impossible to seal.

Mr. Godsman: All the industries asked meter people to work on it, and we were one of them. We, of course, follow the specifications set by our customers. A new computing head design has permitted an additional $7 / 8$ inch extra space in the pump housing, and a low profile meter put out $2 \frac{1}{2}$ years ago improved this by $15 / 16$ inch, for a total of almost two inches of extra space. We have also cut holes in the frame members so you can see where your hands are working.

MR. J. F. LYLES (Virginia) : Mr. Godsman, on the self-service gasoline station that you pointed out, is the remote reader complete? Does it contain all the figures that are on the pump, 
such as total sale, gallons, and price per gallon, or only one of the indications?

Mr. Godsman: It depends upon what the customer orders. Price per gallon would have to be written into the remote readouts in most instances; otherwise you would be getting into something that would be quite complicated and expensive. You could have either gallons or total sale, or both. Impulses could be put on the transmitting equipment at the island to give you either one or the other. And there again, it would be up to what is required locally as to what would have to be put on the equipment. But it would be designed according to the customer's specifications.

Mr. LyLES: How would you interpret Handbook 44 in regard to this system in meeting the requirements for a primary indicating element?

Mr. Godsman: All indicating elements are primary indicating elements, upon which all charges are based, so the same accuracy would have to prevail.

MR. LYLES : The primary indicating element would have to show at least the gallons. And if the total selling price is indicated, the price per gallon would also have to show on the indicating element itself.

Mr. Godsman: Does not Handbook 44 say that the price per gallon must be either printed or written in on the ticket issued?

MR. LYLES: If your device prints a ticket and only one figure is shown, then you must indicate the other values on the ticket itself. But what is required of the primary indicating element itself?

Mr. Godsman: If a customer serves himself, he is responsible to see what he bought when he buys the gasoline. This is indicated on the pump. When he goes inside to pay, all the attendant is interested in at that time is the total sale. If the customer is charged more than is stated on the pump, the information is still on the pump.

Mr. S. H. Christie (New Jersey) : In many areas, weights and measures are tied up with quality where weights or measures determine quality; the count, for instance, of threads per square inch. This is not only a challenge for the 70 's, but has been a challenge in the past. Let's take this challenge up in the 70's and do something about it.

Mr. HASKo: I am sure this has been a highly interesting and informative session for all of us. It certainly is evident that the members of the panel did their homework. We wish to thank you for your interest and participation. 



\section{WEDNESDAY AFTERNOON-JULY 15, 1970}

$* \quad * \quad * \quad * \quad * \quad * \quad * \quad * \quad *$

No Business Session Scheduled

$\begin{array}{lllllllll} & * & * & * & * & * & * & * & *\end{array}$

The delegates and their families enjoyed a sightseeing bus tour which included points of scenic interest through the famed Wasatch Mountains to Treasure Mountains Resort Area at Park City, Utah, followed by an outdoor dinner and entertainment at Treasure Mountains Lodge. 

(M. H. BECKER, Vice Chairman, Presiding)

\section{THE MANAGEMENT OF CHANGE}

by Dr. W. E. Cushen, Chief, Technical Analysis Division, National Bureau of Standards

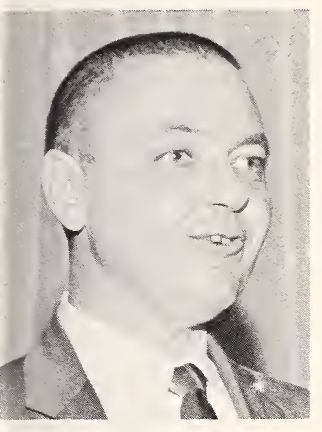

I am going to talk this morning about two kinds of change. Talking about the management of change is like talking about how you hang on to a tiger when all you have is a little bit of his tail. The two kinds of change I want to talk about are the orderly and the disorderly. With respect to the one kind of change, I think we have some hope that we can offer directly to the weights and measures people.

When I say "we," I mean a profession that consists of roughly 20,000 people. The profession is called Operations Research, System Analysis, the Multidisciplinary ProblemSolving Team, and the System Engineer. This has grown pretty much out of World War II through capital investments by our Department of Defense and by American industry; but the civilian functions of government, the civilian function of public administration have only begun to tap resources that are here.

Back in high school we remember reading about Greek philosophers. One of them, called Heraclitus, said, "If you think you want to have some general guideline to analyze the world of affairs, it is not a world of things, it is a world of change." If one wishes to have a general reference point that will satisfy all requirements, do not measure things; measure change, measure progress. We have never learned to do that. The more Paris changes, the more it is the same. People are never the same. I am not the same as I was yesterday, nor are you, nor is George. Machiavelli is perhaps the only man who ever tried to give advice about how to manage change, and that was how to contain city states once they have been taken over.

Now, the world that the federal official is facing these days is one that will reflect on all of you, and probably already has. The federal (national) official is faced by goals, priority statements that he has not the resources to address. He has new technologies to apply, but he feels that we cannot afford them. Nearly every agency in the government has singlehandedly volunteered to use all of the money that is now being spent on Vietnam, Cambodia, 
Korea, West Europe, and the Strategic Air Command if that money were to be made available to it.

Our friendly philosopher Plato once observed that whenever the gross national product of a country is consumed 30 percent by the public establishment, that country's government is best described as State Socialism. We spend 300 billion dollars out of our 1,000 billion dollars a year in the public establishment, and the question now of how to allocate these resources to public use is the thing that bugs the federal officials.

Now, the system approach, needless to say, wants to help out in that particular problem, but it lives up on cloud nine for the most part. This is one of the reasons that it has not made more headway than it has in the civilian agencies of government.

What I want to do is to describe to you an experiment that we conducted in our Technical Analysis Division which we think had its feet on the ground and which we think has direct relevance to the weights and measures activity in which you are all involved. It was a modestly funded effort. We got 10,000 dollars to do it, and we spent 25,000 dollars doing it. It had to do with a fire station location in East Lansing, Michigan.

East Lansing is a city of about 40,000 people, except when students annually arrive, at which time the population is doubled. The city provides fire protection service both for the city and under contract for the university. The center city fire station needed replacement, and everybody agreed on that. The Fire Commissioner would have like a fire station on every street corner.

An engineering study had been made suggesting that four fire stations should be put into East Lansing instead of the two they then had. The proper question, then, was, "How many does East Lansing need, and where should they go?"

Now, a systems analyst begins by measuring things that nobody has thought of measuring before, because he figures that is where the source of the difficulty has been. So the systems analyst took the map of East Lansing. Every street intersection he called a node. Every street connecting those interesections then became a link. This is very much like the highway departments do on their origin-destination studies-their layout of the coded highway network.

From every node to every other node, the elapsed time for travel of a fire engine under normal traffic conditions and under rush-hour traffic conditions was measured. Given all of the nodes on a street network (not nearly so well behaved as those in Salt Lake City), it becomes possible to say that it would take 30 seconds to go from here to there, 40 seconds from here to there, 15 seconds from here to there, 35 seconds from here to there, and so on. You have the whole city covered. 
Now, our friendly computer, which was invented at the same time as the systems approach was invented, remembers all this information. There is a modest computer program, then, that says, "From any point in that city to any other point in the city, count for me the fastest way to get from here to there." The computer does it very efficiently. Regard each of the places that you go from as a potential spot for a fire station, and regard every place that you go to as a place where a fire could break out. The way the insurance underwriters have laid out the cities, they say, "Make it possible so that no node on that network where fire can occur is farther than two minutes or $3 / 4$ of a mile from the station in the downtown area, or five minutes or 11/2 miles in the suburban area. Armed with that information plus the computer-generated information of what is the fastest you can get from here to there, you know you have to have another fire station whenever that number is above two minutes or five minutes. Otherwise the insurance rating on the city shoots up the fire rates.

After you have broken down the city in such a way that you have all of the points that are within two minutes associated around one general node, and the other ones around the other node, calculate the least path from these two fire stations to all the places in the city that need to be covered. If you can make it inside of two minutes, you have it. If you cannot make it inside of two minutes, scramble them up again and put in a third fire station, and then recalculate to see if everything is within two minutes. If not, recalculate, add a fourth fire station, and so on, and then pick the number of fire stations that you need in order to satisfy those requirements.

This was done in East Lansing. It was found that three fire stations were needed, and that they ought to go here, here, and here.

East Lansing, even with that outcome, needs other fire-fighting improvements. Obviously' one way to solve the problem is to take exception with the criteria that had been applied. Therefore, you take this network now and you say, "Look, you are not responding to a city flat now. There are not many people over here, so even if there were a fire there you really would not care quite as much if the fire engine got there on time as if it got to the downtown area." Therefore, take each of those nodes and treat them in proportion to the number of people whose lives would be placed in hazard if they lived at that particular node. Armed with a Civil Defense study, the City Planner had daytime-nighttime populations for East Lansing that he could put on each of those nodes.

A recalculation led still to three fire stations, but it displaced the center city fire station by six blocks. Six city blocks in East Lansing is a small distance. In Washington, D. C., it is a small dis- 
tance. It is the distance between the Washington-Hilton Hotel and Fourteenth and U Streets, N.W.

Recalculate, now, those fire stations for dollar damage that a fire could create at each of the norles. Recompute. The fire station is displaced by two blocks. Now observe what is happening. By a nuts-and-bolts approach, questions that really bug people-the City Council, the City Manager, and the neighborhood groups are being tackled in an indirect way. You are not measuring service directly, but you are sneaking up on it. You are making it possible for people whose job it is to talk about service to address the question substantively. You have enhanced the content of the political debate which goes on.

East Lansing City Council approved three fire stations. They are now in the process of construction for $\$ 25,000$.

People are lazy, and we are lazy. We did not like to have to redistrict this city by hand. If we could do it, the way we did it was an idiot way. Anything you do in an idiot way, a computer can do. So why not make the computer do it? We, therefore, went to the Montgomery County School Board in the State of Maryland and suggested that we try school districting on the computer. By making the computer do the districting automatically, we would give them the answers as to how many schools were needed if they worked with us directly on providing the raw materials.

For schools, the problem is a little bit different. There are so many children coming from certain locations, but you have to look to the future. There are so many children with different grade requirements. There are now only so many existing schools and a capacity of the school logistic system.

We took an area that is now served by eight elementary schools in Takoma Park and put this on a computer-total cost $\$ 5,000$ and calculated where the school district boundaries might very well be, both now and in the future, for the Montgomery County school subjurisdiction that we are talking about here. Among the things that we included in the calculations was a comparison with the number of people who are there, like the fire station example.

In the Montgomery school jurisdiction we counted children on the basis so that nobody would have to walk more than $3 / 4$ mile to school. Suppose it were also necessary to achieve racial balance? How, then, would you reallocate the district boundaries in order to accomplish this purpose?

We went to Charlotte, North Carolina, where the question was the location of the Community Service facility to serve neighborhood groups in the Model Cities area, which is far from being a Model City area. The concept there was to locate these fire stations, locate the Community Service facilities, but consider the demands of the people who were the intended recipients of the 
service that were provided. This meant, then, that there was relatively little purpose in measuring time and distance the way "Whitey" saw it. The purpose was to get inside the heads of the people who were asking for service and see what their perceptual distances were.

A survey in depth did, in fact, yield the information that the perceptual distance of those people was such that one community service facility would be patronized by one of the six model neighborhoods and by none of the others. Therefore, the City of Charlotte decided to put in six referral locations.

Now for weights and measures. We have taken some of these things, as Dave Edgerly will tell you later, and worked with the States of Virginia, Pennsylvania, and Maryland to some extent.

If you took something like a fire station locator, you would be able to tell the best route for an inspector to take, given that he wishes to cover his route in a minimum period of time. You then could multiply each of those nodes by the number of services that he needs to perform and reallocate. You could multiply each of those nodes by the relative importance of doing something. A gas pump that is off more frequently than another gas pump probably needs to be inspected more frequently than the well-behaved one. One could then say, multiply those nodes by some subjective assessment of the relative desirability of inspecting package goods, gas pumps, balances, and scales, and recalculate.

This is the experiment we are trying now, but before you do that kind of thing you have to collect numbers that you have not had before, such as how many gas pumps fall within the category of being 7 cubic inches out of 1,000 off and hence pass the requirement. You need to answer questions like how many fewer violations would be found and what would the economic disutility to the consumer or the seller be if Philadelphia reduced its inspections from four per year to only one per year.

The thing that we found with East Lansing, with Montgomery County, and only to a certain extent with Charlotte (because we really did not follow that one up the way we should have), was that, if you stay at the nuts-and-bolts level, you build credibility. You solve problems the way people who live with the problem solve it. You do not drive the inspector up the walls. You furthermore make sense to the bossman, who has had to live through a Sears Roebuck catalog of fictitious nonsense that we call our annual budget submissions. When he asks why you need two more inspectors, you can say, "If you want this level of service, our computer has said that we need two more inspectors if this is the level of service you expect me to provide, and if I do it as efficiently as possible." 
One of the most precious assets you can have is that you can get meaningful alternatives by asking questions very precisely that go into the computer. You force the boss people and you force yourself to ask the question, "Is this trip necessary, or is there another way of doing it, or what is it that I have not done that I should be doing?"”

These are some things that I feel kind of hopeful about on the management of change when change is well behaved. We can even look a little bit into the future. If you build a fire station in East Lansing, it will be there 50 years from now. If you build a building, it will be there 30 years from now. Population migration you can forecast to a certain extent.

The City Planner made two separate scenarios for East Lansing 12 years in the future, one with high rises and one with further decay, and the computer recalculated the fire station location for them. Looking into the future is not as horrible as you would expect, because you cannot see too well into the future, but you cannot see present data too well either.

The formal organization is never the one that gets things done -it is the informal organization, the power structure-and those things you do not know any better than you know the future. Therefore, just because you cannot measure the accuracy of that to one part in ten to the ninth is no reason to duck the issue of treating it systematically at all. But the thing that bugs me is that our analytical methods are not yet up to handling the kind of change that we really regard as important. These are the step functions, the sudden changes, the shocks, the revolutions.

Another philosopher, Alfred North Whitehead, has said that change really happens in cycles. It is like education. A baby is born. He collects new impressions. He is in a romantic stage. He is not forming anything systematic at all. But after a while the conflict, the competition for those ideas, and an innate desire to be tidy and orderly causes him to make some kind of a philosophy of how he sees things getting together. And so he stylizes his philosophy and then he makes everybody else, including himself live by that philosophy. He tries it out on new ideas and it is helpful. The idea it is not helpful on, he rejects. But sooner or later, there are too many rejections, and the suit of armor is too small, and a new change, a major revolution in that philosophy, takes place. Just so, in my opinion, are we now in our American establishment.

The Declaration of Independence which will be read in the decade that is ahead, because it will be 200 years, has some rabblerousing phrases, such as: "We think these truths are self evident." "Every person is entitled to life, liberty, and the pursuit of happiness." We might call it standard of living now, or options, and that governments are instituted among men to secure these rights. 
And whenever a government fails to accomplish those rights, it is the right of the people, and we might add duty, to alter that government.

That is from the Declaration of Independence. It will be read. There are 30 million people in the United States who regard you and me as failing to communicate, as failing to exercise the stewardship with which we have been entrusted. They see us working on things that seem to them to mean nothing.

This is not true, as you and I know, but they think that it is true. We have not done our marketing and do not know how to reply to questions of relevance. The questions of the operations research man is how to improve efficiency. The questions of today are equity. They are not measured in efficiency terms. Equity means who gets what at whose expense. Equity is the black man's protest. When the Newark riots were completed and an interview was conducted, a set of questions was given to the people who figured in the riot and watched it-Blacks and Whites. The questions drew different answers from the two polarities with one exception. The one exception was the answer to the following question: "The black man must do something for himself." On that there was unanimity.

Further interrogation behind the scenes asked, "How did you interpret that question?" The white man said, "The black man has got to get off his dead tail and do something." Yes, the black man must do something for himself; score yes. The black man interpreted the question in the following way: "The establishment that serves me never has been, is not now, and shows no credible signs of ever solving my problems. If anything is to be done, the black man must do it for himself." Chalk up one answer. Yes, the black man must take care of himself.

We do not know specifically what is the public interest. We tend to believe that the national government must solve all problems. We do not have a well organized plan as to what is fitting and proper for a government to do, but in the year that sees the 200th anniversary of the Declaration of Independence many people will be asking the question, "What is the public interest and who operates on its behalf ?"

We do not have a government that is purely publicly administered. We have a government that is part government and part industry. We do not have a government that is a unified set of federal departments. We have 200 agencies in the federal government, partly collusive, partly competitive. We have 54 state and territorial administrations. We have 2,300 counties. We have 16,000 cities. We have millions of business establishments, and we have 200 million people. 
Under our Constitution, which is the only unifying document that we have, power-to be legitimate-must be derived from the people, and the people are going to say what they believe the government needs to do. We do not know yet how to improve the relations among federal, state, and local governments and business establishments.

One of the studies that was made late in 1968 was a study of the City of Oakland, California, where millions of dollars in federal money had been dumped into that area. The question was, why was the place going from bad to worse? The study yielded the information that some federal programs got into other federal programs' ways, and furthermore it complicated the life of the City Management of Oakland, the County of Alameda, and the State of California to the point that there was no way of seeing their way out.

If it had been possible for those people to communicate in advance whether they used something like we call a business game -if they had been able to say, "What do I do that affects you, and what do you do that affects me, and what can both of us work out together that will achieve the common purposes for which we are looking?"- - they might not have been confronted with the problem that they had.

Communication can take place without loss of sovereignty. You do it here. This is one reason I like this particular Conference. One of the things that has been said about this Conference is that it accomplishes things through the cooperative mode without forcing anybody's will on anybody else. If we are to address the questions of our total government in the future, this must be the mode of discourse. 
T. M. StableR, Office of Weights and Measures, Moderator

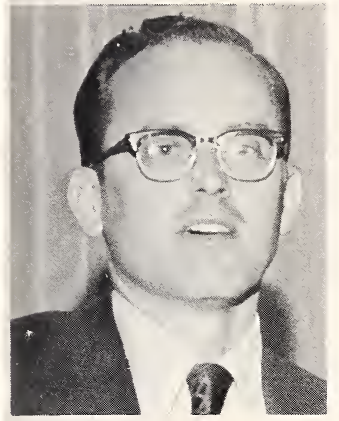

This is the fourth and final forum of this year's Conference program. I have the pleasure of serving a dual role, that of moderator and of participant. In the first capacity I will introduce the members of the panel. We are very fortunate to have four distinguished guests, representing weights and measures, a university, and a consumer organization. We are privileged to welcome Mrs. Jane Byrne, Commissioner, Chicago Department of Consumer Sales, Weights and Measures. Mrs. Byrne was appointed to this position in 1968 by Mayor Richard Daley, and she is the first woman cabinet member in Chicago's history. Her paper is entitled "The Consumer Movement in Chicago."

Next, we have Dr. L. J. Gordon, Director, Weights and Measures Research Center, and Special Assistant to the President of Denison University. Dr. Gordon will report on the Third National Survey. I am sure most of us are familiar with the questionnaire Dr. Gordon has distributed nationaliy.

Mr. D. E. Konsoer is the Director of the Bureau of Weights and Measures in Wisconsin and will present an analysis of the Wisconsin program.

Representing the Consumers Council of Massachusetts is Mr. D. P. Shea, Executive Secretary. Mr. Shea will describe some of the activities of his organization.

In addition, we have two gentlemen representing the Office of Weights and Measures, National Bureau of Standards-Dave Edgerly, who is Program Manager for Management Resource Information, and Steve Hatos, Manager of the Weights and Measures Survey of the U. S. Metric Study.

In my second role as participant, I should like to discuss recent considerations and management decisions we have made relative to OWM program objectives. These decisions have evolved because of the challenge of the 1970's. They are (1) to provide leadership for the future, (2) to meet contemporary needs in areas of concern to weights and measures and industry, and (3) to function effectively within the economic restraints of limited resourcesdollars, people, and time. Our mission is clearly defined; our task is tremendous.

As the byproduct of a recent budgetary exercise, new emphasis and resources will, by necessity, be diverted to the most relevant 
projects-those activities that result in the greatest return per unit of expense. In effect, we have performed a cost-benefit analysis.

Personnel have been assigned to new and different tasks. Some OWM programs will be deemphasized, and others will receive new resources. Of course, the National Conference on Weights and Measures will continue to receive full support by the Office of Weights and Measures. The Technical Education program will have to place new emphasis upon assistance to the states and industry at the administrative and supervisory levels; for example, the seminars that were conducted at Boulder, Colorado, last November and at the University of Maryland this past May.

Last year we participated in 27 state schools for inspectors and played the major role in organization and conduct of most. In the future, this responsibility must be assumed by the state and its designated training officer. We very likely will have to limit our travel to one visit per state per year. This is one way to expand the list of states we can visit annually.

Technical Information and Management Resource Information are key programs. Through effective communication and application of modern management techniques, great strides will be made in the 70's toward uniform weights and measures administration in the United States.

Next year, upon completion of the State Standards program, a vigorous laboratory management and training program will be well underway. Its purpose is to assist the states toward full utilization of laboratory capability and to maintain traceability of state standards to the National Bureau of Standards.

The Railway Track Scale Testing program must be fully supported by the railroads and industries operating scales. No longer are we in a position to expend great sums to carry inspectors and test equipment. We are asking the AAR for this assistance. Repairs to the two test cars, salaries for two inspectors, and maintenance of the Clearing Depot in Chicago cost nearly 70 thousand dollars for the past two years. This is a very expensive program. We hope to coordinate this effort with state directors of weights and measures so that enforcement action will follow the testing procedure.

In the future, the OWM will emphasize examination of prototype weighing and measuring devices, and all states will continue to receive copies of test reports. This has proven to be a valuable program to industry and weights and measures.

The Fair Packaging and Labeling Act program will receive increases in time and people by OWM in 1970-71. Greater effort will be made to improve upon past performances in standardization of package sizes and rate of adoption by the states of the 
Model Packaging and Labeling Regulation. If we can look at the past for a moment, perhaps one of the best examples ever of state-federal cooperation was the surveillance effort last December. Forty states, representing 100 percent, responded to our request to survey the marketplace in 22 product categories. This was truly an outstanding effort.

In addition to program planning and distribution of resources, the weights and measures administrator must surround himself with competent personnel, including project leaders, supervisors, office people, etc. This year we have added to our staff several very capable persons who should contribute significantly to our programs. They include Don Corrigan, working as technical coordinator for the FPLA project; Allen E. Banks (brother of Ben Banks, whom many of you know), a railway track scale expert, currently operating the NBS test car somewhere in the western United States; Leon Carpenter, a technician assisting our engineers in engineering studies and laboratory tests; and Barbara Davis and Julia Corbin, providing valuable assistance in the office.

Now for the presentations from other members of the panel. At the conclusion of these presentations, the forum will be open to discussion, and we will welcome questions from the floor.

\section{THIRD NATIONAL SURVEY}

by DR. L. J. GoRDoN, Director, Weights and Measures Research Center, Denison University, Granville, Ohio

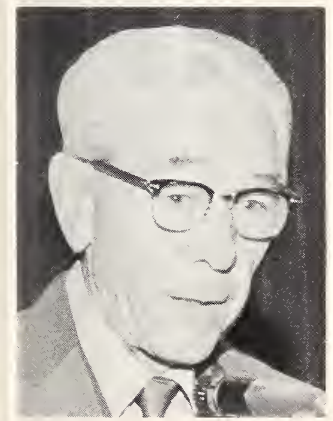

The first national survey of state weights and measures legislation, administration, and enforcement was completed in 1957. The second survey was completed in September 1963, and the third in November 1969. In the survey just completed, 52 officials representing weights and measures offices of the States, District of Columbia, and the Commonwealth of Puerto Rico, responded to 266 questions for a total of 13,632 answers, plus comments. This paper covers only a portion of these responses. The complete survey report, with 15 tables, will be published by Consumers Union this year under the title Weights and Measures and the Consumer, Second Edition, 1970 


\section{Where Should the National Conference Meet?}

This is an especially significant Conference because it is only the second time the Conference has met outside of the Nation's capital. State officials were asked whether they attended the 51st National Conference in Denver in 1966. There were 32 affirmative responses. Those who did not attend were asked to give a reason. Among those who responded, 5 were not on the job in that year, 4 gave the airline strike as their reason, and 3 reported lack of travel money. The officials were asked whether they would favor meeting in the West again. There were 40 affirmative responses, 9 negative, and 3 who gave no answer. Four officials suggested meeting in the West once in every five years, one suggested once every four years, and another said, "not too often." Among the reasons for responding affirmatively, one official said that the voting is now disproportionate. Another said that since the Office of Weights and Measures is the principal in arranging the Conference, it should have the major voice in choosing the location. Obviously, meeting in the West occasionally would give many an opportunity to attend who cannot do so when the meetings are held in Washington.

\section{What About Conference Procedures?}

Officials were asked whether they were satisfied with National Conference procedures. There were 38 affirmative responses, 7 negative, and 7 who did not answer. Five of the negative responses were based on criticism of the present voting procedures. One official said that voting should be limited to those who have to promulgate regulations. Another stated that the Conference "could be more democratic; it is now pretty cut and dried."

\section{Are You Satisfied with Conference Programs?}

There were 45 affirmative responses to this question with only 2 negative and 5 who failed to answer. One official made this perceptive comment: "I favor keeping the programs very simple because most of us are high school graduates." Others commented favorably on the open forum sessions in 1969. Judging by the 1970 program, some of this sentiment must have been expressed in the questionnaire which was circulated at the 54th National Conference. Related comments included suggestions that there should be more time for discussion of reports and papers, more attention to diversification and discussion of everyday problems confronting 
officials, and more emphasis on technical procedures and information. One general recurring comment was to the effect that the delegates to the Conference wish to have an opportunity to talk more and to be talked to much less.

\section{Are Communications with Conference Committees Satisfactory?}

Thirty-seven responded affirmatively, 9 negatively, and 6 failed to respond. Here are some of the comments: "We have not had any." "They could be improved and probably will be." "Some areas of committee action and thinking could and should be more timely. We have very short notice sometimes." One official suggested that each State Director should correspond more frequently with the Conference Secretary to inform the Conference of problems in his area and to give his views. It was also suggested that when a committee rejects a proposal, it should give its reasons.

\section{Are You Satisfied with the Role of Industry in the Conference?}

There were 42 affirmative responses, 3 negative, and 7 no answers. There were a few scattered comments. One official believes that "industry has helped a lot, but should not run the Conference. The Conference is for weights and measures officials." Another said, "The presence of industry representatives provides channels of communication and improves understanding." Most officials would agree with the comment, "We need industry advice, but the National Conference must guard the right to make its own decisions."

\section{Do You Have Any Suggestions Concerning the National Conference?}

Twenty-one officials answered affirmatively, 26 negatively, and 5 failed to answer. Many thoughtful and constructive suggestions were offered. These are typical: "The National Conference is a smoothly running organization." "Membership on the S \& T and L \& R Committees should be limited to state officials." "I would like to have an open forum which would deal with any question on our minds. . . . there is not enough time to talk informally." "There should definitely be more communication between the committees and those in attendance."

Other comments were: "Many jurisdictions are hungry for guidance and recommendations for effective administration. The Conference should recognize the problems at all levels and direct programs and proceedings accordingly." "The National Conference is unwieldy in size: the regional conference programs are much closer to the concerns of state officials." 
It was suggested that the Conference establish meaningful measures of the effectiveness of rejections, inspections, and devices and use them in annual reports through all jurisdictions. More than one official regrets the discontinuance of the Friday morning meetings devoted to state and local problems. One official, who has been in office a long time and has done his share of committee work, feels that "each state shoula be represented on some committee of the National Conference. No state official should be placed repeatedly in key positions." In this connection, it may be worthy of note that of the 17 officers of the National Conference this year, eight are from states west of the Allegheny Mountains and three from west of the Mississippi River. An official representing a Middle Atlantic state opposes the suggestion that there be one vote for each state. "This would not really solve the question of voting balance. Going to Utah will tell a lot." Several western states are dissatisfied with voting procedures. "A few of us will try to change the voting procedures at the next Conference. We favor limiting votes to a population base, regardless of the number of delegates at the Conference." A southern official wants faster action on problems before the Conference. The problem of liquid fertilizer has been under consideration five to seven years. An official in a northwestern state having a small population wants "more time allotted to individual problems which are not of concern to everyone."

\section{Administrative Location of Weights and Measures}

Weights and measures work is spread across the administrative spectrum. In 39 states the primary weights and measures work is located in the Department of Agriculture, but the word "primary" must be emphasized. Among the states, weights and measures work is found under laws covering food and drugs; fish and game; health, education, and welfare; seeds and fertilizer; meat and poultry; grain; coal mines; dairy divisions; petroleum tax divisions; bread law, and egg law. As a consequence, in the words of one official, "There is much joint enforcement and much overlapping. Also, there is noncooperation among various agencies." In the other 13 states, the weights and measures office is found in the Department of Commerce; Plant Board; Consumer Protection Division; Economic Development Division; Board of Health; Labor and Industry; Public Service Commission; Law and Public Safety; Office of the Attorney General, Department of Labor; and one office is independent.

In eight jurisdictions weights and measures work is now called, or related to, Consumer Protection Services. Is this a trend or a fad? In the November 1969 Newsletter of the Western Weights 
and Measures Association, Mr. Maynard Becker, Director, Los Angeles County Department of Weights and Measures, expressed the view that consumer protection is coming and that the logical place for it administratively is in weights and measures departments. The director of an Atlantic Coast state also sees the rising trend toward a broader consumer protection function by weights and measures officials. In his state "the existing weights and measures administration in some municipalities borders on the pathetic. For some, it is just a perfunctory duty imposed by statute and their interest ceases with the collecting of a salary." Some officials resist the trend, feeling that weights and measures will lose its identity. One state office has no such fear. Their new title, Consumer Protection Service, is more in keeping with the work now being done and it appeals to the legislature, making it easier to get larger appropriations. Two other states find the Consumer Protection Service Division much more effective administratively. A variety of laws formerly administered by a variety of agencies can now be administered by a single agency. Inspectors are now trained to enforce all the laws for which the new Consumer Protection Division is responsible.

Some important administrative decisions must be made in the 1970's. In the early days of weights and measures, when the nation was primarily agricultural, weights and measures work was located in the Departments of Agriculture. Now the nation is 80 percent urban and weights and measures needs a broader base from which to operate.

\section{Administration of State Weights and Measures Laws}

\section{Civil Service and Job Security}

Section 6 of the Model Law on Weights and Measures provides that personnel of weights and measures departments shall be appointed from eligible lists prepared by the Civil Service Board and under the rules of that Board. Each director was asked whether his law provides for civil service. In summary, there were 25 affirmative responses and 27 negative. Among the 25, scarcely a state has a civil service provision in its weights and measures law; rather, such a provision is more likely found in the general code of the state.

Section 6 of the Model Law also provides that in the absence of a Civil Service Board employees be granted certain protective job rights. Each State Director was asked whether, in the absence of civil service, his law contained these other provisions of the Model Law. There were 15 affirmative responses and 12 negative. 
What happens to weights and measures employees who do not have civil service protection or job security? Here is the answer of one director: "Our men constantly receive veiled threats of political reprisals from irate business people when illegalities are discovered and corrected. One retailer asked his legislator to get the weights and measures inspector 'off' his back.' Lacking civil service, the inspector was intimidated and did indeed lay off. In the same state actions against three of the largest food chains resulted in heavy political pressure on all public officials involved, including some of the highest ranking, to go easy or terminate the case."

\section{Equal Employment Opportunity?}

Indicative of the social changes which have taken place since the first National Survey in 1956-57 have been the rising demands of minority groups for equal employment opportunities. In this survey each state official was asked this question: "With reference to employment, does your law forbid discrimination on the basis of race, color, creed, or national origin?" There were 39 affirmative responses and 13 negative. Usually the anti-discrimination provisions are found in the general code of a jurisdiction.

I do not have any percentages, but I can report, what many of you know, that there are jurisdictions in which there are no minority employees. Before proceeding further, attention must be directed to the definition of the term "minority employee." In some areas, the term may refer to Blacks; in others, it refers to Indians; in others, it designates Mexican-Americans; in some places, it may refer to Puerto Ricans; and in other places, it may refer to Orientals. It can be reported that there are at least 23 departments of weights and measures in which all employees are white. It must be reported also that discrimination is not limited to any one section of the country.

\section{Number of Employees}

Each state official was asked for the total number of employees in weights and measures. The following summary table shows the number of employees in seven numerical ranges. For comparative purposes, Form I (state only) jurisdictions must be distinguished from Form II (state and local) and Form III (local only) jurisdictions. It is surprising to see the similarities in numbers of employees in Form I and Form II jurisdictions. Some of the difference is to be explained by population differences. In studying the table, it must be remembered that Form II states have additional employees at the county and municipal levels. For example, Pennsylvania has 195 local sealers in addition to the staff of 41 in the state department. 


\begin{tabular}{cccc}
\hline & \multicolumn{3}{c}{ Jurisdiction } \\
\cline { 2 - 4 } Employees & Form I & Form II & Form III \\
\hline $5-10$ & 10 & 6 & \\
$11-20$ & 8 & 7 & 1 \\
$21-30$ & 3 & 3 & 1 \\
$31-50$ & 3 & 2 & \\
$51-75$ & 2 & 2 & \\
$76-100$ & 1 & 1 & \\
Over 100 & 1 & & \\
& (One jurisdiction-no response)
\end{tabular}

\section{Ratio of Employees to Population}

A goal of one inspector for every 50,000 people in a jurisdiction has long been accepted by weights and measures officials. Survey data show that only seven jurisdictions have attained that goal. Among these seven jurisdictions, three are Form I, two are Form II, and two are Form III. Among the 45 jurisdictions not having attained the goal, 25 are Form I and 20 are Form II. The following summary table gives the ratio of inspectors to population in seven population brackets, covering a range from 1 to 20,000 to 1 to $1,500,000$. It will be seen that 24 jurisdictions have a ratio of 1 inspector to 100,000 population, or less.

\section{Summary Table-Inspector Per Population Ratio}

\begin{tabular}{cc}
\hline $\begin{array}{c}\text { Population Range } \\
\text { (Thousand) }\end{array}$ & $\begin{array}{c}\text { Number of States } \\
\text { (One Inspector per Population Range) }\end{array}$ \\
\hline $20-55$ & 7 \\
$56-100$ & 17 \\
$101-125$ & 6 \\
$126-150$ & 7 \\
$151-175$ & 5 \\
$176-200$ & 3 \\
$201-$ over & 4 \\
& 3 (no response) \\
\hline
\end{tabular}

State officials were then asked what they think the ratio should be, and 36 officials indicated the ratio should be in the range of 1 inspector to 50,000 population or less. There were five officials who proposed 1 to 50,000-75,000, three who proposed 1 to 76,000 or over, and eight who gave no response. Perhaps a new goal should be established, using a combination of population, number of establishments, and number of devices. Somehow the number of packages to be checked would also have to be included. 
In each of the three surveys, the salaries of the directors and inspectors have been reported. Comparing those reports over a 15 -year period, it is seen that the economic status of weights and measures personnel has improved. The continuing problem is that of inflation and the continuing question is, "Have salary increases kept up with increases in the general level of prices?" Since the last survey in 1963, the consumer price index of all items has risen 21 points from 107 to 128 . This means that the purchasing power of the dollar has decreased from $94 \phi$ to $82 \phi$ in the same period. In each state this question was asked: "Since 1965, have salaries increased for inspectors?" Responses are summarized in the following table. It will be seen that salaries have increased in every jurisdiction, but the range is from 10 percent to 50 percent.

Summary Table-Five-Year Salary Increases

\begin{tabular}{cc}
\hline $\begin{array}{c}\text { Percentage } \\
\text { Increase }\end{array}$ & $\begin{array}{c}\text { Number } \\
\text { of States }\end{array}$ \\
\hline $10-15$ & 13 \\
$16-20$ & 9 \\
$21-30$ & 15 \\
$31-40$ & 3 \\
$41-50$ & 3 \\
& 9 (no response) \\
\hline
\end{tabular}

The actual salaries paid to directors range from a minimum of $\$ 6,600$ to $\$ 23,868$. In summary, there are four directors whose salaries are $\$ 7,500$ or less; eight whose salaries range from $\$ 7,500$ to $\$ 10,000 ; 17$ whose range from $\$ 10,000$ to $\$ 12,000 ; 11$ whose range from $\$ 12,000$ to $\$ 15,000$; nine whose salaries exceed $\$ 15$,000 ; and three did not answer.

What about the salaries for inspectors? The minimum salaries for inspectors range from $\$ 3,060$ to $\$ 13,176$. In 11 states salaries are less than $\$ 5,000$; in 14 they range from $\$ 5,000$ to $\$ 6,000$; in 16 the range is from $\$ 6,100$ to $\$ 7,000$; in 8 the range is from $\$ 7,100$ to $\$ 10,000$. The minimum salary in two states is over $\$ 10,000$. There was one no answer. What are the maximum salaries being paid to inspectors? The range is from $\$ 4,800$ to $\$ 15,264$. In summary, one jurisdiction has a maximum salary that is less than $\$ 5,000$. There are six states in which the maximum salary for inspectors is in the range from $\$ 5,000$ to $\$ 6,000 ; 9$ states from $\$ 6,100$ to $\$ 7,000 ; 25$ states range from $\$ 7,100$ to $\$ 10,000 ; 8$ states have a maximum over $\$ 10,000$; and 4 did not answer. Clearly, equity does not prevail for weights and measures men in terms of salaries. 
Among the many dramatic changes that have taken place in my lifetime has been the increase in longevity. When I made the first survey in 1956-57, I never thought I would be making a second survey, much less a third survey. Now having met Mr. Lew Wallace in Tennessee who was active at the age of 101, I have raised my sights and might just possibly make a fourth National Survey! The purpose of this note of levity about longevity is to emphasize the importance of retirement income. Time marches on, and you men will be retiring before you realize it. With an adequate income, retirement can be very pleasant. What income can you anticipate?

\section{Budgets}

Each state official was asked to supply budget figures and then was asked whether his budget was adequate. For purposes of analysis and comparison, the summary of responses is divided among Form I states, Form II states, and those having Form III laws. Also, it must be noted that among the 52 jurisdictions, there are ten for which no budget figures are available. In eight jurisdictions there is no separate budget, and in two states, for reasons not explained, the officials refused to supply the information. Among the 28 Form I states, there are responses from 25, showing their budgets for administration and enforcement in cents per capita (the absolute figures are available, but for comparative purposes, are not meaningful). The state-by-state figures range from 2.4 cents to 71 cents per capita. Grouping the states, there are five whose budgets amount to 5 cents or less per capita; eight in the 6 to 10 cent range; six in the 11 to 15 cent range; two in the 16 to 20 cent range; one in the 21 to 25 cent range; two in the 26 to 50 cent range; and one over 51 cents. Perhaps the most significant fact is that 76 percent of the responding Form I states spend 15 cents or less per capita.

How many officials consider their budgets to be adequate? Summarizing, only four of the 25 responding officials think they have enough money to enforce their law. Interestingly, the official who already has the most money to spend for administration and enforcement, considers his budget inadequate. The next question was, "How much money should you have to enforce your law effectively?" Among the 28 Form I states, there were 21 responses. One state, in a class by itself, needs $\$ 1.12$ per capita. Grouping the other 20 states, seven expressed the need for an amount of money ranging from 5 to 10 cents; five want from 11 to 15 cents; four from 16 to 20 cents; two from 21 to 25 cents; two from 26 to 50 cents; and one over 50 cents per capita. 
In reviewing the budget figures for Form II and Form III states, it must be remembered that they do not include expenditures by counties and cities. For example, one state office had a budget of $\$ 837,000$ in 1968 ; in addition, the total budget for the counties was $\$ 3,411,217$. The total of $\$ 4,248,217$ amounts to 31 cents per capita. The budgets of the Form II states ranged from 1 cent to 22 cents per capita. In summary, it is found that 13 of the 15 responding Form II states spend $101 / 2$ cents per capita or less. There were only 12 responses to the question, "How much money should you have to enforce your law effectively?" Eight of those responses are in the range of 5 to 10 cents per capita, three in the range 11 to 15 cents, and one at 25 cents.

From the survey we find that officials in 16 states must retire at age 65 and in 24 states they must retire at age 70 . In each state, I asked the question, "What retirement income can you expect at age 65 , as a percentage of your income at retirement?" The responses for Directors covered a range from 8 percent to 88 percent. In summary, there are seven jurisdictions in which the percentage range is from 8 to 25 ; nine in which the range is from 26 to $49 ; 18$ having a range from 50 to 60 ; and seven over 65 percent. There were 11 which did not answer. The figures for inspectors are not significantly different. The range is from a minimum of 8 percent to a maximum of 66 percent. In summary, there are 8 jurisdictions in which the percentage ranges from 8 to 25 ; nine in the range from 26 to 49 percent; 14 range from 50 to 60 percent; seven range over 61 percent; and there were 14 no answers. It was found that 42 jurisdictions include Social Security in their retirement plans. A significant difference, however, is that in some states Social Security is in addition to the state plan, while in some jurisdictions the state benefit is reduced by the amount of the Social Security payments.

In the early days of economics, there were some economists who assumed that workers in low income areas would move to high income areas and thereby bring about an equality in the wage structure. If such a move were to start among weights and measures officials, it would certainly result in a massive shifting of personnel! Obviously, men cannot move freely. They are tied to their localities by many non-economic factors. But simple justice suggests that in many jurisdictions the salary and retirement plans need drastic revision upward. One small step this Conference could take would be to relate salary schedules to participation in and completion of the Office of Weights and Measures Home Study Course. At present, there are only nine states in which an inspector has the incentive of a promised salary increase if he 
completes the OWM Home Study Course. The other 43 jurisdictions could accomplish two things by following the nine leaders: (1) they could upgrade their salary schedules, and (2) they could stimulate their personnel to make themselves more effective weights and measures officials.

\section{Are Form I State Budgets Adequate?}

If equity is to prevail in buying and selling, there must be a strong and comprehensive law and enough money to hire competent personnel to administer and enforce that law. In this period of rising prices, increasing costs, and higher taxes, all governmental units are finding it increasingly difficult to secure the money necessary to perform the services which the citizens want and demand. The financing of weights and measures work is no exception.

\section{Should Weights and Measures Work Be Financed by Fees?}

To use or not to use fees? This is a controversial question. In the early days of weights and measures when the main operation was that of testing the accuracy of devices, some legislators thought that the owners of the device should pay for the inspection. In response to the question, "Does your law provide for, or permit, the use of fees?", there were 20 affirmative responses, one partial affirmative, and 31 negative. The next question was, "Do you think it is a good idea to charge inspection fees to finance, or help to finance, enforcement of the law?" Although the fee system is in use in 20 jurisdictions, only eight of the officials in those states think it is desirable, while two gave qualified responses.

\section{Experience, Education, In-Service Training}

As weights and measures work becomes increasingly sophisticated, the qualifications of weights and measures officials are subjected to closer scrutiny. This section covers the experience, the education, and the continuing in-service training of weights and measures officials. Each official was asked, "How many years have you been in your present position?" Twenty-five of the 52 respondents have been in their present position five years or less. Among the other 27, 16 officials have served five to ten years, five have been in office 11 to 15 years, one is in the range from 16 to 20 , four in the range 21 to 25 , and one has served.more than 25 years. The next question was, "How many years have you been in weights and measures work?" Fifteen officials have had five years or less experience, while nine have had from five to ten years. Among the 
remaining 28 respondents, seven fall in the range 11 to 15 years, six in the range 16 to 20 , nine from 21 to 25 , and six with more than 25 years experience.

"What is the minimum formal education requirement for a director?" In summary, there are no formal education requirements in eight states. In 11 states a high school diploma is required, and in 26 states a college degree is required. In 15 states the director is a high school graduate, and in 19 states he has had some college work or is a college graduate. Indicative of a new trend is the fact that four state officials have a degree of Master of Science. "What is the minimum formal education requirement for an inspector?" Responses indicated that there are no requirements in six states, but 38 of the states require high school graduation and six require a college degree.

Attendance at the National Conference on Weights and Measures, regional conferences, and state conferences is taken as a measure of in-service training and professional growth. Each state official was asked, "Do you attend the National Conference every year?" There were 43 affirmative responses, and only seven negative, with two qualified answers. Obviously, the responses to this question and the one following are related to the location of the Conference and the availability of travel expense. Forty state directors regularly attend the regional conferences in their areas, compared with nine who are unable to attend. For the other three officials, there are no regional conferences. Nineteen states have state conferences each year, and in those states the director always attends. Inspectors in 26 states never attend the National Conference. From one to five inspectors from 21 states do attend, and in five states, more than five attend. These responses reflect the location of the National Conference in Washington each year. In 29 states no inspectors attend regional conferences. In 17 states from one to five inspectors attend, and in six states more than five attend. Regional conferences usually require traveling long distances, and this is reflected in these figures. Directors in 48 states are reimbursed for expenses incurred in traveling to the National Conference, while three do not have any travel allowance. There is very great disparity among the states in travel allowance. In one state, for example, the director gets travel expenses plus $\$ 7.50$ a day, compared with his colleague in a neighboring state who gets travel allowance, taxi fares, and $\$ 25.00$ a day.

\section{Administrative and Enforcement Procedures}

Administrative and enforcement procedures are in a state of transition. In the early days of weights and measures, emphasis was placed on the testing of weighing and measuring devices. 
With the increased packaging of commodities, some jurisdictions are shifting the emphasis from the testing of devices to the testing of the end product. Practices and trends are revealed in the responses to the questions that follow in this section. Currently the law of 30 states requires the testing of commercial scales every 12 months. In four states the requirement is six months, and in eight states there is no requirement. In seven states scales are to be tested "as often as necessary." In practice weights and measures officials in 33 states test scales every 12 months compared with seven who test them every six months, five as often as necessary, and seven less frequently.

In a paper presented to the 53rd National Conference on Weights and Measures, Mr. M. H. Becker, Director of Los Angeles County Weights and Measures, spoke on the topic, "Maximum Effectiveness with Limited Resources." Mr. Becker suggested seven steps leading to maximum effectiveness which were used as the basis for the following questions in the survey.

\section{Discontinue Seals?}

Officials were asked whether they favor discontinuing the practice of placing a seal on a weighing or measuring device. Only 14 state officials favored this proposal, as compared to 36 who oppose it. One official was unsure, and another gave a qualified answer.

\section{Discontinue Inspection of Certain Devices?}

"Do you favor discontinuing the inspection of such devices as prepackaging scales, postal scales, and customer convenience scales?" Opinions on this question were more evenly divided. There were 23 affirmative responses, 26 negative, two qualified answers, and one who failed to answer.

\section{Inspect Only as Deemed Necessary?}

Each official was asked whether he preferred to inspect devices as often as he deemed necessary, rather than at some fixed period. There was substantial agreement on this question as there were 39 affirmative responses, 12 negative, and one qualified answer.

\section{Use Statistical Sampling for Devices?}

Mr. Becker proposed the application of statistical sampling procedures to the inspection of all devices. He said, "In most situations this procedure would permit the shift of inspection personnel 
to the ever increasing field of packaged commodities. Statistical sampling techniques have been used by industry for years for product quality and quantity control, and since 1962 in the Wisconsin weights and measures selective testing program." When asked whether they agreed with this proposal, 21 officials responded affirmatively, 30 negatively, and one gave a qualified answer.

\section{Let Approved Repairmen Remove Red Tags?}

Section 14 of the Model Law gives the director authority to issue stop-use, stop-removal, and removal orders with respect to commercial weights and measures. State officials were asked whether they had this authority in their laws or regulations. There were 45 affirmative responses and only seven negative.

Section 15 of the Model Law gives the director power to condemn irreparable weights and measures (including weighing and measuring devices). Every state official reported that he has this power. Section 15 also gives the official power to seize and destroy irreparable weights and measures. Fifty of the 52 jurisdictions reported that they have this power. Finally, section 15 gives the enforcement official power to confiscate and destroy weights and measures which have been condemned and have not been corrected. Fifty of the 52 directors have this power also.

Another of Mr. Becker's proposals was related to the three powers just enumerated. He proposed a statewide voluntary registration of weights and measures service and repairmen. Permission would be given to registered repairmen to repair and remove out-of-order tags and mail them to the weights and measures officials, indicating the date of repair, and the repairman's name and registration number. The weights and measures official could then reinspect the device at his convenience. Forty-three states favor such a plan, nine do not. This plan, or variations of it, is now being used in 26 states. The main difference is that some of the states require that the repairman be licensed.

\section{Should Inspectors Be Given Police Power to Issue Citations?}

A controversial proposal to obtain maximum effectiveness with limited resources is that concerning police powers. Mr. Becker said: "To make any enforcement program successful, some simple and expeditious method of admonishing recurrent or flagrant violators is necessary. I am suggesting that the police powers be enlarged to permit weights and measures officials, under certain controlled conditions, to issue citations. ... Such citations, like that of a traffic ticket would require payment of a fine and/or appear- 
ance before a Municipal Court Judge. Other more serious violations requiring prosecution would be handled in the same manner we now handle prosecutions."

When asked for their reactions to this proposal, 27 officials responded affirmatively, 22 negatively, one was not sure, and two gave qualified answers.

\section{Who Should Be Liable for the Accuracy of Devices?}

Section 24 of the Model Law requires that "weights and measures that have been rejected under the authority of the director or a sealer shall remain subject to the control of the rejecting authority until such time as suitable repair or disposition thereof has been made as required by this section. The owners of such rejected weights and measures shall cause the same to be made correct within thirty days or such longer period as may be authorized by the rejecting authority; or, in lieu of this, may dispose of the same, but only in such manner as is specifically authorized by the rejecting authority. Weights and measures that have been rejected shall not again be used commercially until they have been officially reexamined and found to be correct, or until specific written permission for such use is issued by the rejecting authority or until the rejection tag has been removed and the rejected device repaired and replaced in service by a person duly registered to perform such acts under a regulation issued by the director for the registration of weights and measures servicemen and service agencies." Officials in 49 states said they have that provision in their law or regulations.

Mr. Becker proposes that the owners of devices be legally liable for their accuracy and maintenance. In support of this proposal, he said: "Although our present laws clearly hold the merchant liable for the accuracy of the measurement processes and measurement representations, little punitive action, if any, is taken against those guilty of using inaccurate equipment or selling short weight or short measure commodities. We are all aware of the owner or user who does little or nothing in the way of maintenance or accuracy determination of his device until the device is tagged out of order by his local weights and measures official. I am suggesting that we administratively get the monkey off our back, and put it on the back of the rightful and legal owner, the owner and user of the device." Fifty of the 52 state officials are in agreement with this proposal. 
Forty-four officials think it would be feasible and desirable to do more checking at the point of packing. There were 5 negative responses to the first part of the question, with 3 scattered answers, and 6 negative responses to the second part of the question with 2 scattered answers. Ten states responding affirmatively said essentially the same thing: "Much shorting could be taken care of at the source; that is the place to do it. This would save duplication at the retail level." On the other hand, there is the problem of shrinkage from the time of packing until the product is purchased by the ultimate consumer. For this reason, some states feel that their primary responsibility in protecting consumers is to check at the point of sale.

\section{Evaluation of Laws and Enforcement Powers}

\section{What Type of Law Does Your State Have?}

Through the years the National Conference on Weights and Measures has drafted and revised a Model Law for the guidance of state legislatures. One form of the Model, which is found in 28 jurisdictions, provides for testing and inspection by State officers only. A second form, found in 22 states, provides for a State Division of Weights and Measures and for county and state sealers of weights and measures. A third form of the Model, found only in California and Massachusetts, provides for testing and inspection by local officers only, under supervisory control of the state. Among people concerned with weights and measures in industry and in governments, there are divided opinions as to the effectiveness of these types of laws. If I were to attempt at this point to evaluate the arguments for and against each type, this paper would run into excessive length. If I may be permitted a judgment, based upon 15 years of research and observation, I would indicate my preference for the Form I version of the Model Law, which provides for testing and inspection by State officers only. My reasons for this judgment will be found in previous papers and publications.

\section{How Useful Is the Model Law?}

Survey data show that not a single jurisdiction has passed the Model Law verbatim. Twenty-six states have adopted the Model Law with variations, according to the director. In some cases, the variations are so numerous and so contrary to the Model that 
these judgments must be regarded as subjective. For example, only ten states claim to follow the Model Law requirement that loaves of bread shall weigh $1 / 2$ pound, 1 pound, $1 \frac{1}{2}$ pounds, or multiples of 1 pound avoirdupois. The expanse of the United States and the resulting contrasts in climate, geography, industry, and custom make it impossible to draft a law which will be applicable to every jurisdiction. Consider the contrast, for example, between Alaska, Hawaii, and Puerto Rico. In the latter two jurisdictions the Model Law provisions prior to 1968 concerning coal, coke, and charcoal deliveries were inapplicable.

The constant changes which characterize a dynamic economy make it necessary to revise the Model almost every year. In those revisions obsolete provisions must be dropped and new provisions added to meet new conditions. For example, gas and oil have almost completely replaced coal for heating purposes. Increasingly, electricity is being used for heating; yet that source of heat, power, and light is not included in the Model Law.

The relevancy of some provisions of the Model Law is questioned by the fact that fewer than half of the jurisdictions have enacted them. For example, the delivery ticket requirement of the Model Law has been adopted by only 20 states, and the requirement that price be shown on the delivery ticket by only 18. There are other provisions of the Model which have been adopted by only 50 or 60 percent of the states. Why?

The Model Law is poorly arranged and organized. Much of its contents, according to some state officials, should be relegated to regulations. The basic law should be broad in scope and purpose. In its present form, the Model has no pattern of arrangement or organization. There is no index. Section 38 dealing with furnace and stove oil is followed by section 39 dealing with berries and small fruits, and that is, in turn, followed by a section on the construction of contracts. By contrast, some state laws are well organized and indexed. Much more could be said in this vein, but this should be enough to indicate that an attorney in the Office of Weights and Measures could do a signal service for all persons interested in weights and measures by reorganizing, reclassifying, and indexing the Model Law.

All of the foregoing is not to suggest that the Model Law has no usefulness. It does suggest, however, that the usefulness of the Model is limited and that its usefulness could be enhanced. Increasing numbers of officials are convinced that the complexity of modern merchandising requires a broad Form I type of law. 
State officials were asked whether their law has any major weaknesses and whether they contemplated any change in the law in the immediate future. Nineteen states report major weaknesses and 23 reported plans for changes. Twenty-four states reported on special problems which covered a wide variety of administrative and enforcement activities.

\section{Are Enforcement Powers Adequate?}

In response to the question, "Does your state law provide adequate enforcement powers?", there were 45 affirmative answers, five negative, one qualified answer, and one did not answer. What these responses tell us is that all but seven jurisdictions say they have adequate enforcement powers, even though only 26 jurisdictions claim to have a law similar to the Model Law. Some laws are 40 and 50 years old. Some of them are limited in scope to food or to agricultural products. Some of them have not been amended for a generation or more. Yet the men who enforce them say that they have adequate power.

At the time of the first national survey in 1957, the State of Florida reported an injunctive clause in its law which had been used with effectiveness. That was reported in a paper presented at the National Conference in 1957 and subsequently, the following section 44 was included in the Model Law: "The director is authorized to apply to any court of competent jurisdiction for, and such court upon hearing and for cause shown may grant, a temporary or permanent injunction restraining any person from violating any provision of this Act." In the 1969 survey, directors were asked: "Does your law provide for an injunction to restrain any person from violating any provision? If so, how often have you used it? With what results? There were 30 affirmative responses, 21 negative, and one no answer. It was determined that 23 states have never used the injunction power, three use it "rarely," two have used it twice, and two have used it once. In some interviews, I gained the impression that the director was unfamiliar with this provision in his law and not fully aware of its power.

Illustrative of the confusion and uncertainty concerning the injunctive power is the state whose director in 1963 said that he did have injunctive power. In 1968 the official then in office responded negatively. A subsequent search of the state law uncovered an injunctive provision. The injunction was devised to prevent actions which would cause irreparable damage or damage which could not be assessed in monetary terms. A violator is held 
in contempt of court and may be sentenced by the judge who issued the injunction, without a jury trial. It could be a powerful weapon to use against a chronic or deliberate violator of a weights and measures law.

\section{Equipment and Facilities}

\section{Are Testing and Laboratory Facilities Adequate?}

This brings us to another repeat question. In the second survey in 1963, officials were asked whether they considered their testing equipment adequate. In 1963 there were only 18 affirmative responses, compared with 35 in 1969. In 1963 officials were asked whether their laboratory facilities were adequate. There were only 14 affirmative responses then as compared with 29 in the 1969 survey. These dramatic increases in the adequacy of laboratory facilities and equipment reflect the program of the National Bureau of Standards in presenting new standards to state weights and measures offices whose laboratories meet federal standards. It is no accident that the 29 states whose laboratory facilities are considered adequate are also the ones that have received a set of the new federal standards. In my travels I knew that a state had received a set of standards if I were invited to visit their laboratory facilities. The new standards program continues, and by the time I make the next survey, I expect to find affirmative responses to both of these questions in every jurisdiction.

\section{Is NBS Prototype Testing Used and Useful?}

As a member of the Weights and Measures Advisory Committee for a period of six years, I listened to and participated in discussions dealing with the advisability of NBS prototype testing. Those discussions led me to include the following question in the 1963 survey: "Would you favor, in principle, having the National Bureau of Standards test and approve all new equipment as a prerequisite for sale in your state?" There was an 80 percent affirmative response. Subsequently, NBS did adopt a voluntary prototype testing program so that the following question was included in the 1969 survey: "Now that examination of prototype commercial weighing and measuring equipment is offered by NBS, do you use this service? Do you think it is desirable?" Forty-one states (78.8 percent) responded affirmatively and 48 states (92 percent) think the service is desirable. Together with the new standards program, the prototype examination service represents one of the significant advances in the past six years. Nevertheless, some officials expressed contrary views which pointed out, right- 
fully, that NBS does not approve devices. Such approval authority continues to be the responsibility of the states.

\section{Should the United States Convert to the Metric System?}

In 1962, and again in 1963, the Weights and Measures Advisory Committee strongly recommended that the United States change to the metric system of weights and measures "in order to continue to operate most effectively in world commerce." Since that time, Congress has created a special study commission to investigate the problem and the cost of conversion. In the 1963 survey, 35 out of 44 responding directors ( 80 percent) agreed that the United States should go metric. In 1969, only 29 of the 52 officials (55.7 percent) responded affirmatively to the question: "Do you think the United States should make the use of the metric system mandatory?" There were 16 negative responses, and seven undecided.

\section{MANAGEMENT INFORMATION SYSTEMS}

by D. E. EdgerLy, Weights and Measures Coordinator, Office of Weights and Measures

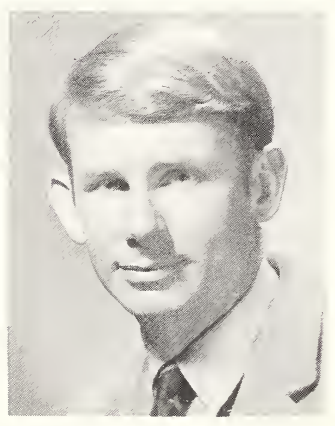

It is estimated that a field force of thirty inspectors generates upwards of 50,000 reports annually in weights and measures regulatory programs. Add to this effort approximately two clerical work years in sorting, posting, and summarizing the data from reports, and one has a good indication of the magnitude of data accumulated in most weights and measures jurisdictions in one year's time.

These data can offer the weights and measures manager valuable information on the effectiveness of his programs. However, the value of the information derived from the data depends on the quality, quantity, and timeliness of the reports received and on how the data are utilized-in short, how well the manager's information system is functioning. By definition, a management information system is that system which furnishes management and operating personnel with the facts necessary for making decisions and conducting operations.

One characteristic of weights and measures administration is the generation of large masses of data. Therefore, it is particularly critical in weights and measures administration that managers think in terms of systematizing the gathering and analysis of 
data to produce information. Without a system a manager is literally groping in the dark, making important decisions without really being able to predict the outcome or impact of such decisions.

The development of a management information system necessitates a great deal of soul searching by a manager and his supervisory staff. For instance, there are three questions that are universally of concern to a weights and measures manager.

1. Do the economic benefits of inspection programs outweigh their costs?

2. Are the economic benefits the best available return for the resource investment?

3. Do the inspection programs function successfully in the given environment?

Whether or not these questions can be answered successfully depends on the type of data currently being generated in the field. If, for instance, data are not being accumulated on the value of packages being inspected and the resultant value of error found in short-weight violations, it is impossible to determine the economic benefit accrued in such an inspection program. To carry this further, if no information is available on the economic benefits of a package inspection program, it is impossible for a manager to compare it with other inspection programs to determine where to best allocate his program resources. Determining whether or not inspection programs function efficiently in the field involves, again, detailed study by a manager and his staff to insure that only necessary data are being recorded and that the administrative procedures to be followed in collecting data work to the inspector's advantage.

For these reasons, a manager designing an information system must spend a great deal of time in just stating what he wants in the way of information. This point is crucial and cannot be overemphasized, because data are not available to fill management's needs unless they were specified prior to that need. This means that a weights and measures manager must be careful to design an information system that is responsive to his needs; further that, once such needs are expressed, he must establish the files necessary to support his needs and the input data necessary to set up and maintain these files. Once this has been accomplished, a manager can expect to obtain the raw data from which valuable information can be drawn as to how best to plan for and utilize program resources. 
As previously stated, weights and measures managers are faced with an enormous amount of data generated from inspection reports. The fact that the manager has determined what he wants from the data in the way of information means that only half the job is done. He must then utilize the data to produce the desired information, and this is an enormous and costly undertaking. However, with the increasing availability of electronic data classification, storage, recall, and manipulation, new avenues have been opened to weights and measures managers which heretofore have been outside the realm of practicability.

The computer, for instance, is now being utilized in most state governments to handle such functions as payroll, tax records, vehicle registration and licensing, and personnel records. In many states, the computer is being opened to various other government functions having a need for its characteristic high speed manipulation of large masses of data. Weights and measures can utilize the computer to great advantage. In fact, such use is becoming a necessity as inspection programs, expanding with the economy, are generating data at a rate where clerical manipulation is inadequate to produce meaningful and timely information for the program manager.

However, the computer is not a superbrain possessed of nearly magical powers. It can only do what it is programmed to do, and its application in weights and measures should be considered an investment with benefits expected, with costs to be incurred, and with risks to be taken. In considering its application then, a manager should be extremely careful to avoid the rather costly and all too frequent mistake of utilizing the computer to simply marshall facts; that is, to automate data for the sake of automation. The main purpose of a data processing unit is to provide information, and the unit should be considered as an element of the management information system.

Recently, the Office of Weights and Measures, National Bureau of Standards, instituted a program to offer the States specialized assistance in developing management information systems and in overcoming the difficult transition to the computer. Though there are currently only a few states utilizing the computer, it is certain that many more will follow in the very near future. NBS is currently analyzing the programs now in existence to render immediate assistance where possible and to document the best programs for the future. We also intend to review variations among the states in the frequency of inspection of weighing and measuring devices and prepackaged commodities to learn how the frequency is established and to recommend how it might be possible to set optimal time intervals for inspecting that will maximize the use of available resources. For instance, we have determined in a limited 
study of several states that the frequency of inspection for gasoline pumps varies from three to twelve months; yet the rate of failure for the three-month cycle and the twelve-month cycle is approximately the same. This implies that the tendency of a pump to fail is independent of how often it is inspected, meaning that states now inspecting more often than annually can lengthen their interval of inspection without a proportionate increase in the failure rate of pumps. The manpower and money saved in doing so can then be applied to other enforcement programs.

The results of the program to date have been gratifying. Staff of the Office of Weights and Measures and systems analysts from the Bureau's Technical Analysis Division have met with managers of four states currently working with computer programs. As a result of these meetings, efforts are now under way at NBS to design and document programs that represent the most up-to-date thinking in weights and measures. For example, working in cooperation with the Pennsylvania Bureau of Standard Weights and Measures, a new concept to allocate resources in the inspection of prepackaged commodities has been formulated.

This concept involves an internal decision plan, meaning that the data-processing system utilized by Pennsylvania is programmed to take appropriate action. The action to be taken by the processing system is spelled out in decision rules formulated by the program manager. These decision rules state how the data is to be processed into the types of information prespecified by the manager as necessary to conduct and evaluate his inspection program. For instance, Pennsylvania wants to maximize the impact of its package inspection program by allocating its resources in such a way so as to emphasize the importance of the product to the consuming public. Also, the state wants to be able to calculate accurately the impact its program has on the economy. With such goals prespecified, the program manager established the data necessary to produce such information. These data include:

1. The classification of commodity classes by Standard Industrial Classification codes.

2. The economic importance of each commodity class in terms of retail sales or value of shipments f.o.b. place of manufacture.

3. The time interval or cyclic rate of inspection as established by the program manager. Such cycle can be defined as the unit of time for which the computer will calculate inspection emphasis; i.e., monthly, quarterly, etc.

The program manager then, in the form of rules as to how the data is to be processed, plans for the internal manipulation of the 
data. These rules state, for instance, that the computer will determine the number of inspections per product class on a monthly basis. This determination is made on the basis of the number of total inspections for all product classes during one month and the relationship of the value of the product to the value of all products inspected during one month. This can be quantified as follows:

$$
\begin{array}{ll}
\text { Where: } & \mathrm{T}_{\mathrm{i}}=\text { Total number of inspections per month. } \\
& \mathrm{N}_{\mathrm{ip}}=\text { Number of inspections per product class. } \\
& \mathrm{V}_{\mathrm{t}}=\text { Total value of product classes. } \\
\mathrm{V}_{\mathrm{pc}}=\text { Value of product class. } \\
\text { Let: } \quad \mathrm{N}_{\mathrm{ip}}=\mathrm{T}_{1} \frac{\mathrm{V}_{\mathrm{pc}}}{\mathrm{V}_{\mathrm{t}}} .
\end{array}
$$

The computer takes appropriate action on the basis of the algorithm and specifies a certain number of inspections per inspector per area per month. The program manager schedules such inspections and, upon completion of the inspections, utilizes the data to adjust the number of inspections per product. Utilizing other decision rules, the manager specifies that, where the rejection rate of a product class is equal to or less than 10 percent of the number of inspections per product class, the computer is to adjust inspections on the basis of $\mathrm{N}_{\mathrm{ip}}=\mathrm{T}_{\mathrm{i}} \frac{\mathrm{V}_{\mathrm{pc}}}{\mathrm{V}_{\mathrm{t}}}$ or continue normal inspection. If, however, the rejection rate of a product class is equal to or less than 5 percent of the number of inspections per product class, the computer is to adjust on the basis of $N_{i p}=1 / 2 T_{i} \frac{V_{p c}}{V_{t}} \quad$ or one-half the inspection emphasis for that product class. Finally, if the rejection rate is greater than 10 percent of the number of inspections per product class, the computer is to adjust on the basis of $\mathrm{N}_{\mathrm{ip}}=2 \mathrm{~T}_{\mathrm{i}} \frac{\mathrm{V}_{\mathrm{pc}}}{\mathrm{V}_{\mathrm{t}}}$ or double the inspection of the product.

Such an internal decision plan can be overruled by the program manager in cases of uncommon problems. However, using an internal decision plan for processing data is highly recommended because it utilizes the computer to its fullest capacity and at the same time relieves the program manager of worry about the gathering of data and permits him to concentrate on decision making.

The outlook for the future can be bright if change is properly managed to work for the benefit of weights and measures. To this end the National Bureau of Standards is deeply involved in seeing to it that today's managers are being prepared for the future by offering such specialized assistance as necessary to design and implement advanced programs. However, NBS needs the support 
The plan does not aim to shirk government's responsibility or to surrender regulatory control. Full authority is still in government's hands, and the program simply permits government to concentrate testing upon the areas of greatest need.

To place our selective testing program into operation, the following steps were taken:

1. A legally sound weights and measures law was adopted which placed the responsibility for accuracy on the shoulders of the device owner-user.

2. The new program was thoroughly reviewed with our own staff. All field test reports, notices to adjust, repair, or replace, warning letters, and other material distributed by our office were revised to better project a program in which responsibility for accuracy and maintenance was on the owner-user.

3. We met with the various scale and meter service agencies to discuss the new Wisconsin program and to emphasize their role in the program.

4. We met with all device owner-users to discuss the reason for and their responsibilities under the selective testing program.

In 1962, with the initiation of the selective testing program, we dramatically altered our policy on sealing devices. Security seals were used on a few select vehicle-truck meters and computing pumps. Noncommercial warning seals were used when needed, but the paper seal was discontinued in all cases.

We have received many inquiries about our new program. The overwhelming majority questions our policy on approval seals. The two comments heard most often were: "Why discontinue the use of the approval seals, a trademark of weights and measures inspection for centuries?" "The scale and meter operators like the seals, and we can tell at a glance when the devices were tested."

It is our consensus that today, as in 1962, there are many good reasons why paper approval seals should not be used. The cornerstone of the Wisconsin testing program is to place the responsibility for the device accuracy on the owner-user. Too often an owner will use the approval seal as a crutch and will not be concerned about service and testing. We want the scale and meter owners to "think" maintenance and testing, which are so necessary for accuracy.

The approval seal may actually confuse the consumer. A consumer noticing a seal on a scale may become complacent and not watch the weighing operation. If questioned about the weight, a dishonest seller may use the seal to support or cover up an illegal weighing practice. 
Also, paper seals can cause embarrassment to enforcement agencies, as they can in no way affect or assure future performance of devices. The seal will still be on a device if it begins to perform inaccurately, if it is moved or used for a different purpose, or if it is abandoned or discarded with the trash.

We do agree that the enforcement agencies must communicate with device operators and consumers. However, we do not feel that the paper approval seal is a good vehicle for this communication. To better communicate with device operators, one of our inspectors a few years ago suggested a responsibility sticker. This suggestion was adopted, and we are now placing this sticker, when needed, on the operator side of the scale or meter.

State statutes require cities of over 5,000 population to have a municipal department of weights and measures or to contract with the state for inspection service. Forty cities do have city departments, and 40 cities (mostly in the up to 35,000 population range) have contracted with our department for inspection service.

An excellent spirit of cooperation exists among the cities and state inspectors who work together on some assignments which may cross territorial boundaries. When the selective testing program was initiated in 1962, most cities were skeptical. Under our present law, these city departments if they so desired could continue to make yearly inspection and use the paper approval seals. Today, a few of the cities have begun to adopt the selective testing program and seem happy with it.

What has been the impact of the selective program in our state? The device operator has become more aware of the importance of accurate weighing and measuring devices. This importance has been emphasized by his trade associations and, of course, by every state inspector on his visits. Many of the retail outlets have taken steps to have routine private scale or meter maintenance and testing. This testing is done in addition to the enforcement testing done by state inspectors.

We have also found new awareness in service agencies. Many service agencies have met the challenge of selling scale and meter service on its merits. They are selling the fact that it is good business to have a well maintained and accurate scale or meter.

Service agencies have increased their service and testing equipment. Presently, we have 20 private vehicle-scale testing units operating in Wisconsin. Two of these units have 20,000 pounds of test standards. Prior to 1962 , we had three private vehicle-scale testing units operating in the state. At the present time we have four independent LP Gas provers and service agencies operating in the state. Before our selective testing program began, there were none. There has also been a definite upgrading in the equipment of meter and gasoline retail pump service agencies. 
We have noted a definite improvement in the caliber of the scale and meter service technicians. Many of the service technicians do diagnostic work rather than just look at a condemned or rejected slip issued through enforcement inspection. Our state staff has worked with all of the service agencies in Wisconsin to be certain that they are following the testing procedures as outlined in Handbook 44 and other National Bureau of Standards publications. These contacts have been made with top management, service management, and right on down to the actual service technician who repairs the scale, meter, or gas pump.

In cases where service technicians have not performed adequately, we have been able to work out the problem with the company. So far, this method has worked fairly well. During this past year we have also adopted a program of voluntary registration of service agencies operating in Wisconsin. We feel that the improved caliber of service technicians in agencies certainly will benefit the installation, testing, repairing, and continued improvement in the accuracy of weighing and measuring devices in Wisconsin.

There have been significant changes in our weights and measures inspection approach since the initiation of the selective testing program. We do accumulate meaningful statistics for many devices tested, such as vehicle scales, gasoline computing pumps, and meters. These statistics will tell us which retailers are doing a good job and which ones are doing a poor job in maintaining their equipment. As a result, inspectors are no longer going down the road or just attempting to check all devices in their areas. Under office guidance based on statistical data, the inspectors must program their work to visit establishments and conduct tests that will do the most good for enforcement within the state.

We have done more testing in some areas, such as feed mills, canning factories, gasoline service stations, and livestock markets. We have also intensified our inspection of packaged commodities. We are also doing more investigational work to be certain that the seller and buyer are doing a good job of weighing with accurate devices. Making over-the-counter meat purchases and spot-checking loads of bulk commodities are two examples of such investigational work.

With an increase in population and commerce in our state, we have still maintained our work staff with the same number of inspectors (14) as we had in 1962. Although more inspection help is needed, we feel that our program is far superior today than it was in 1962. There has been a dramatic increase in the number of service tests being conducted by private agencies on most weighing and measuring devices. This increased testing and maintenance has resulted in improved scale and meter accuracy. When 
state inspectors find it necessary to reject a vehicle scale or vehicle-tank meter, the errors found in the device are usually small and barely exceed the permitted tolerances. In 1962 it was not uncommon for our inspectors to find an occasional vehicle scale with a weighing error of more than 1,000 pounds, or a vehicletank meter with an error of more than a few gallons per 100-gallon delivery. Today we are taking some device owner-users and packers to court, averaging around one a month. Prior to 1962, court cases were infrequent and in most years there were none at all.

Determining the effect of various enforcement programs and where regulatory resources should be assigned has always been a problem. To better assist us in making our decisions, a few years ago we adopted a program of accuracy projection for equipment and packages. Based on past experience and statistical sampling, we project a percentage of accuracy for specific types of equipment and packages if no enforcement supervision is applied. Then we project the accuracy if reasonable enforcement supervision is applied throughout the jurisdiction. With these two figures, we arrive at a numerical base to first project our accuracy goal and to evaluate the effective work measurement of our program and of our individual inspectors. The following chart will indicate this projection for gasoline retail pumps, vehicle scales, and storepacked packages.

\begin{tabular}{|c|c|c|c|c|c|c|}
\hline Area of supervision & \multicolumn{3}{|c|}{ Accuracy estimates $(\%)$} & \multicolumn{3}{|c|}{ Accuracy field results $(\%)$} \\
\hline Equipment or packages & $\begin{array}{l}\text { No. } \\
\text { supv. }\end{array}$ & $\begin{array}{c}\text { Accuracy } \\
\text { goal }\end{array}$ & $\begin{array}{l}\text { *Difference } \\
\text { or supv. } \\
\text { area }\end{array}$ & $\begin{array}{l}\text { Field } \\
\text { sample } \\
\text { results }\end{array}$ & Difference & $\begin{array}{c}\text { Work } \\
\text { measure- } \\
\text { ment }\end{array}$ \\
\hline Pumps (retail gasoline) & 40 & 90 & 50 & 85 & 45 & 90 \\
\hline $\begin{array}{l}\text { Scales (vehicle) } \\
\text { Packages (store- } \\
\text { packed) }\end{array}$ & $\begin{array}{l}40 \\
50\end{array}$ & 85 & $\begin{array}{l}45 \\
45\end{array}$ & & & \\
\hline
\end{tabular}

* This figure represents 100 percent of the accuracy area affected in a jurisdiction by the weights and measures program and/or the work of an individual inspector in whose area a field sampling was taken. 
To check the effectiveness of our program and that of one of our inspectors, a statistical sampling is made of 211 gasoline pumps in District 4 in our state. On the average, the pumps are found to be 85 percent correct. This figure is underlined on the above chart and is further developed in the graph below.
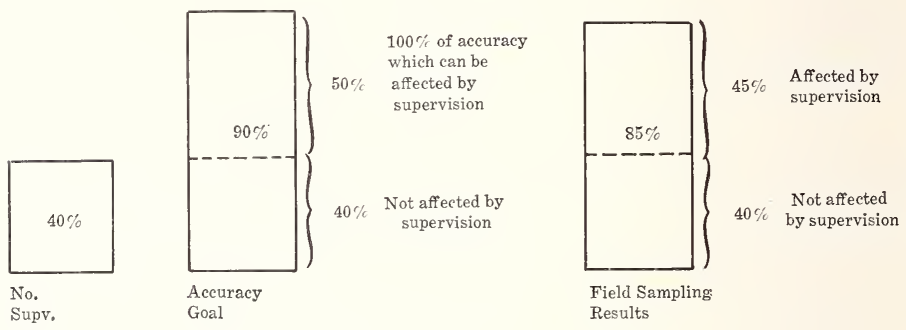

Work Measurement (Program or inspector effectiveness)

We have projected accuracy estimates for all scales, balances, measures, and store random packages. We have worked out the details of this particular program with the Statistical Reporting Service of our Department.

Change and progress are almost synonymous. New methods of weighing, measuring, packaging, and merchandising products continue to be developed with increasing rapidity. It is the job of every weights and measures official to meet the regulatory enforcement needs of the consumers and commerce of his jurisdiction. In this competitive world, we cannot shield ourselves with comfortable illusions or rely on the easy precepts of tradition. We all must dare to grapple with the unfamiliar and wrest solutions and progress from stubborn new facts. By working cooperatively with the NBS and other states, we do hope that we will continue to respond to the measurement needs of the citizens of our state and country. 
by Mrs. JAne Byrne, Commissioner, Consumer Sales, Weights and Measures, Chicago, Illinois

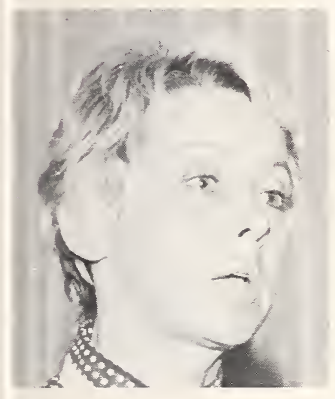

The year 1969 was a vigorous one in consumer affairs for Chicago. The enforcement of the Deceptive Practice Ordinance of the City of Chicago was put into strong use against gasoline filling stations which charged either excessive amounts for sales tax or had pump prices marked higher than advertised prices due to the price of goods or services such as premiums or car washes, which were added to the price of the gasoline. As a result of many complaints, the Department made a survey of heavily traveled streets throughout the city. This survey revealed that a large percentage of the stations which advertised gasoline prices used signs which were at least misleading, if not outright deceptive. The most common misleading or deceptive practice found was the charging of an excessive amount for sales tax. Second in frequency was the practice of advertising gasoline at a low price and then charging from 1 cent to as much as 7 cents more per gallon for premiums or car washes.

As a result of this survey and subsequent investigations, several gasoline service station operators were cited with violating the city's Deceptive Practice Ordinance. In order to clarify the city's position with reference to enforcing this ordinance as it related to gasoline service stations, a series of meetings were held with representatives of the gasoline industry and retail gasoline dealers.

At the final meeting during early 1969, the guidelines to be followed in the advertising of gasoline were established. These guidelines called for full disclosures to the consumer concerning the price to be paid for gasoline, including any goods or services which would add to the final cost.

During 1969, the Department of Consumer Sales, Weights and Measures developed new consumer ordinances which were introduced in the City Council to give the consumer a better break in the market place. The new Ordinance on Clear Packaging will become effective on July 1 of this year. A large food chain is presently carrying out a study in all their stores on unit pricing. Together with many special projects in the past month, the Department has carried out its daily program of processing complaints. In the past twelve months our inspectors have investigated over 1,000 complaints, most of which have been adjusted to the satisfaction of all parties concerned. 
Indications are that Chicago businessmen have become more aware of consumer needs and are more anxious to obtain consumer confidence. Consumer education programs are springing up all over the city to help consumers make intelligent choices based on knowledge and information.

What has developed in Chicago in the past few years is a mutual effort on the part of government, enlightened businessmen, and the general public to assure that the best practices of the market place become common practice and that the consumer gets the best possible value for his hard-earned dollar.

We should all realize that there is much more work to be done in the 70's. We realize that consumer frustration has built up with inflation and with the possibilities of breakdown in quality. Consumers turn to government for redress when they find a lack of response from business. Government agencies will keep providing it. With the gains that are being made, there are still no signs that the consumer is ready to "play it cool." Instead, businesses complain to us that our enthusiasm to champion the cause of the consumer has led to exaggerated charges and has hurt many businesses for the transgressions of a few, but generally our accomplishments are admired and acknowledged by Chicago businesses and consumer groups and are highly significant to consumers.

Now, what will be the direction of impact in the consumer movement on weights and measures organizations? What will be the public policy toward business in the 70's?

To make sure the private enterprise serves the public interest, we in government will more strongly insist wherever possible that competition be maintained. Government will continue to insist that the public interest not be ill affected by the methods used when firms compete.

The consumer movement will continue to magnify the possibilities of adulterated products, misrepresented values, withheld information, and manipulated markets. Business will take notice that these poor practices operate to drag the better firms down to the level of the worst. Our activities and those of related agencies will become increasingly concerned with new consumer legislation and enforcement of existing laws. As we here today know, the formulation of consumer protection has existed for many decades in the National Bureau of Standards and in the programs of the many weights and measures agencies throughout the country.

Government agencies, therefore, will be challenged in the 70's to help businessmen recognize that it is in the vital interest of business to look calmly at the new important forces in the market place and to deal with the needs of the consumer with perception.

Let me briefiy summarize the Department's goals for 1970 and some of our present activities. 
1. Along with the systematic inspection of approximately 8,000 food stores, our Department will endeavor to systematically inspect retailers, wholesalers, and manufacturers selling consumer goods in the City of Chicago.

2. It will bring about new desirable legislation which will broaden existing consumer ordinances in areas of fraud and misrepresentation, especially in matters of labeling and advertising.

3. It will recommend new licensing provisions which will require businesses such as home maintenance, appliance repair shops, door-to-door sales, and automobile dealers to be licensed by the City of Chicago.

4. It will complete development of a central complaint desk which receives and investigates every type of consumer complaint. This phone number will continue to receive citywide distribution. It will enable us to pinpoint problem areas and enhance research and reporting. The complaint desk also reviews all daily newspapers and looks for any misleading advertising.

5. It will emphasize systematic investigation of unpackaged truckload shipments such as fuel oil and petroleum products, coal, sand and gravel, and commodities of this nature.

6. It will initiate laboratory quality testing of certain products sold to consumers such as gasoline where standards are advertised (Octane, Regular, Premium).

7. It will test and certify all weighing and measuring devices and meters in use in the city.

8. It will test and calibrate all meters and tank trucks used for deliveries of fuel oils in Chicago.

9. It will increase fee schedule rates, which have not changed in many years, to offset growing testing expenditures.

Congress passed the Fair Packaging and Labeling Law three and one-half years ago. Government is now responsible to make sure that cereal packages are filled or that "cents-off" labels mean what they say. Related to this is the experiment now being undertaken by a grocery chain to learn the consumer reaction to "unit pricing," under which a shelf label would carry not only the net weight and price, but also the price per unit. The Department of Consumer Sales, Weights and Measures will be watching this closely as a part of its program of assuring clear labeling of net contents of food packages in order to insure that the consumer is accorded a clear designation of what is in a package.

One congressman in Washington claims he has growing support for legislation to outlaw the secret dating codes stamped on supermarket products and to let housewives know in plain English how old the food is. He will introduce a bill which would require stamps on food stating the deadline for removing products from the shelf. 
Our own survey in Chicago stores indicated that some foods are being sold beyond the plainly marked dates placed on the packages by the processors. The survey indicated that some merchants or food processors are violating their own codes by keeping food on sale beyond the date when it is supposed to be removed because of staleness.

Lately our office has received an increasing number of complaints concerning the lack of availability of sale items. We would like to stress the importance of supervision in checking the quantities at the store level to insure both product availability and correct pricing.

The Department has received a grant under the Model Cities Act and a program has been devised for consumer enforcement and education in the four Model Cities target areas.

We have leased four mobile homes which will be set up as consumer service centers, with persons trained in all facets of the Department's operations. These consumer service centers will be located in Lawndale at 3518 West Roosevelt Road, in the Near South Area at 4320 South Drexel Avenue, in the Woodlawn Area at 6600 South Woodlawn Avenue, and in the Uptown Area at 724 West Montrose Avenue.

In addition to the routine enforcement activities in these areas, there will be a concentrated effort of consumer education for the residents of each area. The furnishings for each of the mobile homes will be purchased with quality and low cost in mind.

The Department of Consumer Sales, in conjunction with the Federal Trade Commission and the Illinois Attorney General's Office, has established an Enforcement Coordinating Committee for Consumer Protection. The committee will meet periodically to exchange information and ideas and to establish a better relationship between the agencies. The benefits to be obtained for consumers by coordinated law enforcement are as follows :

1. A one-stop consumer complaint service.-A complaint filed with any agency will be referred to the correct agency for action.

2. The best remedy will be applied to any complaint.-Fed. eral, State, County, and City laws can be applied as required.

3. Aggregated individual complaints will reveal patterns of violations.-Regular violaters will emerge from the aggregation and be identified for corrective action.

4. Priorities can be established from the information pooled. - Law enforcement agencies will be able to make a concerted effort to solve the most difficult and widespread problems first.

5. Duplication of investigative and corrective effort can be avoided. 
6. A quick response liaison system will naturally develop.Face-to-face meetings of agency representatives will encourage personal telephonic communication on difficult complaints and referrals in interiin periods.

Benefits reasonably to be expected for the members will include:

1. A broad intelligence network reporting consumer law violations.

2. Reference of specific matters over which each has local jurisdiction.

3. Complaint evidence and witnesses pertinent to each member's jurisdiction will be made available to him.

4. A regular organization will exist through which members can transmit for action consumer complaints.

Obviously, the typical businessman has not personally been out of sympathy with the aim of our Department or the consumer movement, since he is, after all, a consumer himself. His home is equipped with labor-saving appliances, he is a large buyer of convenience foods, and he also uses credit. The businessman is, himself, a good customer and a tough one. His tolerance for short measure or short weight can also be quite low.

It appears that in the coming months business will be doing something. More and more businessmen are convinced that the rewards for the avoidance of penalties will come only if the consumer and the protective agencies are convinced that the businessman is someone who is interested. Whether an issue is in the real public interest or merely in what the public thinks is in its interest, the businessman will take it into account.

What will the consumer ask of weights and measures agencies in the coming decade?

Consumers indicate that, along with proper quantity, they are interested in products of good quality. Many feel that it is necessary to have standards and specifications to achieve high quality and consistently good performance. There are those who suggest that a strong case can be made for the policy of establishing official grades for all types of consumer goods, especially where the buyer has no means of judging quality, and extending to these goods the requirement of informative labeling.

Some advertising and manufacturing spokesmen become disturbed over what they refer to as the potentially devastating effect of officially adopted standards.

We in weights and measures, of course, realize that the setting of any type of standard is not something to be accomplished by a 
few round-table discussions and the dictation of a definitive memorandum or federal directive. We also realize that in a dynamic system of manufacture, with ever-changing variety and early modification, the problem involved in standards would seem obstinate.

In consumer affairs during the coming years standardization will present the broadest single problem. The solution of the quantitative phase of the standardization problem in weights and measures has been simpler than the phase which will deal with the standardization of the quality of goods.

As with standardization, the subject of labeling will receive increased attention. Business will favor descriptive labeling in a form that will give about as much information as the consumer wishes. Business is beginning to understand that, through honest advertising and proper sales practices, it can avoid restrictive legislation or imposing regulations which could result from deceptive practice by a few.

What does the consumer want? He desires informative labeling which will afford him protection against misrepresentation and provide him with what he needs to obtain high quality for a lower price. The consumer will be requesting objective standards and informative labeling which will tell him exactly what he is getting and direct his attention to quality and performance to facilitate comparisons.

These few points by no means cover the field of important subjects in the broad impact of the consumer movement. Time does not allow us to exhaust the subject by including all the information necessary to proper understanding of these influences. The objective is to point out certain trends, the nature and extent of some problems, and the work and investigation necessary to finding a solution to some of these important issues, so that all of us can meet the challenge of the 70's.

The Department of Consumer Sales, Weights and Measures, under the direction of Mayor Richard J. Daley, is dedicated to setting forth proposals which will protect the rights of all consumers and to promoting a greater understanding of the responsibilities of both the business community and private citizens in creating an atmosphere of trust and fair play in the market places of this great City of Chicago. 
by D. P. ShEA, Executive Secretary, State Consumers' Council, Boston, Massachusetts

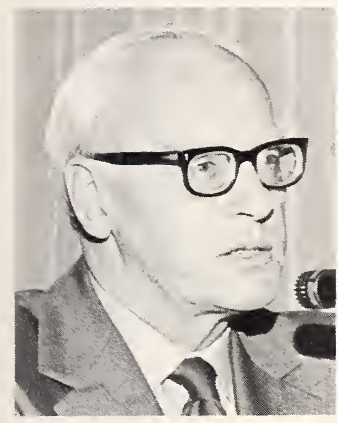

Fellow consumers, it is a pleasure to be invited to give a consumer's viewpoint before such a distinguished representation of the weights and measures officials. It was felt that you might be interested in some of the activities of the Consumers' Council of the Commonwealth of Massachusetts in the field of consumer protection.

First, what is a consumer? The consumer is fundamentally a buyer or user of goods and/or services, making us all consumers.

What is the need of consumer protection by government? It is obvious in the marketplace someone has to be the referee in order to protect the buyer. The first recognition of this fact of the need of consumer protection by the government historically happened in the Massachusetts Bay Colony around the year 1630. Governor Endicott of the Massachusetts Bay Colony became the first sealer of weights and measures, the first such official on the North American Continent. You, of all people, know that the duty of the sealer of weights and measures is to ensure that the consumer receives the full measure and the true weight of the goods he buys. In fact, there is a long history of consumer protection by the government in the Commonwealth of Massachusetts. You may be interested in the following quotation:

The ordinary consumer is interested and affected by retail prices... While there is very little constitutional authority for fixing prices by law, it is of the utmost consequence that the public know that charges are reasonble ... They ought to be informed as to whether the prices in general are fair and reasonable ... Government fails as an administrator of justice if it permits to go unchallenged an exorbitant charge upon the public.

This is an excerpt from the message of Governor Calvin Coolidge to the General Court on June 13, 1919, relative to Special Commission on the Necessaries of Life.

I feel very strongly that one of the major reasons for the social unrest in our country is the direct result of the failure of state governments to act in the interest of their people in this era of rapid socioeconomic change. 
The federal government, by the very nature of our political structure, must be able to coordinate its activities with viable state governments in order to govern in proper concert. True government requires control and direction in the making and administering of policy as basically mandated by the electorate and the public interest. Most of our state governments are merely housekeepers or custodians of the forms of government, the shadow, as it were, not the substance of true government. This is, also, the case in many areas now preempted by the federal government itself. How else can we explain the failure of the state and federal governments to prevent the enormous environmental problems now confronting our country. Many of these areas of environmental concern are public health and conservation matters that could easily have been controllable and solvable by proper government action but a few number of years back. Many of the problems relate directly to the failure of legislative bodies and administrators of government to face up to changing conditions. Just look at the violent changes to our physical and social structure caused by the automobile alone. Consumer protection is, also, another major dimension of environmental concern. The point I am making is government cannot remain static. It must respond to the needs and protection of its people, whether it be in the marketplace, the air we breathe, the water we drink, the home we live in, or what have you. Failure to act in time to redress wrongs has caused government to be identified with the very factors that are causing grave injustice.

Recognition of this social unrest and the need of consumer protection led the General Court to create the State Consumers' Council of Massachusetts. It is the first statutory body of its type in the country and several states have modeled their consumer councils after it. The Council has been operating since 1964. Its function is threefold:

1. To protect the consumers' interests in accordance with the Council's statutory power.

2. To further consumer education.

3. To conduct studies concerning consumer problems.

The fundamental purpose of this Council is to give the citizens of the commonwealth voice in matters that concern the consumer. The Council is charged with coordinating consumer information and reporting violation of laws to the appropriate law enforcement agency. The Council is further required to conduct studies and advise the Governor and the General Court on matters affecting consumer interest. The Council, also, takes complaints and information from the public concerning fraud and deceptive trade prac- 
tices in the marketplace. It can, also, act as a party of interest on behalf of the citizens in any hearing pertaining to the increase of rates or the cost of services. The Council is currently representing the people of the commonwealth in the $\$ 55,000,000$ New England telephone rate case, as well as the $\$ 10,000,000$ rate increase requested by the Massachusetts Electric Company.

Except for a small staff headed by an executive secretary, the Council is a nonpaid body composed of thirteen members, eight of whom are public members. The remaining five are ex officio members of the Council including the Attorney General, the Chairman of the Department of Public Utilities, the Commissioner of Banks, the Commissioner of Insurance, and the Commissioner of Labor and Industries. I have the privilege of being the first Executive Secretary of the Council.

Among other things, the Council sponsored and led the legislative battle in Massachusetts for the enactment of the first Truthin-Lending Law in the United States. This, as you know, in turn led to the enactment of the Federal Truth-in-Lending Law. The Council has, also, sponsored the Retailment Installment Sales Act, Deceptive Trade Practices Act modeled after the Federal Trade Commission Law, a Credit Card Control Act, a Credit Bureau Control Act, as well as a host of other consumer measures.

What the Massachusetts General Court has done is to create a new dimension in government to help safeguard the integrity of governmental action (both executive and legislative) particularly on matters concerning the consumers of the commonwealth. In effect, the Consumers' Council is the ombudsman in the area of consumer protection.

The Council, from its inception, has closely collaborated with the weights and measures officials of the commonwealth, both at the state and at the local level of government. I cannot speak highly enough of the degree of cooperation we have received from the Weights and Measures Association of Massachusetts and the State Division of Standards. No other area of government is so basic to the consumer protection in the marketplace as is the administration of weights and measures. Regretfully, however, I must say this vital area of government has been slow in adapting to the modern marketplace conditions by renewing its function as the consumer's first line of defense. In Massachusetts the Consumers' Council, with the support of the State Division of Standards, was able to effect the first major change in 300 years in the administration of weights and measures in Massachusetts. Because of the almost total lack of protection afforded, the public towns of 5,000 or less inhabitants were relieved of the responsibility of maintaining a sealer of weights and measures office. This responsibility was reassigned to the State Division of Standards 
who had both the equipment and the manpower to properly service these towns. Incidentally, to cry home rule in this area of administration is comparable to saying that the local home town druggist is qualified to treat his customers for appendicitis. The point I am making is that we are in the computer measurement era. The old time Yankee standard of "more or less" has to go.

In the administration of the weights and measures laws throughout the country, with exceptions, you will find that the public thumb is now on the customer's scale thus denying the customer the protection he should have in his every-day purchases. I say this because the laws in Massachusetts, as well as in many other states, have the effect of making it illegal to maintain or use an inaccurate weighing or measuring device only if so found when being checked by law once a year. Since most such devices are not rechecked, the consumer is fair game the other 364 days. Why not take the public thumb off the consumer's scale and use the selected testing technique as done for example in Wisconsin? Why should the burden be on the government to make certain that a weighing or measuring device used by private enterprise is accurate? The burden of maintaining safety standards in elevators and other such equipment is thrown on the user or owner. Why should an owner or user be relieved of the responsibility of maintaining the accuracy of weighing and measuring devices? A bank cannot shortchange a customer and get away with it. Why should there be a different standard of justice? Selective testing by placing the burden on the user to maintain the accuracy of his weighing and measuring devices would enable the local weights and measures administration to have a task force in being capable of making a constant patrol of the marketplace in a random manner similar to the auditing technique used by the best accounting firms.

Fundamentally, the problem is that many administrators of weights and measures laws, as well as many state legislatures, have forgotten that the weights and measures statutes were designed for the public interest in general and not for private industry. As a result, many of these measures are being administered solely for the benefit of industry and not the general welfare. Every state should examine the amount of time and money spent on industrial services that are not adequately reimbursed to the government. This money and this staff should be diverted back to administer the real intent of these laws which is to police the marketplace.

Finally, I think we should all remember that the consumer is concerned with the correct weight and price at the time of purchase. He could care less by what means or determination this is made. He cannot be used as an excuse for the failure to change. I believe that the weights und measures administration is bound to 
have a new look in the 1970's and I think a method of selective testing will be adopted by many states as a progressive reform measure.

THE COMMERCIAL WEIGHTS AND MEASURES SURVEY

(With a Brief Introduction on and Organization of the U.S. Metric Study)

by S. L. Hatos, Manager, Commercial Weights and Measures Survey, U. S. Metric Study, Office of Weights and Measures

\section{Introduction ${ }^{1}$}

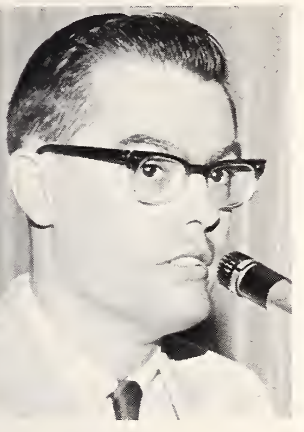

The U.S. Metric Study, authorized by Public Law 90-472, was established to investigate the possible consequences on the United States due to increased metric usage abroad and to investigate the advantages and disadvantages that increasing the use of the metric system would have on this country.

In trying to determine the advantages and disadvantages of metrication, three issues have been established as the basic parameters for all elements of the metric study:

1. What is the present impact within the United States of increasing worldwide and domestic use of the metric system?

2. What would the impact above be in the future, assuming that the use or nonuse of the metric system continues as at present, with no coordination among the various sectors of the society?

3. Alternatively, what would be the effect of a coordinated national program to increase the use of the metric system?

\section{U.S. Metric Study Organization}

\section{Metric Study Surveys}

In order to try and answer the above issues, the U.S. Metric Study has been divided into the following surveys:

1. The Manufacturing Survey is investigating the impacts of possible metrication on those industries that produce mechanical products and on their parts suppliers. The impact of metrication will, no doubt, be severest on these industries.

\footnotetext{
${ }^{1}$ Appendix III, Organization and Issues of the U.S. Metric Study
} 
2. The Nonmanufacturing Survey is studying possible metrication impacts on such businesses as finance, services, agriculture, forestry, fisheries, construction, utilities, and the trades.

3. The International Trade Survey, under the supervision of the Business and Defense Services Administration of the Department of Commerce, has been gathering data on the possible effects of metrication on American exports and imports.

4. The Federal Government Survey is ascertaining the effects of metrication on the federal government activities.

5. As a separate study, the Department of Defense is analyzing the possible impacts of metrication on the U. S. Military.

6. The State and Local Government Survey, like the Federal Government Survey, is examining the impacts of metrication on the operations of state and local governments.

7. The Standards Survey is gathering data on the compatibility of engineering standards based on U.S. Customary units and those based on metric units such as many that have been developed by ISO. ${ }^{2}$ This survey is also considering whether or not our present system of measurement hampers the U. S. from effectively negotiating engineering standards with metric countries.

8. The Consumer Survey will analyze the impacts of metrication on the consumer. This survey is gathering information on the attitudes of consumers and the possible problems they will face in the marketplace.

9. The Education Survey is gathering data on the problems faced by educational institutions if metric usage is increased.

10. The Labor Survey is gathering information on the impacts of metrication on all workers and occupations.

11. The Commercial Weights and Measures Survey, under the direction of the Office of Weights and Measures, is examining:

(a) The problems (cost, time, etc.) of adapting weighing and measuring devices to record in metric units.

(b) The impacts of metrication on state and local weights and measures jurisdictions. More details on this survey will be given below.

National Metric Study Conferences

In addition, a series of national conferences will be held (most

${ }^{2}$ International Standards Organization 
of them this fall). These conferences will solicit the views of trade associations, labor organizations, and professional societies (law, engineering, etc.). These conferences are designed to supplement the information gathered by the various surveys.

\section{Historical Analysis}

Also, a historical analysis, especially prepared for this study, will give the history of measurement usage and metrication efforts in the United States.

\section{The National Metric Advisory Panel}

Finally, the Secretary of Commerce has established the National Metric Advisory Panel, whose members represent the various sectors of the American economic and social community. This panel advises the National Bureau of Standards on the conduct of the metric study.

\section{Commercial Weights and Measures Survey}

And now for a detailed look at the Commercial Weights and Measures Survey. As mentioned above, this survey is concerned with the problems associated with the adaptation ${ }^{3}$ of weighing and measuring devices to record in metric units and with the effects that metrication might have on weights and measures jurisdictions.

\section{Assumption}

This survey assumes that a planned program for metrication would have to be established in this area. Why such an assumption? Consider the history of metrication in the U. S. commercial weights and measures area. Since 1866 it has been legal ${ }^{4}$ to use the metric system of weights and measures in commercial transactions. However, due principally to custom, there has been little or no move to metricate in the commercial area.

\footnotetext{
${ }^{3}$ Adaptation does not mean that the device itself (internal components, housing, etc.) must be redesigned to metric specifications and tolerances, etc. Adaptation in this case means a language change from U.S. Customary units to metric units. That is, the device will now record in metric units instead of U.S. Customary units. Any new parts required to make this language change would be designed in the most convenient units and standards. The end result would, no doubt, be a device designed in U.S. Customary units, which is the present situation, but said device will read in metric units.

${ }^{4} 15$ U.S.C. 204
} 
It has, therefore, been concluded that metrication will not, in all likelihood, come about in this area by evolutionary means. Consequently, this survey assumes that some action to bring about metrication in commercial transactions would have to be taken by both federal and state governments, and such action would almost certainly have to have wide citizen support before it was taken. ${ }^{5}$

\section{Device Adaptation}

The first area of this survey, the adaptation of devices, concerns the study of three classes of commercial weighing and measuring devices: (1) Weighing devices, both small and large capacity, (2) volumetric metering devices such as gasoline-pumping systems, and (3) fabric-measuring devices. Within each class the problems of adaptation are being examined at both the manufacturing and user levels. To begin with, consider some of the general requirements for adapting each of these classes.

Weighing Devices (General).-First, the adaptation of some types of weighing devices: Adapting small-capacity mechanicaltype scales such as drum or fan-computing types would require (1) installation of new metric charts and faceplates; (2) in some cases, new weighbeams and poises; and (3) since the break points would be in whole metric units, recalibration. For large-capacity mechanical scales, not only would the above be necessary, but in many cases new unit weights would be required. Also, modification of the lever system in some types of platform scales may be necessary. Prepackaging computing scales (electronic type) may be adapted by adjusting the mechanical elements of the device so that it will record 1.00 kilogram instead of 1.00 pound. However, the smallest indication, using this method of adaptation, would be 0.01 kilogram (10 grams) after adaptation, whereas now it is 0.01 pound (4.54 grams). Thus, minimum graduations would be over twice as large as they are now by this method of adaptation. If weights and measures officials do not accept these new minimum metric graduations, considerable problems may arise in order to adapt this type of device.

Metering Devices (General).--Second, the adaptation of metering devices: In general, the adaptation of metering devices requires a speedup of the input shaft into the mechanical computer and the changing of a dial (faceplate) on the computer register to indicate metric units. For example, gasoline-pumping systems may

"It is further assumed that, unless a metrication program is adopted, no costs will arise in the commercial weights and measures area, since nothing would have to be changed or replaced if the present situation continued. 
be adapted by (1) changing the gear ratio in the meter so that the rotating shaft into the computer will rotate 3.785 times faster than at the present time, and (2) equipping three-wheel registers (computer) so that the lefthand indications in the quantity section would record from $0-14$. (Conversion kits are now available for this purpose.) This would allow the computer to read up to 149.9 liters. Such an upper limit would be quite adequate for most service-station requirements. Four-wheel registers, it appears, would not have to be changed. Finally, (3) the dial or faceplate would have to be changed to indicate metric units.

Fabric-Measuring Devices (General).-Third, the adaptation of fabric-measuring devices: The adaptation of these devices would probably require (1) a gear change so that each revolution of the dial would be one meter instead of one yard, and (2) a change of price computation charts.

Adaptation Manufacturing Level.-From preliminary evidence, it appears that adaptation at the manufacturing level will not be a major problem for any of the above three classes of devices. Since both scale and meter manufacturers produce devices that record in metric units, either in their domestic or foreign plants, these companies already have expertise in producing metric devices. Measuregraph Company, the only producer of fabric-measuring devices in the United States, is developing a device which can be easily adapted to record in metric units. Thus, it would appear that they will have few major problems in adapting this device at the plant level. However, preliminary data indicate that adaptation at the user or field level will be a major problem for all three classes of devices.

Adaptation User Level: Scales.-Field adaptation for the scale industry will be difficult because of the many types and ages of weighing devices now in use, coupled with a relatively small number of qualified service personnel to accomplish the task. (To adapt some old scales now in use may be prohibitive because of the high expense involved, since their small numbers would not justify mass production of parts which could help keep costs down.) In fact, the limited number of service personnel implies that field adaptation will take some time, and as a consequence the country will have a mixture of metric and U. S. Customary devices for some time. Also, service agencies that are under contract to several scale companies will face special hardships because of the increased number of parts they will have to inventory and the increased knowledge their personnel will have to have in order to adapt various manufacturers' devices.

Adaptation User Level: Meters.-The field adaptation for the metering industry will not, it seems, be as severe as that of the scale industry. First, meters mounted on vehicles can, because of 
their mobility, be taken to a convenient place for adaptation. Secondly, it may be possible to install gasoline-pumping systems with a dual gearing system which would allow the pumps to record in present U. S. Customary units until the time came for the final changeover, when the new gearing system would be locked into place, allowing the device to record in metric units. Also, new faceplates could be installed with metric units permanently painted on the dial and with U. S. Customary units over them on pulloff decals. These would be removed when the new system was put into operation. This procedure, provided it could be used by all gasoline-pump manufacturers, would take advantage of the fact that, since gasoline pumps have an age of about ten years, all gasoline-pumping systems nationwide could be ready for the final changeover at the end of a ten-year period. Another advantage is the fact that servicing policies would not be seriously disturbed during this preparation state.

Servicing policies would be severely disrupted during the time it would take to shift gearing systems and remove the U. S. Customary indicating decals for all of the million-plus gasoline pumps in the country. This procedure, however, would reduce the time period in which there would be a mixture of U. S. Customary and metric-indicating gasoline-pumping systems in the country.

Adaptation User Level: Fabric-Measuring Devices.-Adaptation of fabric-measuring devices in the field may prove to be very difficult. Preliminary information indicates that it may be extremely difficult, if not impossible in some cases, to adapt present devices now in use. Coupled with the mechanical problems is the fact that there are very few qualified service personnel available to adapt these devices. It therefore appears that adapting these devices will be costly as well as time-consuming.

\section{Weights and Measures Jurisdictions}

The second area of this survey is concerned with the impacts that metrication might have on state and local weights and measures programs. To help the Office of Weights and Measures in this area, the 54th National Conference on Weights and Measures established a Task Force on Metrication. The Task Force members have been appointed, and Mr. M. Jennings, Director, Division of Marketing, Department of Agriculture, State of Tennessee, serves as chairman. ${ }^{6}$

Impacts for this area of the survey have been divided into three categories: (1) Changes required for state weights and measures

${ }^{\circ}$ Appendix I, List of Task Force Members

Appendix II, Task Force Organization 
laws and regulations (for example, packaging regulations and NBS Handbook 44, Specifications, Tolerances, and Other Technical Requirements for Commercial Weighing and Measuring Devices); (2) costs and time needed to train weights and measures officials to effectively use the metric system; and (3) laboratory and field standards and equipment that would either be needed, or costs for adapting present standards and equipment to nominal metric values.

Laws and Regulations.-There appears to be little impact on state weights and measures laws for the majority of states, since these laws recognize both the U. S. Customary and metric systems of measurement in commercial transactions. However, there are sections in most weights and measures laws which require certain commodities such as milk and bread to be sold in specified quantities. These sizes, if translated into metric equivalents, would not be convenient round numbers; thus, size changes would be desirable. However, since changes in the sizes of these commodities would affect manufacturing practice, great care would have to be taken in order to insure that industry could meet any new metric commodity sizes wihtout incurring large costs.

In the area of packaging and labeling, it appears that the federal government will have to take the initiative toward metrication. Federal laws in many cases restrict the freedom of the states to legislate in this area. For example, the Fair Packaging and Labeling Act and regulations promulgated thereunder supersede all state laws or the laws of their political subdivisions which are less stringent than or inconsistent with FPLA or its regulations with respect to the labeling of the quantity of contents on a packaged consumer commodity as defined in this law. ${ }^{7}$ In the case of NBS Handbook 44, Specifications, Tolerances, and Other Technical Requirements for Commercial Weighing and Measuring Devices, the tolerances and test procedures were established in round U. S. Customary units. Even though metric equivalents could be used as an interim measure in the metrication process, it would be more advantageous for future metric usage to establish such tolerances and procedures in round metric units. Of course, any changes to $\mathrm{H}-44$ would have to be made with the approval of the National Conference. Many of the same problems arise with NBS Handbook 67, Checking Prepackaged Commodities.

Metric Education Program.- Since weights and measures officials, on the whole, have had little experience in using the metric system, a metric education program will be necessary. It would seem that costs for this program could be kept fairly low by

\footnotetext{
${ }^{7}$ Section 12, Public Law 89-755
} 
incorporating it as part of present technical training programs. However, this approach may not be effective or may take a good deal of time. For example, the Office of Weights and Measures training program takes several years before it has completed its tour throughout the country. Also, some jurisdictions have irregularly scheduled training programs, and some jurisdictions have few, if any, training programs at all.

One possible type of education program would consist of two stages. In the first stage, state and local officials would receive the fundamentals of the metric system from local sources such as special training programs arranged in cooperation with state or private colleges or universities. In the second stage, the Office of Weights and Measures would give specialized training to officials on inspecting devices and packages using or labeled in metric units. It would appear that revision of Handbooks 44 and 67 and other similar documents would have to take place before any meaningful specialized training could begin.

Standards and Equipment (General).--From preliminary data, it appears that the adaptation of existing standards and equipment or the purchase of new standards and equipment represents the area of greatest impact to state and local weights and measures jurisdictions. ${ }^{8}$ So far as the state laboratories are concerned, only large-capacity weights and provers would be a problem, as small-capacity metric standards and equipment are already available. ${ }^{9}$ The largest impact would be on field standards and equipment, since very few weights and measures jurisdictions have metric field standards.

Mass Standards.-For mass standards (large-capacity laboratory-type and all types of field standards), three possible ways exist to metricate in this area: (1) Purchase of new metric standards. This, of course, would probably be the most expensive way to metricate, especially in the case of large-capacity weights. (2) Purchase of correction weights to use with present U. S. Customary standards so that they will weigh some round metric unit. This would, no doubt, be less expensive than the first possibility. (3) Adaptation of present standards; that is, adjusting the actual weight of standards to some nominal metric value. If this can be

\footnotetext{
${ }^{8}$ The assumption is made here that weights and measures inspectors and metrologists would prefer to use standards and equipment which record in round metric units when testing metric-indicating devices or checking metriclabeled packages, since metric equivalents of U.S. Customary units would be nonround figures. As a result, changes would, no doubt, come about because of this preference, and thus costs would be incurred.

${ }^{8} \mathrm{New}$ state laboratory weights and measures standards and equipment are being provided by NBS via the New State Standards Program.
} 
done at very low cost, this type of metrication would be ideal from a cost point of view for high value items such as large-capacity weights. ${ }^{10}$

Volume Standards.-Metrication in the volume standards area, both in the laboratory and in the field, will consist either of buying new provers or adjusting present ones to nominal metric values. New metric field glassware will be needed. Volumetric glass flasks cannot be adjusted to any nominal metric value. As a result, the metrication costs for jurisdictions who need a lot of glassware will no doubt be rather high. However, preliminary data indicate that it does appear to be technically feasible to adjust large provers, both laboratory and field, to some nominal metric value. If this is proven to be the case, costs for metricating these provers may be kept fairly low. Of course, the present U. S. Customary indicators on these devices would have to be replaced with metric ones. ${ }^{10}$

Package-Checking Scales.-Finally, in the case of packagechecking scales, the present devices may be used to check quantities in the metric system provided the scale is used as a comparison device only. This may be accomplished by (1) setting all poises at the zero indication and (2) adjusting the scale by using metric weights so that the tower indicator always reads zero. Thus, the metric weights would be read in order to find the weight of the unknown item. This procedure could be used until the device could be adapted or until a new one was purchased, and it would also allow the various weights and measures jurisdictions to defray some of their metrication costs by putting off to a convenient time the adaptation or replacement of such scales.

\section{Conclusion}

The Commercial Weights and Measures Survey has tentatively concluded that, even though the problems arising from metrication for device manufacturers and their service agencies and for weights and measures jurisdictions are not insurmountable, they do represent costs, possibly even considerable costs, for the United States.

\footnotetext{
${ }^{10}$ The Engineering and Standards Unit of the Office of Weights and Measures is now studying the feasibility of adjusting or otherwise adapting existing mass and volumetric standards both for laboratory and field use to nominal metric values.
} 
Matt Jennings (Chairman). Director, Division of Marketing Department of Agriculture Melrose Station, Box 9039 Nashville, Tennessee 37204

R. T. Williams, Director Consumer Service Division Texas Department of

$$
\text { Agriculture }
$$

John Reagan Building P.O. Drawer BB Austin, Texas 78711

Trafford F. Brink, Director Division of Standards Department of Agriculture Agriculture Building Montpelier, Vermont 05602
Kendrick J. Simila

Assistant Chief for Weights and Measures

Dairy \& Consumer Services Division

Agriculture Building

Salem, Oregon 97310

James H. Akey

City Sealer of Weights and Measures 400 Myron Street Wausau, Wisconsin 54401

Maynard H. Becker County Sealer of Weights and Measures 3200 North Main Street Los Angeles, California 90031

\author{
Ronald Roof, Metrologist \\ Bureau of Standard Weights \\ and Measures \\ Room B-130, Highway and \\ Safety Building \\ Harrisburg, Pennsylvania 17120
}

Appendix II

Organization of the Task Force on Metrication

\title{
Establishment
}

Under authority granted by the Executive Committee of the 54th National Conference on Weights and Measures, a Task Force on Metrication is hereby established by the Conference Executive Secretary to study the possible effects that increased use or nonuse of the metric system might have on the wieghing and measuring field. 


\section{Function}

The Task Force shall study the problems and costs associated with increased use or nonuse of the metric system in the commercial weighing and measuring field.

\section{Membership}

1. The Task Force shall be composed of members appointed by the Executive Secretary representing the field of weights and measures.

2. Members of the Task Force shall be appointed for the duration of the study unless they voluntarily terminate such membership. In such cases, the Executive Secretary will select appropriate replacements.

\section{Organization}

1. The Executive Secretary shall designate one member of the Task Force to serve as chairman.

2. The Office of Weights and Measures, National Bureau of Standards, shall serve as the secretariat of the Task Force, and as such it will provide clerical, administrative, and technical staff along with the necessary support facilities and materials to assist the Task Force in carrying out its objectives. The manager of the Commercial Weights and Measures Survey, U. S. Metric Study, shall be ex officio the secretary of the Task Force.

3. The Task Force will meet at the times and places designated by its chairman, subject to the advance approval of the Executive Secretary, by means of written notices to the Task Force members.

4. Members of the Task Force will be reimbursed for travel and expenses (per U. S. Government per diem rates) connected with attendance at Task Force meetings.

\section{Procedures}

1. Business will be transacted by the Task Force at meetings and by correspondence and telephone.

2. A majority of the members of the Task Force shall constitute a quorum for the transaction of business. A vote of the majority shall decide any question that may come before the Task Force. If at any meeting of the Task Force there shall be less than a quorum present, those present may act on the business before it subject to ratification in writing by a majority of the members. 
3. The Task Force shall observe in all of its procedures the principles of due process and the protection of the rights and interests of affected parties.

\section{Reports}

1. The Task Force shall submit a report, including any recommendations it may have, to the Executive Secretary not later than November 30,1970 , unless another time shall be established by the Conference or the Executive Secretary.

2. The Task Force may also submit interim reports, data, and recommendations to the Executive Secretary for his infomation, advice, or action.

\section{Termination}

The Task Force shall expire at the close of the 56th National Conference on Weights and Measures in July of 1971, unless it is decided to extend its existence beyond this date.

Harold F. Wollin, Executive Secretary

National Conference on Weights and Measures

April 20, 1970

\section{Appendix III}

\section{U. S. Metric Study}

Established by Authority of the United States Congress (Public Law 90-472) Director: Daniel V. De Simone

Manufacturing Industry

Nonmanufacturing Sector

Federal Government Operations and Responsibilities

National Security

Historical Analysis

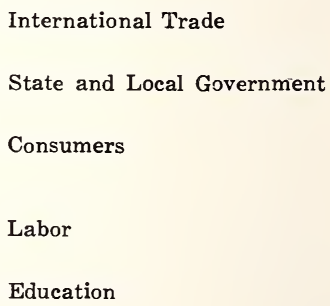


1. What is the present impact within the United States of increasing worldwide and domestic use of the metric system?

2. What would this impact be in the future, assuming that the use or nonuse of the metric system continues as at present, with no coordination among the various sectors of the society?

3. Alternatively, what would be the effect of a coordinated national program to increase the use of the metric system?

Note:

Metrication is defined as any act tending to increase the use of the metric system (SI).

\section{FORUM DISCUSSION}

Mr. H. E. Smith (San Mateo County, Calif.): Dr. Gordon, what is your opinion of the administrative effectiveness of an organization structured with the administration of several diverse functions of government assigned to one administrator? For example, more specifically, what is the effect on weights and measures when a city or county jurisdiction appoints a person who has a background in and an excellent technical knowledge of weed control to administer and control the budgets of several functions of the governmental body, such as his own field, weed control, foreign agent, dog catcher, and weights and measures?

DR. GoRDoN : It seems to me that the question answers itself the way you have presented it. But that is not really the alternative. Some years ago I was teaching in the University of Maryland's Military Overseas Program, and one of the colonels in my class emphasized the number of officers, particularly general officers, who went on into administrative work upon the conclusion of their military service. I was impressed with his point of view that a general officer is really in charge of a complete community and that he has experience, administratively, in administering everything from a hospital to a commissary, to a mess hall, and that this is one reason why such men are subsequently in demand.

This can be carried over into state, county, and city administration. There are people with administrative techniques who do not have to know the details. The details can be delegated. In a sense, this is what the practice is now with 37 Departments of Agriculture. The Commissioner of Agriculture may not know very much about the details of weights and measures, but he certainly can 
delegate to a director the responsibility for the enforcement of state law.

Mr. F. P. Gallo (Ohio) : Dr. Gordon, in your third survey you indicated that 55 percent of the weights and measures officials favored the metric system, whereas in the previous survey the percentage was higher.

DR. GORDON : Yes.

MR. GALLO: Do you have any information at hand to indicate why there might have been a decrease in that percentage favoring the metric system?

DR. GORDON: Well, not really. I can only guess. There has been considerable change in personnel in the intervening period between 1963 and 1969. But the thing that startled me is that, with the change in personnel and with all the talk we have heard about the metric system, one finds fewer at the present time in favor of the metric system than before. No, I must admit that I did not go into this question in depth as Mr. Hatos is doing. Perhaps he will be the one to find that answer.

Mr. D. I. OFfner (St. Louis, Mo.) : I have two brief questions directed to Don Konsoer. First, Don, obviously you must have a different attitude toward an inaccurate device now than you had before 1962, since you shifted the responsibility primarily to the owner. So therefore, my first question is: What action do you take now when you do find an inaccurate device on a sample test as compared to similar findings made before 1962? In other words, how do you implement this greater responsibility placed upon the owner?

My second question: On a slide you indicated an expected 50 percent "accuracy" (without supervision) on store packages. I am not sure what you mean by the term "accurate." In Handbook 44, when talking about an accurate device, you refer to a device that performs within certain prescribed tolerances. But we do not have tolerances on package fill. Are you referring to guidelines of $\mathrm{H}-67$ ?

Mr. KonsoER: In answer to your first question, prior to 1962 there was no effective action we could take when, in response to a request, we tested a vehicle scale, with an outdated approval seal, that had not been tested in over a year and that we found to be inaccurate. Today, we have explained our program to all of the canning associations, feed associations, and other groups that use vehicle scales. When we find a scale inaccurate on the second or third test, depending on past experience, we take the person to court. Before 1962, court cases were very few in Wisconsin.

On gas pumps, we can make a statistical sampling and then say to the company management, "Now look, we know that you own and operate certain stations in Wisconsin. What is your mainte- 
nance program? How often are you getting out there?" Unless they take some broad constructive action, we will go to court against the individual station, not the company of course.

In reply to your second question, the accuracy projection with no supervision is one that we have to work out with our statistical service, because no one really knows what the situation would be if there were no supervision. And when you talk about accuracy projections of store-packed items, there are many variables. Are you talking about total volume? Are you talking about establishments? Particular chains? Independents? We lump this together and consider this a representative figure. Whereas the projected accuracy percentage may not be correct, we have a standard to start with, and we now can judge our programs accordingly. We also apply it universally to our different inspectors. This procedure, it is granted, is not from $\mathrm{H}-44$. We have a slight administrative tolerance.

There is just one other point I would like to mention in addition to your two questions, Dan. We have the Wisconsin forms and literature that hopefully project the responsibility of the owneruser. We will gladly send these to you.

Mr. J. E. Bowen (Newton, Mass.): The theme of the 55th National Conference, entitled the Challenge of the 70's, has so far appeared to be based primarily on consumerism and communication, both of which are necessary, both of which contain merit, and both of which have opened Pandora's box. After nearly four years since the enactment of the Fair Packaging and Labeling Act, there has not been a meeting of minds relative to interpretation thereof between the National Conference, Food and Drug Administration, and Federal Trade Commission.

An interesting conflict was recently experienced in my home state when some member officials of the Eastern Massachusetts Association learned that a Consumer Council had thrown into the legislative hopper a proposal to discontinue mandatory testing and sealing. In response to an inquiry forwarded to the Executive Secretary of the National Conference, it was learned that the Conference had never expressed any view on the desirability of such legislation and that a study of the possibilities of improving administrative procedure would encompass such a study. I was interested to hear Dr. Gordon report that, of 70 percent of the state directors contacted, 70 percent currently oppose this approach.

The proposed legislation was discussed at a meeting of the Eastern Massachusetts Association, and, with the exception of one abstaining vote, was unanimously opposed. Many local weights and measures officials subsequently appeared at the Legislative Committee hearing and opposed it. 
There seem to be two schools of thought on the abolishment of mandatory annual sealing and testing, deeply involving both consumerism and communication. I feel that, in the interest of encouraging uniformity throughout the states, this matter is of such importance that it demands immediate and thorough study without delay.

Mr. R. E. Clark (Springfield, Mass.) : I am presently serving as President of the Weights and Measures Association of Massachusetts. I would like to offer an observation. Now we have geographic boundary lines, and I think they are a thing of the past. Each jurisdiction has its own problems. I feel that the Bureau of Standards should have field agents throughout the country to come in and speak with us at the local level as well as the state level not just on a program of education or a three-day seminar-but come in and say, "What's your problem" or "What can I help you with?" We are just about at the point where 50 states are conforming to Handbook 44. Handbook 44 at this time needs a complete revision. Can't the 50 states come up with uniform administration? Can't we all be the same, at least in weights and measures?

Mr. STABleR: Mr. Shea, will you briefly describe your contact and relationship with the Massachusetts weights and measures personnel? What is your rapport with Mr. Hughes and his group, and do you function cooperatively?

Mr. SHEA: A member of the Council is the Commissioner of Labor and Industries, and under him is the State Division of Standards. From the very beginning, the Council has functioned as a statutory body. The Division of Standards has been a member from its inception, and every recommendation that they have made in this area or have requested has been extremely valuable and of pronounced influence on us. We all cannot agree on everything, but I can say frankly that the Division of Standards and the Weights and Measures Association have been a tremendous help to me in my work in reaching out in the field. I could give you one example after another where the local sealer has written me of problems not exactly in his field, but where he feels that something should be done. I am particularly talking about the sealer from West Springfield and the one from Newton. These sealers have been feeding information to us on deceptive practices even slightly out of their field where they have no jurisdiction.

Mr. M. Greenspan (New York City, N. Y.) : Mrs. Byrne, you are probably aware of our interest in the area of unit pricing in New York City. Has any study been made as to the effect of the increased overhead cost involved in unit pricing? I am not talking primarily of the studies in the supermarkets. These are about $2 \frac{1 / 2}{2}$ percent. In the total picture, what is the increased overhead, and is that increased overhead so great that it will be reflected in increased costs to the consumer? 
MRS. BYRnE: That is one of the reasons unit pricing is still under study. In Chicago, we did not feel at the beginning, when all the discussion began, that it would be fair to promulgate a law on unit pricing because of the small stores involved. By the same token, many of the smaller independent stores, such as Certified Foods, belong to a group organization. The group is now undertaking to do the printout sheets for all their member independent stores. I don't have the actual cost standing.

Mr. SHEA: I think I can add to Commissioner Byrne's statement. The situation is the same in Massachusetts. We do not have a law as of now. I went to the Massachusetts House. It exempts single-owner stores, which would answer part of the problem. This amendment was put in Monday or Tuesday. Whether that will prevail in the Senate, I don't know. The large chains may resent it. Secondly, with regard to the cost, the largest independent grocers and associations have already informed me they will do the printout for their members.

We wanted to make it very clear to the legislature, to the public, and to industry that we intended to do this in a very orderly manner afer a public hearing and gradual phasing-in. We have under our proposed statute a latitude to propose different types of regulations. For example, at the "Mom and Pop" store, maybe a shelf listing would be impractical. The commodities sold are so few in number and, after they are put on the shelf, I doubt that their prices change once a year. 
MR. WoLLIN : I received a communication from the White House yesterday, dated July 10, 1970, which I feel has significance to the discussion this morning, and which I would like to read.

\author{
Mr. Harold Wollin, Executive Secretary \\ National Conference on Weights and Measures \\ Hotel Utah \\ Salt Lake City, Utah
}

I wish to extend my greeting to the officers and members attending the 1970 National Conference on Weights and Measures. As Special Assistant to the President on Consumer Affairs, I have appreciated your cooperation in the past and hope that we may continue to work together closely to assist consumers.

In order that we may cooperate with you more effectively, I am pleased to announce the establishment of a new Division of Federal-State Relations within my office. Emphasis will be on the exchange of information and the development of a strong network of consumer protection at all levels of government.

I hope the national officers and staff, as well as the individual members and their staff associates, will not hesitate to contact our new Division Director, Mrs. Betty Bay, at any time. She will be eager to discuss with each the specific ways we can assist the consumer and with consumer problems in their respective states.

(Signed) Virginia S. Knauer

Special Assistant to the President for Consumer Affairs

Mr. R. W. Richards (Pennsylvania) : Mrs. Byrne, we in Pennsylvania are presently examining the possibility of merging our State Bureau of Weights and Measures and our State Bureau of Consumer Protection. For very good reasons, we believe, we have made a recommendation not to intermix the duties of the various investigators or inspectors of the two agencies. The weights and measures inspector in our state is involved in legal, technical matters. The investigator of the Bureau of Consumer Protection is involved in matters legal and contractual.

In the first case, our weights and measures inspector must be able to contend with about five state laws in weights and measures, plus a number of technical publications from the National Bureau of Standards, including Handbook 44. On the other hand, our Consumer Protection investigators must cope with five basic laws on consumer protection, including our Installment Sales Act, our Consumer Protection Act, our Real Estate Act, and automobile sales, plus a great number of provisions in our criminal code such as those dealing with advertising. 
I was intrigued by your comment that you had one inspector assigned to your neighborhood units. Does this mean he intermixes duties between weights and measures and consumer protection activities? If so, what effect does his assignment to his dual responsibilities have upon weights and measures supervision in that assigned district, such as device control and package control?

MRS. BYRNE: All of our inspectors perform the same duties. It is not just that one man. The Corporation Council does our legal work as in any city. If a violation is found or a complaint is called in, we'go out and investigate it.

Our Department has a law that deals with misrepresentation, and all inspectors have police powers to enforce that law. A complaint goes first to the Corporation Council for prosecution in the Circuit Court. If the Corporation Council says the complaint comes under the jurisdiction of the State's Attorney, it is given to the State's Attorney. Any legitimate complaint is given to whoever can best prosecute it.

MR.RICHARDS: Your inspectors are still working for weights and measures? I was thinking they were not.

MRS. BYRNE: Our inspectors are still engaged in the work of weights and measures.

Mr. J. C. MAYs (Dade County, Fla.): My question is with regard to advertising and your method of enforcement, specifically in regard to merchandise advertised short in supply. Do you have a raincheck system in effect?

MrS. ByRne: Our law on advertising is, I believe, very fair and equitable. If we receive complaints that an advertised item is not in a store, one of our inspectors will go to the store and attempt to buy the advertised item. If it is not available, the inspector may ask when the item will be available and request a raincheck. If the item continues to be advertised and he returns at a later date to buy the item and it is still not available, we will then issue a citation and go to court. In our view, this would constitute contempt. The raincheck system is not compulsory; it is purely voluntary. However, under our law a store may not continue to advertise items that are not available.

MR. STABLER: I have a question for Dave Edgerly. What can a state or local jurisdiction do to prepare for the day when it will have available a computer or computer service? What can be done to prepare for this eventuality?

MR. EDGERLY: I think this is a very relevant question, because many of the state's administrators- now are in a position where computer technology, although available in the state government, has not really come down to their level yet. But I do not think that you should recognize this as an opportunity for you to sit back and wait. I think I can give you a particular instance in Virginia with 
Jim Lyles. When he learned that the computer was going to be available to weights and measures, he called us, knowing that we had just established a program to find out what could be done.

I might add, before the computer people from the Department of Agriculture got to Jim to ask him what he could do, Jim got to them telling them what he wanted to do. This has drastically reduced the time it is going to take us to get Jim and his program converted into the use of the computer. We have written some sample programs, and we have met with Jim and his people and discussed what they want in the way of a data processing program. Considerable red tape can be avoided by having the administrator state what he needs rather than waiting to have the systems analysts come and say, "What do you want?"

Mr. GREENSPAN: We were involved in a very small automatic data processing program six years ago and we have had some pretty horrible experiences. I would like to relate this to the people assembled here so that they do not fall into the trap that occurred in New York. We started out with a very minor program without really thinking out the total picture. As a result, we acquired hardware that was limited in its potential. As we worked with this hardware, we realized that we were not even scratching the surface, and also that the potentials with better hardware would be much greater. However, once having been committed to this system, we found that a change at this point became ten times more difficult and expensive than if we had thought out the problem, taken our time, analyzed it, sought outside help, and established a well-rounded program before we even attempted the first step. I think this is a word of caution to everyone present who contemplates the use of automatic data processing.

MR. S. D. ANDREWS (Florida) : I would like to direct this question to Don Konsoer, with a side question to Dr. Gordon. First of all, Don, you spoke of "administrative tolerances" adopted in the State of Wisconsin. I would like to ask if these are used in the field to judge whether or not packages or lots of packages are to be placed off sale or are only for administrative purposes in statistical work in evaluating the program?

Mr. KONSOER: Well, the tolerance that we do use on packages (these are store-packed items), is a fraction of a percentage, and I would just as soon not give it out. But we do not want our inspector out in the field making a statistical sampling of 49 packages and determining whether the lot is going to be over or under, based on the last package. In other words, we do not want our field inspectors ordering something off sale until the percentage, a fraction of the percentage, is a certain amount under. If they find it just any amount under, they will advise the packer and the store; but before they order it off sale, there is a certain amount, a 
fraction of a percentage, that we require them to have before they tell the store owner it is off sale. That is our policy. We follow Handbook 67 all the way through.

Mr. ANDREWS: This really leads to my principal question. As a result of the rather well publicized citation on five of the largest supermarkets in the State of Florida for short-weight packages, they are now asking our State Commissioner of Agriculture, who is our chief administrative officer, to sit down in conference with them and set up tolerances which will be published in the future. This, of course, we are resisting as advised in Handbook 67. But this is going to be a difficult thing to resist, because there is a certain element of reasonableness in their request. They want the same consideration that we give to scales when we set up tolerances. The question I had for Dr. Gordon was: In your survey, Dr. Gordon, did you have any evaluation from the states as to how many have actually published tolerances for packages?

DR. GoRDon: I cannot give any figures offhand. I do recall that some of the states have legal tolerances for packaged loaves of bread.

Mr. ANDREws: Unfortunately, our law says "reasonable variations" and "tolerances," and so these people are asking us to carry out only what the law specifies.

Mr. STABLER: Dr. Gordon, what is the intent of the survey and what will be the ultimate distribution of your survey data?

Dr. GoRdon: The intent of the survey is the same as the first and the second, to ascertain the facts concerning state legislation, administration, and enforcement, and to publicize that information in the hope that it may be helpful to men in your position in upgrading your laws, in improving your administration, and in strengthening your enforcement. I have had many evidences during the years that I have been engaged in this voluntary work that the material I have provided has been very helpful; for example, to help upgrade salary scales. The availability of it will be the same on this survey as the last one. The survey was sponsored by Consumer's Union. They gave the financial support, and they now have the manuscript of approximately 200 hundred pages, together with supporting statistical evidence. This will be ready, I judge, in four or five weeks, and will be available from Consumer's Union, Mt. Vernon, New York.

Mr. J. R. Bird (New Jersey): Mr. Shea, in the last page of your paper you said that many weights and measures administrators have forgotten their public interest and, in effect, were working for private industry. I am wondering, after your attendance at this Conference, you still believe this. I have attended 13 Conferences myself, and I have never believed this. If you had the time to 
read our 53 Conference Reports, you would see a great indication of the interest that the administrators have had.

MR. SHEA: I seem to be referring to emphasis rather than suggesting improper conduct. Many communities have industrial firms, and the state itself works with these industrial firms, and this is a lot of time, effort, and money. I am not talking about state money, public money. What I am talking about is the failure to go into a random marketplace for the average consumer. That was probably very poorly expressed by me, but that was what I was trying to paraphrase by my remarks. I am perfectly aware of the dedication of many of the sealers. I am also aware of our laws that have developed into somewhat of a straight-jacket by overemphasis on the industrial aspect. When I think of testing in the local marketplace, the average consumer is much more important.

To give you statistics in Massachusetts compiled by the sealers of weights and measures, they checked 138,285 weighing and measuring devices in 1968, and 1.8 percent were condemned because they were not accurate. A good percentage of that amount were scales that in many instances were slow and, therefore, against the user. The Division of Standards in its policing program found 25 percent of the prepackaged items deficient of purported weights, and consequently overpriced. It would seem to me, then, that at the time these weights and measures were inspected additional effort should have been directed to determine whether or not the items were of correct weight at the time of sale. I am talking, of course, from the consumer viewpoint, as I explained before when I spoke.

A VoICE: Mr. Konsoer, how many men were used prior to 1962 in testing equipment, and how many went to packaging?

Mr. Konnsoer: Prior to 1962, Wisconsin did not have a strong packaging program. Today, we try to spend at least 50 percent of our time on packages, bulk weighing, and so forth. I do not think that there was a real shift to one area or the other. On vehicle scales, we had two trucks, and we still have two trucks. Today, we are testing vehicle scales that we feel need testing, rather than those the user wants tested. In the device area, I think we have moved away from the prepack scale. We test these only on rare occasions. We spend more time checking packages. We are doing a little bit more in the areas of buying, purchasing, and so forth, and probably not spending as much time on the computing scale. But there has not really been a dramatic change, you might say. We are still out there testing; we are still out there checking packages. Basically, we are directing our efforts toward the devices and packages, where we feel we have the most impact and do the most for the consumer in our state. 
Mr. L. L. Elliott (Everett, Mass.) : Mr. Konsoer, has your plan provided adequate testing and servicing by the private companies, and what is the cost of these services to the owner of the devices?

Mr. Konsoer: In answer to your first question, I think in some areas adequate service is available. I might cite the vehicle-scale area. When our program started, we had three privately owned units in Wisconsin; today we have 20. Some of the companies do a very, very good job. Some users have met with their managers and have contracted across the state with a couple of the different service agencies, such as Fairbanks, Toledo, and others. In this contract, they spell out exactly what services they will get for a test. As for the cost, this is something that I can speculate on. I believe that many of the scale companies are charging from $\$ 35$ to $\$ 50$ a visit. If we move our state truck out there with our men, it certainly costs us a great deal more than this. In fact, in one of our smaller units, we projected the cost between $\$ 50$ and $\$ 100$ a day just to put a man on the road with his equipment, plus the administrative cost.

In some areas the service has not really developed as well as we would like to see it. I think in LP Gas we have made some strides. We have four units that are working through the state, but due to the limited number of meters these companies move through quickly and then return to Omaha. We have some service companies working out of St. Paul, Minneapolis, some out of Illinois, and one is based in Wisconsin. Sometimes service may be slow because there just is not the market.

Another particular area is in pharmaceutical balances. We can reject the device and it will be serviced. Again the service is a little bit better, but not as good as we would like to see. You go to some of the main metropolitan business areas in the Midwest, and you will get service on pharmaceutical balances; but it is different in the Far North. It just is not advantageous for a serviceman to move out there and take care of this balance and charge a reasonable fee; so he has to work it on a route basis.

Mr. EDGERLY: There has been considerable discussion this morning about selective testing and about the responsibility of accuracy in weights and measures being that of the device owner. This is a personal observation, but I do not think that we can be absolutely sure that selective testing or putting the responsibility of the device on the owner is the ultimate solution to the problem of the increased population of devices and activities in weights and measures.

There are arguments pro and con. Some people will say that this is the only solution to the workload facing us. Other people will 
say that selective testing is the only means, and that you do the best with what you have and that really is all that it gives you. What I am saying is that I think we should move cautiously. In this decade, especially with the use of automated data processing equipment, we can considerably cut short our workload, and I think that we should not lose sight of the alternatives to handling the job that we have at hand, other than the selective testing.

MR. STABLER: We have come to the conclusion of this particular session. There are important reports and announcements to follow. I want to take this opportunity to thank Mrs. Byrne, Mr. Shea, Dr. Gordon, Mr. Konsoer, Mr. Edgerly, and Mr. Hatos for their interesting presentations and for the professional way in which you fielded the questions from the floor, the effort required in the preparation of your papers, and then traveling the long distance to Salt Lake. 
C. Wooten, Vice Chairman, Presiding

(Thursday's afternoon session was devoted to reports of the Conference committees.)

\section{REPORTS OF THE CONFERENCE COMMITTEES}

\section{REPORT OF THE COMMITTEE ON LIAISON WITH THE NATIONAL GOVERNMENT}

Presented by J. H. Lewis, Chairman, Chief, Weights and Meassures Section, Dairy and Food Division, Washington Department of Agriculture

(Tuesday, July 14, 1970)

\section{General}

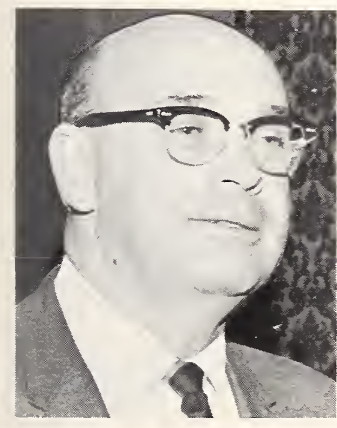

The Committee on Liaison with the National Government submits its report to the 55th National Conference on Weights and Measures. The report consists of the tentative report, transmitted in April as part of the Conference Announcement as amended by the final report.

The report represents recommendations of the Committee that have been formed on the basis of written comments received during the year and oral representations made during the open meeting of the Committee. The Committee intends to maintain the line of communications already established with Federal agencies and to aggressively pursue all matters involving Federal and State relations in the weights and measures field.

\section{Relations With Federal Regulatory Agencies}

During its interim meeting, the Committee received a report from the Office of Weights and Measures concerning relations with the Food and Drug Administration, the Federal Trade Commission, the U. S. Department of Agriculture, and the Alcohol and Tobacco Tax Division of the Department of Treasury. The report covered the status of various regulations and proposals currently underway in those agencies.

The Committee sent letters to the Food and Drug Administration and to the Federal Trade Commission applauding their favor- 
able ruling on the Conference's views on the labeling of multi-unit packages. Additionally, in response to communications from State and local officials concerning the need for prompt interpretive rulings, the Committee met with officials from FDA and FTC during the Conference and discussed establishing a mechanism for the issuance and wide circulation of such rulings. It is the opinion of the Committee:

1. That the mechanism for interpretive rulings has been established in the labeling manuals disseminated by FDA, FTC, and that soon to be disseminated by OWM.

2. That interpretive bulletins establishing labeling precedence will be disseminated widely using the manuals and the means of information dissemination available to OWM.

3. That individual labeling problems encountered by the States should continue to be sent to FDA and FTC for interpretive rulings.

4. That what is additionally needed is a concerted effort on the part of the States to further disseminate to local officials such information as is received from Federal agencies.

The Committee also sent a letter to the Department of Treasury concerning their recently published regulations under the Federal Alcohol Administration Act, applauding the efforts of that Department in achieving "some degree of conformity with the Model State Packaging and Labeling Regulation" in the labeling of distilled spirits. The letter also urged that the same consideration be given when publishing regulations on the labeling of wine and malt beverages.

The Committee heard from the Office of Weights and Measures that the U. S. Department of Agriculture plans to republish, as a proposal, Part 317, Labeling, of its Meat Inspection Regulations, and to also publish proposed Poultry Inspection Regulations. The Committee authorized OWM to prepare a letter for the Committee commenting on the proposed regulations as soon as they are published.

The Committee received written comment during the year concerning possible conflicts between new amendments to the Interstate Commerce Commission rules and many State laws governing the shipment of household goods. The Committee is of the opinion that there appears to be conflict between weighing practices sanctioned by the ICC and those practices of many of the States. Accordingly, the Committee has authorized OWM to study the extent of the conflict and, if warranted, to prepare a letter for the Committee to ICC urging adoption of rules consistent with those of the States.

The Committee also received written comment during the year concerning the need for the development of test equipment and 
procedures for the verification and control of noise-monitoring systems by weights and measures authorities. The Committee is not convinced that this is a weights and measures problem; however, it will retain the item on its agenda for further study and consideration.

Weights and Measures Enforcement on Federal Establishments

\title{
1. Military Installations
}

In response to meetings with top officials of the Office of the Assistant Secretary of Defense (Manpower and Reserve Affairs), plans have been completed for a DOD sponsored program of cooperation with State and local officials to permit weights and measures enforcement in military bases and installations. The DOD memorandum establishing military personnel policy was submitted to the respective Armed Services on June 8, 1970, and is presented herein in its entirety:

\section{ASSISTANT SECRETARY OF DEFENSE}

WASHINGTON, D.C. 20301

\author{
MANPOWER AND \\ RESERVE: AFFAIRS \\ (Military Personnel Policy)
}

MEMORANDUM FOR The Assistant Secretaries of the Military Departments (M\&RA)

SUBJEC'T: Weights and Measures Enforcement in Resale Activities at Military Installations Within the United States.

By letter of 12 September 1969, to this office, the Assistant Secretary of Commerce recommended that a policy be developed to provide weights and measures supervisory services to the people who purchase at retail from Armed Services commissaries and the resale outlets.

Accordingly, this office has indicated to the National Bureau of Standards its willingness to implement a program of weights and measures enforcement in resale activities, such as military commissary stores and exchanges, at military installations within the United States, including the District of Columbia. Such program will, as a minimum, provide for required checks of weighing and measuring devices used in serving resale activity patrons together with appropriate checks of accuracy of stated weights and price computations on labels of foodstuffs or goods packaged by store personnel.

Attached are copies of a List of State, Commonwealth and District Weights and Measures Offices of the United States, prepared by the Office of Weights and Measures, National Bureau of Standards. Each Military Department is requested to direct the commander of each of its installations within the United States to contact the office having general cognizance of the area in which the installation is located. 
In making this contact, the installation commander should arrange for an on-site visit by the weights and measures officials for the purpose of evaluating existing weights and measures enforcement program currently being conducted at the installation or determining what steps must be taken to implement an effective enforcement program.

At such prefatory meetings, military commanders should determine:

1. Extent to which these official agencies carry out inspections or checks with their own personnel.

2. Costs, if any, associated with inspections or checks utilizing the official agency's personnel.

3. Extent to which commercial firms must be utilized in carrying out inspections or checks.

4. Costs involved in inspections or checks by commercial firms.

5. Steps required to facilitate inspections and checks, including access to military installations and resale facility on an unannounced basis where possible or with a minimum of delay.

6. Procedures to be utilized in the reporting of inspections and checks, including deficiences found and recommendations for corrective action when required.

Any costs incurred in the carrying out of such inspections and checks are to be considered as operating costs and be borne by surcharge or markup funds in the case of military commissary stores. In the case of military exchanges the costs will be borne by funds generated from exchange sales.

Leo E. Benade

Major General, USA

Deputy Assistant Secretary of Defense

Attachment

The Committee recognizes this important step toward progress in relations with the Federal Government in the weights and measures field, and has prepared and submitted to the Committee on Resolutions a request that a resolution be adopted applauding the action of the Department of Defense. The Committee also wishes to strongly urge the support of this joint endeavor by all weights and measures officials, and has authorized OWM to prepare and circulate a listing of military resale activities and their locations throughout the United States, so that officials can begin planning for inspection programs in these installations.

\section{Post Offices}

The Committee discussed communications during the year with the Post Office Department concerning possible assistance in the inspection of postal scales currently used in commerce. Acting in behalf of the Committee, OWM completed a limited survey of the condition of postal scales in the Washington, D. C. area. The survey did not reveal conclusive evidence of the need for an immediate assistance program; however, on the basis of comments re- 
ceived from delegates during the open meeting and in light of the success of the program with the Department of Defense to participate in a joint $\mathrm{DOD} /$ weights and measures inspection program, the Committee is of the opinion that formal communication should be established with the Postal Department to actively pursue such a program. Accordingly, the Committee directed its secretary to prepare a letter to the Post Office Department on this matter.

\section{National Bureau of Standards Enabling Act}

It is the recommendation of the Committee that the National Bureau of Standards actively seek to extend its Enabling Act to include specific responsibility to promote uniformity between laws, regulations, and practices, adopted by Federal agencies and bearing on weights and measures enforcement.

\section{Fair Packaging and Labeling Act Manual}

The Committee received a report from the Office of Weights and Measures that a manual has been prepared incorporating all Federal regulations adopted under the Fair Packaging and Labeling Act, together with the requirements of the Model State Packaging and Labeling Regulation. The manual has been published in a limited first edition run of 250 copies. These 250 copies will be circulated to State weights and measures officials and selected industry and trade association executives by August 1 for a period of three months, during which time comments will be requested as to format and utility of the manual. Once all comments have been received and necessary revisions completed, the manual will be submitted as an NBS Special Publication available for sale to the general publjc through the Superintendent of Documents. 
The Committee believes that its title would be more explicit if it were changed by substituting "Federal" for "National" so as to read Committee on Liaison with the Federal Government. It has recommended that the Executive Committee approve this change and offer it as a proposal to amend the Conference Organization and Procedure.

J. H. LEWIS, Chairman

M. GREENSPAN

R. C. PRIMLEY

A. SANDERS

E. E. WoLSKI

H. F. Wollin, Secretary

D. E. Edgerly, Staff Assistant

Committee on Liaison with the National Government

(On motion of the Committee Chairman, seconded from the floor, the report of the Committee on Liaison with the National Government was unanimously adopted by voice vote.)

\section{REPORT OF THE COMMITTEE ON EDUCATION}

Presented by G. E. MatTimoe, Chairman, Deputy Director, Division of Weights and Measures, Hawaii Department of Agriculture

(Thursday, July 16, 1970)

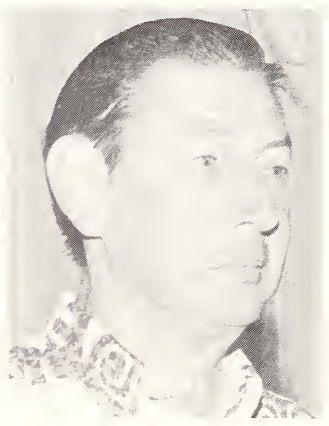

The Committee on Education submits its report to the 55th National Conference on Weights and Measures. The report consists of the tentative report, transmitted in April as part of the Conference Announcement, as amended by the final report.

The theme of this year's Conference, "The Challenge of the 70's," seems most appropriate as we ponder the role of the Committee on Education. Last year it was reported that the Committee was at a crossroads and desired guidance on its future. In a spirit of revitalization, the Committee traveled to Washington in February for an interim meeting, which resulted in a renewed dedication to this important work in weights and measures. 
During the interim meeting, the aim of the Committee on Education was analyzed and the areas in which the Committee can be useful were evaluated. With the support of weights and measures officials throughout the country, the Committee feels it can become a vital segment of the National Conference and can render an important service to consumers, business and industry, and weights and measures officials. However, such support must be demonstrated not only during the annual meeting of the National Conference, but throughout the year.

\section{Seminar on Computer Technology in Weights and Measures}

In recent years weights and measures jurisdictions have taken an interest in the computer and its ability to store, recall, and manipulate large masses of data. On February 6 the Committee hosted a seminar attended by several state officials and representatives of the National Bureau of Standards to discuss the extent of current involvement in electronic data processing and to explore what future role the Committee on Education could play in helping the States to realize the full potential of the computer in weights and measures administration.

The Committee was advised that Hawaii has developed an electronic data processing program for its several enforcement activities, and that material detailing this program will be available during the Conference for interested state officials. The Committee also learned that the Office of Weights and Measures of the National Bureau of Standards is developing a program that will offer State administrators assistance in planning and implementing enforcement programs that will make the most judicious use of available resources and manpower. This program of systems research and analysis will include assistance, where applicable, in adapting to electronic data processing.

The seminar concluded on a note of appreciation to the States of Hawaii, New Jersey, Pennsylvania, and Virginia for their initiative in exploring the application of computer technology to their programs and for their willingness to avail the Conference of their progress in this area.

Additionally, the Office of Weights and Measures was asked by the Committee to study and evaluate those EDP programs currently proposed or in operation in the states and, on the basis of such study, to consider the development of formats for writing computer programs in the weights and measures field. The Committee felt that the establishment of such formats would serve to foster uniformity in weights and measures computer programs and, at some future time, allow for the study and analysis of weights and measures problems on a national scale by permitting 
the interchange of electronically stored data between the states and the National Bureau of Standards.

The Committee received a recommendation, which was discussed and endorsed during the open meeting, to establish a subcommittee to coordinate and lend direction to the application of the computer in weights and measures administration. This subcommittee would serve a minimum of two years and would be responsible for (1) surveying and determining the extent of programs now in operation at the state level, (2) establishing goals for computer usage, and (3) establishing standards for design of computer programs, including programming, coding, language, operations, and input and output parameters. The members of the subcommittee will be chosen by the chairman of the Education Committee.

\section{Consumer Protection}

Weights and measures officials, by the very nature of their activities, have been deeply involved in consumer protection. Those jurisdictions that have maintained a judicial balance in their laws and regulations by enacting the Model Law and promulgating the Model Regulations have done much to protect the consumer without prejudice to the rights of the producer.

But this Committee is now vitally concerned over the effect of the overt encroachment of consumer protection movements upon the lasting efficiency of weights and measures operations. This concern is not directed to the consumer protection movement per se, but to those jurisdictions that forsake the strength of untiy for the more immediate glamour of acting independently, with the result that uniformity in weights and measures administration is jeopardized.

No need would have existed, nor could any legitimate reason have been cited, to substantiate enactment of such fractionated weights and measures enforcement as is now embodied in the Fair Packaging and Labeling Act, had weights and measures enforcement in this area been a truly uniform and national effort at the state level. The Committee desires to go on record as strongly recommending the immediate adoption by all jurisdictions of all National Conference Model Laws and Model Regulations.

The National Conference on Weights and Measures, with 50 States alined in a national effort, is a potent influence on future legislation and expansion programs involving both weights and measures and consumer protection, and is the organization that is by far the best equipped to assure the orderly implementation of such programs. 
One of the benefits of the National Conference on Weights and Measures is the exchange of information among the states. At one time all of the states represented at the Conference made oral reports to the Conference delegates concerning their weights and measures activities. Later, instead of oral reports, the state jurisdictions submitted written reports to the Office of Weights and Measures in advance of the Conference which were incorporated into a pamphlet and distributed to the Conference delegates. This practice was discontinued several years ago. However, the Committee now believes that it would be beneficial to reinstate this procedure, and the Executive Secretary was instructed to contact the States for the purpose of preparing such a pamphlet.

\section{Home Study Course}

In its report to the 54th National Conference, the Committee indicated that it would undertake the preparation of an advanced Home Study Course. The Committee announced in its tentative report that the course would be made available at the 55th Conference. The Committee is pleased to announce that the course is currently in its final revision and notice of its availability will be announced shortly after the Conference. Subjects included in the course will be the Metric System, the Model Law, the Model Package Regulation, Handbook 82, Handbook 44, and Handbook 67.

The Committee feels that the Home Study Course offers an effective means of self-education for weights and measures officials. All officials are encouraged to take advantage of this course.

\section{Uniform Telephone Listings and Numbers}

The Committee has had several contacts with the Telephone Company officials concerning a uniform listing and also a national uniform number for all weights and measures offices. The idea of a national uniform number was appealing, but found to be "too ambitious."

The Telephone Company did offer a plan for a uniform statewide listing. The plan, called "Enterprise Service," may be described briefly as follows: The telephone number of each state weights and measures office would be listed in directories of cities and counties throughout the state when there was no local weights and measures listing. Thus, a troubled consumer in any part of the state could call directly to the state office at no charge to the caller. 
The cost for this service is $\$ 3.00$ per month plus the cost of the incoming calls and directory charges. For further details, officials should contact the telephone company in their jurisdictions.

The Committee feels that it is the responsibility of each State Director to monitor the matter of uniform telephone listings and numbers. It is recommended that effort should be made to have weights and measures offices in all jurisdictions listed under the W's-Weights and Measures. Where the weights and measures office is combined with another department, we suggest a dual listing. This will help retain the identity of weights and measures.

\section{National Publicity}

Publication of "The Weights and Measures Men-A Pamphlet for Consumers" has provided the weights and measures profession with some outstanding publicity during the past year.

The pamphlet was reprinted in its entirety by the National Canners Association in "Roll Call-The Newspaper of Capitol Hill." This newspaper is read by thousands, including members of the House and Senate, congressional staff lobbyists, business representatives who visit Congress, and many top government officials.

Margaret Dana distributed 5,000 copies of "The Weights and Measures Men" through her syndicated consumer column. The Office of Weights and Measures distributed 20,000 copies to officials during National Weights and Measures Week, and sent numerous copies on request to colleges, universities, civic organizations, and consumer groups. Incidentally, the Committee discussed plans for the preparation of other pamphlets of this nature in the future.

The Committee cannot overemphasize the important contributions of Mrs. Margaret Dana in her syndicated columns "Before You Buy" and "Consumers Question Box." Mrs. Dana has great influence on consumers throughout the country, and her "publicity" for weights and measures is sincerely appreciated by the Committee and, for that matter, by weights and measures officials everywhere.

On September 24, 1969, the Committee sent a press release to weights and measures officials concerning the responsibility of the states for packaging and labeling requirements for consumer commodities not covered under the Fair Packaging and Labeling Act. Most jurisdictions distributed the release to the news media, and excellent coverage was received. Many states indicated a desire for more press releases of this type. 
The Committee acknowledges with great satisfaction the expanding content and distribution of the "Tech Memo" that is prepared by the Office of Weights and Measures. The Tech Memo is now published about every other month and is received by approximately 1,000 officials. We urge any weights and measures official who is not now receiving the Tech Memo to write to the Office of Weights and Measures and get his name added to the mailing list.

The Committee also discussed the desirability of having established a "slide file exchange program" that would be coordinated by the Office of Weights and Measures. Many weights and measures officials have an excellent selection of slides that are used for talks or program reviews. The Committee suggests that duplicate copies of appropriate slides and slide series be sent to OWM to be catalogued into their master slide file. Such copies can then be loaned to other jurisdictions for their reference and use.

\section{Method of Sale of Commodities}

The Committee considered the possibility of publishing informational guidelines concerning the proper method of sale and labeling of commodities. Cooked ready-to-eat poultry and beef sold by hanging (gross) weight are two good examples of commodities that represent problems and for which guidelines are needed.

The guidelines, published in sheet form or as pamphlets, would be based on the Model Law and Model Packaging and Labeling Regulation. They would be developed with the cooperation and assistance of the Committee on Laws and Regulations. Distribution could be made to the states and to the operators of franchised outlets, restaurant associations, supermarkets, and the like. Bearing the imprimatur of the Conference, such guidelines should have a strong impact on those concerned and should help put an end to the confusion that exists in these areas. The Committee will develop a list of commodities and a recommended method of sale of these commodities for consideration during its interim meeting next year.

\section{Problems in Railroad Weighing}

Last December the Committee's attention was called to various problems in railroad weighing practices by the Colorado Weights and Measures Department. It was decided to hold a joint interim meeting of the Committee on Education and the Committee on Specifications and Tolerances for the purpose of discussing the 
matter with officials from the Association of American Railroads, the Scale Industry, and the Western Weighing and Inspection Bureau. A very informative meeting was held on February 4, and topics discussed included the frequency of checking and restenciling tare weights on railroad cars, the testing and accuracy of railroad scales, the role of the weighing bureaus, and weight agreements.

Mr. C. A. Lauby, Executive Vice Chairman, Operating-Transportation Division, AAR, agreed to get a memo out immediately to all railroads urging them to step up their efforts in the frequency of checking and restenciling tare weights on their cars.

Subsequent meetings have been held between the National Bureau of Standards and industry and railroad officials regarding plans for a cooperative study of this entire area, including electronic scale weighing, both static and in-motion. The National Bureau of Standards Research Associate Program was discussed as a possible approach to this problem. Under the terms of this program, an industry engineer (from either the scale or railroad industry, or both) would be sent to the National Bureau of Standards for a stipulated period of time to conduct the study in cooperation with NBS staff members. Mr. Lauby of AAR indicated that he would survey the industry officials to determine the level of interest by the industry in a program such as this.

The Committee appreciates the cooperative spirit exhibited by the railroad industry in this important area of commerce.

\section{National Weights and Measures Week}

Mr. Earl Prideaux of the State of Colorado, who accepted the responsibility of chairing this important subcommittee, demonstrated outstanding enthusiasm and initiative in the promotion of National Weights and Measures Week. All but three states and many local jurisdictions have reported a keen interest in the "Week." Most states have appointed one man to coordinate the activities of all jurisdictions within the State.

The states were requested to bring to Salt Lake City a National Weights and Measures Week album outlining their promotional activities. Space was made available to display this material, thus giving weights and measures officials a chance to exchange ideas. Prizes for the three most outstanding efforts were awarded to $\mathrm{Mr}$. Prideaux of Colorado, Mr. Richards of Pennsylvania, and Mr. Konsoer of Wisconsin.

The Office of Weights and Measures reports that 20,000 weights and measures men pamphlets, 15,000 third man posters, and 1,500 newspaper mats were distributed this year. The total demand more than doubled the actual number sent out. This suggests that 
perhaps the budget of the Committee on Education should be increased to satisfy the needs of supply and demand.

The suggestion of the Associate Membership Committee for more industry participation in National Weights and Measures Week is in line with the thinking of the Education Committee. Their help is invited and encouraged.

The National Conference of Standards Laboratories, a nonprofit organization, has expressed interest in combining their efforts with this Conference in promoting National Weights and Measures Week.

Its membership consists of academic, scientific, industrial, commercial, and government laboratories concerned with the measurement of physical quantities, calibration of various types of standards and instruments, as well as the development of standards of practice.

After careful consideration, the Committee is of the opinion that, because of their closely related interest and activity, they can provide valuable assistance in the promotion of the National Weights and Measures Week. We therefore recommend that this Conference inform the NCSL that their support and assistance will be greatly appreciated.

\section{Change of Name}

It was mentioned during the interim meeting that the word "education" did not fully relate to the total scope of the Committee's endeavors and that the name of the Committee be changed to more clearly identify its role. A weights and measures official suggested a more appropriate and descriptive name-Committee on Education, Administration, and Consumer Affairs. The Committee feels that this suggestion is an excellent one. Officials present during the open committee meeting responded favorably and encouraged further expansion in these areas.

The Committee recommends that the Executive Committee approve this proposed change.

\section{Metric Education}

The U. S. Metric Study will report to the Congress before August 9,1971 . The Committee feels that if the report recommends adoption of the Metric System, weights and measures officials will play a role in the area of public education. How active that role will be depends upon the planning and preparation of guidelines and materials at the national level and the implementation of such guidelines at the state and local levels. 
The Committee will work closely with the Weights and Measures Metric Task Force during the coming year in this vital effort.

\section{Registration Fee}

The Committee recommends that the Executive Committee consider increasing the Conference registration by $\$ 5.00$, for a total of $\$ 25.00$, this additional income to be used in part for promoting National Weights and Measures Week and financing other projects undertaken by the Committee.
G. E. Mattimoe, Chairman
J. I. MOORE
B. A. Pettit
E. PRIDEAUX
W. I. THOMPSON
H. F. WoLlin, Secretary
R. L. KOESER, Staff Assistant
Committee on Education

(On motion of the Committee Chairman, seconded from the floor, the report of the Committee on Education was adopted by voice vote.)

\section{REPORT OF THE COMMITTEE ON SPECIFICATIONS AND TOLERANCES}

Presented by R. Rebuffo, Chairman, Chief Deputy State Sealer, Bureau of Weights and Measures, Department of Agriculture, State of Nevada

(Thursday, July 16, 1970)

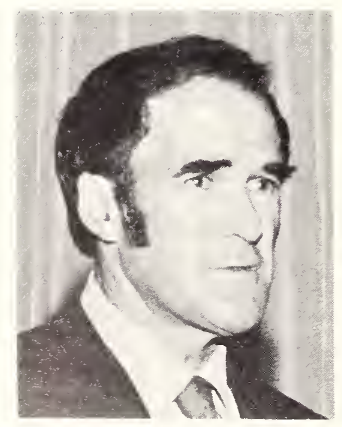

The Committee on Specifications and Tolerances submits its report to the 55th National Conference on Weights and Measures. The report consists of the tentative report, transmitted in April as part of the Conference Announcement, as amended by the final report.

The report represents recommendations of the Committee that have been formed on the basis of written and oral comments received during the year and oral representations made during the open meeting of the Committee. All recommended amendments are to appropriate provisions of the codes of $\mathrm{Na}$ - 
tional Bureau of Standards Handbook 44, 3d Edition, Specifications, Tolerances, and Other Technical Requirements for Commercial Weighing and Measuring Devices.

\section{General Code}

1. In most cases, whenever regulations are promulgated by an authority, a future enforcement date is stipulated to allow affected parties time to comply. The Committee agrees with the several suggestions it received concerning the need for establishing effective enforcement dates for amendments to Handbook 44 and recommends the following addition to the General Code:

G-A.7. EFFECTIVE ENFORCEMENT DATES OF CODE REQUIREMENTS. -Unless otherwise specificed, each new or amended code requirement shall become effective, and be subject to enforcement, on January 1 of the year following its adoption by the National Conference on Weights and Measures and publication by the National Bureau of Standards.

It was suggested during the open meeting that this new paragraph was in need of clarification. It is the Committee's view that the key phrases "unless otherwise specified" and "each new or amended code requirement" clearly indicate the intent of this provision. The Committee recommends amendment to the code as per the tentative report.

(The foregoing item was adopted by voice vote.)

2. G-S.5. Indicating Elements and Recorded Representations.The Committee believes that certain changes in this section are desirable and necessary to adequately cover the range of needed requirements dealing with indicating and recording elements, graduations, indications, and recorded representations. Accordingly, the Committee recommended in its tentative report the following amendments :

\section{G-S.5. INDICATING AND RECORDING ELEMENTS.-}

G-S.5.2. GRADUATIONS, INDICATIONS, AND RECORDED REPRESENTATIONS.

G-S.5.2.3. SIZE AND CHARACTER.-In any series of graduations, indications, or recorded representations, corresponding graduations and units shall be uniform in size and character.

In the open meeting the Committee heard an alternate suggestion for this specification offered by an industry representative. The Committee has reconsidered and now recommends that this specification be amended to read as follows: 
G-S.5.2.3. SIZE AND CHARACTER.-In any series of graduations, indications, or recorded representations, corresponding graduations and units shall be uniform in size and character. Graduations, indications, or recorded representations which are subordinate to or of a lesser value than others with which they are associated shall be appropriately portrayed or designated. (This specification will become retroactive as of January 1, 1975.)

G-S.5.2.4. VALUES.-If graduations, indications, or recorded representations are intended to have specific values, these shall be adequate defined by a sufficient number of figures, words, symbols, or combinations thereof, uniformly placed with reference to the graduations, indications, or recorded representations and as close thereto as practicable, but not so positioned as to interfere with the accuracy of reading.

G-S.5.2.5. PERMANENCE.-Graduations, indications, or recorded representations and their defining figures, words, and symbols shall be of such character that they will not tend easily to become obliterated or illegible.

G-S.5.3. VALUES OF GRADUATED INTERVALS OR INCREMENTS.-In any series of graduations, indications, or recorded representations, the values of the graduated intervals or increments shall be uniform throughout the series.

(G-S.5., G-S.5.2., G-S.5.2.4., G-S.5.2.5., and G-S.5.3. as presented in the tentative report and G-S.5.2.3. as amended in the final report were adopted by voice vote.)

3. G-T.1. Acceptance Tolerances, subparagraph (c).-A State official suggested that a definition of the term "performance requirements" is needed to provide for uniform interpretation. The Committee recommends that the following be added to the General Code :

performance requirements. Performance requirements include all tolerance requirements and, in the case of nonautomatic-indicating scales, sensitivity requirements (SR). (See General Code definition for "tolerance" and Scale Code defiinition for "sensitivity requirement.")

(The foregoing item was adopted by voice vote.)

\section{Scale Code}

1. S.1.1. Zero Indication.-The Western Weights and Measures Association has recommended that this paragraph as amended at the 54th National Conference was in need of further clarification. The Committee has also received comments on this item from the scale industry. To satisfy the need for greater clarity, the Committee recommended in its tentative report that this paragraph be amended to read as follows:

\section{S.1.1. ZERO BALANCE INDICATION.-A scale shall}

(a) indicate a zero balance condition,

(b) indicate an out-of-balance condition on both sides of zero, and

(c) record a zero balance condition if equipped to record. 
On the basis of comments received both prior to and during the open meeting, the Committee has reconsidered this item and, accordingly, withdraws its recommendation in the tentative report.

(The withdrawal of S.1.1. was adopted by voice vote.)

2. T.1.1. To Underregistration And To Overregistration.-The Committee was advised that the second sentence of this requirement was being interpreted in several ways. To clarify this requirement, the Committee recommends the deletion of the second sentence of T.1.1. and the addition of a new requirement as follows:

T.1.1.1. WITH TWO OR MORE ELEMENTS.-When a single test load can be indicated or recorded by a scale with two or more elements designed to be used in combination, these elements shall not differ by an amount greater than the value of the minimum graduated interval on the device, except that the elements shall not differ under a no-load, zero-balance condition.

In the open meeting it was suggested that the Committee's recommendation in the tentative report would create an undue hardship on device owners and operators. The Committee disagrees with the suggestion that was made and recommends the change to T.1.1. and the addition of a new paragraph T.1.1.1. as per the tentative report.

\section{Discussion on Foregoing Item}

Mr. A. SANDERS (Scale Manufacturers Association): We want to commend the Committee and the Conference on its very diplomatic way of handling all the provisions that have been suggested, on the interim meeting, and on the deliberations. In our association we have a technical committee that considers these technical matters. We work on them all throughout the year, and we have one man to speak for us on technical discussions such as this. I want to introduce Don B. Kendall of the Toledo Scale Company, who is chairman of the SMA Technical Committee, to speak for our industry on this and one or two other matters.

MR. KENDALL: The change to T.1.1. per the interim report does accomplish the change which we were requesting in permitting separate tolerance application for a dial and a beam connected to the same lever system, and it seemed at first that it was suitable for the purpose. It remains to be seen whether the proposed wording will cause additional problems because of interpretation. We believe that the proposed wording is different from what SMA recommended, but we cannot say that it is wrong right now. We will have to see what possible interpretations will be made in the future.

(The amendment to T.1.1. and the addition of T.1.1.1. were adopted by voice vote.) 
3. N.1.4. Test for Sensitiveness for Nonautomatic-Indicating Scales and the section on Sr. Sensitivity Requirements.-The Committee feels that these sections are often misunderstood. To clarify this situation, the Committee recommends that N.1.4. be amended by substituting "by a specified amount (see SR. Sensitivity Requirements)" for "(in appropriate amount)" in line 6, and by adding the word "minimum" in line 8 , so that the paragraph will read as follows:

\section{N.1.4. TEST FOR SENSITIVENESS FOR NONAUTOMATIC-INDICATING SCALES.-The test for sensitiveness shall be conducted on all nonautomatic indicating scales. SR tests shall be made at zero load and at the maximum test load applied to the scale by either increasing or decreasing by a specified amount (see SR. Sensivity Requirements) the test-weight load on the load- receiving element of the scale. The minimum response of the scale shall be as follows:}

and that paragraph SR.1. be amended to read as follows:

SR.1. APPLICATION.-The sensitivity requirement (SR) applicable to a scale is the same regardless of whether acceptance or maintenance tolerances apply.

(The foregoing item was adopted by voice vote.)

4. T.3.\%. For Wheel-Load Weighers.-Two suggestions were received requesting that tolerances in this paragraph be reduced. The Committee recognized the possibility of such a need. However, adequate information was not available on the capability of devices presently in use to perform within closer limits. The Committee recommends that the Office of Weights and Measures gather appropriate data and report to the Committee following the 55th Conference. It strongly urges that weights and measures officials during the ensuing year provide the Office of Weights and Measures with as much information as possible on this subject. It also recommends that the Liaison Committee of the National Conference contact appropriate government agencies and trade associations in a search for an appropriate solution to this problem.

\section{Discussion on Foregoing Item}

MR. SANDERS : I happen to be a member of the Liaison Committee, and I would like to know what action the Liaison Committee is expected to take in its search for an appropriate solution to this problem.

MR. REBUFFO: The requirements for wheel-load weighers apply only to such scales in official use for the enforcement of traffic and highway laws or for the collection of statistical information by 
government agencies. Since the requirements for wheel-load weighers and other types of scales, such as axle-load scales, vary among the various agencies responsible for the enforcement of truck load limit laws, the Committee feels that the appropriate organizations should be contacted in order to work out uniform requirements for these scales, and it feels that the Committee on Liaison with the Federal Government could perform a useful function in assisting the Committee on Specifications and Tolerances in this project.

Mr. R. L. Thompson (Maryland): There are some who feel that wheel-load weighers are not acceptable devices for use. However, Handbook 44 does contain requirements for wheel-load weighers for use in the enforcement of traffic and highway laws. Based on this, many law enforcement agencies aside from weights and measures are using them. Problems have been encountered with these devices, but these problems are not solely based on the capability of the scale to weigh accurately. It is the opinion of some weights and measures officials that wheel-load weighers can meet more rigid requirements, and it is the objective of the Committee to gather the necessary information to substantiate this.

(Item 4 was adopted by voice vote.)

5. The Committee received a recommendation from the Scale Manufacturers Association that said in effect:

To promote education in the Metric System, the Scale Manufacturers Association recommends modification of Scale Tolerance Table 4 and Minimum Tolerance Values Table 3 to include equivalent metric units.

The Committee appreciates this progressive proposal by SMA. However, such modification would require the elimination of those columns expressing values in grains. It is felt that it would be inappropriate to eliminate these columns at the present time.

(Item 5 was adopted by voice vote.)

6. Pit Depth.-The Southern Weights and Measures Association has recommended that a study be made on the practicality of a specification for pit depth on vehicle, livestock, and animal scales. Inquiry into the matter disclosed that the Scale Manufacturers Association has submitted a request to the National Bureau of Standards for the development of a voluntary standard on design features and installation recommendations for vehicle and livestock scales. It is the Committee's opinion that this will result in an appropriate solution to problems of uniform recommendations relating to pit depth.

(Item 6 was adopted by voice vote.) 
1. The Committee received comments from the Southern and Western Weights and Measures Associations concerning N.3.1. ZERO-LOAD TEST and S.1.4. VALUE OF THE SMALLEST UNIT. The problem is that a belt-conveyor scale may meet the requirements of S.1.4.; however, the smallest unit may be too large to read the maximum change allowed in the zero-load test as stipulated in N.3.1. The Committee recommended in its tentative report that S.1.4. be amended to read as follows:

S.1.4. VALUE OF THE SMALLEST UNIT.-The value of the smallest unit of the primary indicating or recording element shall not be greater than 1/1200 of the rated capacity of the device. However, provision must be made so that compliance with the requirements of the zero-load test as prescribed in N.3.1. may be readily and accurately determined.

In the open meeting the Committee recommended the addition of the words "in 20 minutes operation" to this specification for technical appropriateness. Accordingly, the Committee recommends that paragraph S.1.4. be amended to read as follows:

S.1.4. VALUE OF THE SMALLEST UNIT.-The value of the smallest unit of the primary indicating or recording element shall not be greater than $1 / 1200$ of the rated capacity of the device. However, provision must be made so that compliance with the requirements of the zero-load test as prescribed in N.3.1. may be readily and accurately determined in 20 minutes operation.

The Committee also recommends that a new definition be added to read as follows :

rated capacity. That value representing the weight that can be delivered by the device in one hour.

Remarks on Foregoing Item

Mr. Kendall: There is one manufacturer, who is very prominent in the field, who has a problem with the basic wording of this paragraph. This problem came to my attention after the interim meeting of the Committee. My purpose in calling this to the attention of the Conference is to ask that you bear with us until this can be corrected, hopefully next year.

(S.1.4. as amended and the new definition for "rated capacity" were adopted by voice vote.)

2. There were several comments expressing the need for a minimum weighing requirement for belt-conveyor scales. The Committee recommended in its tentative report the following addition: 
UR.3.3. MINIMUM WEIGHING.-A belt-conveyor scale shall not be used for individual weighings of less than 2 percent of the rated capacity, nor less than 100 significant figures on the master weight totalizer.

The Committee received several written comments and heard discussion on this recommended addition. The Committee recognizes a need for such a requirement. However, the Committee felt that further information and study of this proposal was necessary and recommends that UR.3.3. be tabled for further consideration. It urges manufacturers, users, and weights and measures officials to communicate with the Specifications and Tolerances Committee on this matter in the ensuing year.

(The motion to table UR.3.3. was adopted by voice vote.)

\section{Weight Code}

A need has been expressed to the Committee for extending Table 3, MAINTENANCE TOLERANCES FOR APOTHECARIES AND TROY WEIGHTS, to higher nominal values up to 1,000 ounces troy. It is noted that the ratios of tolerance values to nominal values in the range of 1 to 12 troy ounces in Table 3 are nearly the same as the tolerance to nominal value ratios for the corresponding range of 30 to 300 grams in Table 2, MAINTENANCE TOLERANCES FOR METRIC WEIGHTS. The Committee feels that the range of tolerances in Table 3 should be extended in a way that maintains this similarity with the metric tolerances. Thus, the Committee recommends extending the range of the troy ounce tolerances in Table 3 as follows:

\begin{tabular}{|c|c|c|}
\hline \multirow{2}{*}{$\begin{array}{c}\text { Nominal Value } \\
\text { Ounces }\end{array}$} & \multicolumn{2}{|c|}{ Maintenance Tolerance } \\
\hline & Grains & Milligrams \\
\hline \multicolumn{3}{|c|}{ [Note: No change is recommended in the values from 1 ounce to 12 ounces } \\
\hline 20 & 2.9 & 190.0 \\
\hline 30 & 3.7 & 240.0 \\
\hline 50 & 5.4 & 350.0 \\
\hline 100 & 7.7 & 500.0 \\
\hline 200 & 12.3 & 800.0 \\
\hline 300 & 15.4 & 1000.0 \\
\hline 500 & 23.1 & 1500.0 \\
\hline 1000 & 38.6 & 2500.0 \\
\hline
\end{tabular}

(The foregoing item was adopted by voice vote.) 
1. A manufacturer of computing register devices used in wholesale transactions of petroleum products has requested the addition of a new specification paragraph relating to money-value calculations in the Codes for Liquid-Measuring Devices, for Vehicle-Tank Meters, and for Liquefied Petroleum Gas Liquid-Measuring Devices. The purpose of the new paragraph is to permit such devices used in wholesale trade to calculate money values to within one cent. It was also suggested that the new paragraph would eliminate any misunderstanding as to the applicability of General Code paragraph G-S.5.5. MONEY VALUES, MATHEMATICAL AGREEMENT, which requires money-value calculations to the nearest one cent. The manufacturer pointed out that, if these devices were required to comply with G-S.5.5., the cost of redesign and manufacturing would be prohibitive.

The Committee accepts the reasoning behind this request and recommends the addition of a new paragraph under section S.1.5. FOR WHOLESALE DEVICES as follows:

S.1.5.2. MONEY VALUES-MATHEMATICAL AGREEMENT.-Any recorded money value and any digital money-value indication on a computing-type device shall be in mathematical agreement with its associated quantity representation or indication to within one cent of money value.

[NOTE: A similar paragraph will be added to the Codes for Vehicle-Tank Meters and for Liquefied Petroleum Gas Liquid-Measuring Devices.]

At the open meeting two proposals were presented recommending that this requirement also be applicable to retail devices. Since S.1.5.2. is a new requirement and, in the tentative report, was directed to wholesale devices only, it is the opinion of the Committee that ample time has not been provided to study the impact and appropriateness to have a similar requirement apply to retail devices. The Committee will consider these new proposals in the ensuing year. Thus, the Committee recommends the addition of paragraph S.1.5.2. as per the tentative report.

\section{Discussion on Foregoing Item}

Mr. Siebold (Liquid Controls Corporation): Speaking for the Meter Manufacturers Technical Committee, I would like to say that the meter manufacturers are not opposed to the basic thought of this section. However, we feel that the wording is open to various interpretations. For instance, if this section were interpreted to mean comparison of the printed money value to the registration of the wholesale meter, agreement would not be possi- 
ble, due to the fact that the information may be transmitted by pulses and the smallest increment possible is $1 / 10$ gallon on a liquid such as propane, thus making one pulse equal to about 3 cents.

Mr. Love (Dresser Industries) : I represent the Gasoline Pump Manufacturers Association. There seems to be conflict between the Committee's statement that further study will be made and the Committee's recommendation for the adoption of this section.

MR. REBUFFO: We are talking about the recorded representation -agreement of the money value with the printed gallons to the nearest one cent, and not the comparison of the printed ticket with what might be on the primary recording element at the wholesale plant. This section is applicable only to wholesale devices, and not to retail devices. During the ensuing year the Committee will undertake a study on a similar requirement for retail devices. In the meantime, if further clarification is needed, this may be obtained by writing to the Office of Weights and Measures.

Mr. LOVE: We have no objection to the wording of this paragraph if it does not close the door.

Mr. REBUfFo: No, it will not close the door. We realize that there are many new technical innovations and that these all require further study and consideration.

(S.1.5.2. was adopted by voice vote.)

2. S.2.1. Vapor Elimination.-For reasons explained in item 3 of the Vehicle-Tank Meter Code, the Committee recommends that this paragraph be amended as follows:

S.2.1. VAPOR ELIMINATION.-A liquid-measuring device or metering system shall be equipped with an effective vapor eliminator or other effective means to prevent the passage of vapor and air through the meter. Vent lines from the air or vapor eliminator shall be of metal tubing or or some other suitably rigid material.

Comments were heard that this requirement would cause an undue hardship on device operators for equipment already in service. It is the opinion of the Committee that the change to this requirement is important and it recommends amendment to the code as per the tentative report.

(S.2.1. was adopted by voice vote.)

3. S.2.5.1. Zero-Set-Back Interlock.-There are retail motor-fuel devices in use throughout the country that are equipped with recording elements. Such recording elements are not corered by 
this specification paragraph and, consequently, not required to have an effective automatic interlock. In the Committee's opinion, both indicating and recording elements should be required to comply with S.2.5.1.

It has also been suggested that the wording in the first sentence of S.2.5.1. be changed to require that, whenever the starting lever reaches any position which shuts off the device, the interlock is engaged. The Committee recommended in its tentative report that the paragraph be amended to read as follows:

S.2.5.1. ZERO-SET-BACK INTERLOCK.-A retail motor-fuel device of the meter type shall be so constructed that, after a particular delivery cycle has been completed by movement of the starting lever to any position that shuts off the device, an effective automatic interlock will prevent a subsequent delivery being started until the indicating elements and recording elements, if the device is equipped to record, have been returned to their correct zero positions. The starting lever must be in its designed shutoff position and the zero-set-back interlock engaged before the discharge nozzle can be returned to its designed hanging position.

During the open meeting comments on this paragraph were made by both weights and measures officials and representatives from industry. As a result of these comments and further deliberations by the Committee, several modifications in the paragraph have been made. Of particular note is that the final sentence is given nonretroactive status. The Committee now recommends that specification paragraph S.2.5.1. be amended to read as follows:

S.2.5.1. ZERO-SET-BACK INTERLOCK.-A retail motor-fuel device of the meter type shall be so constructed that, after a particular delivery cycle has been completed by movement of the starting lever to any position that shuts off the device, an effective automatic interlock will prevent a subsequent delivery being started until the indicating elements and recording elements, if the device is equipped and activated to record, have been returned to their correct zero positions. Provision shall be made for the starting lever to be in its designed shutoff position and the zero-set-back interlock engaged before the discharge nozzle can be returned to its designed hanging position.

The nonretroactivity character of the final sentence deserves further comment. On the basis of a very thorough investigation, the Committee is of the opinion that devices installed after July 1, 1969, fully meet this requirement, but that devices installed prior to that date not only. may not meet the requirement, but may require major modifications to bring about full conformance. Accordingly, it is the recommendation of the Committee and, upon adoption by the Conference, will be the recommendation of the entire body that, from an enforcement standpoint, this requirement be made effective with respect to devices installed after July 1, 1969. The Committee urges that retail gasoline dispenser users 
make every effort to bring about modification of nonconforming devices as soon as this is practicable.

(S.2.5.1. as amended was adopted by voice vote.)

\section{Remarks on Foregoing Item}

Mr. R. C. Primley (Cities Service Oil Company): We appreciate very much the action of the Specifications and Tolerances Committee in giving nonretroactive status in its final report to the last sentence in this section.

We in the petroleum industry have tremendous concern for the dishonesty that has taken place in some service stations. The API Operations and Engineering Committee is going to take definite action to see that educational programs are instituted to help alleviate any conditions that would not be beneficial to our industry and to the weights and measures officials. I assure you that they bother us more than they bother you. We will be working on this educational effort throughout this next year, and you will feel the impact of this before the next Conference.

4. S.3.1. Diversion of Measured Liquid.-Proposals were received and heard from both industry representatives and weights and measures officials on the need to amend this paragraph to permit the use of dual outlets on motor-fuel devices that are used at installations which service trucks equipped with saddle tanks. Simply stated, the basic need or reason for these proposals was an economic one, to allow for the ease and speed of operation in the fueling of trucks.

The Committee is well aware of the concern some weights and measures officials may have toward this proposal. On the other hand, it must recognize such obvious factors as (1) the modern trend in the design of motor-fuel dispensing equipment, (2) the special provision for dual outlets as found in S.3.1. DIVERSION OF MEASURED LIQUID in the Vehicle-Tank Meters Code, (3) the fact that some jurisdictions have recognized the need and approved these systems, and (4) the economic and other equally persuasive reasons. In doing so, the Committee has concluded that, if adequate safeguards and provisions are set forth in a new specification, the proposal should be acted on favorably. It was, therefore, recommended by the Committee in its tentative report to amend S.3.1. as follows :

S.3.1. DIVERSION OF MEASURED LIQUID.-No means shall be provided by which any measured liquid can be diverted from the measuring chamber or the discharge line therefrom, except that two delivery outlets may be installed on a motor-fuel device used exclusively in the fueling of trucks equipped with saddle tanks if means are provided to insure that: 
(a) liquid can flow from only one delivery outlet at one time,

(b) the direction of flow for which the device is set is definitely and conspicuously indicated, and

(c) the flow from either of the delivery outlets cannot conveniently be diverted to some other truck or vehicle.

Several proposals were made at the open meeting for various changes to this amendment. The Committee has reconsidered its recommendation in the tentative report and now recommends that specification paragraph S.3.1. be amended to read:

S.3.1. DIVERSION OF MEASURED LIQUID.-No means shall be provided by which any measured liquid can be diverted from the measuring chamber or the discharge line therefrom, except that two delivery outlets may be installed on a motor-fuel device used exclusively in the fueling of trucks if means are provided to insure that:

(a) liquid can flow from only one delivery outlet at one time, and

(b) the flow from either of the delivery outlets cannot be diverted from the truck being served.

(S.3.1. as amended was adopted by voice vote.)

5. UR.3.4. Activation of Zero-Set-back Interlock and Position of Discharge Nozzle.-The American Petroleum Institute has proposed a change in this paragraph to eliminate the requirement concerning the return of the discharge nozzle to its designed hanging position following each delivery to a customer. Industry representatives point out that in many busy service stations it is common practice for an operator to hold the discharge nozzle in his hand while resetting the pump mechanism to zero. They fail to see this practice as being either deceptive or fraudulent. They also claim that few weights and measures jurisdictions have attempted to enforce this requirement.

The Committee has carefully weighed the pros and cons of this proposal and the problems that surround it. The real issue boils down to "How can we prevent an operator of a gasoline pump from fraudlently manipulating the pump in such a way that he can add the delivery charge of one customer to the delivery charge of another unsuspecting customer?" The Committee firmly believes that specification paragraph S.2.5.1. has provided proper safeguards in the design and construction of gasoline pumps. User requirement UR.3.4. should, therefore, be directed to the proper and practical usage of pumps. Any attempt to have requirements go beyond this point, however desirable such requirements may seem from a total protection standpoint, is considered to be unwise. Thus, the Committee recommended in its tentative report the amendment of UR.3.4. as follows: 
UR.3.4. POSITION OF STARTING LEVER AND ACTIVATION OF ZERO-SET-BACK INTERLOCK.-The starting lever on a retail motorfuel device shall be returned to its shutoff position and the zero-set-back interlock engaged following each delivery to a customer.

Many comments were offered at the open meeting. On the basis of that discussion, the Committee has reconsidered its recommendation in the tentative report and recommends that this paragraph be amended to read:

UR.3.4. ACTIVATION OF ZERO-SET-BACK INTERLOCK AND POSITION OF STARTING LEVER AND DISCHARGE NOZZLE.-On a retail motor-fuel device the starting lever shall be returned to its shutoff position and the zero-set-back interlock engaged following each delivery to a customer. The discharge nozzle shall be returned to its designed hanging position following each delivery to a customer unless the primary indicating and recording elements, if the device is equipped and activated to record, have been returned to a definite zero indication.

(The foregoing item was adopted by voice vote.)

6. The Conference last year adopted a number of amendments to the Codes for Liquid-Measuring Devices and for LPG Liquid-Measuring Devices to provide for proper control of temperature-compensating devices used in the sale and delivery of petroleum and other products at wholesale. In paragraph S.4.3.2. TEMPERATURE COMPENSATION, provision is made for indicating elements, recording elements, and recorded representations to clearly and conspicuously show that the volume delivered has been adjusted to the volume at $60^{\circ} \mathrm{F}$. The Committee feels that written invoices based on the reading of such devices should likewise be required to show the adjusted volume. It is recommended that this be accomplished through the addition of a new user requirement UR.3.5.2. and by amending UR.3.5. as follows:

\section{UR.3.5. TEMPERATURE COMPENSATION ON WHOLESALE DEVICES.}

UR.3.5.1. USE OF AUTOMATIC TEMPERATURE COMPENSATORS.-If a wholesale device is equipped with an automatic temperature compensator, this shall be connected, operable, and in use at all times. Such automatic temperature compensator may not be removed, nor may a compensated device be replaced with an uncompensated device, without the written approval of the weights and measures authority having jurisdiction over the device.

UR.3.5.2. WRITTEN INVOICES.-Any written invoice based on a reading of a wholesale device that is equipped with an automatic temperature compensator shall have shown thereon that the volume delivered has been adjusted to the volume at $60^{\circ} \mathrm{F}$. 
[NOTE: A similar addition will be made to UR.2.4. in the LPG LiquidMeasuring Devices Code.]

(The foregoing items were adpoted by voice vote.)

7. Meters Used at Marinas.- The Committee wishes to acknowledge the suggestion it received from the Committee on Specifications and Tolerances of the Southern Weights and Measures Association to study the feasibility of a separate code for liquid-measuring devices used at marinas and aircraft-fueling stations. It is hoped that such a study can be conducted in time for a report to the 56th National Conference.

(The foregoing item was adopted by voice vote.)

\section{Code For Vehicle-Tank Meters}

1. Proposed Specification for Zero-Set-Back Interlock.-A proposal was made last year for the addition of a new specification paragraph requiring a zero-set-back interlock on vehicle-tank meters. The Conference approved the Committee's recommndation to keep this matter on its agenda for future consideration. A motion was subsequently made by a weights and measures official and passed by the Conference to have the Committee consider the possibility of including the proposed specification in its report this year as a tentative specification to become effective for new vehicle-tank meters in July 1974 and for all vehicle-tank-meter installations in July 1978.

This matter was reviewed by the Committee, and it was decided that it would be inappropriate to recommend the proposed tentative specification without further study of its feasibility and impact. Thus, no action is recommended, and the item will be carried on the Committee's agenda for future study.

(The foregoing item was adopted by voice vote.)

2. As explained in item 1 of the Code for Liquid-Measuring Devices, it is recommended that the following paragraph be added to the Code for Vehicle-Tank Meters:

S.1.4.4. MONEY VALUES-MATHEMATICAL AGREEMENT.-Any recorded money value and any digital money-value indication on a computingtype device shall be in mathematical agreement with its associated quantity representation or indication to within one cent of money value.

It is also recommended that the parenthetical reference at the end of paragraph S.1.4.2. be deleted. 
3. S.2.1. Vapor Elimination.-Officials in the State of Pennsylvania have found that some fuel-oil dealers have used rubber hoses on vehicle-tank-meter installations as vent lines from the air eliminators for fraudulent purposes. They say, and the Committee agrees, that it is simple for an unscrupulous operator to use a pair of vise-grip pliers, or some such means, to pinch the rubber hose and render the air eliminator useless. To combat this problem, the Committee recommends that an additional requirement be added to paragraph S.2.1., so that the paragraph will read as follows:

S.2.1. VAPOR ELIMINATION.-A metering system shall be equipped with an effective vapor eliminator or other effective means to prevent the passage of vapor and air through the meter. Vent lines from the air or vapor eliminator shall be of metal tubing or of some other suitably rigid material.

(The foregoing item was adopted by voice vote.)

4. S.3.6. Antidrain Valve.-The Committee was advised that there is some uncertainty surrounding the intended meaning of the second sentence in this paragraph, which reads, "The antidrain valve shall function so as to prevent the drainage of the discharge hose when an automatic valve adjacent to the meter is closed following the delivery of a predetermined volume of liquid." The purpose of the antidrain valve in a wet-hose system is to prevent drainage of product from the hose when the pump in the delivery system is not operating. Obviously, any drainage of the hose will create a shortage in the "metered" volume of liquid that is stored between the meter chamber and the discharge nozzle. Such a void in the hose would naturally cause an inaccurate delivery of the next metered volume.

One must also recognize that the antidrain valve is not capable of resisting the head pressures of the supply in the vehicle-tank compartment or system. Thus, a valve in the system between the supply and the discharge valve must be closed to facilitate the effectiveness of the antidrain valve. There are few, if any, vehicle-tank metering systems that do not employ automatic valves or have manually operable valves that accomplish this purpose.

Thus, to limit the function of an antidrain valve as called for in the second sentence seems unwarranted. The Committee believes that the following amendment to S.3.6. and the addition of a new paragraph in the Notes section should correct any uncertainties.

S.3.6. ANTIDRAIN VALVE.-In a wet-hose, pressure-type device, an effective antidrain valve shall be incorporated in the discharge valve or immediately adjacent thereto. The antidrain valve shall function so as to prevent the drainage of the discharge hose. However, a device used exclusively for fueling and defueling aircraft may be of the pressure type without an antidrain valve. 
N.4.3. ANTIDRAIN VALVE TEST.-The effectiveness of the antidrain valve shall be tested after the pump pressure in the meter system has been released and a valve between the supply tank and the discharge valve is closed.

(The foregoing items were adopted by voice vote.)

Code for LPG Liquid-Measuring Devices

1. As reported in item 1 of the Code for Liquid-Measuring Devices, it is recommended that the following paragraph be added to the Code for LPG Liquid-Measuring Devices:

S.1.1.5. MONEY VALUES-MATHEMATICAL AGREEMENT.-Any recorded money value and any digital money-value indication on a computing-type device shall be in mathematical agreement with its associated quantity representation or indication to within one cent of money value, except on a motorfuel device, which must be to the nearest one cent of money value. (See GS.5.5.)

(The foregoing item was adopted by voice vote.)

2. UR.2.4. Automatic Temperature Compensator.-For the reasons explained in item 6 of the Code for Liquid-Measuring Devices, the following amendments are recommended:

\section{UR.2.4. TEMPERATURE COMPENSATION.}

UR.2.4.1. USE OF AUTOMATIC TEMPERATURE COMPENSATORS.-If a device is equipped with an automatic temperature compensator, this shall be connected, operable, and in use at all times. Such automatic temperature compensator may not be removed, nor may a compensated device be replaced with an uncompensated device, without the written approval of the weights and measures authority having jurisdiction over the device.

UR.2.4.2. WRITTEN INVOICES.-Any written invoice based on a reading of a device that is equipped with an automatic temperature compensator shall have shown thereon that the volume delivered has been adjusted to the volume at $60^{\circ} \mathrm{F}$.

(The foregoing items were adopted by voice vote.)

Tentative Code for LPG Vapor-Measuring Devices

The Committee received a communication from the National LP-Gas Association listing items of concern and reporting progress on the study of "units" recommended by the Conference last year. The Committee was disturbed by the progress report on the study of units used when it was noted that one large manufacturer had only 23 percent and another 43 percent of last year's sales of meters in units of cubic feet. It feels that industry is not seriously considering an orderly transition to expression in terms of cubic feet. 
Items of concern to industry with respect to tolerance values and definition of base pressure were answered. A proposed altitude correction table was offered for review. A suggested addition to provide for an alternative means to show the altitude multiplier (i.e., on the customer's statement) was taken under consideration. The association reported that it was still in the process of accumulating data from industry to support their request for longer intervals between tests.

The industry apparently is concerned that only the bell prover has been recommended as the acceptable means for checking meters. The Committee does not feel that the industry is limited to checking meters with bell provers. It is conceivable that other reproducible methods, and test equipment that is calibrated at frequent intervals with a certified bell prover, may be satisfactory.

(The foregoing item was adopted by voice vote.)

\section{Code for Farm Milk Tanks}

The Milk Market Administration of the U. S. Department of Agriculture, Boston, Massachusetts, has urged the Committee to reduce the tolerance requirement for test drafts from 501 to 1,000 gallons in Table 1 from 3 gallons to 2 gallons. Similar requesis have also been received from several State weights and measures officials. It was pointed out that this smaller tolerance value was in effect prior to the extensive ameridments made to the Code for Farm Milk Tanks last year, and that such liberalization was not necessary.

The Committee has reviewed the entire tolerance structure for farm milk tanks and agrees with the suggestions it has received to amend Table 1 as follows:

\section{TABLE 1.-BASIC MAINTENANCE AND ACCEPTANCE TOLERANCES FOR FARM MILK TANKS}

\begin{tabular}{l|c}
\hline \multicolumn{1}{c|}{ Test draft } & Tolerance in excess and in deficiency \\
\hline \multicolumn{1}{c|}{ Gallons } & Gallons \\
250 or less & $1^{1 / 2}$ \\
251 to 500 inclusive & 2 \\
501 to 1,000 , inclusive & 3 \\
1,001 to 1,500, inclusive & 4 \\
1,501 to 2,000, inclusive & 5 \\
2,001 to 2,500, inclusive & 6 \\
2,501 to 5,000, inclusive & Add 2 gallons per 2,500 gallons or fraction thereof. \\
Over 5,000 &
\end{tabular}

(The foregoing item was adopted by voice vote.) 
This Committee and the Committee on Laws and Regulations received a request from the Milk Industry Foundation to amend Handbook 44 and the Model Law to allow the foods yogurt and sour cream to be sold by weight. The details of this request are explained in the tentative report of the Committee on Laws and Regulations under item 2 of the Model Law section.

It is the view of this Committee that sufficient justification for the requested amendment has been given, and thus the Committee recommends the deletion of the words "sour cream" and "yogurt" from the parenthetical statement in paragraph A.1. GENERAL subparagraph (b), of the Code for Measure-Containers. It should be noted, however, that, should the Conference not act favorably on the recommendation of the Committee on Laws and Regulations in this matter, then this shall automatically revoke any action by the Conference on this recommendation by the Committee on Specifications and Tolerances.

(The foregoing item was adopted by voice vote.)

(Subsequent to the adoption of this item, the Conference voted favorably on the recommendation of the Committee on Laws and Regulations.)

\section{Code For Taximeters}

1. On the basis of engineering studies by the Office of Weights and Measures, additional test methods which measure the rolling circumference of vehicles have been found to be suitable simulated procedures along with the roller-type device. The Committee recommended in its tentative report including these techniques in the permissible test methods by changing N.1.1.(c) as follows:

(c) SIMULATED-ROAD TEST.-A simulated-road test consists of determining the distance actually traveled by use of a properly calibrated roller device, or by computation from rolling circumference and wheelturn data.

On the basis of recommendations to the Committee by the Automobile Manufacturers Association and further study by the Office of Weights and Measures, several changes to the tentative report were presented at the open meeting. Such changes are included in the following amendments recommended by the Committee:

(c) A simulated road test consists of determining the distance traveled by use of a roller device, or by computation from rolling circumference and wheel-turn data. The distance so determined shall adequately correlate with methods (a) or (b) had they been used.

(The foregoing item as amended was adopted by voice vote.) 
2. Some simulated-road tests require an observer outside the vehicle during tests. To avoid the need for three persons to perform these tests, the Committee recommends amending paragraph N.1.3.1. as follows :

N.1.3.1. VEHICLE LADING.-During the mileage test of a taximeter, the vehicle shall carry two persons, or in the case of a simulated-road test, 150 pounds of test weights may be used in lieu of the second person.

(The foregoing item was adopted by voice vote.)

3. The Committee recommends replacing "normal operating pressure" by "cold tire pressure" in paragraph UR.1., since the tire pressure recommended by manufacturers is in fact a cold tire pressure.

UR.1. INFLATION OF VEHICLE TIRES.-The cold tire pressure of the vehicle tires shall be maintained at not less than the cold tire pressure recommended by the manufacturer of the vehicle.

(The foregoing item was adopted by voice vote.)

4. Definitions of Terms.-The Committee recommends adding "cold tire pressure" and "rolling circumference" to the list of defined terms, and amending the definition of "simulated-road test" as follows:

cold tire pressure. The pressure of a tire which is at ambient air temperature.

rolling circumference. The rolling circumference is the straight line distance traveled per revolution of the wheel (or wheels) that actuates the taximeter. In the case where more than one wheel actuates the taximeter, the rolling circumference is the average distance traveled per revolution of the wheels.

simulated-road test. A mileage test where the taximeter may be actuated by some means other than road travel. The distance traveled is either measured by a properly calibrated roller device, or computed from rolling circumference and wheel-turn data.

(The foregoing items were adopted by voice vote.)

\section{Code for Odometers}

The items presented under this code by the Committee are, for the most part, the result of suggestions made by the Engineering Unit of the NBS Office of Weights and Measures. The Committee wishes to acknowledge the excellent assistance of this Unit on these as well as other technical matters in the Committee's tentative report.

1. The Committee is of the opinion that the Odometer Code should be amended to include trucks having a cargo capacity of up 
to 15,000 pounds. Accordingly, it recommended in its tentative report that application paragraphs A.1. and A.2. be amended as follows :

A.1.-This code applies to odometers that are used or are to be used to determine the charges for rent or hire of passenger vehicles and of trucks rated at a cargo capacity of 15,000 pounds or less. (When official examinations are undertaken on odometers that form the basis for the payment of fees or taxes to, or the preparation of reports for, governmental agencies, and in similar cases, the requirements of this code shall be applied insofar as they are applicable and appropriate to the conditions of such special uses.)

A.2.- This code does not apply to odometers on trucks having a cargo capacity rating in excess of 15,000 pounds, or to taximeters ( for which see Code for Taximeters).

On the basis of recommendations to the Committee by the Automobile Manufacturers Association and further study by the Office of Weights and Measures, several changes to the tentative report were presented at the open meeting. Such changes are included in the following amendments recommended by the Committee:

1. Paragraph A.1. - This code applies to odometers that are used or are to be used to determine the charges for rent or hire of passenger vehicles and of trucks rated by the manufacturer at 10,000 pounds gross vehicle weight or less. (When official examinations are undertaken on odometers that form the basis for the payment of fees or taxes to, or the preparation of reports for, governmental agencies, and in similar cases, the requirements of this code shall be applied insofar as they are applicable and appropriate to the conditions of such special uses.)

Paragraph A.2.-This code does not apply to odometers on trucks having a gross vehicle weight rating in excess of 10,000 pounds, or to taximeters (for which see Code for Taximeters).

(The foregoing items as amended were adopted by voice vote.)

2. The Committee believes that a simulated-road test can be a proper test for odometers. It recommended in its tentative report adding the simulated-road test to the acceptable test methods by the addition of paragraph N.1.1.(c) as follows:

(c) SIMULATED-ROAD TEST.-A simulated-road test consists of determining the distance actually traveled by use of a properly calibrated roller device, or by computation from rolling circumference and wheel-turn data. 
This paragraph was amended during the open meeting as follows :

(c) A simulated-road test consists of determining the distance traveled by use of a roller device, or by computation from rolling circumference and wheel-turn data. The distance so determined shall adequately correlate with methods (a) or (b) had they been used.

(The foregoing item as amended was adopted by voice vote.)

3. N.1.3. Test Conditions.-_Some simulated-road tests require an observer outside the vehicle during tests. To avoid the need for three persons to perform these tests, the Committee recommends amending paragraph N.1.3.1. to be consistent with the corresponding change in the Code for Taximeters. It is possible for one person to perform fifth-wheel and road tests.

\section{N.1.3.1. VEHICLE LADING.}

(a) PASSENGER LOAD.-During the mileage test of an odometer, the vehicle shall carry two persons, or 150 pounds of test weights may be substituted in lieu of the second person.

The rolling circumference, and therefore the calibration of truck odometers, depends on the size of the cargo load at the time of testing. It is to the rental truck user's advantage to have the truck odometer calibrated at full load, and to his disadvantage to have it calibrated at zero load.

The Committee suggests that testing truck odometers at 50 percent of the rated load capacity is a fair compromise, since most rental trucks are loaded only about half of the driven distance. The Committee recommends the following addition to N.1.3.1.:

(b) TRUCK CARGO LOAD.-Truck odometers shall be tested at 50 percent of the maximum cargo capacity.

[NOTE: The Committee has requested the Office of Weights and Measures to study the feasibility of testing trucks at zero cargo load using appropriate correction factors.]

(The foregoing items were adopted by voice vote.)

4. N.1.3.2. Tire Pressure.-Recommended pressures for truck tires cover too large a range to specify one test pressure, as is done in testing passenger vehicle odometers. The Committee, therefore, recommends dividing paragraph N.1.3.2. TIRE PRESSURE as amended below: 
(a) PASSENGER VEHICLES.-At the beginning of each test run, the tires on the vehicle under test shall be adjusted to 28 pounds per square inch at stabilized tire temperatures.

(b) TRUCKS.-At the beginning of each test run, the tires on the truck under test shall be adjusted to the cold tire pressure recommended by the truck manufacturer plus 10 percent of this pressure when measured at stabilized tire temperature (minimum of 4 psi gage above cold tire pressure).

(The foregoing item was adopted by voice vote.)

5. As with the recommended change in the corresponding paragraph of the Code for Taximeters, the Committee recommends replacing "normal operating pressure" by "cold tire pressure" in paragraph UR.1., since the tire pressure recommended by manufacturers is in fact a cold tire presslire.

UR.1. INFLATION OF VEHICLE TIRES.-The cold tire pressure of passenger vehicle and of truck tires shall be maintained at not less than the cold tire pressure recommended by the manufacturer of the vehicle.

(The foregoing item was adopted by voice vote.)

6. Definitions of Terms.-As in the recommended changes to the Code for Taximeters, the Committee recommends adding "cold tire pressure" and "rolling circumference" to the list of defined terms, and amending the definition of "simulated-road test" as follows :

cold tire pressure. The pressure of a tire which is at ambient air temperature.

rolling circumference. The rolling circumference is the straight line distance traveled per revolution of the wheel (or wheels) that actuates the odometer. In the case where more than one wheel actuates the odometer, the rolling circumference is the average distance traveled per revolution of the wheels.

simulated-road test. A mileage test where the odometer may be actuated by some means other than road travel. The distance traveled is either measured by a properly calibrated roller device or computed from rolling circumference and wheel-turn data.

maximum cargo load. The maximum cargo load for trucks is the difference between the manufacturer's rated gross vehicle weight and the weight of the vehicle having no cargo load. 
In accordance with its recommendation to the Conference last year, the Committee has studied the usefulness of this code. The findings of the Committee leave no doubt as to the need and usefulness of the Code for Berry Baskets and Boxes. Accordingly, no action is recommended.

(The foregoing item was adopted by voice vote.)

\section{Other Items}

1. Tire Air-Pressure Gages.-The Conference Executive Secretary received a letter from the Chairman of the National Motor Vehicle Safety Advisory Council, U. S. Department of Transportation, requesting the National Conference on Weights and Measures to consider, in the interests of public safety, participation in a national effort to upgrade the accuracy of air pressure gages.

Evidence considered by the Council has led to the conclusion that air pressure in automobile tires has a significant effect on the safe operation of motor vehicles. Studies have also revealed that installed compressed air dispenser gages and small hand gages used in service stations are frequently in substantial error.

This matter was placed on the agenda of the Committee on Specifications and Tolerances to consider and bring before the Conference for further discussion and possible action.

During the interim meeting, the Committee was thoroughly briefed on developments in this area by Mr. Paul Brown, Chief, Office of Vehicle Systems Research, National Bureau of Standards, who is one of the nation's leading authorities in this field. The Committee was impressed by the importance of the problem and the need for action as explained by Mr. Brown. Specifically, there is a need to test air pressure gages in service stations and to recommend improvements where inaccuracies are found.

It is recognized that some weights and measures jurisdictions may be constrained in participating in a testing program that is outside the field of "commercial" weighing and measuring. However, the Committee believes that, since the program under consideration would not be a regulatory one, most officials would be interested in providing assistance as a public service.

Operating on this assumption, and in response to the request from the National Motor Vehicle Safety Advisory Council, the Committee recommends favorable consideration of this matter by the Conference and support for a national testing program by weights and measures officials on a "public service" basis. 
The OWM Engineering Unit, working with the NBS Office of Vehicle Systems Research, will develop testing equipment, test methods, accuracy criteria, and other technical guidelines for weights and measures officials in the establishment of the program. Full details will be reported by OWM at the Conference, if not sooner.

(The foregoing item was adopted by voice vote.)

2. Time-Measuring Devices.-Requests for a code for time-measuring devices have been received from many sources, including recommendations from the Western Weights and Measures Association and the Northeast Regional Weights and Measures Division of NASDA. Interest in the subject appears to be universal enough among weights and measures officials to remove any doubt that the topic "timing devices" is a proper one for the Conference to consider. The Committee is informed that the Office of Weights and Measures is studying this matter with the intention of proposing a code, as well as suitable testing equipment and test procedures. The initial OWM study is concerned with four types of devices: Coin-operated clothes driers, coin-operated car washes, parking meters, and parking lot (or garage) clocks. Progress in this area will be reported during the Conference.

(The foregoing item was adopted by voice vote.)

3. Railroad Weighing.-As reported by the Committee on Education, a joint meeting was held with that Committee and industry representatives to explore matters relating to railroad weighing practices. The Committee will watch, with interest, developments between the National Bureau of Standards and railroad interests. It is quite possible that additional Handbook 44 requirements may be advisable to more adequately cover railroad scales.

(The foregoing item was adopted by voice vote.)

4. Concrete-Mobile.-The Committee received several inquiries from State officials and from the manufacturer concerning the application of Handbook 44 requirements to a device called "Concrete-Mobile," which is used to measure and deliver concrete. Representatives of the manufacturer made a presentation to the Committee during the interim meeting that included a live demonstration of the equipment.

Although the device does "measure" concrete ingredients somewhat volumetrically and does indicate certain "units" on a metertype register, it was the opinion of the Committee that it is not within the meaning of a measuring device as defined in H-44. 
The Committee recommends to all weights and measures officials that this equipment not be interpreted as a commercial device and that the accuracy of its use be determined by the measurement of the volume actually delivered. The Committee wishes to remind officials that this equipment was discussed in OWM Tech Memo No. 10, dated October 10, 1968, and that the Committee agrees with the philosophy as expressed. Further inquiries or comments may be directed to the Office of Weights and Measures.

(The foregoing item was adopted by voice vote.)

5. Grain-Moisture Meters.-The Committee heard a progress report concerning the Office of Weights and Measures study to verify the feasibility of using a gas chromatograph for accurately measuring grain moisture content. The technique continues to look promising. Tests having sufficient precision can be made in about six minutes (instrument and data calculation time). Sample preparation requires an additional five minutes, but this can be done while other samples are in the instrument.

The goals of the study are (a) to determine exactly what type of gas chromatograph and supporting equipment is needed, (b) to write a test procedure for grain-moisture measurements, and (c) to write a code for grain-moisture meters. It is clear at this point that the gas chromatograph can be used as a laboratory standard for checking moisture meters. It remains to be seen whether the instrument can be portable and the technique simple enough for field testing of other meters.

(The foregoing item was adopted by voice vote.)

6. NBS Handbook 105-1.-The Committee's attention was called to a problem several scale manufacturers were having in some States regarding NBS Handbook 105-1, Specifications and Tolerances for Field Standard Weights. Manufacturers pointed out that the officials in these States were requiring test weights used by the scale industry for their own testing purposes to comply with the $\mathrm{H}-105-1$ requirements.

The Committee was advised by the Office of Weights and Measures that this matter would be taken care of through certain revisions in Handbook 105-1 and that State officials and manufacturers of weights would be notified of these changes and of the proper application of $\mathrm{H}-105-1$ requirements by weights and measures officials. Handbook 105-1 was obviously intended to cover field standard weights used by weights and measures officials in the performance of their official duties, and not weights used by the industry for their testing purposes. 
The Committee hopes this matter has been resolved to the satisfaction of all concerned. The publication of Handbook 105-1 by OWM was a most needed and progressive step in upgrading requirements in this area, and the Committee wishes to acknowledge its appreciation and support of such publication.

(The foregoing item was adopted by voice vote.)

7. General.-There were several other major technical areas that received some consideration by the Committee over the year, but developments in these areas have not advanced sufficiently to report on them in detail. So that those who may be interested are at least informed on what the future holds, the list includes (1) milk meters, (2) liquid-fertilizer meters, (3) cryogenic meters, and (4) standard provers.

(The foregoing item was adopted by voice vote.)

The Committee expresses its appreciation to all who have contributed to and participated in the committee deliberations. The Committee urges all weights and measures officials and other affected parties to promptly communicate with the Committee on all matters of concern. It is only in this manner that the Committee can consider all problems and fully evaluate all situations prior to issuing its tentative report.

\author{
R. REBUfFo, Chairman \\ W. C. Hughes, \\ D. E. KONSOER, \\ J. C. MAYS, \\ R. L. THOMPSON \\ H. F. Wollin, Secretary \\ O. K. WarnloF, Staff Assistant \\ Committee on Specifications \\ and Tolerances
}

(Mr. Rebuffo moved for adoption, and after a second from the floor, the report of the Committee on Specifications and Tolerances as amended was adopted in its entirety by the Conference by voice vote.)

(On motion of the committee chairman, seconded from the floor, the Conference by voice vote authorized the Executive Secretary to make any appropriate editorial changes in the language adopted by the Conference, so long as the principles thus adopted are strictly adhered to.) 
Presented by J. F. Lyles, Chairman, Supervisor, Weights and Measures Regulatory Section, Division of Regulatory Services, State of Virginia

(Thursday, July 16,1970 )

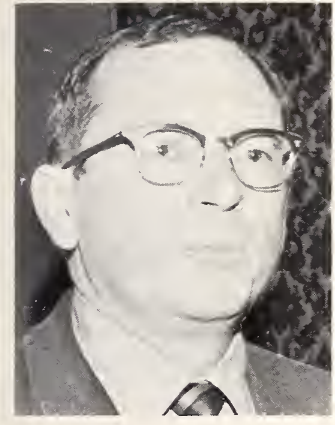

mittee.

The Committee on Laws and Regulations submits its report to the 55th National Conference on Weights and Measures. The report consists of the tentative report, transmitted in April as part of the Conference Announcement, as amended by the final report.

The report represents recommendations of the Committee that have been formed on the basis of comments received during the year and during the open meeting of the Com-

The Model State Law on Weights and Measures

1. Section 13. Inspection of Packages.-The Western Weights and Measures Association requested that the phrase "from time to time" be deleted from the first sentence in section 13, and substitute in its place "as often as necessary to provide adequate protection." It was noted that the new language would be more specific and meaningful. The Committee agrees and recommends that section 13 be amended in accordance with this request.

(The foregoing item was adopted by voice vote.)

2. Section 35. Fluid Dairy Products.-The Committee has been requested to consider changes to section 35 for packaged sour cream and yogurt. Requests for such changes have been received from industry and weights and measures officials. Current industry practice is to fill packages of sour cream and yogurt while the product is still in liquid form. Thereafter the products cool and become semisolid or viscous. At times, this procedure results in an unavoidable shrinkage, presenting a problem when the products are sold on a fluid-measure basis.

Additionally, some jurisdictions require these products to be sold by liquid measure, some require sale by net weight, while others accept either method of sale. This lack of uniformity may well cause consumer confusion in purchasing these products. The 
nonuniformity has also caused some difficulty for firms that ship these products into several jurisdictions.

The Milk industry Foundation has requested that sour cream be required to be sold by weight in specified quantities. They have also requested that yogurt be required to be sold by weight. However, the market for yogurt has not been fully developed, and specified quantities that will serve consumer needs are yet to be determined. For these reasons, the Committee recommends the following:

SECTION 35. FLUID DAIRY PRODUCTS.-All fluid dairy products, including but not limited to whole milk, skimmed milk, cultured milk, sweet cream, and buttermilk, shall be packaged for retail sale only in units of 1 gill, $1 / 2$ liquid pint, 10 fluid ounces, 1 liquid pint, 1 liquid quart, $1 / 2$ gallon, 1 gallon, $1 \frac{1}{2}$ gallons, 2 gallons, $2 \frac{1}{2}$ gallons, or multiples of a gallon: Provided, That packages in units of less than 1 gill shall be permitted: And provided further, That sour cream and yogurt shall be sold in terms of weight, and sour cream shall be packaged for retail sale only in units of $4,8,12,16,32,64$, and 128 ounces avoirdupois. The effective date of the requirements for the sale of sour cream and yogurt shall be July 1, 1971.

The Committee recognizes the problem of an appropriate definition for the term "fluid dairy products," and will take it under consideration.

(The foregoing item was adopted by voice vote.)

3. Adoption of Regulations.-The Committee has been advised that one jurisdiction inadvertently eliminated regulations adopted under their basic weights and measures statute at the time the Model State Weights and Measures Law was being enacted. This oversight has forced this particular jurisdiction to go through the time-consuming process of readopting regulations. In order to avoid this situation in the future, the Committee recommends the addition of a note at the end of the Model Law bringing attention to the need for preserving existing regulations, as follows :

NOTE: Special mention of existing regulations should be made when considering enactment of the Model Law. Jurisdictions wishing to preserve existing regulations adopted under old statutes should consider providing for them when adopting the Model Law.

The Committee will explore the feasibility of adding a specific section to the Model Law covering the preservation or continuation of existing regulations. 
The Committee finds it necessary to recommend several additions and changes to the Model State Packaging and Labeling Regulation. These changes and additions are made necessary as a result of regulations issued by the Food and Drug Administration and the Federal Trade Commission under the Fair Packaging and Labeling Act. Changes were also made necessary by the actions of the Federal Trade Commission in excluding a number of commodities from coverage under FPLA. Accordingly, the Committee recommends the following amendments and additions:

SECTION 6.7. FRACTIONS.-A statement of net quantity of contents of any consumer commodity may contain common or decimal fractions. A common fraction shall be in terms of halves, quarters, eighths, sixteenths, or thirtyseconds, except that

(a) if there exists a firmly established general consumer usage and trade custom of employing different common fractions in the net quantity declaration of a particular commodity, they may be employed, and

(b) if linear measurements are required in terms of yards or feet, common fractions may be in terms of thirds.

A common fraction shall be reduced to its lowest terms; a decimal fraction shall not be carried out to more than two places.

(The foregoing item was adopted by voice vote.)

\section{SECTION 10.8. MEASUREMENT OF CONTAINER-TYPE COMMODITIES, HOW EXPRESSED.}

10.8.1 GENERAL.-Commodities designed and sold at retail to be used as containers for other materials or objects, such as bags, cups, boxes, and pans, shall be labeled with the declaration of net quantity as follows:

(a) For bag-type commodities, in terms of count followed by linear dimensions of the bag (whether, packaged in a perforated roll or otherwise). When the unit bag is characterized by two dimensions because of the absence of a gusset, the width and length will be expressed in inches, except that a dimension of 2 feet or more will be expressed in feet with any remainder in terms of inches or common or decimal fractions of the foot. (Example: " 25 bags, 17 in $\times 20$ in" or "100 bags, 20 in $\times 2 \mathrm{ft}$ 6 in" or " 00 bags, 20 in $\times 2 \frac{1}{2} \mathrm{ft}$ ".)

When the unit bag is gusseted, the dimensions will be expressed as width, depth, and length, in terms of inches, except that any dimension of 2 feet or more will be expressed in feet with any remainder in terms of inches or the common or decimal fractions of the foot. (Examples: " 25 bags, 17 in $\times 4$ in $\times 20$ in" or " 100 bags, 20 in $\times 12$ in $\times 2 \frac{1}{2} \mathrm{ft}$ ".)

(b) For other square, oblong, rectangular, or similarly shaped containers, in terms of count followed by length, width, and depth, except depth need not be listed when less than 2 inches. (Example: " 2 cake pans, $S$ in $\times$ 8 in" or "roasting pan, 12 in $\times 8$ in $\times 3$ in".)

(c) For circular or other generally round-shaped containers, except cups, and the like, in terms of count followed by diameter and depth, 
except depth need not be listed when less than 2 inches. (Example: "4 pie pans, 8 in diameter" or "2 cake pans, 8 in diameter $\times 4$ in".)

(The foregoing item was adopted by voice vote.)

10.8.2 CAPACITY.-When the functional use of the container is related by label references in standard terms of measure to the capability of holding a specific quantity of substance or class of substances such references shall be a part of the net quantity statement and shall specify capacity as follows :

(a) Liquid measure for containers which are intended to be used for liquids, semisolids, viscous materials, or mixtures of solids and liquids. The expressed capacity will be stated in terms of the largest whole unit (gallon, quart, pint, ounce), with any remainder in terms of the common or decimal fraction of that unit. (Example: Freezer Boxes: " 4 boxes, 1quart capacity, 5 in $\times 4$ in $\times 3$ in".)

(b) Dry measure for containers which are intended to be used for solids. The expressed capacity will be stated in terms of the largest whole unit (bushel, peck), with any remainder in terms of the common or decimal fraction of that unit. (Example: Leaf Bags: "8 bags, 6-bushel capacity, $3 \mathrm{ft} \times 5 \mathrm{ft}$ ".)

(c) Where containers are used as liners for other more permanent containers, in the same terms as are normally used to express the capacity of the more permanent container. (Example: Garbage Can Liners: "10 liners, $2 \mathrm{ft} 6$ in $\times 3 \mathrm{ft} 9 \mathrm{in}$, fits up to 30 -gallon cans.")

Notwithstanding the above requirements, the net quantity statement for containers such as cups will be listed in terms of count and liquid capacity per unit. (Example: " 24 cups, 6 fl. oz capacity.") For purposes of this section, the use of the terms "capacity," "diameter," and "fluid" is optional.

(The foregoing item was adopted by voice vote.)

\section{SECTION 10.9. TEXTILE PRODUCTS, THREADS, AND YARNS.}

10.9.1 WEARING APPAREL.-Wearing apparel (including nontextile apparel and accessories such as leather goods and footwear) sold as single-unit items, or if normally sold in pairs (such as hosiery, gloves, and shoes) sold as singleunit pairs, shall be exempt from the requirements for a net quantity statement by count, as required by subsection 6.3. of this regulation.

(The foregoing item was adopted by voice vote.)

10.9.2 TEXTILES.-Bedsheets, pillowcases, blankets, bedspreads, afghans, throws, flags, dresser and other furniture scarfs, curtains, drapes, facecloths, tablecloths, and napkins shall be exempt from the requirements of subsection 6.6.7. of this regulation: Provided, That:

(a) The net quantity statement for fitted sheets shall be expressed in terms of length and width measurement in inches of the size of mattress which the sheet will fit. The principal display panel may also contain a designation for the size of mattress which the sheet will fit, such as "twin," "double," "king," etc.

(b) The net quantity statement for nonfitted or flat sheets shall be expressed in terms of the finished length and width measurements of the sheet in inches, which may be followed in parentheses by a statement of the length and width of the sheet prior to hemming in inches, 
such parenthetical expression to include the phrase "size before hemming" or words of similar import in the same type size as the required statement. The principal display panel may also contain a designation for the size of the mattress which the sheet was intended to fit, such as "twin," "double," etc.

(c) The net quantity statement for pillowcases shall be expressed in terms of the finished length and width measurements in inches of the pillowcase, which may be followed in parentheses by a statement of length and width in inches of the pillowcase prior to hemming, such parenthetical expression to include the qualification "size before hemming" or "prehemming size." A designation of the size of the pillow which the pillowcase will fit may be included, such as "regular," "queen," "king," "bolster," etc.

(d) The net quantity statement for blankets, bedspreads, afghans, and throws shall be expressed in terms of the finished length and width measurements in inches, which shall be followed in parentheses by a statement of the length of any ornamentation, such as "including 2-inch fringe." A designation of the size of the mattress which the commodity is intended to fit may be included, such as "twin," "double," "king," "queen," etc.

(e) The net quantity statement for tablecloths and napkins shall be expressed in terms of finished length and width in inches, which may be followed in parentheses by a statement of length and width in inches in terms of the cut size (size before hemming) and properly identified as such.

(f) The net quantity statement for curtains, drapes, facecloths, flags, dresser and other furniture scarfs shall be expressed in terms of linear dimensions in inches for the finished size, which shall be followed in parentheses by a statement of the length of any ornamentation, such as "including 2 -inch fringe."

(g) The net quantity statement for carpets and rugs shall be expressed in terms of length and width in feet, with any remainder in common or decimal fractions of the foot or in inches, which shall be followed in parentheses by a statement of the length of any ornamentation, such as "including 2 -inch fringe."

(The foregoing item was adopted by voice vote.)

10.9.3. SEWING THREADS, HANDICRAFT THREADS, AND YARNS.Sewing and handicraft threads shall be exempt from the requirements of subsection 6.6.2. of this regulation: Provided, That:

(a) The net quantity statement for sewing and handicraft threads shall be expressed in terms of yards.

(b) The net quantity statement for yarns shall be expressed in terms of weight.

(c) Thread products may, in lieu of name and address, bear a trademark, symbol, brand, or other mark that positively identifies the manufacturer, packer, or distributor, provided that such marks employed to identify the vendor shall be filed with the director.

(d) Each unit of industrial thread shall be marked to show its net measure in terms of yards or its net weight in terms of avoirdupois pounds or ounces, except that ready-wound bobbins which are not sold separately shall not be required to be individually marked, but the package con- 
taining such bobbins shall be marked to show the number of bobbins contained therein and the net yards of thread on each bobbin.

(The foregoing item was adopted by voice vote.)

SECTION 11.2. RANDOM PACKAGES.-A random package bearing a label conspicuously declaring

(a) the net weight,

(b) the price per pound, and

(c) the total price

shall be exempt from the type size, dual declaration, placement, and free area requirements of this regulation. In the case of a random package packed at one place for subsequent sale at another, neither the price per unit of weight nor the total selling price need appear on the package, provided the package label includes both such prices at the time it is offered or exposed for sale at retail.

This exemption shall also apply to uniform weight packages of cheese and cheese products labeled in the same manner and by the same type of equipment as random packages exempted by this section.

(The foregoing item was adopted by voice vote.)

SECTION 11.3. SMALL CONFECTIONS.-Individually wrapped pieces of "penny candy" and other confectionery of less than one-half ounce net weight per individual piece shall be exempt from the labeling requirements of this regulation when the container in which such confectionery is shipped is in conformance with the labeling requirements of this regulation. Similarly, when such confectionery items are sold in bags or boxes, such items shall be exempt from the labeling requirements of this regulation, including the required declaration of net quantity of contents, when the declaration of the bag or box meets the requirements of this regulation.

(The foregoing item was adopted by voice vote.)

\section{SECTION 11.9. FLUID DAIRY PRODUCTS, ICE CREAM, AND SIMILAR FROZEN DESSERTS.-}

(a) When packaged in $1 / 2$-liquid-pint and $1 / 2$-gallon containers, are exempt from the requirements for stating net contents of 8 fluid ounces and 64 fluid ounces, which may be expressed as $1 / 2$ pint and $1 / 2$ gallon, respectively.

(b) When packaged in 1-liquid-pint, 1-liquid-quart, and 1/2 gallon containers, are exempt from the dual net contents declaration requirements of subsection 6.6.4.

(c) No change.

(d) No change.

(e) Delete.

(The foregoing item was adopted by voice vote.) 
[NOTE: Add new section 11.10. as follows and renumber subsequent sections.]

SECTION 11.10. SINGLE STRENGTH AND LESS THAN SINGLE STRENGTH FRUIT JUICE BEVERAGES, IMITATIONS THEREOF, AND DRINKING WATER.-

(a) When packaged in glass, plastic, or fluid milk type paper containers of 8- and 64-fluid-ounce capacity, are exempt from the requirements of subsection 6.4(b), to the extent that net contents of 8 fluid ounces and 64 fluid ounces (or 2 quarts) may be expressed as $1 / 2$ pint (or half pint) and $1 / 2$ gallon (or half gallon), respectively.

(b) When packaged in glass, plastic, or fluid milk type paper containers of 1-pint, 1-quart, and $1 / 2$ gallon capacities, are exempt from the dual net contents declaration requirements of subsection 6.6.4.

(c) When packaged in glass or plastic containers of $1 / 2$-pint, 1-pint, 1-quart, $1 / 2$-gallon, and 1-gallon capacities, are exempt from the placement requirement of subsection 8.1.1. that the declaration of net contents be located within the bottom 30 percent of the principal display panel: Provided, That other required label information is conspicuously displayed on the cap or outside closure and the required net quantity of contents declaration is conspicuously blown, formed, or molded into or permanently applied to that part of the glass or plastic container that is at or above the shoulder of the container.

(The foregoing item was adopted by voice vote.)

SECTION 11.22. PRESCRIPTION AND INSULIN-CONTAINING DRUGS. -Prescription and insulin-containing drugs subject to the provisions of section 503(b)(1) or 506 of the Federal Food, Drug, and Cosmetic Act shall be exempt from the provisions of this regulation.

\section{[Delete reference to drugs in 6.4. and 11.8.]}

(The foregoing item was adopted by voice vote.)

SECTION 11.23. CAMERA FILM.-Camera film packaged and labeled for retail sale is exempt from the net quantity statement requirements of this regulation which specify how measurement of commodities should be expressed: Provided, That:

(a) The net quantity of contents on packages of movie film and bulk still film is expressed in terms of the number of lineal feet of usable film contained therein.

(b) The net quantity of contents on packages of still film is expressed in terms of the number of exposures the contents will provide. The length and width measurements of the individual exposures, expressed in millimeters or inches, are authorized as an optional statement. (Example: "36 exposures, $36 \times 24 \mathrm{~mm}$ " or " 12 exposures, $2 \frac{1 / 4}{4} \times 2 \frac{1}{1}$ in.") 
The Committee has been requested to provide an exemption from dual quantity statements for paints, motor oils, and antifreeze, because such products are, for the most part, sold in standard quantities. Additionally, the end use to which such products are put are generally referred to in standard units. For example, protection charts for antifreeze are presented in terms of the number of quarts necessary to reach a given level of protection, based on the capacity of a cooling system measured in terms of quarts. Similarly, crankcase capacities for motor oils are presented in terms of quarts. In order to encourage standardization of package quantities, and because of the end use nature of the products, the Committee recommends exemption from dual quantity statements. Additionally, the Committee, on its own initiative, recommends an exemption from identity requirements for packaged motor oils to minimize the number of different containers necessary to pack the various motor oils.

SECTION 11.24. PAINTS AND KINDRED PRODUCTS.-Paints, varnishes, lacquers, thinners, removers, oils, resins, and solvents, when packed in 1liquid-pint and 1-liquid-quart units shall be exempt from the dual quantity declaration requirements of subsection 6.6.4.

(The foregoing item was adopted by voice vote.)

SECTION 11.25. AUTOMOTIVE COOLING SYSTEM ANTIFREEZE.-Antifreeze, when packed in 1-liquid-quart units, in metal or plastic containers, shall be exempt from the dual quantity declaration requirements of subsection 6.6.4.

(The foregoing item was adopted by voice vote.)

SECTION 11.26. MOTOR OILS,-Motor oils, when packed in 1-liquid-quart units, shall be exempt from the dual quantity declaration requirements of subsection 6.6.4. Additionally, motor oil in 1-liquid-quart, 1-gallon, 11/4-gallon, 2-gallon, and $21 / 2$-gallon units, bearing the principal display panel on the body of the container, is exempt from the requirements of section 3, Identity, to the extent that the SAE grade is required to appear on the principal display panel, provided the SAE grade appears on the can lid and is expressed in letters and numerals in type size of at least one-fourth inch.

(The foregoing item was adopted by voice vote.)

\section{Interpretations}

The Committee has been requested to provide interpretive material concerning particular requirements of the Model State Packaging and Labeling Regulation. In response to these requests, the Committee has considered four such items for inclusion in this 
tentative report. It is planned that these interpretations will be incorporated into the Weights and Measures Packaging and Labeling Manual now under preparation in the Office of Weights and Measures. From time to time, the Committee will continue to provide interpretive material and make it available through the Manual.

1. Supplementary Quantity Declarations-It has been brought to the attention of the Committee that some clarification on the subject of supplementary quantity declarations on packaged consumer commodities is necessary. The use of supplementary quantity declarations that are not deceptive or misleading is certainly anticipated in the Model State Packaging and Labeling Regulation. Specific provisions for their use are presented in subsection 6.8.1.

It is the view of the Committee that a clear distinction between required and supplemental quantity declarations is mandated by the Model Regulation. Supplementary quantity declarations are those which are additive to the required statement. Presentation of such additional quantity information is at the option of the producer with the clear prohibition that such additional information cannot appear on the principal display panel(s).

The use of supplementary quantity statements does not create a conflict with the requirements of section 2.7. pertaining to principal display panels. The mere appearance on a panel other than the principal display panel of the identity and a supplemental statement as permitted by subsention 6.8.1 does not, in and of itself, transform such panel into a principal display panel. Also, the repetition of a portion of the required quantity statement in a nondeceptive or nonmisleading manner on the prinicpal display panel or other panel is not prohibited by section 2.7 or 6.8.1.

(The foregoing item was adopted by voice vote.)

2. Retroactive Requirements.-A request has been made that the Committee recommend the addition of a clause to the Model State Packaging and Labeling Regulation prohibiting the requirements from being made retroactive for products in the stream of commerce at the time the Model Regulation is adopted. It is the Committee's view that this is not necessary. Many of the requirements in the Model Regulation are of long standing, and a blanket exclusion for products in the stream of commerce would be inappropriate. The Committee cautions, however, that the question of which requirements are retroactive and which are new should be carefully considered when implementing new regulations. 
3. Quantity Statements by Count.-The Committee endorses the policy of the Federal Trade Commission with respect to the "Statement of Net Quantity by Count for a Single Packaged Commodity," as stated in FTC Interpretive Bulletin No. 3 of November 1,1969 . It is felt that this policy is a reasonable one, and its application will in no way be detrimental to the interests of consumers or manufacturers, packers, and distributors.

Accordingly, it is the Committee's recommendation that this policy be adopted by weights and measures officials in all instances concerning single-unit packaged commodities :

When a consumer commodity is properly measured in terms of count only, or in terms of count and weight, volume, area, or dimension, the regulations are interpreted not to require the declaration of the net content as "one," provided the statement of identity clearly expresses the fact that only one unit is contained in the package. Thus, the unit synthetic sponge, the unit light bulb, and the unit dry cell battery do not require a net quantity statement of "one sponge," "one light bulb," or "one dry cell battery." However, there still exists the necessity to provide a net quantity statement to specify weight, volume, area, or dimensions when such are required. For example, the synthetic sponge which is packaged requires dimensions, such as " 5 in $\times 3$ in $\times 1$ in". This interpretation does not preclude the option to enumerate a unit count on a single packaged commodity if so desired.

(The foregoing item was adopted by voice vote.)

4. Principal Display Panel-General Merchandise Items.-Section 2.7. of the Model State Packaging and Labeling Regulation defines principal display panel as "that part, or those parts, of a label that is, or are, so designed as to most likely be displayed, presented, shown, or examined under normal and customary conditions of display and purchase." It is this portion or panel of the label which must bear the statement of identity and the quantity of contents declaration.

The principal display panel of the package is that surface of the package which bears the principal label panel. It is the area of this surface of the package that determines the size of the quantity of contents declaration. Use of the area of the principal display panel of the package to determine type size ensures that packages of substantially the same size will bear a quantity of contents declaration statement of a corresponding uniformity. The size of the label itself is not the subject of regulation. The label need be only of sufficient size to accommodate the required information, in a proper type size, adequately separated from other printed information, and in a conspicuous manner. It is important to note, however, that the presence of either a statement of identity or a statement of contents declaration alone on a label panel does not necessarily qualify the surface as a principal display 
panel. The criterion to be used is whether the manufacturer, either by design or through trade practice, customarily designates a specific package surface, or surfaces, for display of the product at retail.

A "header label," for example, attached at the top of a transparent or opaque bag could be utilized as a principal display panel, provided the header bears the required mandatory information and the bag itself is devoid of other mandatory information. In packages of this type, the quantity of contents declaration would appear in the lower 30 percent of the "header label." The size of the quantity of contents declaration would be determined by the area of the principal display panel of the package which in this case includes not only the "header label," but the entire front of the bag.

These considerations are important in determining the appropriateness of package labeling for general merchandise items that are displayed, for example, in step-up rack displays. In such circumstances, it is obviously the intent and responsibility of the manufacturer to designate a specific area of the package surface as the principal display panel. The required statement of quantity must appear in the lower 30 percent of the area specified as the principal display panel. There is, of course, a prohibition against any mandatory labeling information appearing below the specified principal display panel area.

(The foregoing item was adopted by voice vote.)

Model State Regulation Pertaining to Dimensions for Manufactured Lumber

For close to a century, lumber generally has been advertised for sale, offered for sale, and sold at nominal dimensions, as contrasted with actual dimensions. The nominal 2 by 4 , for example, actually has measured $15 / 8$ by $35 / 8$ inches.

This practice of nominal representation was the result of an evolution in the lumber production industry from hand-cut to roughly-sawn, to planed (surfaced) pieces. Although there has not been a general outcry for actual dimension representation, there has been a significant number of questions and complaints.

The actual dimensions have been standardized through voluntary standards published by the Department of Commerce for many years. During December 1969 the Department published a revision of the voluntary standard for softwood lumber that reduced the actual size of dimension lumber substantially. The 2 by 4 surfaced at 19 percent moisture content or less is to become $11 / 2$ by $31 / 2$ inches; this same nominal dimension when surfaced at a moisture content above 19 percent is fixed at $1 \% / 16$ by $3 \% 16$ inches. 
Because these new standard dimensions represent a significant reduction in the cross-sectional area of dimensional lumber and because of the increasing concern of public bodies and consumers with respect to the integrity of representations, the Committee recommends the adoption by the National Conference of a model regulation covering the advertising, selling, and invoicing of lumber as follows:

\section{MODEL STATE LUMBER REGULATION}

1. APPLICATION.-This regulation shall apply to dressed (surfaced) lumber, boards, timbers, and dimension lumber, but shall not apply to rough lumber or to dressed lumber that has been matched, patterned, shiplapped, or otherwise remanufactured or joined so as to have changed the form or identity, such as individual, assembled. or packaged millwork items.

2. DEFINITIONS.-

2.1. DRESSED (SURFACED) LUMBER.-Lumber that has been dressed by a planing machine (for the purpose of attaining smoothness of surface and uniformity of size) on one side, two sides, one edge, two edges, or a combination of sides and edges.

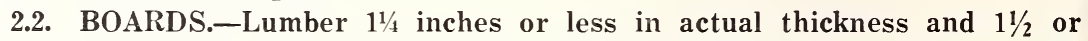
more inches in actual width. Boards less than $51 / 2$ inches in actual width may be classified as strips.

2.3. DIMENSION LUMBER.-Lumber from $1 \frac{1}{2}$ inches to, but not exceeding, $4 \frac{1}{2}$ inches in actual thickness, and $1 \frac{1}{2}$ or more inches in actual width. Dimension lumber may be classified as framing, joists, planks, rafters, studs, small timbers, etc.

2.4. TIMBERS.-Lumber $4 \frac{1}{2}$ or more inches in least actual dimension. Timber may be classified as beams, stringers, posts, caps, sills, girders, purlins, etc.

2.5. ROUGH LUMBER.-Lumber which has not been dressed (surfaced) but which has been sawed, edged, and trimmed at least to the extent of showing saw marks in the wood on the four longitudinal surfaces of each piece for its overall length.

2.6. MATCHED LUMBER.-Lumber that has been worked with a tongue on one edge of each piece and a groove on the opposite edge to provide a closetongue-and-groove joint by fitting two pieces together; when end-matched, the tongue and groove are worked in the ends also.

2.7. SHIPLAPPED LUMBER.-Lumber that has been worked or rabbeted on both edges of each piece to provide a close-lapped joint by fitting two pieces together.

2.8. PATTERNED LUMBER.-Lumber that is shaped to a pattern or to a molded form, in addition to being dressed, matched, or shiplapped, or any combination of these workings.

2.9. SPECIES.-The botanical name assigned to a class of trees having common characteristics.

2.10. SPECIES GROUP.-The commercial name assigned to two or more individual species have similar growth characteristics.

2.11. GRADE.-The commercial name assigned to lumber meeting specifications established by a nationally recognized lumber organization.

3. IDENTITY.-The identity of individual pieces, or lots of individual pieces, of lumber, subject to this regulation, shall include the grade of the lumber and the species or species group in any advertisement, sales slip, bill of sale, invoice, or the like. 
4. QUANTITY.-All lumber, subject to this regulation, shall be offered for sale, sold, and invoiced (including sales slips, billing, and the like) in terms of the number of pieces, the price per single piece, and the actual dimensions of width, thickness, and length of the pieces at time of sale; Provided, That in the case of an individual piece and in the case of a lot, shipment, or delivery, the tolerance in deficiency on the length shall be $1 / 16$ inch and the tolerance in deficiency on the width and on the thickness shall be 1 percent of the dimension for each 4 percent moisture content below 30 percent.

5. EFECTIVE DATE.-The requirements of this regulation, with respect to advertising, shall become effective on January 1, 1971; all other requirements shall be effective on September 1, 1971.

The Committee is confident that the proposed Model State Lumber Regulation can be speedily adopted and implemented by the States under the authority of Sections 9 and 25 of the Model State Weights and Measures Law.

(Lengthy discussion followed the presentation of the Model State Lumber Regulation. A motion was made to amend section 1 to make it apply only to retail lumber sales. It was noted that weights and measures officials had to be concerned with all commercial transactions, including those at retail. The Executive Secretary offered an explanation of the new voluntary standard for lumber. Following these developments, the motion to amend was tabled, and the Regulation was adopted by voice vote.)

Other Items

1. Survey of Lawn Care and Soil Conditioner Products.-At the request of the Committee, the Office of Weights and Measures is currently conducting a survey of the marketplace to determine the extent of the problems in the lawn care and soil conditioner fields. The survey includes information concerning method of sale, package labeling, and package quantities. Depending on the results of the survey, the Committee will keep this item on its agenda for future action.

(The foregoing item was adopted by voice vote.)

2. Coin-operated Devices.-A request has been made to study the necessity for amending the Model State Weights and Measures Law to specifically include coin-operated devices used in commercial service. It is the opinion of the Committee that no such change is necessary, since such devices are clearly in commercial service and, therefore, adequately covered by the Model Law.

Additionally, the Committee has been asked to study the question of the need for quantity statements on vending machines. It has been brought to our attention that there might be some need for a clear representation of the quantity for items sold through vending machines. The Committee would like to hear from 
weights and measures officials concerning their experiences in this area.

(The foregoing item was adopted by voice vote.)

\title{
Summary
}

The Laws and Regulations Committee extends its thanks to all those members of the Conference and business and industry representatives who submitted items for consideration. Only through such continuing communications can the Committee fulfill its function to the Conference.

\author{
J. F. LYLES, Chairman \\ S. D. ANDREWS \\ G. L. Delano \\ M. R. DETTLER \\ R. W. RICHARDS \\ H. F. Wollin, Secretary \\ E. A. VAdELund, Staff Assistant
}

Committee on Laws and Regulations

(Mr. Lyles moved for adoption, and after a second from the floor, the report of the Committee on Laws and Regulations was adopted in its entirety by the Conference by voice vote.)

(On motion of the committee chairman, seconded from the floor, the Conference by voice vote authorized the Executive Secretary to make any appropriate editorial changes in the language adopted by the Conference, so long as the principles thus adopted are strictly adhered to.)

\section{REPORT OF THE EXECUTIVE COMMITTEE}

Presented by R. W. SEARLES, Chairman, Sealer of Weights and Measures, Medina County, Ohio

Wednesday, July 15, 1970

The Executive Committee of the National Conference on Weights and Measures met in open session on Monday, July 13, 1970, at 11:00 A. M. Discussion was held on the following items:

1. Plans for the 56th National Conference.-The Executive Committee has heard and discussed the following general arrangements for the 56th National Conference:

$\begin{array}{ll}\text { Site: } & \text { Washington, D. C. } \\ \text { Hotel: } & \text { The Shoreham } \\ \text { Dates: } & \text { July } 12-16,1971 \\ \text { Rates: } & \$ 19 \text { single, } \$ 23 \text { double, } \$ 45 \text {-up suites }\end{array}$


The Committee is in agreement with these arrangements and recommends action accordingly to the incoming Executive Committee.

2. Program Details.-The Committee heard discussion during its open meeting concerning the possible need for an increase in the registration fee for the 56th National Conference. It was the consensus of the Committee that the matter of registration fee be left to the discretion of the Executive Secretary to recommend such action to the incoming Executive Committee if and when needed.

3. Statement of Policy on Procedures of Standing Committees. -The Committee recommends adoption of the procedural guidelines as listed in the Committee's Special Report as published in the Conference Announcement Booklet, reading as follows:

\section{Statement of Policy on Procedures of Standing Committees}

\section{Interim Meetings.}

(a) An interim meeting of the standing committees of the National Conference on Weights and Measures shall be scheduled approximately five months prior to the annual Conference meeting.

(b) All matters to be considered by a committee for action during the Conference shall be presented in writing to the committee before or during the interim meeting.

(c) On request, committees will hold hearings for presentations by government officials and by industry representatives during the interim meeting.

2. Tentative Reports.

(a) Matters under consideration by a committee, and upon which it offers comments or recommendations for action by the Conference during the annual meeting, shall be included in the committee's tentative report as published in the Conference Announcement.

(b) The Conference Announcement 'shall be prepared and distributed approximately three months prior to the annual Conference meeting.

3. Comments on Tentative Reports.

(a) Written comments, suggestions, and proposals by weights and measures officials, industry representatives, and all others on items in the tentative report shall be encouraged.

(b) All comments, suggestions, or proposals on the tentative reports shall be submitted to the Conference Executive Secretary no later than one month preceding the opening of the National Conference meeting. This schedule provides a two-month period for consideration of the tentative report by all persons and allows the committee the necessary time to study and consider the comments received prior to the Conference opening.

(c) Except by unanimous consent of the Conference, the proposal of new or additional items shall not be accepted (see 6(b) that follows) by a committee after the interim meeting and publication of its tentative report for action by the forthcoming Conference. However, such items may be offered for discussion and future consideration by a committee during the open committee meeting that is held during the annual Conference. 
4. Open Committee Meetings-Annual Conference.

(a) Each standing committee shall hold an open session during the early part (usually Monday) of Conference week for the purpose of hearing discussion on all items in its tentative report, as well as those items suggested to the committee for consideration during the following year.

5. Final Committee Reports and Conference Action.

(a) Following the open hearings, each committee shall prepare its final report for action by the voting membership of the Conference later in the week. Copies of each final report shall be made available for study prior to the session during which it is presented and acted upon.

(b) The chairman of each committee shall present the final report of the committee to the Conference body. A vote shall be taken on individual items in the report as circumstances require, and on the entire final report as presented. Parliamentary procedure according to Roberts Rules of Order shall be strictly adhered to in the presentation of and action on standing committee reports. Time limitations on the discussion of a question or amendments may be imposed by the presiding officer as required. Voting shall be supervised according to parliamentary procedures and to the procedures established by the Conference.

6. Exceptions to the Above Policy.

(a) Circumstances beyond the control of those responsible may cause slight changes in the time schedules outlined in this policy. If necessary, allowance for such changes shall be announced by the committees.

(b) A committee may be obligated to accept a new item for study and recommended action after the interim meeting and publication of its tentative report to meet an emergency situation. (For example, to comply with actions taken by Federal agencies which have a responsibility under the Fair Packaging and Labeling Act.) It shall be the responsibility of the committee to decide which new items justify emergency action and to request unanimous consent of the Conference for such action.

4. Voting.-A thorough discussion of Conference voting procedures took place both during the open meeting of the Committee and during its executive session following the open meeting. It should be noted that present Committee members do represent the major geographical areas of the United States. Following a free flow of comments and suggestions from those present, the Committee voted unanimously to retain the present voting procedures with the very strong proposal to the Executive Secretary that the Conference be held periodically in different areas of the country.

5. Appointment of Parliamentarian and Sergeant-at-Arms.Inasmuch as the Conference Chairman is authorized to appoint various Conference officials, the Committee recommends that a Parliamentarian and Sergeant-at-Arms be appointed to serve during each new Chairman's term.

6. Report of Associate Membership Committee.-During the open meeting, Arthur Sanders, Chairman of the Associate Membership Committee, reported the following items: 
(a) It was decided to retain present Committee membership on a continuing basis, rotating the Chairmanship each year. Emmett Wehmann of Neptune Meter Company was recommended to serve as Chairman of the Committee for the coming year.

(b) Mr. Charles (Chuck) Campbell of Toledo Scale Company has agreed to serve as Coordinator for the Industry Trade Party for the next several years. The Executive Committee wishes to express its appreciation to Mr. Mack Rapp of Detecto Scale Company for serving as Coordinator this year.

(c) The Committee urges and will solicit greater participation by all segments of industry for National Weights and Measures Week promotion.

(d) The Committee recommends that the Executive Committee authorize the Office of Weights and Measures of NBS to make a survey of the industry to determine the feasibility of industry exhibits at future Conferences.

Based on this report from the Associate Membership Committee, the Executive Committee voted in favor of authorizing OWM to begin an immediate survey of the industry to determine the feasibility of future exhibits. The Committee wishes to express its appreciation to the Associate Membership Committee for their helpful suggestions and support.

The Committee is grateful to those delegates who offered written comments on the items under consideration and to those attending the open meeting for their comments and guidance.
R. W. Searles, Chairman
M. H. Becker
J. R. Bird
L. A. Gredy
C. Wooten
C. C. Morgan
J. I. Moore
E. W. Ballentine
R. C. Baumgartner

J. T. Bennett

R. J. Cord

F. J. Fallon

B. R. Haught

F. D. Morgan

L. A. Rick

L. W. Vezina

R. T. Williams

H. F. Wollin, Secretary

R. N. Smith, Staff Asst.

\section{Executive Committee}

(On motion of the Committee Chairman, seconded from the floor, the report of the Executive Committee was adopted by voice vote.) 
Presiding Officer, M. Jennings, Conference Chairman, Director, Division of Marketing, Tennessee Department of Agriculture

(Friday, July 17, 1970)

The Executive Committee held its breakfast meeting on Friday morning, July 17, for the purpose of considering plans for the 56th National Conference on Weights and Measures and to discuss and take action on matters referred to it by the outgoing Executive Committee. A summary of the discussion and decisions that were reached follow:

1. The 56th National Conference on Weights and Measures will be held in Washington, D. C., at the Shoreham Hotel, the week of July 12-16, 1971.

2. The Executive Secretary was authorized to make the necessary arrangements with the Shoreham Hotel, including agreed-to room rates of $\$ 19$ single, $\$ 23$ double, and $\$ 45$-up for suites, and for meeting rooms, social functions, and the like.

3. The program format will remain essentially the same as for the 55th Conference, with emphasis on open-forum sessions and the development of a Conference theme. It was suggested that the topics for the open-forum sessions be pertinent to matters under consideration by the Committee on Laws and Regulations and the Committee on Specifications and Tolerances. An effort will be made to better locate floor microphones and encourage the use of more visual aids during the presentations.

4. The Committee voted to retain the $\$ 20.00$ registration fee until such time as the need for a definite increase was evident.

5. An allocation of $\$ 750$ was approved for expenditures by the Committee on Education to cover expenses associated with $\mathrm{Na}$ tional Weights and Measures Week and other educational projects.

6. The Committee voted its approval to bring the proposed changes in the titles of the Committee on Education and the Committee on Liaison with the National Government before the Conference for a vote in 1971. It was suggested that both committees discuss this matter thoroughly at their interim meetings and come forth with their suggested changes.

7. The Committee voted its approval to hold interim meetings of the four standing committees of the Conference and to pay the travel expenses of committee members and the Conference Chairman.

8. Mr. Emmett Wehmann, Chairman of the Associate Membership Committee, met briefly with the Executive Committee to offer the complete cooperation and support of his committee. 
9. The Committee authorized the Executive Secretary to arrange a dinner meeting of Conference officers to discuss the plans and program for the 56th Conference on Sunday evening of the Conference week. The Committee voted its approval to have each attendee pay the cost of his dinner.

\section{REPORT OF THE COMMITTEE ON NOMINATIONS}

Presented by C. C. Morgan, Chairman, Sealer of Weights and Measures, City of Gary, Indiana

\section{(Thursday, July 16, 1970)}

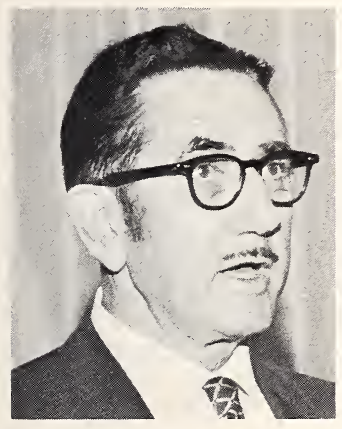

In line with the requirements of the Organization and Procedure of the Conference, Dr. L. M. Branscomb, the Director of the National Bureau of Standards, is the President of the Conference and is authorized to designate the Executive Secretary. All other officers are to be elected by the vote of the Conference.

We are indebted to the Executive Secretary for furnishing a list of those who have attended past Conferences and the number of years each has served on various committees.

Due consideration was given by this Committee to attendance records, geographical distribution, the Conference participation and interest shown in promoting weights and measures administration of the various officials.

Your Committee nominates for office for the 56th National Conference on Weights and Measures the following:

Chairman : M. Jennings, Tennessee.

Vice Chairmen: A. T. Anderson, Cambridge, Massachusetts; M. L. Kinlaw, North Carolina; F. D. Morgan, Utah;

J. O'Neill, Kansas.

Treasurer: C. C. Morgan, Gary, Indiana.

Chaplain: R. W. Searles, Medina County, Ohio.

Executive Committee: N. Bucur, Lake County, Indiana; H. E. Smith, San Mateo County, California; S. F. Valtri, Philadelphia, Pennsylvania; L. D. Holloway, Idaho; R. Glendenning, Maryland; J. A. J. Bovie, Monmouth County, New Jersey; C. O. Cottom, Michigan; J. V. Pugh, South Carolina; W. J. Tusen, New Hampshire; F. P. Gallo, Ohio. 

C. C. Morgan, Chairman
E. H. BLACK
J. E. BOWEN
S. H. CHRISTIE
G. L. JOHNSON
J. I. MOORE
F. D. MORGAN

\section{Committee on Nominations}

(There being no further nominations from the floor, nominations were declared closed and the officers nominated by the Committee were elected unanimously by voice vote.)

\section{REPORT OF THE COMMITTEE ON RESOLUTIONS}

Presented by M. H. BECKER, Chairman, Sealer of Weights and Measures, Los Angeles County, California

(Thursday, July 16, 1970)

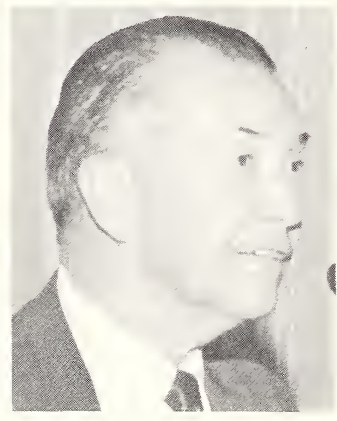

The Committee on Resolutions wishes to express the appreciation of the 55 th $\mathrm{Na}$ tional Conference on Weights and Measures to all who contributed in any way toward the conduct of a successful meeting. A special vote of thanks is extended to the following:

1. To Senator Frank E. Moss for his untiring efforts to serve the cause of consumers throughout the nation and for his enlightening presentation as guest speaker to the annual Conference Luncheon.

2. To Dr. Myron Tribus, Assistant Secretary of Commerce for Science and Technology, for his interest in the concerns of the National Conference.

3. To the Director and staff of the National Bureau of Standards for planning and administering the program.

4. To Mr. A. J. van Male for his splendid address to the Conference and for his active interest in weights and measures administration in the United States as well as throughout the world.

5. To Dr. James C. Fletcher for his excellent and thought-provoking presentation on the subject of science and technology.

6. To Mr. Joseph H. Francis, Commissioner of Agriculture, for his warm welcoming remarks and for making available to the Conference the many facilities of the Utah Department of Agriculture.

7. To all program speakers and committees for having given generously of their time and efforts in their excellent presentations.

8. To the governing officials of all State and local jurisdictions for their manifest interest in weights and measures work.

9. To Mr. Frank B. Newman and the staff of the Hotel Utah for their many courtesies in contributing to the enjoyment and comforts of the delegates. 
10. To representatives of business and industry for their liberal cooperation and hospitality.

11. To Mr. Fred D. Morgan, Supervisor of Weights and Measures, for his superb assistance to the Executive Secretary of the National Conference in arranging the many local details incident to holding the Conference in a distant city.

12. To the Morman Tabernacle Choir for the inspirational musical program presented for the enjoyment of the delegates.

The following resolutions are presented in their entirety for consideration of the members of the Conference :

\title{
Resolution on Department of Defense
}

Whereas, the interests, goals, and objectives of the National Conference on Weights and Measures in providing for equity in all commercial transactions for all buyers and sellers in both the civilian and military populace is shared by the Department of Defense, and

Whereas, the Department of Defense has announced the development of a program of weights and measures enforcement in resale activities at military installations within the United States: Therefore, be it

Resolved, That the National Conference on Weights and Measures does affirm its support and encouragement for such a program as being another important step toward progress in relations with the Federal government in the weights and measures field.

\section{Resolution on Margaret Dana}

Whereas, Margaret Dana, syndicated columnist, is widely read throughout the United States and has great influence upon our nation's consumers, and Whereas, Margaret Dana, with great enthusiasm, has strongly supported the weights and measures profession on numerous occasions in the Nation's press, thereby providing outstanding and needed publicity, and

Whereas, Margaret Dana, with succinct definitions and examples, alerts the consumer to potential dangers in the marketplace: Therefore, be it

Resolved, That the Committee on Education, through the National Conference on Weights and Measures, does hereby commend Margaret Dana for her accomplishments and efforts on behalf of weights and measures officials.

\author{
M. H. BECKER, Chairman \\ T. F. BRINK \\ G. E. MILLER \\ R. L. SHARP \\ H. E. SMITH \\ C. B. WHIGHAM \\ G. E. YARD
}

Committee on Resolutions

(On motion of the Committee Chairman, seconded from the floor, the report of the Committee on Resolutions was adopted by voice vote.) 
Presented by J. C. BoYD, Chairman, Chief, Standard Control, Weights and Measures Division, Iowa Department of Agriculture

(Thursday, July 16, 1970)

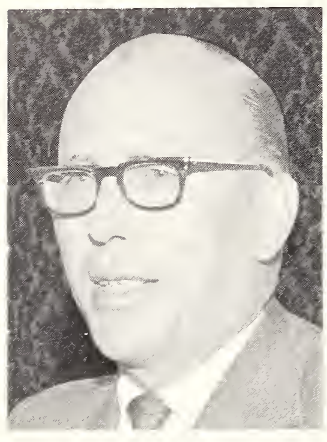

The Auditing Committee met on July 13, 1970, and inspected the financial statements of the Conference Treasurer, Mr. C. C. Morgan. We found them to be complete and accurate.

J. C. BOYD, Chairman

S. J. DARSEY

S. L. HATOS, Staff Assistant

Committee on Auditing

(On motion of the committee chairman, seconded from the floor, the report of the Auditing Committee was adopted by voice vote.) 
Presented by C. C. Morgan, City Sealer of Weights and Measures, Gary, Indiana

(Thursday, July 16, 1970)

Balance on hand June 1, 1969

$\$ 7,691.90$

\section{RECEIPTS :}

Registration,377@\$15.00

Ballgame bus tickets

Luncheon tickets

Return from Education Committee

Bank interest accrued

Trade party

$1,215,00$

Subtotal

Total

\section{DISBURSEMENTS:}

Ladies embassy tour

Franklin Press, Inc., envelope enclosures

Jerome Proper Co., gavel and engraving

National Detective Agency, Inc., service

American Sightseeing Corp., ballgame

Stephen Lesieur's Music

Sheraton-Park Hotel, Executive breakfast, Luncheon,

Cotillion Room, Party, Flowers, Audio charges, and

Headquarters expense

C. \& P. Telephone Company

Specifications and Tolerances Committee

Education Committee

$1,063.80$

Laws and Regulations Committee

762.85

Franklin Press, printing "Weights and Measures Men"

Bank charges _-_-_-_-_-_-_-_-_-_-_-_-

Miscellaneous registration and operating expense, cash

Ladies party, cash

Subtotal

$10,987.93$

Balance on hand June 1, 1970

$\$ 4,352.05$

Depository: Bank of Indiana

(Signed) C. C. Morgax, Treasurer

(On motion of the Treasurer, seconded from the floor, the Report of the Treasurer was adopted by the Conference.) 


\section{Delegates-State, City, and County Weights and Measures Officials}

\section{ARKANSAS}

State

J. E. Holiman, Assistant Director, Division of Weights and Measures, State Plant Board, P.O. Box 1069, Little Rock 72203

B. W. Sullivant, Metrologist, Division of Weights and Measures, State Plant Board, 4608 W. 61st St., Little Rock 72209

\section{CALIFORNIA}

State

W. S. Watson, Chief, Bureau of Weights and Measures, Dept. of Agriculture, 1120 N St., Sacramento 95814

County Sealers of Weights and Measures:

Alameda

Contra Costa

El Dorado

Los Angeles

San Mateo

Santa Clara

Sonoma

Ventura
R. H. Fernsten, 333 Fifth St., Oakland 94607 K. E. Danielson, Assistant Sealer, 161 John Glenn Dr., Buchanan Airport, Concord 94520 E. P. Delfino, 2850 Cold Springs Rd., Placerville 95709

M. H. Becker, 3200 N. Main St., Los Angeles 90031

H. E. Sмiтн, 702 Chestnut St., Redwood City 94063

R. W. Horger, 409 Mathew St., Santa Clara 95050

E. J. Bologna, 2555 Mendocino Ave., Santa Rosa 95401

E. H. Black, P.O. Box W, Ventura 93001

\section{COLORADO}

State

E. Prideaux, Supervisor, Weights and Measures Section, Division of Inspection and Consumer Services, Dept. of Agriculture, 3130 Zuni St., Denver 80211

\section{CONNECTICUT}

State

A. M. NeLson, Metrologist, Division of Weights and Measures, State Office Building, Hartford 06115

City Sealer of Weights and Measures: 


\section{DELAWARE}

State

W. C. BAUmgardT, Inspector, Department of Weights and Measures, State Board of Agriculture, Dover 19901

\section{DISTRICT OF COLUMBIA}

District

K. G. HAYDEN, Assistant Chief, Weights, Measures and Markets Branch, Inspection Division, Bureau of Licenses and Inspections, Dept. of Economic Development, District Building, 1350 E St., N.W., Washington, D.C. 20004

\section{FLORIDA}

State

S. D. ANDREws, Director, Division of Standards, Dept. of Agriculture, Mayo Building, Tallahassee 32304

C. Wooten, Chief, Weights and Measures Section

S. J. DARSEY, Supervisor of Weights and Measures, 1118 S. 17th Ave., Hollywood 33020

County Sealer of Weights and Measures:

Dade

J. C. MAYS, Director, Division of Consumer

\section{HAWAII}

State

G. E. Mattimoe, Deputy Director, Division of Weights and Measures, Dept. of Agriculture, 1428 S. King St., P.O. Box 5425, Honolulu 96814

G. Yoкотаке, Metrologist, Division of Weights and Measures

\section{IDAHO}

State

L. D. Holloway, Supervisor, Weights and Measures Division, Dept. of Agriculture, 2120 Warm Springs Ave., P.O. Box 790, Boise 83701

A. D. HuRd, Inspector

H. G. KORSMEYER, Inspector

K. MAGEE, Inspector 


\section{ILLINOIS}

G. E. YARD, Superintendent, Division of Feeds, Fertilizers, and Standards, Dept. of Agriculture, State Fairgrounds, 531 E. Sangamon Ave., Springfield 62706

City Sealers of Weights and Measures:

Chicago 60610

Mrs. J. BYrne, Commissioner, Consumer Sales, Weights and Measures, 320 N. Clark St., Rm. 302

Chicago 60605

Springfield 62701

L. Prendergast, Inspector, Public Vehicle License Commission, Rm. 105, 1111 S. State St.

J. P. KNox, Commissioner, Weights and Measures, Municipal Building

J. E. UNDERWOOD, Sealer

\section{INDIANA}

State

L. A. GREDY, Director, Division of Weights and Measures, State Board of Health, 1330 W. Michigan St., Indianapolis 46206

County Inspectors of Weights and Measures:

Clark

Floyd

Grant

Johnson

Knox

Lake

LaPorte

Madison

Marshall

Porter

St. Joseph

Tippecanoe

Vigo
R. W. WALKer, City-County Building, Rm. 314, Jeffersonville 47130

E. G. Silver, P. O. Box 362, Rm. L-244, CityCounty Building, New Albany 47150

H. Cline, P. O. Box 421, Marion 46592

W. E. HANDY, Johnson County Courthouse, Franklin 46131

W. D. LIDDIL, 840 State St., Vincennes 47591

N. BUCUR, 524 Roosevelt St., Gary 46404

E. Hanish, 2702 Franklin St., Michigan City 46360

C. W. Moore, Box 84, Lapel 46051

G. W. Schultz, Route \#1, Bremen 46506

R. H. Claussen, Rm. 13 Courthouse, Valparaiso 46383

C. S. Zmudzinski, County-City Building, 227 W. Jefferson Blvd., South Bend 46601

W. McMurry, P.O. Box 444, Lafayette 47902

R. J. Silcock, Rm. 12 Courthouse, Terre Haute 47885

City Sealers of Weights and Measures:

Anderson 46011

Gary 46407

Hammond 46320

Indianapolis 46204
E. Gadberry, City Hall, P.O. Box 2100

C. C. Morgan, 1100 Massachusetts St.

D. Brahos, City Hall, Rm. 315, 5925 Calumet Ave.

F. L. BRUGH, Rm. G-6 City-County Building

W. R. Copeland, Deputy Inspector 


\section{IOWA}

State

J. C. Boyd, Chief, Standard Control, Weights and Measures Division, Consumer Protection Services, Dept. of Agriculture, Capitol Bldg., Des Moines 50319

\section{KANSAS}

State

J. L. O’NeILL, Acting State Sealer, Division of Weights and Measures, State Board of Agriculture, State Office Building, Topeka 66612

\section{KENTUCKY}

State

G. L. Johnson, Director, Division of Weights and Measures, Dept. of Agriculture, $106 \mathrm{~W}$. Second St., Frankfort 40601

\section{LOUISIANA}

State

J. H. Johnson, Director, Division of Weights and Measures, Dept. of Agriculture, P.O. Box 44292 Capitol Station, Baton Rouge 70801

\section{MAINE}

State

H. D. Robinson, Deputy State Sealer, Bureau of Weights and Measures, Division of Consumer Protection, Dept. of Agriculture, Capitol Building Augusta 04330

\section{MARYLAND}

State

R. L. Thompson, Assistant State Superintendent, Weights and Measures, Dept. of Markets, Board of Agriculture, University of Maryland, College Park 20742

County Sealer of Weights and Measures:

Prince George's

R. J. Cord, County Service Building, Rm. 101, Hyattsville 20781

City Sealers of Weights and Measures:

Baltimore 21202

T. A. Considine, Chief, Division of Tests, Rm. 1106 Municipal Building,. Holliday and Lexington Sts.

J. W. Fincham, Chief Inspector 


\section{MASSACHUSETTS}

State

W. C. Hughes, Head Administrative Assistant, Division of Standards, Dept. of Labor and Industries, State House, Boston 02133

J. W. BRADLEY, Inspector

City Sealers of Weights and Measures:

Cambridge 02139

Everett 02149

Fitchberg 01420

Newton 02159

Springfield 01103
A. T. Anderson, City Hall, Rm. 202

L. L. Elliott, City Hall, Rm. 2

W. T. DELOGE, 42 Elm St.

J. E. Bowen, City Hall

R. E. ClarK, Municipal Building

\section{MICHIGAN}

State

G. L. Whitehead, Deputy Director, Bureau of Consumer Protection, Dept. of Agriculture, 5 th floor, Lewis Cass Building, Lansing 48913

R M. LEACH, Acting Chief, Food Inspection Division, Dept. of Agriculture

G. V. Teachman, Supervisor, Food Inspection Division, 1120 W. State Fair, Detroit 48203

C. О. Соттом, State Supervisor, Weights and Measures, Food Inspection Division, Dept. of Agriculture, Lewis Cass Building

County Sealer of Weights and Measures:

Saginaw

W. E. Hoffman, 6358 Mackinaw Rd., Saginaw 48604

City Sealers of Weights and Measures:

Dearborn 48120

J. A. Hughes, Director, Dept. of Licenses, Weights and Measures, 2951 Greenfield Rd.

E. J. Dombrowski, City Councilman, Municipal Building

Detroit 48207

J. T. DANiEll, Deputy Sealer, 1445 Adelaide St.

Livonia 48154

R. C. Baumgartner, Police Dept., 15050 Farmington $\mathrm{Rd}$.

\section{MINNESOTA}

State

W. E. Czaia, Supervisor, Division of Weights and Measures, Dept. of Public Service, 1015 Currie Ave., Minneapolis 55415

R. A. THARALSON, Inspector

A. W. Fenger, Inspector, 553 Monroe, Mankato 56001

City Inspector of Weights and Measures:

Minneapolis 55415

J. G. Gustafson, Dept. of Licenses, Weights and Measures, City Hall, Rm. 101-A 


\section{MISSISSIPPI}

State

C. B. Noblin, Deputy Director, Weights and Measures Division, Dept. of Agriculture and Commerce, State Office Building, P. O. Box 1609, Jackson 39205

\section{MISSOURI}

State

J. H. WiLson, Director, Weights and Measures Division, Dept. of Agriculture, Jefferson Building, Jefferson City 65102

County Sealer of Weights and Measures:

St. Louis

L. A. RICK, 8008 Carondelet \#5, Clayton 63105

City Sealer of Weights and Measures:

St. Louis 63104

D. I. OfFner, Commissioner, Rm. 145, 1220 Carr Lane Ave.

\section{MONTANA}

State

G. L. Delano, Chief Sealer, Division of Weights and Measures, Dept. of Agriculture, Mitchell Building, Helena 59601

\section{NEBRASKA}

State

M. Dennis, Supervisor of Weights and Measures, Bureau of Dairies, Foods, and Weights and Measures, Dept. of Agriculture, Rm. 1200 State Capitol, Lincoln 68509

City Sealer of Weights and Measures:

Omaha 68102

N. M. Ross, Chief, Weights and Measures Section, City Hall, 108 S. 18th St., Rm. 104

\section{NEVADA}

State

R. Rebuffo, Chief Deputy State Sealer, Bureau of Weights and Measures, Dept. of Agriculture, P. O. Box 1209, Reno 89504 W. F. HEADRICK, Inspector

\section{NEW HAMPSHIRE}

State

W. J. Tusen, Chief, Bureau of Weights and Measures, Division of Markets and Standards, Dept. of Agriculture, State House Annex, Concord 03301 


\section{NEW JERSEY}

State

\section{Bergen}

County Superintendents of Weights and Measures:

Camden

Cumberland

Essex

Gloucester

Mercer

Middlesex

Monmouth

Salem 07601 den 08101 08360 07109 08607 07711
S. H. Christie, JR., State Superintendent, Division of Weights and Measures, Dept. of Law and Public Safety, 187 W. Hanover St., Trenton 08625

J. R. BIRD, Supervisor, Technical Services

C. P. ConraD, JR., Weights and Measures Technician

J. A. Pollock, 66 Zabriskie St., Hackensack

A. J. Francesconi, Room 403 City Hall, Cam-

G. S. Franks, 1142 Landis Ave., Vineland

N. DiMarco, Deputy Superintendent, County Court House, Bridgeton 08302

W. C. Lesino, 520 Belleville Ave., Belleville

R. J. MorRIS, 49 Wood St., Woodbury 08096

J. Silvestro, Assistant Superintendent

R. M. Bodenweiser, Court House, Trenton

J. M. Сhoнamin, County Records Building, New Brunswick 08901

W. I. Thompson, P. O. Box 74, Allenhurst

R. B. Jones, Box 24, Salem 08079

Municipal Superintendents of Weights and Measures:

Atlantic City 08401

Camden 08105

Kearny 07032

Nutley 07110

Trenton 08608
R. Schwartz, City Hall

A. DiPiero, Convention Hall

J. Pollock, Room 402 Town Hall

W. L. Callanan, Town Hall

R. J. BoneY, Trenton Civic Centre

\section{NEW MEXICO}

State

C. B. Whigham, Chief, Division of Weights and Measures, Dept. of Agriculture, Box 3170, Las Cruces 88001

F. BARTolucci, Chief Chemist, Bureau of Revenue, 5929 Ave. La Barranca, N.W., Albuquerque 87114

\section{NEW YORK}

State

F. J. FALLON, Director, Bureau of Weights and Measures, Dept. of Agriculture and Markets, State Campus, Albany 12226 
City Sealers of Weights and Measures:

Glen Cove 11542

E. T. Hunter, City Hall, Bridge St.

New York 10013

M. Greenspan, 80 Lafayette St.

\section{NORTH CAROLINA}

State

J. I. MOoRe, Superintendent, Weights and Measures Division, Dept. of Agriculture, P. O. Box 27647, Raleigh 27611

M. L. Kinlaw, Supervisor

\section{OHIO}

State

F. P. Gallo, Chief, Division of Weights and Measures, Dept. of Agriculture, Reynoldsburg 43068

County Sealers of Weights and Measures:

Auglaize

F. Wellman, 309 S. Main St., New Knoxville 45871

Clark

J. S. Powers, SR., County Building, Auditor's Office 45502

Medina

R. W. Searles, 137 W. Friendship, Medina 44256

Ross

G. D. Thacker, County Court House, Chillicothe 45601

City Sealers of Weights and Measures:

Akron 44304

Dayton 45402
A. J. LADD, 69 N. Union St.

K. Gulledge, 960 Ottawa St.

\section{OKLAHOMA}

H. K. ShARP, Assistant Director, Marketing Division, Board of Agriculture, 122 State Capitol, Oklahoma City 73044

R. L. Smith, Assistant Director, State Bureau of Standards, 1808 Newton Dr., Norman 73069

\section{OREGON}

State

K. J. Simila, Assistant Chief for Weights and Measures, Dairy and Consumer Services Division, Dept. of Agriculture, Agriculture Bldg., Salem 97310 


\section{PENNSYLVANIA}

State

R. W. RICHARDS, Director, Bureau of Standard Weights and Measures, Highway and Safety Building, Rm. B-130, Harrisburg 17120

Miss Irene I. Boone, Assistant Director

R. W. Buchanan, Supervisor

County Sealer of Weights and Measures:

Allegheny

W. D. Scotr, Court House, Room 4, Pittsburgh 15219

City Sealer of Weights and Measures:

Bethlehem 18018

Chester 19013

Philadelphia 19107
W. G. Gasdaska, 10 E. Church St.

A. OsowskI, 5th and Welsh Sts.

S. F. VAltri, Chief, 622 City Hall Annex

C. E. McHUGH, Supervisor

\section{RHODE ISLAND}

State

E. R. Fisher, State Sealer of Weights and Measures, Dept. of Labor, 235 Promenade St., Providence 02908

\section{SOUTH CAROLINA}

State

W. L. Harrelson, Commissioner, State Dept. of Agriculture, Box 11280, Columbia 29211

E. W. Ballentine, Executive Assistant

J. V. PUGH, Director, Consumer Protection Division

D. RAmage, Chief Auditor

\section{SOUTH DAKOTA}

State

D. SPIEGEL, Director, Division of Inspections, Dept. of Agriculture, State Office Building, Pierre 57501

\section{TENNESSEE}

State

M. Jennings, Director, Division of Marketing, Dept. of Agriculture, Melrose Station, Box 9039, Nashville 37204

\section{TEXAS}

State

R. T. Williams, Director, Consumer Protection Division, Dept. of Agriculture, John Reagan Building, P. O. Drawer BB, Austin 78711

C. H. Vincent, Assistant Director

L. Z. Florence, Administrative Assistant 
City Sealers of Weights and Measures:

Dallas 75201

Fort Worth 76107
J. D. Walton, 303 City Hall

R. L. ShaRP, 1800 University Dr.

\section{UTAH}

State

\section{City Sealers of Weights and Measures:}

Provo 84601

Salt Lake City 84101

T. A. Мотт, Provo City Corporation

F. C. Westwood, 140 South 3rd West

C. T. KeITH, Inspector

G. M. BAI, Inspector

\section{VERMONT}

State

T. F. BRINk, Director, Division of Standards, Dept. of Agriculture, Agriculture Building, Vermont 05602

\section{VIRGINIA}

State

J. F. LyLEs, Supervisor, Weights and Measures Regulatory Section, Division of Regulatory Services, Dept. of Agriculture and Commerce, 1436 E. Main St., Room 302, Richmon 23219

J. C. StewaRT, Assistant Supervisor

City Sealers of Weights and Measures:

Newport News 23601

J. L. Davis, 118 Main St., City Hall

\section{WASHINGTON}

State

J. H. LEwis, Chief, Weights and Measures Section, Dairy and Food Division, Dept. of Agriculture, 115 E. State St., Olympia 98501

City Sealers of Weights and Measures:

Everett 98201

Seattle 98104
J. C. ADAms, 3002 Wetmore Ave.

R. K. SNell, 600 Fourth Ave.

M. R. Dettler, Assistant Director 


\section{WEST VIRGINIA}

State

B. R. Haught, Director, Division of Consumer Protection, Dept. of Labor, Capitol Complex, Charleston 25305

\section{WISCONSIN}

State

D. E. Konsoer, Director, Bureau of Weights and Measures, Food Division, Dept. of Agriculture, Hill Farms State Office Building, Madison 53702

A. LEMkE, Packaging Specialist

City Sealers of Weights and Measures:

Fond du Lac 54935

Green Bay 54301

Sheboygan 53081

Wausau 54401
R. P. KNIPPle, City Hall, 76 E. 2d St.

N. Tilleman, City Hall

R. K. LoRENZ, City Hall

J. H. AKEY, 400 Myron St.

\section{WYOMING}

State

W. PATCH, JR., Weights and Measures Inspector, Tensleep 82224

J. W. Salisbury, Inspector, P. O. Box 1371, Rock Springs 82901

\section{VIRGIN ISLANDS}

Territory

E. E. Francors, Deputy Commissioner, Property, Weights, and Measures, P. O. Box 1437, St. Thomas 00801

L. HENDRICKS, Inspector 


\section{ADVISORY MEMBERS-U.S. GOVERNMENT}

U.S. Department of Commerce:

Hon. Myron Tribus, Assistant Secretary of Commerce for Science and Technology

National Bureau of Standards:

Dr. Lewis M. Branscomb, Director

Dr. A. V. Astin, Director Emeritus

A. J. FARraR, Legal Advisor, Office of the Director

Institute for Applied Technology:

M. W. Jensen, Acting Director

Office of Weights and Measures:

T. M. STABLER, Chief

H. F. Wollin, Assistant Chief, and Executive Secretary

National Conference on Weights and Measures

E. A. VAdelund, Program Manager, Fair Packaging and Labelin ${ }_{\varepsilon}$ " Act

D. E. EDGERLY, Coordinator, Packaging and Labeling

O. K. WARNLOF, Technical Coordinator, Training

R. N. Sмiтн, Technical Coordinator, Railway Track Scales

R. L. KoEser, Weights and Measures Coordinator, Information

S. L. Hatos, Manager, Commercial Weights and Measures Survey, U.S. Metric Study

R. M. MILLS, Head, Engineering Unit

S. HAsko, Engineer

Mrs. F. C. BELL, Administrative Assistant

MrS. E. M. BuRnetTE, Secretary

Mrs. B. A. DAvis, Secretary

R. M. Eisenifard, Conference Manager, National Conference of States on Building Codes and Standards, Building Research Division

Dr. W. E. Cushen, Chief, Technical Analysis Division

Institute for Basic Standards:

D. B. Mann, Chief, Cryogenic Metrology Section, Cryogenic Division, Boulder, Colorado 80302

U.S. Department of Agriculture:

Packers and Stockyards Administration, Scales and Weighing Branch:

R. D. Thompson, Chief

J. T. LACY, Scales and Weighing Specialist, 5905 Pacific Blvd., Huntington Park, Calif. 90255

J. L. Alcorn, Scales and Weighing Specialist, 406 Livestock Exchange Bldg., Denver, Col. 80216

C. J. Peters, Scales and Weighing Specialist, 208 Post Office Bldg., South St. Paul, Minn. 55075

D. Music, Scales and Weighing Specialist, 435 Livestock Exchange Bldg., Omaha, Neb. 68107

Federal Trade Commission:

R. R. Hannum, Attorney, Fair Packaging and Labeling Section

E. W. Johnson, Attorney, Fair Packaging and Labeling Section

U.S. Food and Drug Administration:

R. E. Dickinson, Assistant to the Director, State Services Staff (CF-40), 5600 Fishers Lane, Rockville, Md. 20852

J. Gomilla, Food and Drug Officer, 200 C St., S.W., Washington, D.C. 20201 


\section{MANUFACTURERS, INDUSTRY, AND BUSINESS}

Allied Chemical Corporation (Agricultural Division).

H. J. KerR, Technical Service, P.O. Box 61, Hopewell, Va. 23860

American Frozen Food Institute:

L. S. FenN, Director of Technical Services, 919 18th St., N.W., Washington, D.C. 20006

American Home Economics Association:

Mary Pizza, Professor, Home Economics, College of Eastern Utah, Price, Utah 84501

American Meter Company:

T. J. Sмгтн, Product Manager, 13500 Philmont St., Philadelphia, Pa. 19116 American Oil Company:

D. P. Darling, Petroleum Packaging Committee (Packaging Institute), 910 S. Michigan Ave., Chicago, Ill. 60680

A. H. WelCH, Senior Service Engineer, P.O. Box 898, Salt Lake City, Utah 84101

American Paper Institute:

W. V. Driscoll, Executive Secretary, Tissue Division, 260 Madison Ave., New York, N.Y. 10016

M. B. WeIR, Attorney (Plate, Cup, and Container Institute), 161 E. 42nd St., New York, N.Y. 10017

American Petroleum Institute:

W. A. Kerlin, Special Representative, 1271 Avenue of the Americas, New York, N.Y. 10020

W. N. SEWARD, Petroleum Measurement Coordinator.

R. Southers, Operations and Engineering Coordinator

American Sugar Company:

R. P. Fremgen, Quality Control Supervisor, 120 Wall St., New York, N.Y. 10005

E. P. Lorfanfant, Attorney

Amway Corporation:

C. F. Graham, Manager, Industry and Government Technical Relations, 7575 E. Fulton Dr., Ada, Mich. 49301

Applied Information Industries:

F. J. Sutrill, Director, New Product Development, 345 New Albany Rd., Moorestown, N.J. 08057

Arkstrom Industries:

A. Franzblau, President, 415 Avon Ave., Newark, N.J. 07108

Armour \& Company:

V. J. Delgiudice, Manager, Government Regulatory Agencies, 111 E. Wacker Dr., Chicago, Ill. 60611

Association of General Merchandise Chains:

P. W. Schindel, President, 1441 Broadway, New York, N.Y. 10018

Automobile Manufacturers Association:

J. H. Venema, Staff Engineer, New Center Building, Detroit, Mich. 48202. Benett Pump Division, John Wood Company:

J. B. Dennis, Western Regional Sales Manager, 3125 E. 12th St., Los Angeles, Calif. 90023

M. S. Godsman, Service Manager, Broadway \& Wood Sts., Muskegon, Mich. 49444

C-G Systems :

A. J. Smith, Engineer, 313 N. Rexford, Colton, Calif. 92324 
Cato Oil and Grease Company:

R. JENks, Vice President, Administration (Petroleum Packaging Committee), P.O. Box 26868, Oklahoma City, Okla. 73126

Central Scale Company:

J. A. KELCH, General Service Manager, 1138 W. 48th St., Chicago, Ill. 60609 Chambers Scale Corporation:

L. H. Chambers, President, 2419 State St., Boise, Idaho 83702

Chemical Specialties Manufacturers Association:

A. A. Mulliken, Executive Director, 50 E. 41st St., New York, N.Y. 10017 Chesapeake \& Ohio-Baltimore \& Ohio Railroads :

E. SzAKs, Assistant Chief Engineer, Room 1107 C \& O Building, Huntington, W. Va. 25701

Chevron Oil Company-dba Standard Oil Company of California:

C. R. CHILd, Regional Engineer, 136 E. South Temple, Salt Lake City, Utah 84111

Cities Service Oil Company:

R. C. Primley, Operation Manager, Field Engineer, 1207 Broad St., St. Joseph, Mich. 49085

Coca-Cola Company:

R. L. Callahan, JR., Attorney, 310 North Ave. (P.O. Drawer 1734), Atlanta, Ga. 30301

Colgate-Palmolive Company:

E. E. Wolski, Manager of Quality Control, 300 Park Ave., New York, N.Y. 10022

Consumers' Council of Massachusetts :

D. P. SheA, Executive Secretary, 100 Cambridge St., Boston, Mass. 02202 Continental Oil Company:

J. M. Flewharty, Division Engineer, Box 225, Salt Lake City, Utah 84110 Covington \& Burling:

P. M. Phillipes, Attorney, 888 16th St., N.W., Washington, D.C. 20006 CPC International, Inc.:

A. E. Johansen, Attorney, International Plaza, Englewood Cliffs, N.J. 07632

Crown Zellerbach Corporation:

F. C. Chace, Product Development Manager, 1 Bush St., San Francisco, Calif. 94119

Dee, J. B., \& Company:

E. H. Fishman, General Manager, 1722 W. 16th St., Indianapolis, Ind. 46207

Detecto Scales, Inc.:

MACK RAPP, Vice President, 540 Park Ave., Brooklyn, N.Y. 11205

Dresser Industries, Inc.:

F. W. Love, Administrative Assistant, Petroleum Equipment Division, 124

W. College Ave., Salisbury, Md. 21801

Exact Weight Scale Company:

B. TAYLOR, Vice President, 944 W. Fifth Ave., Columbus, Ohio 43212

R. W. Grant, Vice President, Sales, 1005 W. 3rd Ave., Columbus, Ohio 43212 Fairbanks Morse:

K. E. Hammer, President, St. Johnsbury, Vt. 05819

C. H. KNOdeL, Vice President, Engineering.

T. G. SOPER, Vice President, Marketing

Food Fair Stores, Inc.:

E. W. Gruber, JR., Assistant Division Meat Merchandiser, 3175 John F. Kennedy Blvd., Philadelphia, Pa. 19104 
Fuller, H. J., \& Sons, Inc.:

W. A. Scheurer, Public Relations, 1212 Chesapeake Ave., Columbus, Ohio 43212

Gasoline Pump Manufacturers Association:

R. M. BYRne, Technical Director, 331 Madison Ave., New York, N.Y. 10017 General Mills, Inc.:

D. B. Colpits, Technical Manager, Weights and Measures, 1081 21st Ave., S.E., Minneapolis, Minn. 55414

D. G. McPherson, Vice President, Quality Control, 9200 Wayzata Blvd., Minneapolis, Minn. 55426

O. A. Oudal, Consultant, 1411 E. 99th St., Minneapolis, Minn. 55420

General Scale Repairing \& Engineering Company:

A. J. Isaacsen, Owner, 21 S. 10th West, Salt Lake City, Utah 84104

Gerber Products Company:

J. L. Littlefield, 445 State St., Fremont, Mich. 49412

Getty Oil Company:

J. C. Gassert, Chief Engineer, 660 Madison Ave., New York, N.Y. 10021 Gilbarco, Inc.:

R. E. NIX, Assistant to Manager of Engineering, Friendly Road, Greensboro, No. Carolina 27420

C. R. Parent, Manager, Special Accounts, 5800 Christie Ave., Emeryville, Calif. 94608

Glass Container Manufacturers Institute, Inc.:

C. E. Wagner, Director of Technical Services, 330 Madison Ave., New York, N.Y. 10017

E. J. Mentz, Assistant Director of Technical Services

Great Western Sugar Company:

D. E. EbneR, Packaging Coordinator, 1530 16th St., Box 5308, Denver, Col. 80217

Grocery Manufacturers of America :

F. T. Dierson, Attorney, 420 Lexington Ave., New York, N.Y. 10017

Gulf Oil Company:

G. R. Davis, Director, Plant Operations, P.O. Box 611, Tulsa, Okla. 74135

Hardy Scales Company:

F. J. HALE, Director of Engineering, 155 31st St., Ogden, Utah 84401

W. G. VANDEheI, Division Manager

A. D. Gerlach, Executive Vice President and General Manager, 5701 Atlantic, Maywood, Calif. 90270

Hobart Manufacturing Company:

K. C. Allen, Vice President, Scale Operations, 216 S. Torrence St., Dayton, Ohio 45403

M. E. BonE, Weights and Measures Representative

E. G. Boshinski, Manager, Dayton Research Division, 228 N. Irwin St., Dayton, Ohio 45403

Howe Richardson Scale Company:

G. D. Wilkinson, National Service Manager, 668 Van Houten Ave., Clifton, N.J. 07015

W. M. Young, President

Idaho Nuclear Corporation:

R. R. Boyce, Branch Manager, Standards Laboratory, P. O. Box 1845, Idaho Falls, Idaho 83401

Institute of Shortening and Edible Oils, Inc.:

M. R. Stephens, President, 888 16th St., N.W., Washington, D.C. 20006 
International Oil Marketers Association:

J. A. Murphy, Executive Director, 2330 S. Main, Salt Lake City, Utah 84115

ITT Continental Baking Company:

J. N. Wiltrakis, Attorney, P.O. Box 731, Rye, N.Y. 10580

Jewel Companies, Inc.:

R. W .Miller, Jr., General Attorney, 1955 W. North Ave., Melrose Park, Ill. 60610

Johnson \& Johnson:

G. E. Heinze, National Director, Testing Laboratories, Route No. 1, ESDP, New Brunswick, N.J. 08903

Keene Corporation:

R. D. Perrenoud, Project Engineer, P.O. Box 250, Greeneville, Tennessee 37743

Kimberly-Clark Corporation:

W. W. Whitlinger, Director, Quality Assurance, N. Lake St., Neenah, Wis. 54956

Kraft Foods :

J. B. Stine, Vice President, Quality Standards and Regulatory Compliance, 500 Peshtigo Court, Chicago, Ill. 60690

Kraftco Corporation:

R. M. Hersh, Attorney, 260 Madison Ave., New York, N.Y. 10016

M. S. Thompson, Attorney, Chadwell, Keck, Kayser \& Ruggles, Room 2360, 136 S. LaSalle St., Chicago, Ill. 60603

Kroger Company:

D. P. Leahy, Director, Kroger Food Foundation, 1014 Vine St., Cincinnati, Ohio 45201

Lehn \& Fink Products, Division of Sterling Drug:

F. G. TAYLOR, Aerosol Research, 225 Summit Ave., Mont Vale, N.J. 07645 Lever Brothers Company:

L. H. Bloom, Vice President and General Counsel, 390 Park Ave., N.Y. 10022

H. R. MCDoNALD, Manufacturing Services Manager

Liberty Glass Company:

E. K. Mills, Technical Director, P.O. Box 520, Sapulpa, Okla. 74066

Lily-Tulip Division, Owens-Illinois, Inc.:

R. F. BAKER, Marketing Manager, Packaging Products, P.O. Box 1035, Toledo, Ohio 45501

Liquid Controls Corporation:

H. E. Siebold, Vice President, Engineering, P.O. Box 101, North Chicago, Ill. 60064

Lockheed Electronics Company:

J. F. Devitt, Service Manager, U.S. Route 22, Plainfield, N.J. 07061

Louisville and Nashville Railroad:

J. L. Finneld, General Scale Inspector, 908 W. Broadway, Louisville, Ky. 40201

Lumberman's Association of Texas:

J. Butler, Executive Vice President, P.O. Box 5222, Austin, Texas 78703

Lunn Laminates, Inc. :

J. S. Lunv, Chairman of the Board, Straight Path, Wyandanch, N.Y. 11798

Martin-Decker Corporation:

E. I. Shelley, Industrial Sales Manager, 1928 S. Grand Ave., Santa Ana, Calif. 92705 
Michigan Dairy Foods Association:

F. Koval, Executive Director, P.O. Box 74, Lansing, Mich. 48901

Milk Industry Foundation:

J. F. SPEer, Executive Assistant, 1105 Barr Bldg., 910 17th St., N.W., Washington, D.C. 20006

Mira-Pak, Inc.:

W. W. Mills, Vice President, P.O. Box 14049, 7000 Ardmore, Houston, Tex. 77021

Mobil Oil Corporation:

F. C. Swerz, Wholesale Plant Manager, 150 E. 42nd St., New York, N.Y. 10017

R. R. Galdo, Field Operating Supervisor, West Coast Division, 612 S. Flower St., Los Angeles, Calif. 90017

Monsanto Company:

D. Levine, Market Manager, N. 8th St. \& Monroe Ave., Kenilworth, N.J. 07033

T. RAlles, Western District Manager, 2710 Lafayette St., Santa Clara, Calif. 95052

Mountain States Lumber Dealers Association:

C. W. Nortz, Executive Secretary, 256 S. 6th E., Salt Lake City, Utah 84111

McDowell-Wellman Engineering Company:

D. L. RopP, Project Engineer, ABC Weighing Systems, 113 St. Clair Ave., N.E., Cleveland, Ohio 44114

J. J. Wiegand, Product Manager

National Canners Association:

R. B. HeIney, Director, Government-Industry Relations Division, 1133 20th St., N.W., Washington, D.C. 20036

R. J. Tolley, Head of Food Regulations and Standards, 1133 20th St., N.W., Washington, D.C. 20036

National LP-Gas Association:

M. E. Galleger, Director, 1212 Beck St., Salt Lake City, Utah 84116

O. L. Garretson, President, Plateau, Inc., Box 108, Farmington, N.M. 87401

W. H. Johnson, Vice President, Technical Services, 79 W. Monroe St., Chicago, Ill. 60603

L. T. HANCOCK, Regional Manager, 6767 E. 39th Ave., Denver, Col. 80651

National Lumber Building Material Dealers Association:

G. H. Bowers, 302 Ring Building, Washington, D.C. 20036

R. H. HARRELL, Vice President

Neptune Meter Company:

B. A. BALENDock, West Coast Regional Manager, Petroleum and Industrial Properties, 5540 E. Harbor St., Los Angeles, Calif. 90022

J. C. Hart, Assistant Sales Manager, 47-25 34th St., Long Island City, N.Y. 11101

E. F. Wehmann, Assistant Chief Engineer, Liquid Meter Division

Nestle Company:

M. Fisher, Quality Control Specialist, 100 Bloomingdale Rd., White Plains, N.Y. 10605

Northeastern Lumbermen's Association:

W. C. Ives, 134 S. LaSalle St., Chicago, Ill. 60603

Paperboard Packaging Council:

R. R. Lovelace, Director, Government Relations, Public Information, 1250

Connecticut Ave., N.W., Washington, D.C. 20036 
Peabody Coal Company:

S. L. Disiewski, 301 N. Memorial Dr., St. Louis, Mo. 63102

Petroleum Equipment Institute:

H. B. Upton, JR., Executive Vice President, 525 Dowell Building, Tulsa, Okla. 74114

Pillsbury Company:

C. E. Joyce, Manager, Customer and Product Protection, Pillsbury Building, 608 2nd Ave., S., Minneapolis, Minn. 55402

Plate, Cup and Container Institute:

R. W. Foster, Executive Director, 250 Park Ave., New York, N.Y. 10017

L. J. Moremen, Manager, General Services

Presto Products, Inc.:

T. ZeLleR, Director of Packaging, Box 407, Appleon, Wis. 54911

Procter and Gamble Company:

A. H. Every, Associate Director, Product Development, Ivorydale Technical Center, Cincinnati, Ohio 45217

G. HoPPer, Attorney, 301 E. 7th St., Cincinnati, Ohio 45202

J. SPINNER, Ivorydale Technical Center, Cincinnati, Ohio 45231

T. N. Thomas, Ivorydale Technical Center, Cincinnati, Ohio 45231 Purex Corporation, Ltd.:

L. O. Leenerts, Manager, Technical Copy Control, Corp. R \& D, 24600 S. Main St., Wilmington, Calif. 90744

Quaker Oats Company:

F. A. Dobbins, Director of Quality Assurance, Merchandise Mart, Chicago, Ill. 60654

Ramsey Engineering Company:

W. M. HARRIS, Manager, Application Engineering, 1853 W. County Road C, St. Paul, Minn. 55113

Rockwell Manufacturing Company:

A. J. Комісн, Product Manager, P.O. Box 450, Statesboro, Ga. 30458

Safeway Stores, Inc.:

H. N. Couden, Quality Control Manager, 510 16th St. (P.O. Box 1168), Oakland, Calif. 94601

Sanitary Scale Company:

J. V. FARWell, Sales Manager, 910 E. Lincoln Ave., Belvidere, Ill. 61008

E. C. KARP, Vice President

Scale Journal Publishing Company:

Mrs. Sylvia T. Pickell, Business Manager, 2141/1/2 S. Washington St., Naperville, Ill. 60540

Scale Manufacturers Association, Inc.:

A. Sanders, Executive Secretary, 1 Thomas Circle, Washington, D.C. 20005 Sears, Roebuck and Company:

J. E. Lehrer, Attorney, Dept. 766, 925 S. Homan Ave., Chicago, Ill. 60607 Seraphin Test Measure Company:

L. C. Schloder, General Manager, 1314 N. 7th St., Philadelphia, Pa. 19122 Shell Oil Company:

W. B. Waterman, Senior Engineer, P.O. Box 2463, Houston, Tex. 77001 Skelly Oil Company:

R. R. Wellington, Chief Engineer, Skelgas, P.O. Box 436, Kansas City, Mo. 64141

Smith, A. O., Corporation:

N. Markoff, Supervisor, Service Station Equipment, Meter Systems Division, 1602 Wagner Ave., Erie, Pa. 16512 
Soap and Detergent Association:

E. S. Pattison, President, 485 Madison Ave., New York, N.Y. 10022

AnNe M. Fallon, Legislative Assistant to the President

D. Machanie, Counsel, 1000 Ring Building, Washington, D.C. 20036

Standard Oil Company of California:

C. A. GARL, Manager, Maintenance Division, 555 Market St., San Francisco, Calif. 94105

Swift and Company:

H. L. Hensel, Attorney, 115 Jackson Blvd., Chicago, Ill. 60604

Texaco, Inc.:

R. H. Tolson, Supervisor, Construction, Terminals, 135 E. 42nd St., New York, N.Y. 10017

Thread Institute, Inc.:

W. F. OPerer, 15 E. 40th St., New York, N.Y. 10016

Thurman Scale Company:

J. R. Schaeffer, Vice President, 1939 Refugee Rd., Columbus, Ohio 43216 Tobacco Institute, Inc. :

F. J. Welch, Vice President, State Activities, 1776 K St.. N.W., Suite 1200, Washington, D.C. 20006

Tokheim Corporation:

W. F. Gerdom, JR., Manager, Product Performance, 1600 Wabash Ave., Fort Wayne, Ind. 46801

Toledo Scale Division, Reliance Electric Company:

C. CAMPBell, Manager, Weights and Measures. 5225 Telegraph Rd., Toledo, Ohio 43612

D. B. Kendall, Chief Scale Engineer

R. V. MiLleR

Union Oil Company of California:

G. H. Hemmen, General Manager, Marketing Distribution, 461 S. Boylston St., Los Angeles, Calif. 90017

U.S. Slicing Machine Company, Inc.:

P. F. A. WulfF, President, One Berkel Dr., LaPorte, Ind. 46350

Veeder Root Company:

H. W. Barnes, General Sales Manager, Sargeant St., Hartford, Conn. 06102

T. J. McLaughlin, Product Sales Manager, Petroleum Products Div.

Western Wood Products Association:

V. Riolo, Western Regional Manager, 700 Yeon Building, Portland, Ore. 97204

Wilson's, William M., Sons, Inc. :

C. J. Denny, Manager, Customer and Technical Service, P.O. Box 309, Lansdale, Pa. 19446

\section{OTHER GUESTS}

A. J. VAN MALE, President, Organization of International Legal Metrology, and Chief Director, Service of Weights and Measures, Stadhouderslaan 140, The Hague, Holland

G. Smith, Divisional Inspector of Weights and Measures and Consumer Protection, Thorn Bank, Moorgate, Rotherham, England

Dr. J. C. Fletcher, President, University of Utah, Salt Lake City, Utah 84112

Dr. L. J. Gordon, Director, Weights and Measures Research Center, Denison University, Granville, Ohio 43023

W. S. Bussey, Advisory Member, National Conference on Weights and Measures, 1511 W. 29th St., Austin, Tex. 78703

H. H. WRIGHT, Box 5, Lyons, N.Y. 14489 


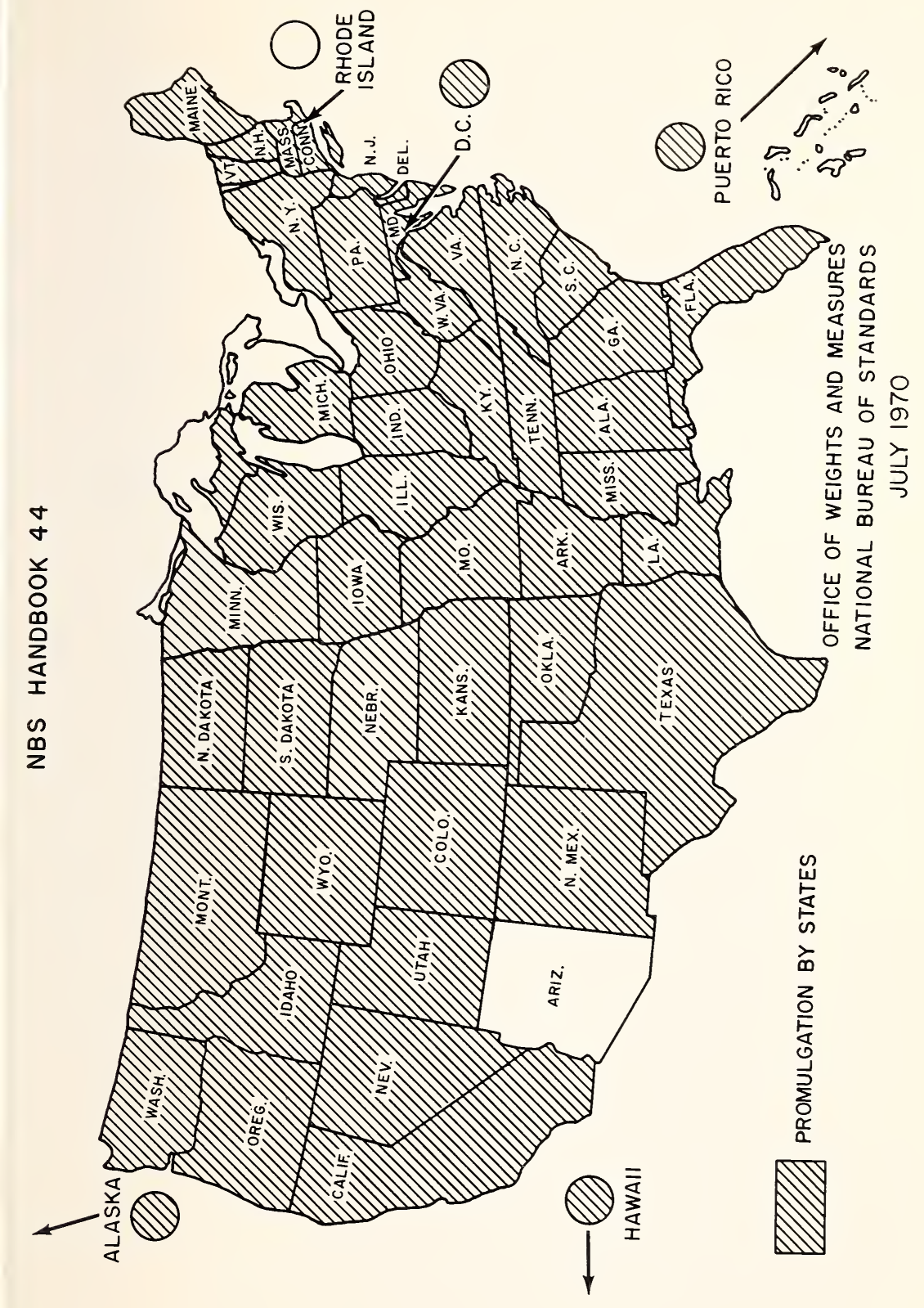



Latest developments in the subject area of this publication, as well as in other areas where the National Bureau of Standards is active, are reported in the NBS Technical News Bulletin. See following page. 


\section{HOW TO KEEP ABREAST OF NBS ACTIVITIES}

Your purchase of this publication indicates an interest in the research, development, technology, or service activities of the National Bureau of Standards.

The best source of current awareness in your specific area, as well as in other NBS programs of possible interest, is the TECHNICAL NEWS BULLETIN, a monthly magazine designed for engineers, chemists, physicists, research and product development managers, librarians, and company executives.

If you do not now receive the TECHNICAL NEWS BULLETIN and would Iike to subscribe, and/or to review some recent issues, please fill out and return the form below.

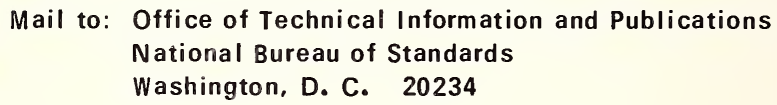

Name

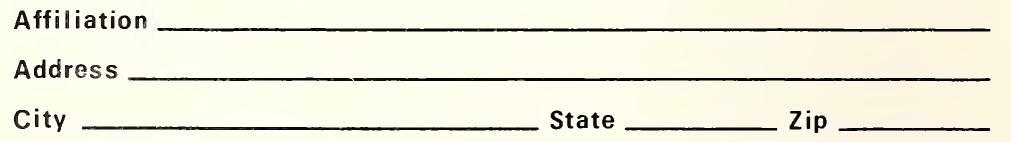

Please send complimentary past issues of the Technical News Bulletin.

Please enter my 1-yr subscription. Enclosed is my check or money order for $\$ 3.00$ (additional $\$ 1.00$ for foreign mailing). Check is made payable to: SUPERINTENDENT OF DOCUMENTS. 


\section{SELECTED WEIGHTS AND MEASURES PUBLICATIONS OF THE NATIONAL BUREAU OF STANDARDS}

NBS HANDBOOK 44 1965 (Replacement Sheets issued annually)

NBS HANDBOOK 67 NBS HANDBOOK 82 NBS HANDBOOK 94 NBS HANDBOOK 98 NBS HANDBOOK 99

NBS HANDBOOK 105-1

NBS CIRCULAR 593

NBS MisCELlaneOUS PUBLICATION 247

NBS Miscellaneous PUBLICATION 286

NBS TECHNICAL NoTE 196
Specifications, Tolerances, and Other Technical Requirements for Commercial Weighing and Measuring Devices. Looseleaf (binder not included)

Checking Prepackaged Commodities

Examination of Weighing Equipment $\quad 3.00$

Examination of Farm Milk Tanks .35

Examination of Liquefied Petroleum Gas Liquid-Measuring Devices

Specifications and Tolerances for Field Standard Weights

Weights and Measures Standards of the United States-a brief history

Units of Weight and Measure-Definitions and Tables of Equivalents

Report of the Investigation of Slow-Flow Meters for Fuel Oil Distribution Systems

Mission of the Office of Weights and Measures

REPORTS OF THE NATIONAL CONFERENCE ON WEIGHTS AND MEASURES

MISCELLANEOUS PUBLICATION 290

ORDER ALL PUBLICATIONS, WITH REMITTANCE, FROM THE SUPERINTENDENT OF DOCUMENTS, U.S. GOVERNMENT PRINTING OFFICE, WASHINGTON, D.C. 20402 





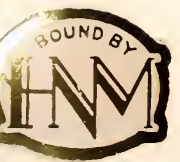


